ORNL/TM-2004/88

\title{
Prediction of External Corrosion for Steel Cylinders-2004 Report
}

\author{
July 2004
}

Rick Schmoyer

Oak Ridge National Laboratory 
This report has been reproduced directly from the best available copy.

Available to DOE and DOE contractors from the Office of Scientific and Technical Information, P.O. Box 62, Oak Ridge, TN 37831; prices available from 845-576-8401, FTS 626-8401.

Available to the public from the National Technical Information Service, U.S. Department of Commerce, 5285 Port Royal Rd., Springfield, VA 22161.

This report was prepared as an account of work sponsored by an agency of the United States Government. Neither the United States Government nor any agency thereof, nor any of their employees, makes any warranty, express or implied, or assumes any legal liability or responsibility for the accuracy, completeness, or usefulness of any information, apparatus, product, or process disclosed, or represents that its use would not infringe privately owned rights. Reference herein to any specific commercial product, process, or service by trade name, trademark, manufacturer, or otherwise, does not necessarily constitute or imply its endorsement, recommendation, or favoring by the United States Government or any agency thereof. The views and opinions of authors expressed herein do not necessarily state or reflect those of the United States Government or any agency thereof. 
ORNL/TM-2004/88

\title{
PREDICTION OF EXTERNAL CORROSION FOR STEEL CYLINDERS-2004 REPORT
}

\author{
Rick Schmoyer \\ Oak Ridge National Laboratory
}

July 2004

\author{
Prepared for \\ U.S. Department of Energy \\ Office of Environmental Restoration and Waste Management \\ under budget and reporting code EW 20
}

Prepared by OAK RIDGE NATIONAL LABORATORY

P.O. Box 2008

Oak Ridge, Tennessee 37831-6285

managed by

UT-Battelle, LLC

for the

U.S. DEPARTMENT OF ENERGY

under contract DE-AC05-00OR22725 



\section{TABLE OF CONTENTS}

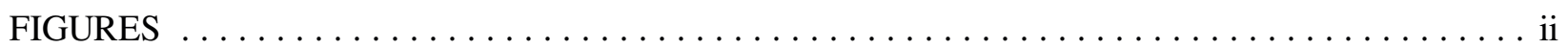

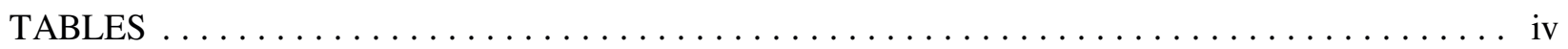

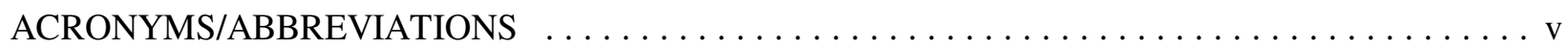

ACKNOWLEDGMENT $\ldots \ldots \ldots \ldots \ldots \ldots \ldots \ldots \ldots \ldots \ldots \ldots \ldots \ldots \ldots \ldots \ldots \ldots \ldots$

EXECUTIVE SUMMARY $\ldots \ldots \ldots \ldots \ldots \ldots \ldots \ldots \ldots \ldots \ldots \ldots \ldots \ldots \ldots \ldots$ vii

1. INTRODUCTION $\ldots \ldots \ldots \ldots \ldots \ldots \ldots \ldots \ldots \ldots \ldots \ldots \ldots \ldots \ldots \ldots \ldots \ldots$

2. APPROACHES TO MODELING CYLINDER WALL THICKNESS $\ldots \ldots \ldots \ldots \ldots \ldots \ldots \ldots 3$

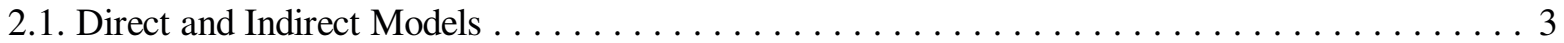

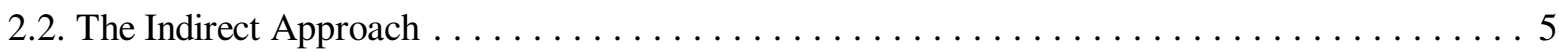

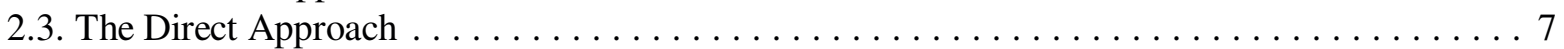

3. ULTRASONIC THICKNESS DATA AND CID DATA $\ldots \ldots \ldots \ldots \ldots \ldots \ldots \ldots \ldots \ldots$

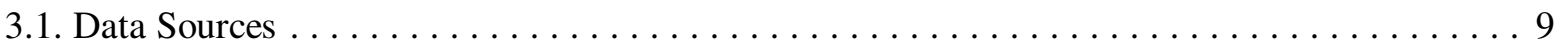

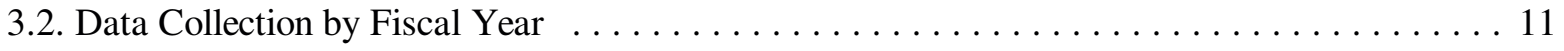

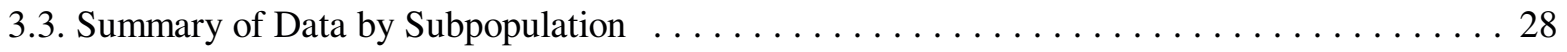

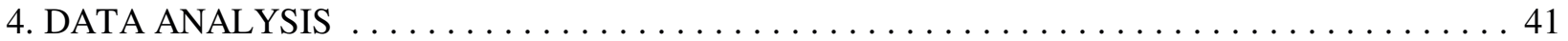

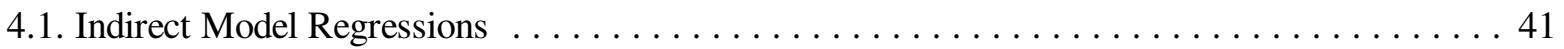

4.2. Direct Model Regressions $\ldots \ldots \ldots \ldots \ldots \ldots \ldots \ldots \ldots \ldots \ldots \ldots \ldots \ldots \ldots . \ldots \ldots 4$

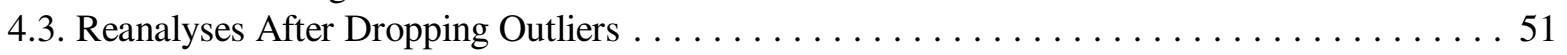

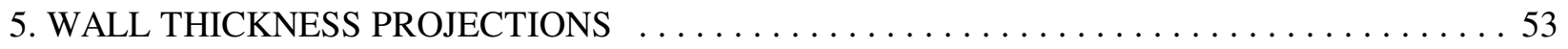

6. MODEL EVALUATION AND COMPARISON $\ldots \ldots \ldots \ldots \ldots \ldots \ldots \ldots \ldots \ldots \ldots \ldots \ldots$

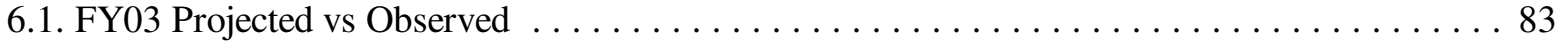

6.2. Comparison by Akaike Information Criterion $\ldots \ldots \ldots \ldots \ldots \ldots \ldots \ldots \ldots \ldots \ldots \ldots$

7. LIMITATIONS, CONCLUSIONS, AND RECOMMENDATIONS . . . . . . . . . . . . . 89

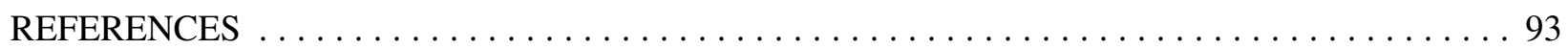

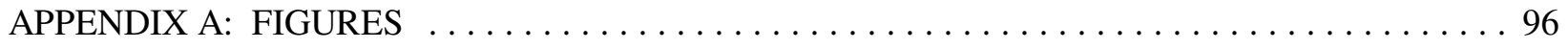




\section{FIGURES}

1. Differences between FY03 and earlier UT measurements for fifteen cylinders selected because the earlier thickness measurements were low-side statistical outliers $\ldots \ldots \ldots \ldots \ldots \ldots \ldots \ldots \ldots$

2. Differences between later and earlier UT measurements made on 90 randomly sampled Portsmouth cylinders, excluding one cylinder, which had a 157 mil difference. . . . . . . . . . . 46

3. A comparison of the cylinder age distributions for two thin-wall, bottom-row cylinder

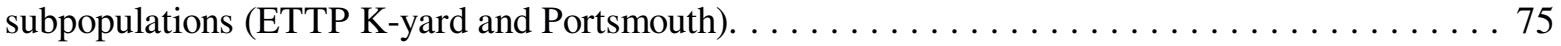

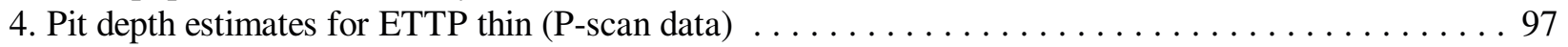

5. Pit depth estimates for ETTP thin, K-yard bottom $\ldots \ldots \ldots \ldots \ldots \ldots \ldots \ldots \ldots \ldots \ldots \ldots$

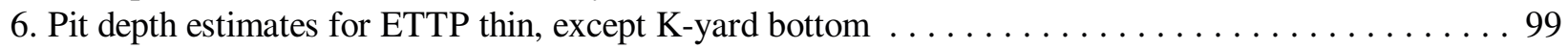

7. Pit depth estimates for PGDP thin (P-scan data) $\ldots \ldots \ldots \ldots \ldots \ldots \ldots \ldots \ldots \ldots \ldots \ldots \ldots$

8. Pit depth estimates for PGDP thin bottom, former G-yard $\ldots \ldots \ldots \ldots \ldots \ldots \ldots \ldots \ldots \ldots \ldots 1$

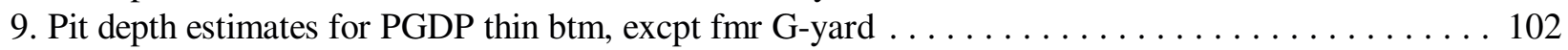

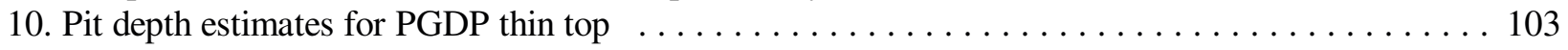

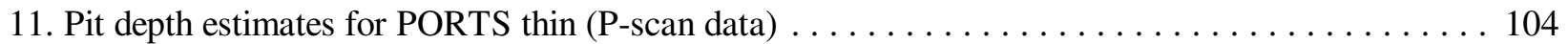

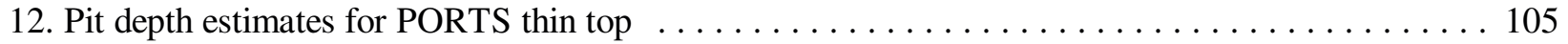

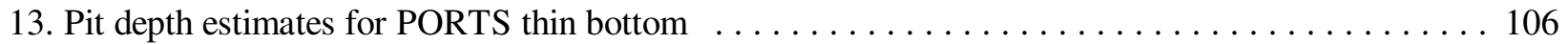

14. Pit depth estimates for ETTP/PGDP/PORTS thick top $\ldots \ldots \ldots \ldots \ldots \ldots \ldots \ldots \ldots \ldots \ldots$

15. Pit depth estimates for ETTP/PGDP/PORTS thick bottom $\ldots \ldots \ldots \ldots \ldots \ldots \ldots \ldots \ldots \ldots$

16. Pit depth estimates for ETTP/PGDP/PORTS thin skirted top $\ldots \ldots \ldots \ldots \ldots \ldots \ldots \ldots$

17. Pit depth estimates for ETTP/PGDP/PORTS thin skirted $b t m \ldots \ldots \ldots \ldots \ldots \ldots \ldots \ldots \ldots 110$

18. Pit depth estimates for ETTP/PGDP/PORTS thick skirted $\ldots \ldots \ldots \ldots \ldots \ldots \ldots \ldots \ldots \ldots 111$

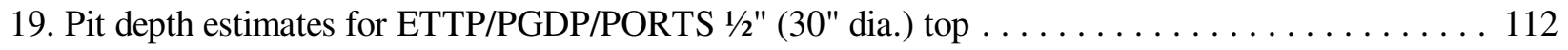

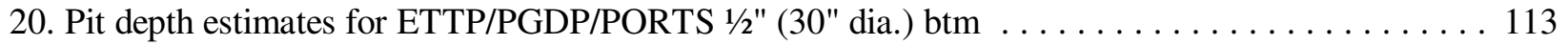

21. Minimum thicknesses (top) and cylinder age distribution (below) for ETTP thin (P-scan data)

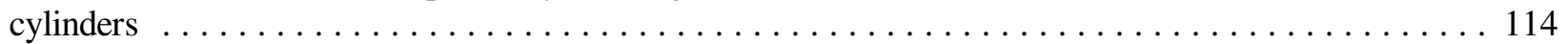

22. Minimum thicknesses (top) and cylinder age distribution (below) for ETTP thin, K-yard bottom

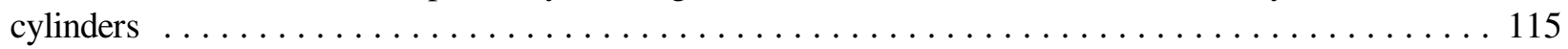

23. Minimum thicknesses (top) and cylinder age distribution (below) for ETTP thin, except K-yard

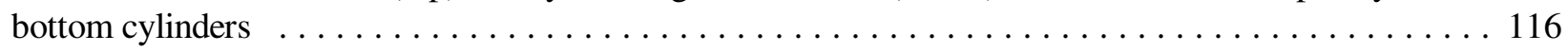

24. Minimum thicknesses (top) and cylinder age distribution (below) for PGDP thin (P-scan data)

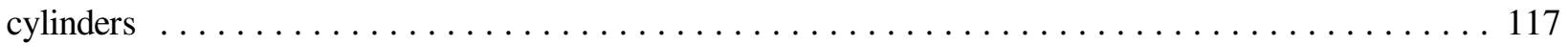

25. Minimum thicknesses (top) and cylinder age distribution (below) for PGDP thin bottom, former

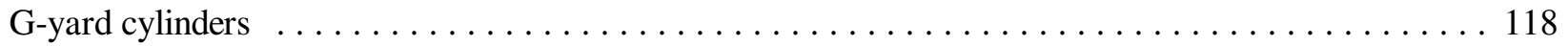
26. Minimum thicknesses (top) and cylinder age distribution (below) for PGDP thin btm, excpt fmr

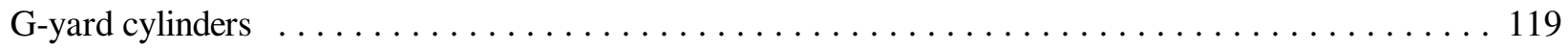

27. Minimum thicknesses (top) and cylinder age distribution (below) for PGDP thin top cylinders . . . 120 28. Minimum thicknesses (top) and cylinder age distribution (below) for PORTS thin (P-scan data)

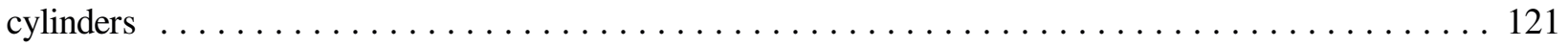

29. Minimum thicknesses (top) and cylinder age distribution (below) for PORTS thin top cylinders .. 122 30. Minimum thicknesses (top) and cylinder age distribution (below) for PORTS thin bottom cylinders 123 31. Minimum thicknesses (top) and cylinder age distribution (below) for ETTP/PGDP/PORTS

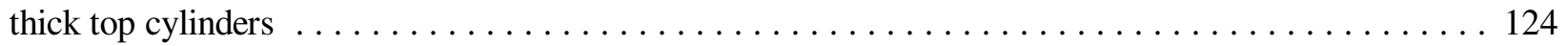
32. Minimum thicknesses (top) and cylinder age distribution (below) for ETTP/PGDP/PORTS

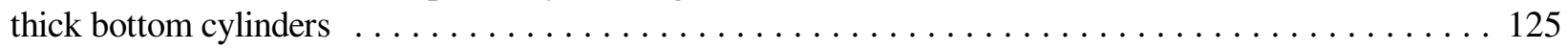
33. Minimum thicknesses (top) and cylinder age distribution (below) for ETTP/PGDP/PORTS thin

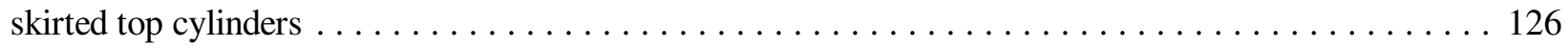
34. Minimum thicknesses (top) and cylinder age distribution (below) for ETTP/PGDP/PORTS thin

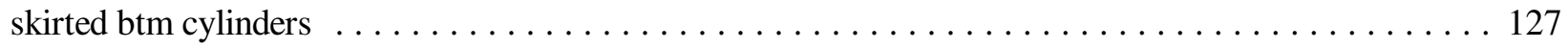
35. Minimum thicknesses (top) and cylinder age distribution (below) for ETTP/PGDP/PORTS thick

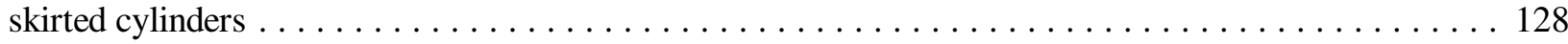


36. Minimum thicknesses (top) and cylinder age distribution (below) for ETTP/PGDP/PORTS $1 \frac{12 "}{2}$ (30" dia.) top cylinders . . . . . . . . . . . . . . . . . . . . . . . . . . . . . . . . . . 129

37. Minimum thicknesses (top) and cylinder age distribution (below) for ETTP/PGDP/PORTS $1 / 2 "$

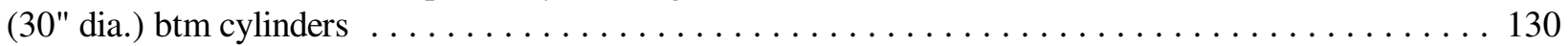

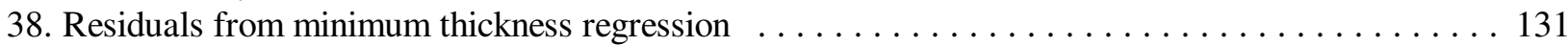

39. Normal probability plot for the regression residuals $\ldots \ldots \ldots \ldots \ldots \ldots \ldots \ldots \ldots \ldots \ldots \ldots \ldots$ 


\section{TABLES}

1. CID Counts by Site and Cylinder Thickness Type (Cylinders of Known Age) . . . . . . . . . . 9

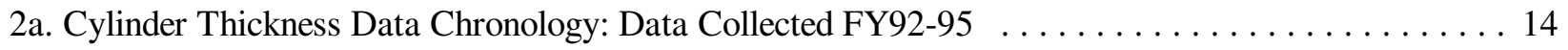

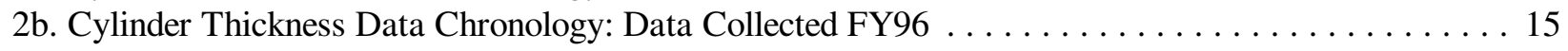

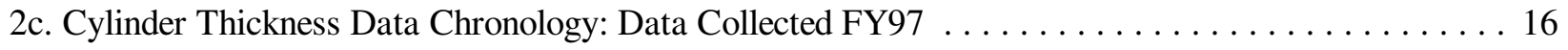

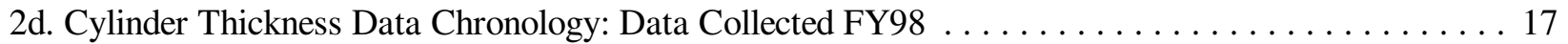

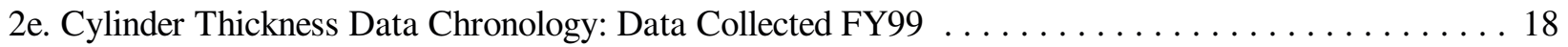

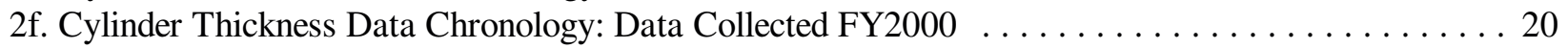

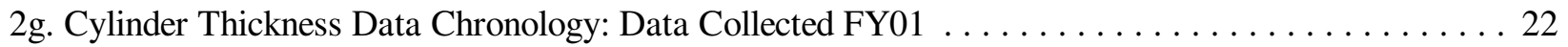

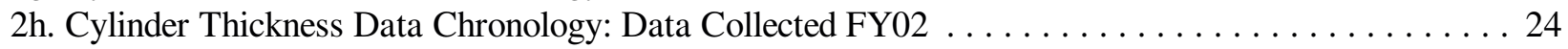

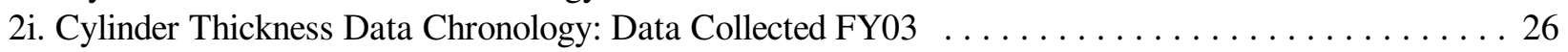

3a. ETTP Cylinder Population and Thickness Data Inventory $\ldots \ldots \ldots \ldots \ldots \ldots \ldots \ldots \ldots \ldots \ldots$

3b. PGDP Cylinder Population and Thickness Data Inventory $\ldots \ldots \ldots \ldots \ldots \ldots \ldots \ldots \ldots \ldots \ldots$

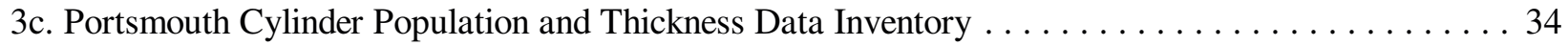

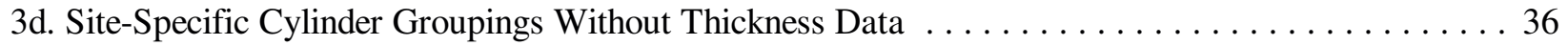

4. The Seventeen Subpopulation Classification System Used for the Regression Modeling . . . . . 40

5. Summary of Indirect-Model Populations and Modeling Assumptions $\ldots \ldots \ldots \ldots \ldots \ldots \ldots \ldots$

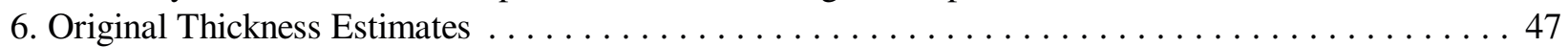

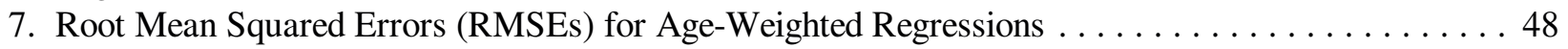

8. Direct-Model Parameter Estimates and Standard Errors $\ldots \ldots \ldots \ldots \ldots \ldots \ldots \ldots \ldots \ldots \ldots$

9. Cylinders Excluded from Tables 10B (Indirect Model) or 11B (Direct Model) . . . . . . . . . 50

10A. Summary of Indirect-Model Projections for Target Years and Minimum Thickness Criteria . . . . 54

10B. Summary of Indirect-Model Projections for Data with Outlier Exclusions . . . . . . . . . . . 57

10C. Indirect-Model Projected Proportions for Target Years and Minimum Thickness Criteria . . . . . 60

11A. Summary of Direct-Model Projections for Target Years and Thickness Criteria . . . . . . . 63

11B. Summary of Direct-Model Projections for Data with Outlier Exclusions . . . . . . . . . . 66

11C. Direct-Model Projected Proportions for Target Years and Thickness Criteria . . . . . . . . . . . 69

12. Cylinder Subpopulation/Age Groups With Year 2005 Projections of the Percentage Failing

the 62.5 Mil Thickness Criteria (By Descending Direct-Model Percentage Estimate) . . . . . . . . 76

13. FY03 Indirect and Direct-Model Projected and Observed Counts for Sampled Cylinders . . . . . . 84

14. Values of the Log-likelihood and Akaike Information Criterion $\ldots \ldots \ldots \ldots \ldots \ldots \ldots \ldots \ldots$ 


\section{ACRONYMS/ABBREVIATIONS}

$\begin{array}{ll}\text { AIC } & \text { Akaike Information Criterion } \\ \text { ANSI } & \text { American National Standards Institute } \\ \text { BJC } & \text { Bechtel Jacobs Company, LLC } \\ \text { CID } & \text { Cylinder Inventory Database } \\ \text { DOE } & \text { Department of Energy } \\ \text { DUF }_{6} & \text { Depleted uranium hexafluoride } \\ \text { ETTP } & \text { East Tennessee Technology Park } \\ \text { FY } & \text { Fiscal Year } \\ \text { LCL } & \text { Lower confidence limit } \\ \text { mil } & \text { 0.001 inch } \\ \text { ORNL } & \text { Oak Ridge National Laboratory } \\ \text { PGDP } & \text { Paducah Gaseous Diffusion Plant } \\ \text { PORTS } & \text { Portsmouth Gaseous Diffusion Plant } \\ \text { SEMP } & \text { System Engineering Management Plan } \\ \text { SRD } & \text { System Requirements Document } \\ \text { UF } 6 & \text { Uranium hexafluoride } \\ \text { UCL } & \text { Upper confidence limit } \\ \text { UT } & \text { Ultrasonic thickness }\end{array}$




\section{ACKNOWLEDGMENT}

The author would like to thank Dr. Steven J. Pawel, Corrosion Science \& Technology Group, Oak Ridge National Laboratory, and Dr. Bradford F. Lyon, Technical Computing, Y-12 National Security Complex, for carefully reviewing this report and for many helpful suggestions. 


\section{EXECUTIVE SUMMARY}

Depleted uranium hexafluoride $\left(\mathrm{UF}_{6}\right)$ is stored in over 60,000 steel cylinders at the East Tennessee Technology Park (ETTP) in Oak Ridge, Tennessee, at the Paducah Gaseous Diffusion Plant (PGDP) in Paducah, Kentucky, and at the Portsmouth Gaseous Diffusion Plant (PORTS) in Portsmouth, Ohio. The cylinders range in age from 4 to 53 years. Although when new the cylinders had wall thicknesses specified to within manufacturing tolerances, over the years corrosion has reduced their actual wall thicknesses.

The $\mathrm{UF}_{6}$ Cylinder Project is managed by the United States Department of Energy (DOE) to safely maintain the $\mathrm{UF}_{6}$ and the cylinders containing it. This report documents activities that address $\mathrm{UF}_{6}$ Cylinder Project requirements and actions involving forecasting cylinder wall thicknesses. These requirements are delineated in the System Requirements Document (LMES 1997a), and the actions needed to fulfill them are specified in the System Engineering Management Plan (LMES 1997b). The report documents cylinder wall thickness projections based on models fit to ultrasonic thickness (UT) measurement data.

UT data is collected at various locations on randomly sampled cylinders. For each cylinder sampled, the minimum UT measurement approximates the actual minimum thickness of the cylinder. Projections of numbers of cylinders expected to fail various thickness criteria are computed from corrosion models relating minimum wall thickness to cylinder age, initial thickness estimates, and cylinder subpopulations defined in terms of plant site, yard, top or bottom storage positions, nominal thickness, etc.

In this report, UT data collected during FY03 is combined with UT data collected in earlier years (FY94FY02), and all of the data is inventoried chronologically and by various subpopulations. The UT data is used to fit models of maximum pit depth and minimum thickness, and the fitted models are used to extrapolate minimum thickness estimates into the future and in turn to compute estimates of numbers of cylinders expected to fail various thickness criteria. A model evaluation is performed comparing UT measurements made in FY03 with model-fitted projections based only on data collected before FY03.

The new FY03 UT data consists of 80 minimum thickness measurements for 48" thin-wall (312.5 mil nominal thickness) cylinders at Paducah and 20 minimum thickness measurements for 30A (500 mil) cylinders at Paducah, and measurements of 155 cylinders at Portsmouth, of which 109 are 48" thin-wall cylinders and 46 are thick-wall (625 mil) cylinders. Wall thicknesses measurements were made on the main bodies of each of these cylinders, and, in addition, at the head/skirt interfaces of 68 of the 109 Portsmouth thin-wall cylinders and all 46 of the Portsmouth thick-wall cylinders.

Of particular interest are fifteen of the Paducah cylinder thickness measurements made in FY03, which are remeasurements of cylinders identified as statistical outliers in the 2003 edition of this report (Schmoyer and Lyon, 2003). Considering their age and subpopulations, these cylinders were flagged as having unusually low minimum thickness measurements, according to the fitted corrosion models. Outliers and high statistical variability, particularly among 30A cylinders, have been a difficulty in the analysis of the UT data in the past, because, after the high variability is accounted for, projections of numbers of cylinders likely to fail various thickness criteria have seemed too conservative. Yet there has been no basis for excluding statistical outliers from the analysis or for treating 30A cylinders differently from other cylinders. It has been conjectured that internal corrosion is the reason for greater variability in $30 \mathrm{~A}$ minimum thicknesses (because the cylinders may at one time have been used to store materials other than $\mathrm{UF}_{6}$ ), but no direct evidence supporting that conjecture has been discovered.

Five of the fifteen remeasured cylinders are thin-wall cylinders, and ten are 30A cylinders. Of the five thinwall remeasurements, all were substantially higher than the corresponding original measurements. Thus the thin-wall cylinder remeasurements support the idea that unusually low minimum thickness measurements for thin-wall cylinders may be due to measurement error, and that discarding some of the outliers from the analysis could lead to more accurate projections. However, the story for the remeasured 
30A outlier cylinders is different. For seven of the ten remeasured 30A cylinders, the 2003 minimum thickness measurement is actually smaller than the original measurement, and in three cases, it is substantially smaller. This is surprising because these cylinders were selected for remeasurement because they had unusually low minimum thicknesses. Therefore the remeasurements tend to confirm the unusually low original minimum thickness measurements for the 30As, and suggest that the statistical variability of minimum thicknesses for 30A cylinders is indeed different than for the other cylinder subpopulations.

For whatever reason-differences in steel, different life cycles, internal vs external corrosion-the conclusion that corrosion is more variable for 30As than for other cylinders motivates treating 30As differently in the corrosion model. On the other hand, the remeasurements of the thin-wall cylinders support an analysis that excludes flagrant statistical outliers. In the analyses for this (2004) report, the variance of $30 \mathrm{~A}$ minimum thicknesses is estimated separately from the variance for the other cylinder types, and that estimate is used to weight the 30As in the main regression. As in the 2003 corrosion report, analyses are performed both with and without statistical outliers.

Treating the 30A variance differently affects the analysis. Because 30A cylinders are nominally 3/16" thicker than thin-wall cylinders, minimum thicknesses variability can be greater for them without their failing minimum thickness specifications. In the fitted corrosion model with the $30 \mathrm{~A}$ variance estimated separately, the 30As have higher variance, yet projections about their future integrity still seem acceptable. At the same time, the model also leads to smaller variance estimates for thin-wall cylinders and thus to thinwall projections that are less pessimistic than in previous editions of this report.

In addition to the changed treatment of the variance of $30 \mathrm{~A}$ cylinders and to updating to the corrosion analysis for additional UT measurement data, the analysis is also updated for changes in cylinder subpopulation definitions and counts, according to the latest (as of January 2004) information from the Cylinder Inventory Database (CID). Cylinders identified in the CID as painted during the last ten years are excluded from subpopulations considered at-risk of failing minimum thickness criteria, because it is assumed that painting fully arrests corrosion for ten years. As a check on this assumption, UT measurements of several painted cylinders will be made in FY04.

The UT data used to fit the corrosion models is from cylinders sampled randomly or approximately randomly starting in FY94. With the exception of some Portsmouth cylinders that were scanned several times over the years, the sampling design is cross-sectional-each year, new samples of cylinders are selected for scanning. In the earlier years, P-scanning was the primary UT measurement method. Although the P-scan thickness measurements are included in the modeling, manual UT measurements are superseding them. In this report, as in previous editions, P-scanned cylinders are treated as separate cylinder subpopulations. Estimates and projections are still computed for the P-scanned subpopulations, but they are deprecated in all of the discussion and conclusions.

The minimum wall thickness criteria used in this report are as follows. For thin-wall cylinders (design nominal wall thickness 312.5 mils; 1 mil $=0.001$ inch): 0 (breach), 62.5, and 250 mils. For thick-wall cylinders (design nominal wall thickness 625 mils): 0, 62.5, and 500 mils. For 1/2" (30" diameter) cylinders: 0, 62.5, and 100 mils. These criteria triplets are based respectively on (1) loss of $\mathrm{UF}_{6}$ (breaching), (2) safe handling and stacking operations, and (3) standards for off-site transport and contents transfer criteria.

As in the previous two editions of the report, two different approaches to corrosion modeling are pursued: (1) a direct approach in which minimum thickness is modeled directly as a function of age, subpopulation, and initial thickness estimates; and (2) an indirect approach, in which maximum pit depth is modeled, and the pit-depth model is then combined with a model of initial thickness to compute estimates of minimum thickness. Because the indirect approach models corrosion in each cylinder subpopulation separately, both the mean and variance of each subpopulation are estimated separately. For this reason, unlike the direct model, the indirect model has not been modified on the basis of the remeasured 30A cylinders. Conclusions 
based on the indirect model are similar to the conclusion in the 2003 report, and the improvements in the direct model now tend to support this model over the indirect model. The main conclusions of this report are thus based on the direct model. Nevertheless, the indirect model still provides a useful check on those conclusions.

Though the risk estimates are low, the direct corrosion model suggests that the cylinders most likely to fail either the breach or 62.5 mil criteria are the ETTP thin-wall K-yard bottom cylinders, followed by the PGDP thin-wall former G-yard bottom cylinders, followed by the ETTP thin-wall cylinders other than $K$-yard bottom. These conclusions pertain to both near-term (e.g., FYO5) and longer-term projections (e.g., FY25).

These conclusions pertain to these cylinder subpopulations as a whole. Because the cylinder age distributions of the various subpopulations are not the same, risks for subpopulations as a whole may not reflect risks for certain older cylinders. This is addressed in the report in tables of projections broken down by both age and subpopulation.

A validation exercise was performed to compare FY03 measured results with projections based on fitting the corrosion model with data only from FY02 and before. The FY03 cylinder thickness measurements are consistent with the projections. It should be noted, however, that the validation exercise is inconclusive in the sense that failures of the thickness criteria are very unusual. Therefore a higher thickness criterion is also considered. The higher criterion suggests that the projections are conservative.

As in the 2003 edition of this report, excluding a few outliers also affects the projections. With the model weighted to adjust for a separate 30A variance, and with only six of 2,809 cylinders excluded from the analysis (none of them 30As), the direct-model projections of the number of cylinder breaches are all below the resolution of the regression projections. (The resolution of the regression projections is discussed in Section 5.) This is the first edition of the cylinder corrosion report for which the data and modeling processes have been in sufficient control that no breaches are projected for years 2005-2025, for any cylinder subpopulation. Note, however, that this is for the corrosion model fit after excluding six statistical outliers. One of the recommendations of the report is to remeasure those six cylinders.

Other recommendations include continuing to deprecate the P-scan data in favor of the manual UT data, continuing to focus on the direct model for the main analytical conclusions, remeasuring statistical outliers in FY05, and prioritizing inspection and maintenance as well as disposition/conversion schedules in terms of cylinder subpopulation and age differences as characterized in the report.

In addition to age and subpopulation, a myriad of other variables might effect corrosion but are not accounted for in the modeling here. Examples include how many use cycles the cylinders went through, how many nicks and scrapes, and the nature of former surface coatings, now perhaps long gone. Add to the variables not accounted for, possible biases introduced in the UT measurements, and the result is a problem with plenty of statistical error. Corrosion physics and the effects of time are only a part of the story. In addition to a good model, good cylinder thickness forecasts are and will continue to be contingent on careful UT measurements, careful data quality control (e.g., elimination of outliers), and UT sample sizes sufficient, through laws of large numbers, to control the statistical noise.

This report complements and extends previous editions by Lyon (1995, 1996, 1997, 1998, 2000) and by Schmoyer and Lyon $(2001,2002,2003)$. 


\section{INTRODUCTION}

The United States Department of Energy (DOE) maintains depleted uranium hexafluoride $\left(\mathrm{UF}_{6}\right)$ in over 60,000 carbon steel cylinders stored at the East Tennessee Technology Park (ETTP) in Oak Ridge, Tennessee, the Paducah Gaseous Diffusion Plant (PGDP) in Paducah, Kentucky, and the Portsmouth Gaseous Diffusion Plant (PORTS) in Portsmouth, Ohio. The $\mathrm{UF}_{6}$ Cylinder Project was designed to safely manage this material. The $U F_{6}$ Cylinder Project System Requirements Document (SRD, LMES 1997a) delineates the requirements of the project, and the actions needed to fulfill those requirements are specified in the $U_{6}$ Cylinder Project System Engineering Management Plan (SEMP, LMES 1997b).

This cylinder corrosion report documents activities that address specific requirements and actions stated in the SRD and SEMP with respect to forecasting cylinder wall thicknesses. SEMP Action 2.1.2 is to "model corrosion to project cylinder integrity" and the corresponding System Requirement 1.2.2 is that "performance shall be monitored and evaluated to identify potential risks within the Project." This report documents the method for projecting cylinder wall thicknesses and numbers of cylinders expected to fail various thickness criteria.

SEMP Action 3.1.2 is to "statistically determine the baseline condition of cylinder populations by obtaining quantitative data," and the corresponding System Requirement 4.1.2 calls for monitoring cylinder conditions. This report documents statistical methods used to characterize cylinder populations on the basis of ultrasonic thickness (UT) measurements. Wall thickness data has been collected annually since FY94 at the three DOE sites. UT data is collected by sampling cylinders and by making UT measurements at various locations on each sampled cylinder. By assumption, for each cylinder sampled, the minimum UT measurement approximates the actual minimum thickness of the cylinder. This report describes corrosion models fit to the UT data, which have been updated and refined with each annual installment of data.

System Requirement 4.2.1 states that "cylinders shall be categorized to ensure that risks are identified," and SEMP Action 2.2 is to define and describe categories in terms of cylinder functional criteria and/or factors that could adversely impact cylinder integrity. The analyses in this report are based on cylinder populations defined in terms of cylinder types (e.g., thick-wall, thin-wall), historical storage locations (yard and top/bottom position), as well as UT measurement methods (P-scan or manual UT). Wall thickness projections are computed from corrosion models relating minimum wall thickness to cylinder age, subpopulation, and initial thickness estimates.

System Requirement 4.2.2 states that "cylinder conditions shall be forecast to direct surveillance and maintenance resources," and SEMP Action 2.4 is to "define procedures for forecasting cylinder conditions." System Requirement 4.2.2a is to "identify which collected data will be used for forecasting" (SEMP Action 2.2.) and to "integrate forecasting with modeling efforts" (SEMP Action 2.3). System Requirement 4.2.b (SEMP Action 2.3.1) is to "forecast cylinder conditions using the parameters identified." Cylinder wall thickness, the subject of this report, is one parameter identified in the project for forecasting cylinder conditions. SEMP Action 3.1.1 is to "project the number of noncompliant cylinders."

These projections are the primary purpose of this report, which complements and extends previous editions by Lyon $(1995,1996,1997,1998,2000)$ and by Schmoyer and Lyon $(2001,2002,2003)$. Each annual installment of UT measurement data has led to refinements in both the functional forms used for corrosion modeling and in the fitted parameters that describe the forms. Section 2 of this report introduces the two general approaches used to model and forecast cylinder wall thicknesses, a "direct" approach, in which wall thickness is modeled directly, and an "indirect" approach based on separate models of pit depth and original thickness. Although both models can be used to project cylinder minimum thicknesses on the basis of observed UT measurements, the projections are different functions of the observed measurements, and 
they have different statistical errors. Because of substantial statistical variation in the measurements themselves, the statistical error of the projections is as important in the corrosion modeling as the physical relationship between corrosion and time.

Section 3 of the report is an inventory of cylinder wall thickness data collected at Oak Ridge, Paducah, and Portsmouth. Section 4 is about regression model fitting with the models introduced in Section 2 and the data discussed in Section 3.

As prescribed by SEMP Action 3.1.1, Section 5 contains projections, based on the models fit in Section 4, of numbers of cylinders expected to fail various thickness criteria. Projections are also expressed as proportions (rates) expected to fail the criteria. Separate projections are presented for the direct and indirect modeling approaches. Projections are given by age and by cylinder subpopulation, and both with and without statistical outliers in the analysis. Model validation is considered in Section 6, where the direct and indirect models are evaluated by comparing actual FY03 observations with projections based on fitting the models with data only from before FY03. Limitations, conclusions, and recommendations are discussed in Section 7.

Essentially all of the UT measurements were made in FY94 or later. Design sheets cite original thickness specifications, but (as discussed in Section 4) actual and nominal cylinder thicknesses apparently tended to differ, at least for cylinders that are forty or fifty years old. No initial thickness measurements were ever documented for these cylinders. Therefore corrosion changes reflected in the UT data are all changes subsequent to FY94. Thus, even though the cylinders were maintained at less than post-1994 standards for much of their lives, thickness measurements made since 1994 are at least in theory sufficient to characterize the current status and rate of cylinder corrosion.

The disposition of any particular cylinder for storage, handling, and transfer should depend on the condition of the cylinder. In this report "condition" is the minimum wall thickness of the cylinder. Wall thickness criteria, 0, 62.5, and 250 mils for thin-wall cylinders, and 0, 62.5, and 500 mils for thick-wall cylinders, are limits based on (1) loss of $\mathrm{UF}_{6},(2)$ safe handling and stacking operations, and (3) standard off-site transport and contents transfer. In general, these criteria refer to an area of wall thinning, not a single a point. On the other hand, minimum wall thickness measurements collected for the report are for areas of only about 0.01 square inches, which is essentially a point. For thickness criteria greater than zero, conclusions based on minimum wall thicknesses are, in this respect, conservative. However, because of the interaction of $\mathrm{UF}_{6}$ with atmospheric moisture and steel, a point breach would deteriorate in a year to oneinch diameter hole (DNFSB 1995), and so small-area approximations should be close, at least for the breach criteria.

In past editions of the report, projections of the numbers of cylinders expected to fail the 0 or 62.5 mil thickness criteria have seemed too conservative-more cylinders were projected to fail the criteria than seemed likely to people familiar with the cylinders and cylinder yards. Previous editions have focused on model formulation as a way to improve the projections. The 2003 edition also focused on data issues, particularly on statistical outliers. A conclusion of the 2003 report is that cylinders with anomalous thickness measurements should be remeasured to either confirm or refute the prior measurements. Remeasurements of five thin-wall and ten 30A cylinders with anomalous measurements were made at Paducah in FY03. These remeasurements are analyzed in Section 4 of this (2004) report. The remeasurements motivate a modification in the treatment of the variance of $30 \mathrm{~A}$ cylinders in the direct corrosion model, and, for the thin-wall cylinders, the remeasurements also support the idea that excluding statistical outliers improves the projections. As shown in Section 5, these approaches lead to projections that seem less conservative and more reasonable than the projections in previous editions of the report. 


\section{APPROACHES TO MODELING CYLINDER WALL THICKNESS}

\subsection{Direct and Indirect Models}

The basic problem addressed in this report is to project numbers of noncompliant cylinders-to predict how many cylinders, in cylinder subpopulations defined by age, location, storage position (top or bottom) and perhaps other predictor variables, will have minimum wall thickness below a specified thickness at a specified time. For a cylinder randomly selected from a subpopulation, let $M(t)$ denote the minimum wall thickness at time $t . M(t)$ is random because of variations in initial thickness (manufacturing variability), the steel substrate, the corrosion process, and storage conditions. Consider $\operatorname{Prob}(M(t)<l)$, the probability that $M(t)$ is less than $l$. For a group of $N$ cylinders, the expected number of cylinders with minimum thickness below $l$ at time $t$ is $N \times \operatorname{Prob}(M(t)<l)$. Because the number of cylinders at risk is affected by maintenance (e.g., painting may temporarily stop corrosion), $N$ may change over time. For a group of cylinders having various ages, the expected number of cylinders with a minimum thickness below a given value $l$ at time $t$ is

Expected number of cylinders with minimum thickness below $\mathrm{z}$ at time $\mathrm{t}=$

$$
\sum_{\mathrm{a}}(\text { Number of cylinders of age a at time } \mathrm{t}) \times \operatorname{Prob}(M(t)<z \text {; for cylinders of age a }),
$$

where the summation extends over all cylinder ages a. The number of cylinders of age a at time $t$ is known, but the individual probabilities (for each age a) are unknown.

Note that (2.1) is the expected number of noncompliant cylinders. The actual number of noncompliant cylinders-what we would most like to predict—-tends to differ from (2.1) because of variation in the actual number about (2.1), its expectation. Furthermore, (2.1) is unknown, though it can be estimated by estimating the individual probabilities $\operatorname{Prob}(M(t)<z$; for cylinder of age a) for the various ages a for which there are cylinders. The actual number of noncompliant compliant cylinders may then depart from the estimate of (2.1), because of error in estimating (2.1) and because of error due to variation in the actual number about (2.1) itself. The estimation error becomes negligible for very large sample sizes (and very accurate estimates). However, error due to variation of the actual number of noncompliant cylinders about its expectation exists regardless of the sample size.

Methods of accounting for estimation error and error due to variation in the actual number of noncompliant cylinders are discussed below. For a specified confidence level 1- $\alpha$ and time $t$, we would like to compute a bound $U$ for the actual number $B$ of noncompliant cylinders, such that $\operatorname{Prob}(B<U)=1-\alpha$. Such a bound would then simultaneously account for both forms of error. None of the methods proposed in this report completely achieve this goal, however.

An approach to the problem of estimating (2.1) is to make UT measurements of cylinder wall thicknesses, deliberately trying to locate the actual thickness minima. By doing this for cylinders of various ages and from various subpopulations, data so collected can be used to model the minimum thicknesses as a function of age, subpopulation, and estimates of initial thicknesses. Initial thickness estimates are based on nominal thickness data (from design sheet data), as well as maximum wall thickness measurements, and judgment. In this report, this approach will be called "direct," because minimum thicknesses are modeled directly, and because the objective is to make projections about minimum thicknesses. Approximations are incurred in the direct approach because of error in initial thickness estimates, and because actual minimum thicknesses may not be discovered, either because of insufficient searching or because searches may be focused on areas of maximum pitting rather than the minimum thickness. If a cylinder's initial thickness is not 
uniform (e.g., because of variations introduced in forming), then where pitting is worst may not be where the minimum thickness actually occurs.

Another approach is to model maximum pit (i.e., corrosion) depths. As discussed below, pit depth models are more common in the literature than minimum thickness models. Given a pit depth model, projections about minimum thicknesses can be computed as differences between initial thickness estimates and maximum pit depth estimates computed from the pit depth model. As in the direct approach, initial thickness estimates can be based on nominal specifications as well as maximum thickness measurements.

Besides the initial thickness approximation, an approach based on maximum pit depths is approximate because minimum thicknesses need not occur where initial thicknesses are minimum or where pit depths are maximum. More specifically, for a particular cylinder, let $C_{0}(x)$ denote the initial wall thickness at a location $x$, and let $P(t, x)$ denote the pit depth at location $x$ at time $t$. Then the thickness at point $x$ is $C_{0}(x)$ - $P(t, x)$, and the minimum thickness is

$$
M(t)=\min _{x}\left\{C_{0}(x)-P(t, x)\right\}
$$

where the min is over all points $x$ on the cylinder. For time $t$, let $x^{*}(t)$ denote the point $x$ at which the thickness is minimized. Then $M(t)=C_{0}\left(x^{*}(t)\right)-P\left(t, x^{*}(t)\right)$. Note that $P\left(t, x^{*}(t)\right)$ is the pit depth at the point of minimum thickness, which is not necessarily the maximum pit depth. Similarly $C_{0}\left(x^{*}(t)\right)$ is not necessarily the minimum initial thickness.

If $x^{*}(t)$ is estimated through UT scanning, and if UT thickness measurements are made at $x^{*}(t)$ (approximately) and at relatively uncorroded areas in the vicinity of $x^{*}(t)$, then $P\left(t, x^{*}(t)\right)$ and $C_{0}\left(x^{*}(t)\right)$ can be estimated. Those estimates could be used to develop models for pit depths and initial thicknesses at $x^{*}(t)$, which in turn can be combined to produce minimum thickness estimates and projections. Note, however that this approach would not really be based on a maximum pit depths. Furthermore, the approach would be very heavily dependent on proper thickness measurements being made at relatively uncorroded areas near $x^{*}(t)$. Uncorroded areas might not exist. A common notation on cylinder reports is "uniform corrosion," which suggests that for those cylinders an assessment of initial thickness based on thickness measurements is not possible.

Lyon (2000) developed a method based on a maximum pit depth model and a conservative approximation based on the following inequality:

$$
\begin{aligned}
M(t) & \geq \min _{x}\left\{C_{0}(x)\right\}-\max _{x}\{P(t, x)\} \\
& =C_{0}-\max _{x}\{P(t, x)\} \\
& =C_{0}-P(t)
\end{aligned}
$$

where $C_{0}$ is the initial minimum thickness, and $P(t)$ is the maximum pit depth at age $t$. By this inequality, $C_{0}-P(t)$ is a lower bound for $M(t)$, and conclusions about $C_{0}-P(t)$ are conservative conclusions about $M(t)$. 
Because it starts with a conservative approximation, Lyon's approach may be more appropriate than the above approach based on estimates of $P\left(t, x^{*}(t)\right)$ and $C_{0}\left(x^{*}(t)\right)$, especially in view of limitations in the UT measurement data. In Lyon's approach, the $C_{0}$ are estimated either with thickness measurements made at uncorroded areas near the area of minimum wall thickness, or else with "original thickness estimates" measured at areas of approximate maximum thickness. The $P(t)$ are estimated by subtracting thickness measurements made either where the worst pitting occurs or where the wall thickness is minimum. (In practice, $x^{*}(t)$ has been estimated by searching with UT scans, but those searches have almost surely been biased towards areas of maximum pitting.) To make estimates and projections about minimum thicknesses, the statistical distributions of the $C_{0}$ and $P(t)$ are combined (see Lyon 2000) in a way that assumes the two distributions are statistically independent. The statistical independence is an assumption that could fail, however, for example if steel quality and initial thickness are correlated. In this report, because the minimum thicknesses are modeled indirectly through separate models of maximum pit depth and initial thickness, this approach is referred to as "indirect."

\subsection{The Indirect Approach}

Maximum Pit Depth Models. The indirect model used in this report is based on the power law, which has been used in many previous applications of corrosion modeling (e.g., Felieu et al. 1993a; Felieu et al. 1993b; Legault and Preban 1975; Pourbaix 1982; Mughabghab and Sullivan 1989; Romanoff 1957). The power law is $P($ age $)=A \times(\text { age })^{n}$, where $P$ denotes pit depth (or penetration), and $A$ and $n$ are constants. For $n<1$ the power law allows for "leveling off" in corrosion, which is commonly seen in the atmospheric corrosion of steel, because of the semi-protective qualities of iron oxides.

The model parameters $A$ and $n$ can be estimated using the log-linear regression model ${ }^{1}$

$$
\log (P(\text { age }))=\log (A)+n \log (\text { age })+\text { random error, }
$$

which is the estimation approach taken in this report. The random errors are assumed to be statistically independent and independent of the cylinder initial thickness. Separate regression models are fit for each of seventeen cylinder subpopulations, which are discussed in Sections 3 and 4. For the regressions, maximum pit depth measurements for each cylinder are estimated from minimum thickness measurements and estimates of initial thickness, which are based on maximum wall thickness measurements made for each cylinder.

According to Pourbaix (1982), Passano (1934) was the first to use the power law relationship in corrosion prediction. This law is considered to be valid for different types of atmospheres (rural, marine, industrial) and a number of materials. The parameter $A$ can be interpreted as the corrosion in the first year, and the parameter $n$ represents the attenuation of the corrosion because of the passivation of the material in the atmosphere (Pourbaix, p.115).

From model (2.2) it follows that for a cylinder of given age, the mean corrosion rate is $P($ age $) /$ age $=$ $A \times(\text { age })^{n-1}$. If $n=1$, this implies that the age-averaged corrosion rate is constant, while if $n<1$ (which is typical), the corrosion rate decreases with time. Mechanistic interpretations of $n$ have also been made (Horton 1964). If $n=0.5$, then the relationship is said to be parabolic, with the corrosion rate controlled by diffusion through the rust layer. If $n<0.5$, the rust layer is showing protective properties, while if $n>0.5$, the rust layer is not fully protective because of factors that may be preventing the homogeneous thickening of the layer.

\footnotetext{
${ }^{1}$ All logarithms in this report are natural logarithms.
} 
Because estimates of the "leveling off" $(n<1)$ pattern usually expected for pit depths can be sensitive to narrow data ranges, outliers, and other data anomalies, the power law approach should be used with caution. In fact, a failure of either the leveling off $(n<1)$ hypothesis or the increasing corrosion $(n>0)$ hypotheses is observed for ten of the seventeen cylinder subpopulations considered in this report (see Section 4), and an alternative model developed by Lyon $(1995,1996)$ is then applied. The alternative model is $P($ age $)=A \times($ age $)$ or $\log (P($ age $))=\log (A)+\log ($ age $)$, that is, the same model except that exponent $n$, that is, the log-scale slope, is constrained to be 1 . The proportionality constant A, or, equivalently, the log-scale intercept, is still estimated. The inconsistency between the data and the leveling off hypothesis - the need for the slope-set-to-one model — was the main motivation for the direct approach.

In order to address the variability inherent in the corrosion process (and ultimately to account for variability in projections), it is assumed in the indirect model that pit depths are lognormally distributed at each age (or time). This can also be expressed on the $\log$ scale as $\log (P($ age $)) \sim N(\log (A)+n \log ($ age $), \sigma)$, where $N(\mu, \sigma)$ denotes a normal distribution with mean $\mu$ and standard deviation $\sigma$. For this model, on the arithmetic scale, the median is equal to $A(\text { age })^{n}$, the mean is $A(\text { age })^{n} \exp \left[\sigma^{2} / 2\right]$, and the standard deviation is $A(\text { age })^{n} \exp \left[\sigma^{2} / 2\right]\left[\exp \left(\sigma^{2}\right)-1\right]^{1 / 2}$. The coefficient of variation (ratio of the standard deviation to the mean) is constant in time and equal to $\left[\exp \left(\sigma^{2}\right)-1\right]^{1 / 2}$. The lognormal assumption has been checked by goodness of fit tests discussed in previous cylinder reports (Lyon 2000).

Extreme Value Distribution. Given that the data consists of maximum pit depth estimates, it would seem natural to apply extreme-value statistics to this problem. Application of the extreme value distribution (without confidence limits) is discussed in several papers and has also been suggested within the Project by Rosen and Glaser (1996). The basic idea is that using large-sample statistical theory (see, for example, David 1981), it can be shown that for $\mathrm{P}$, the maximum pit depth in $\mathrm{m}$ pit depth measurements made on a randomly selected cylinder, there is a standardization $\mathrm{a}_{\mathrm{m}}$ and $\mathrm{b}_{\mathrm{m}}$ (depending only on $\mathrm{m}$ ) such that as $\mathrm{m}$ increases (i.e., as $m$ approaches infinity), the statistical distribution of $a_{m}+b_{m} \times P$ converges to a particular parametric form known as the extreme value distribution. That form, along with estimates of its unknown parameters, would seem like a good choice for projecting pit depths forward in time.

In fact, however, $m$ actually never gets very large. The number of UT measurements made on each cylinder is generally in the range of 5-15. Operator discretion in locating areas of cylinders most likely to be worst in terms of thickness or corrosion might tend to increase the effective sample size, but not in any way we know how to quantify.

It is actually the number of cylinders with thickness measurements that is large. Thus large-sample statistical theory suggests that the distribution of the minimum over all cylinders of the per-cylinder minimum thicknesses (i.e., the minimum of the minima) converges to the extreme value distribution, but the theory does not tell us much about the distribution of per-cylinder minimum thicknesses. Although it would be of interest to project the smallest minimum thickness, estimating the number of noncompliant cylinders requires estimating the per-cylinder minimum thickness distribution. This, together with statistical issues about data quality, outliers, and the basic corrosion-age relationship motivated the direct model as an alternative to the indirect model, rather than development an extreme value approach. The direct model (see below) is nonparametric (not based on any parametric distribution) and does not require choosing any form of parametric statistical distribution.

Initial Thickness Models. Fitting the indirect model entails first estimating the parameters A, n, and $\sigma$ (lognormal standard deviation) from maximum pit depth data. With those estimates, pit depths can be extrapolated forward in time. To project minimum thicknesses, however, the pit depths must be subtracted from initial thickness estimates. A stochastic model is used for initial thicknesses, in the indirect modeling approach, because of concerns that variability in initial thickness could be a critical factor (Rosen and Glaser 1995). (In the direct approach, variability in initial thickness is modeled as part of the variability of the minimum wall thicknesses.) 
With the exception of cylinders purchased very recently, there is no way to know the distributions of initial thicknesses. Therefore, in the indirect model, the initial thickness distribution is approximated with a truncated normal distribution (see Johnson and Kotz, 1970, p 81.) A truncated normal random variable has the distribution of a normal random variable conditional on the variable being in the truncated range. The lower end of the truncation range is taken as the lower end of the design thickness range, 312.5 and 615

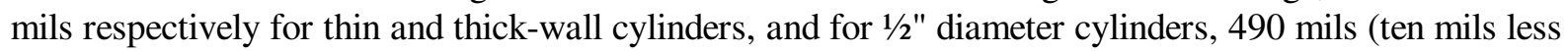
than the $1 / 2$ " nominal thickness). The upper end of the truncation range, as well as the mean and standard deviation of the underlying normal distribution are estimated from maximum wall thickness data.

With the exception of the data at the head/skirt interface (discussed below), the maximum wall thickness data consists of wall thickness measurements made at relatively uncorroded regions of the cylinders. The data collected so far suggest that the maximum wall thickness at relatively uncorroded cylinder areas is often larger than the nominal design thickness. On the other hand, if there is uniform corrosion, then maximum thickness measurements could underestimate the design maximum thickness.

Probability and Confidence Limits. Indirect-model estimates of probabilities that cylinders will fail various thickness criteria are calculated using a convolution of the lognormal pit-depth and truncated normal initial-thickness distribution estimates, which are assumed to be statistically independent. These estimates are used to compute a point estimate of the expected number of noncompliant cylinders (2.1). Approximate confidence bounds for the point estimate of (2.1) are computed using the same convolution of lognormal and truncated normal distributions along with confidence bounds for the regression parameter estimates. The confidence bounds for the estimate of (2.1) thus account for estimation error, but do not account for variability of the actual number of noncompliant cylinders about the expectation (2.1). The confidence limits have in practice seemed too conservative. These methods are developed by Lyon (2000) and refined by Schmoyer and Lyon (2003, Appendix B).

\subsection{The Direct Approach}

The direct model was first investigated as an alternative to the indirect approach, because of anomalous results based on the indirect approach, due in part to the high variability that has been seen in the minimum thickness and maximum pit depth data. Thickness projections based on the direct model were first computed in the 2002 edition of this report (Schmoyer and Lyon 2002); indirect model projections were computed since the 1997 edition. Although the direct model appears to perform favorably, a conclusion of the 2003 report is that both models should continue to be explored. Modeling results for both the direct and indirect approaches are discussed in Section 4.

There are other reasons, besides just data variability, for exploring alternatives to the indirect approach. For example, pits or other surface relief developed in fabrication or handling hold moisture differently than a uniform surface. The myriad of possible variations on the statistical "nick and cut" distribution cannot possibly all be described by the power law. The power law also might fail because of the thermal inertia ${ }^{2}$ of cylinders. ${ }^{3}$

The direct model considered in this report is

$$
M(\text { age })=\alpha \times(\text { Initial Thickness Estimate })+\beta(\text { group }) \times \log (\text { age })+\text { random error, for age }>1,
$$

where $\alpha$ is a model parameter, and " $\beta$ (group)" denotes a model parameter, one for each cylinder group. The " age $>1$ " condition is imposed, because $\log ($ age $)$ is unbounded and negative for age $<1$, and so the

\footnotetext{
${ }^{2}$ The tendency of objects of large mass to temporarily differ in temperature from their environment.

${ }^{3}$ Steve Pawel, ORNL Corrosion Science \& Technology Group, personal communication.
} 
model cannot hold for arbitrarily small ages. Presumably another model would hold, but the point is moot for this report, because there are no thickness measurements for cylinders of age less than one year.

According to this model, $M(1)=\alpha \times$ (Initial Thickness Estimate) is the mean thickness at age one year, which is essentially, though not exactly, the initial thickness. The expression "initial thickness estimate" is used loosely here to refer to the thickness at age $=1$ year (though no further approximation is so incurred). Initial thickness estimates, which are computed from design specifications, maximum thickness measurements, and judgment, are incorporated into the model as predictors, but are also further refined by fitting the parameter $\alpha$-using minimum thickness measurements. Thus, the direct model is designed to best fit current minimum thicknesses, and the estimate of $a$ is adjusted to improve the current fit.

The cylinder groups (subpopulations) used for the direct model are the same as for the indirect model (except that thin-wall cylinders are not included in the thick-wall groups; see Sections 3 and 4). However, unlike the indirect approach, in which a separate model with its own intercept and slope is fit for each group, in the direct approach, there is one model with separate parameters for each cylinder group. For the indirect model, the total number of parameters (including standard deviations) is three times the number of groups, not including the additional estimated parameters in the initial thickness distributions. For the direct model, the total number of parameters is the number of groups plus two (including one for the standard deviation). This includes all parameters used to model initial thickness. As seventeen groups are currently being used, there are currently 51 parameters for the indirect model, and 19 parameters for the direct model.

Having fewer parameters can be either a disadvantage or an advantage. Models with fewer parameters are less flexible, but if they fit, less flexibility reduces the likelihood that anomalous data will lead to anomalous modeling results, which turns out to be difficulty in the indirect approach.

For either the direct or indirect approaches, how random error terms and their variances are modeled can have a critical effect on corrosion projections. Regardless of the mean minimum thickness, if the variance of the (true) error term is high enough, there will always be cylinders whose minimum thicknesses are below any of the various thickness criteria. This applies to both the direct and indirect models. Because, in the direct approach, multiple cylinder groups are handled with one model, high variability in one group affects projections for all groups. Therefore several ways of relating variance to age and consequential regressions weightings are considered for the direct model (see Section 4). Further, the random error term in the direct model is not assumed to be lognormal or, in fact, to have any particular distribution. A nonparametric method is used instead, which may help in handling data problems (e.g., outliers).

In the direct model and in the indirect model with $0<n<1$, corrosion is assumed to be a concave increasing function of age. In the indirect model, the corrosion rate is $d P($ age $) / d($ age $)=n P($ age $) /$ age, with a different parameter $n$ for each cylinder group. Thus the corrosion rate depends on the pit depth. In the direct model, the corrosion rate is $-d M($ age $) / d($ age $)=\beta$ (group)/age, which decreases with age, but does not depend explicitly on pit depth.

The $\alpha$ and $\beta$ (group) parameters in (2.3) are estimated using minimum thickness data and weighted least squares regression. The regression thus leads, for any specified age, to estimates of the mean minimum thickness as well as prediction bounds for the minimum thickness. A level $\gamma$ lower prediction bound $L$ for a random variable $Y$ (e.g., minimum thickness) satisfies $\operatorname{Prob}(Y>L)=\gamma$, thus accounting for parameter estimation error. This relation can also be inverted to obtain a corresponding probability estimate $\gamma$ for any specified thickness $L$. The prediction bounds used with the direct model are based on a nonparametric analog of usual normal-theory regression prediction bounds, so inverted. Details are in Section 5. 


\section{ULTRASONIC THICKNESS DATA AND CID DATA}

The primary goal of this report is to project numbers of cylinders (possibly zero) that will fail certain wall thickness specifications by certain specified years. These projections are computed from regressions with UT measurement data that relate minimum thickness or maximum pit depth to cylinder age and subpopulation. The subpopulations are defined in terms of cylinder characteristics such as nominal wall thickness (312.5, 500, 625 mils) and storage location history. The regressions are used to estimate failure rates, but the absolute numbers likely to fail also depend on the numbers of cylinders at risk. Counts of cylinders at risk, as well as nominal wall thicknesses, location histories, and other data are obtained from the Cylinder Inventory Database (Bechtel Jacobs, 1998) or CID. The CID and the UT data are described generally in Section 3.1 .

The ultrasonic thickness (UT) measurement data used to fit the corrosion models is obtained from UT measurement data sheets. A subset of the UT data (the observed minimum thickness, but not all of the measurements) is also recorded in the CID. The previous version of this report (Schmoyer and Lyon 2003) was based on wall thickness data that had been collected through FY02. This report incorporates additional UT data collected in FY03. The UT data collection is chronicled by fiscal year in Section 3.2, and in Section 3.3, by subpopulations defined by cylinder type (thin-wall, thick-wall, $1 / 2$ "), cylinder location (site, yard, top/bottom status), whether the data is for the head/skirt interface or the main cylinder body, and so on. Because the corrosion projections are based on regressions with actual measurement data, the subpopulations are also defined so that there are actual UT measurements for a reasonable number of cylinders in each subpopulation. The cylinder classification developed in Section 3.3 is used in the regression modeling in Section 4.

\subsection{Data Sources}

Cylinder Inventory Database (CID). CID data is used to classify cylinders and to count the cylinders in each class. The CID (as of January 2004) contains records for 63,393 cylinders. Of those, however, 1,028 are listed as made of either nickel or Monel and are assumed in this report not to be at risk of corrosion. Another 53 cylinders are of unknown (UKN or missing) material type, unknown age, and unknown nominal wall thickness. As those cylinders cannot be classified, they are excluded from the subpopulation counts. Another 127 cylinders are of type "10A." These 10" cylinders are steel, but because no UT measurements have been made on them, no wall thickness projections are made for them in this report. Thus, 62,185 $(63,393-1,028-53-127)$ cylinders are considered "at risk" for this report.

Of the 62,185 cylinders, 52 are of unknown age, of which 31 are 1/2" 30B cylinders, and 21 are thick-wall cylinders. Because projections are made only for cylinders of known age, only the 62,133 $(62,185-52)$ age-known cylinders are included in the CID population counts. Table 1 shows counts by plant site and wall thickness type.

Table 1. CID Counts by Site and Cylinder Thickness Type (Cylinders of Known Age)

\begin{tabular}{ccccc}
\hline Site & $\begin{array}{c}\text { Thin-wall } \\
(\mathbf{3 1 2 . 5} \text { }\end{array}$ & $\begin{array}{c}\text { Thil }) \\
(\mathbf{6 2 5} \text { mil })\end{array}$ & $\begin{array}{c}\text { 1/2" (30A } \\
\text { and 30B })\end{array}$ & Total \\
\hline ETTP & 4,718 & 390 & 310 & 5,418 \\
PGPD & 35,559 & 347 & 1,825 & 37,771 \\
PORTS & 17,269 & 1,265 & 410 & 18,944 \\
\hline Total & 57,586 & 2,002 & 2,545 & 62,133 \\
\hline
\end{tabular}


Of these 62,133, additional cylinders are also excluded from cylinders considered at risk of corrosion, because they were painted in the last ten years. This is discussed in Section 3.1.

Types of UT Data. Two general cylinder areas are studied in the corrosion modeling: the main cylinder body, and the head/skirt interface area. For this report, hand-held UT methods (Lykins and Pawel 1997) were used for all wall thickness data collected in FY98 and later. Except for head/skirt interface data and for the data for two breached cylinders, UT measurements from before FY98 were made with an automated P-scan system (see Schmidt et al 1996 for a description of the equipment). P-scan measurements were made during FY94 at K-1066-K yard at ETTP, in the fall of 1995 at PGDP, between March and September 1996 at both Portsmouth and PGDP, and during FY97 primarily at Portsmouth. The P-scan wall thickness data consists of measurements made for a square region of width and height about $2.54 \mathrm{~mm}$ (0.1 in). Initial thicknesses were estimated with measurements near the maximum-depth pit made either with the P-scanner or with a hand-held probe.

Breached cylinders. Two breached cylinders were discovered by visual inspection in FY92 in K-1066-K yard at ETTP. Mechanical damage may have been a factor, but the strength of the evidence points to external corrosion as the principal cause of those breaches (Barber et al, 1992). In past editions of this report, the data for those two breaches has been used in the corrosion modeling.

Two other breaches were discovered at ETTP in FY92, and two breaches were discovered at Portsmouth in FY90. It was concluded, however, that those breaches were caused by mechanical damage rather than external corrosion (Barber et al, 1990; Barber et al, 1992). Three other breaches, all due to handling damage, are also mentioned in DOE (2003, Chapter 2). As the intent of this report is to model and project effects of corrosion, these mechanically breached, zero minimum thickness cylinders are excluded from the corrosion modeling.

A reviewer of the 2002 report expressed another reason for excluding them-that the breaches "represent a corrosion situation that simply no longer exists (e.g., corr rate $\approx 30$ mils/yr), and using data skewed by that to project future conditions is technically inappropriate." 4 In practice a breached cylinder is either repaired or replaced, so it is certainly inappropriate to use a zero minimum thickness in characterizing a subpopulation of cylinders. A similar argument could also be made, however, for other cylinders besides those that have breached. Much of the cylinder thickness data used for this report is for cylinders that have spent at least part of their lifetimes in conditions similar to the situation for the breached cylinders.

Another reason for excluding the breach data for even the corrosion-induced breaches from the corrosion analyses is that those breaches were discovered by visual inspection rather than random sampling. Including them would induce a pessimistic sampling bias.

The measurements for the FY92 breached cylinders are handled more or less by default as follows: For the indirect model, the breach data is carried along in the analysis, but in a separate cylinder subpopulation, which is not used as the basis for final conclusions. For the direct model, a requirement is that each cylinder have at most one main-body minimum thickness measurement, even over different subpopulations. As discussed below, if cylinders are remeasured, the new data replaces the old. Since the two breached cylinders were remeasured in FY01, the FY01 data is assumed to supercede the old FY92 breach (zero minimum thickness) data.

Statistical Sampling Model. For the corrosion modeling in this report, cylinder sampling is assumed to emulate (or to actually be) random sampling. This is an approximation. Cylinders have sometimes been sampled as a matter of convenience, for example, when they were moved. Cylinders with difficult physical

${ }^{4}$ Steve Pawel, ORNL Corrosion Science \& Technology Group, personal communication.. 
access have been excluded. Cylinders at Portsmouth have been sampled multiple times over the years. Several other cylinders (e.g., FY03 outlier remeasurements) were resampled. When cylinders are measured multiple times, only the most recent measurements are used to fit the corrosion models, because independent observations is a requirement in the regressions.

Independence is violated slightly in the direct-model regression in that head/skirt observations are treated as statistically independent of main body measurements, even when two sets of measurements are from the same cylinder. This assumption could be avoided by analyzing head/skirt and main body data in separate models, just as all cylinder groups are analyzed separately in the indirect model. However, the direct model was deliberately formulated to collectively fit the data, to avoid anomalous parameters estimates by using fewer model parameters representing a wider subset of the data. Furthermore, because the direct model approach is based on a nonparametric approximation, the lowest probabilities direct-model projections can represent are limited by the underlying sample size. (These resolution limits are discussed in Section 5.) Pooling observations minimizes the resolution limit by keeping the sample size as large as possible.

With the exception of the sampling at Portsmouth, the sampling design is cross-sectional — each year, new samples of cylinders are selected for scanning. An alternative to cross-sectional sampling is longitudinal sampling, with the same cylinders measured multiple times over the years. A randomly selected sample of cylinders measured repeatedly over the years can serve as bellwethers for all of the cylinders. Because each cylinder in such a sample can serve as its own control, changes in the sample can be measured on a cylinder to cylinder basis. Measuring the same cylinders compensates for measurement bias.

However, there are disadvantages to the longitudinal approach: (1) Although longitudinal sampling compensates for biases in the measurements that are consistent from year to year, it does not compensate for biases due to changes in the measurement method such as changes in instrument calibration or the change from P-scanning to manual UT scanning. (2) Because the atmospheric corrosion of steel is a very slow process, it takes a very long time to acquire enough longitudinal data to model corrosion effectively. The majority of UT data already collected has been sampled on a cross-sectional basis and is needed to support near-term decisions about cylinder movements and dispositions. (3) Perhaps most important, though an express objective in the cylinder monitoring is characterization, inspection is also a goal. Because year-to-year changes are so small, there is little point, from the perspective of inspection, in rescanning the same cylinders. Measuring the same cylinders year after year diverts resources that could be used to scan cylinders that were not scanned previously. In a cross-sectional approach, new cylinders are scanned, and thus inspected, each year.

\subsection{Data Collection by Fiscal Year}

In this section data collections are discussed in order of the fiscal year they were performed. Tables $2 \mathrm{a}-\mathrm{h}$ are inventories of the data organized this way.

FY92. (See Table 2a.) This data consists of the two breached cylinders discovered in FY92 in K-1066-K yard, for which external corrosion is considered to have caused the breach. The breached cylinders are classified with other pre-FY98 (P-scan) data in the regression analyses performed with this data.

FY94. (See Table 2a.) Between December 1993 and May 1994, wall thickness measurements were made on 136 cylinders in K-1066-K yard (Philpot 1995) using an automated scanner. It was intended that the cylinders selected for measurement should be chosen at random, though a random number generator was not used to select them, and there were limitations imposed by the automated scanner (e.g., length of power cord, clearance between adjacent cylinders). For these reasons, the cylinders selected are not a truly random sample from the population, though they may emulate a random sample. There were questions about the accuracy of the wall thickness measurements of the first 21 of these cylinders, and only minimum wall thickness data was recorded for the first 21 , while maximum thicknesses were also recorded for the 
remaining 115 cylinders. Since maximum thickness data was not recorded for the first 21 cylinders, maximum pit depths could not be used for these cylinders, and they are not included in either the direct or indirect-model analyses in this report. Only the last 115 cylinders are indicated in Table 2a.

Because of accuracy limits in the equipment used to collect this data, only increments of 5 mils were recorded for pit depth. As a result, there are several cylinders with the same pit depth measurement, and which, due to data overlaying, appear to be absent in plots of this data (see Figure 4 in Appendix A).

FY95. (See Table 2a.) During FY95, data was collected for 100 thin-wall cylinders at PGDP using the automated P-scanner (Blue 1995). The primary purpose of this effort was to assess "the condition of the more vulnerable portion" of the cylinder population at PGDP (Blue 1995). The cylinders were selected from various yards on the basis of judgement and thus do not constitute a random sample, though they may emulate one.

FY96. (See Table 2b.) During FY96, wall thicknesses of almost 600 cylinders were measured at Portsmouth and almost 250 cylinders were measured at PGDP. Measurements at both sites were by Pscanning. At Portsmouth, $10 \%$ of the cylinders that were being relocated at the time were selected using a random number generator. The $10 \%$ evaluation criterion was required by a Consent Decree with the Ohio Environmental Protection Agency. Most of the cylinders measured at PGDP were from the old C-745-G yard and had been set aside as part of relocation efforts performed during FY95 and FY96. These cylinders compose a systematic sample from the first 3,900 cylinders moved out of the C-745-G yard. (They were selected from approximately 390 cylinders that had been set aside from the first 3,900 cylinders moved out of the C-745-G yard.) An additional 6 cylinders from both C-745-F and C-745-K yard were also evaluated. For C-745-F yard, single stacked cylinders from the north end were selected, while the C$745-\mathrm{K}$ yard cylinders were selected based on the ease of accessibility with the equipment. In both cases, these samples were not random.

FY97. (See Table 2c.) During FY97, both head/skirt interface and overall minimum wall thickness UT measurements were made, nearly all at Portsmouth, mostly for the head/skirt interface. Head/skirt measurements were made for 114 thick-wall and 230 thin-wall cylinders. The head/skirt measurements were made using manual UT procedures; the overall cylinder body measurements were by P-scanning. (FY97 marks the end of P-scan data used for this report.) The cylinders measured at Portsmouth, which had originally been systematically set aside as part of the $10 \%$ criterion, were randomly selected from those cylinders moved during the year. Originally, it was suggested that approximately 250 cylinders should be measured (Lykins 1996). However, budget constraints allowed only 87 P-scan evaluations. Three P-scan evaluations of thin-wall cylinders were also made at Paducah. These cylinders were located in the north end of the C-745-F yard when they were measured.

FY98. (See Table 2d.) Four populations were sampled in FY98, though the data for only three of the samples is used for this report. The first sample consisted of 40 thin-wall cylinders randomly selected from $\mathrm{K}-1066-\mathrm{K}$ yard at ETTP. These cylinders were chosen from a population of 400 cylinders that were moved to K-1066-E yard during FY98. The second sample consisted of 200 thin-wall cylinders randomly selected from Paducah yards. The Paducah data was representative only of relatively uncorroded locations on each cylinder and therefore is not used for determining either minimum wall thickness or wall loss (and is not indicated in Table 2d. The Paducah cylinders were remeasured in FY99 to estimate minimum wall thicknesses for each cylinder). The third sample consisted of 129 thin-wall, 2 thick-wall, and $12 \frac{1 / 2}{2}$ thick cylinders at Portsmouth X-745-C and E yards. Some of the Portsmouth cylinders were also measured in FY96. All of these UT measurements were manual.

FY99. (See Table 2e.) There were four sampling efforts in FY99, all using manual UT measurements. One effort consisted of 30 thin-wall cylinders randomly selected from ETTP K-1066-K yard. The cylinders were from a subpopulation of 155 cylinders that could be measured without cylinder movement. 
All but one of these cylinders was chosen randomly, with the additional one selected by field personnel because of its history of ground/water contact. The second effort was an evaluation of 199 thin-wall cylinders at Paducah (originally slated for measurement in FY98). In the third effort, which was conducted at Portsmouth, measurements were made of 141 thin-wall 48" cylinders. The fourth effort consisted of measurements of 100 model 30A cylinders from the population of 1,825 at Paducah

FY2000. (See Table 2f.) Additional data for FY2000 included manual UT data for 58 thin-wall cylinders from K-1066-K yard at ETTP, 101 thin-wall cylinders at Paducah, and 129 thin-wall and 23 thick-wall cylinders at Portsmouth. At ETTP, the UT procedure involved making nine measurements along the bottom and top (six and twelve o'clock) lines of the cylinders. At PGDP nine measurements were made at various locations. At Portsmouth fourteen measurements were made at approximately equally spaced points on the cylinder ends and bodies, and five additional measurements were made in the areas considered to have the worst corrosion. Head-skirt measurements were also made at Portsmouth for all 23 of the thick-wall cylinders and for 87 of the thin-wall and cylinders. On each of these cylinders, five measurements were made at the head/skirt interface. Some of the Portsmouth cylinders had also been measured previously.

FY01. (See Table 2g.) FY01 UT measurements were made for 100 thin-wall ETTP cylinders ETTP, 301 thin-wall cylinders at Paducah, mostly from bottom rows of K-1066-K yard. At Paducah, 301 48" thinwall cylinders were measured from (present or former) B, C, F, and K yards, and 99 30A cylinders from A and D yards were measured. At Portsmouth, 139 thin-wall cylinders and 14 thick-wall cylinders were measured, all from X-745-E yard. Head-skirt measurements were also made at Portsmouth for 14 thickwall cylinders and for 99 thin-wall cylinders. At ETTP, the UT procedure involved making four measurement considered to be of the original thickness and five or six additional measurements. The PGDP cylinders were sampled using a random number generator, and the locations of the measurements on the cylinders were as for ETTP. Locations on the cylinders of the Portsmouth measurements were as in FY2000. Some of the Portsmouth cylinders had been measured before.

FY02. (See Table 2h.) FY02 UT measurements were made for 10448 " thin-wall cylinders sampled at ETTP. At PGDP, 77 thin-wall cylinders and 25 30A cylinders were sampled and measured. At Portsmouth, 117 thin-wall and 36 thick-wall were measured. The ETTP and PGDP measurements were located on the cylinders as in FY01. Head-skirt measurements were also made at Portsmouth for the 36 thick-wall cylinders and for 75 of the thin-wall cylinders. Locations on the cylinders of the Portsmouth measurements were as in FY2000.

FY03. (See Table 2i.) FY03 UT measurements were made for 80 thin-wall and $201 \frac{1}{2}$ " 30A cylinders. Ten of the 30A measurements and five of the thin-wall measurements were remeasurements of cylinders identified as outliers in the corrosion model analysis for the 2003 edition of this report. The remaining 85 cylinders (75 thin-wall and 10 30A cylinders) were sampled randomly from unpainted PGDP cylinders that are ten or more years old. At Portsmouth, 109 thin-wall and 46 thick-wall cylinders were measured. These cylinders were sampled as in previous years, and most had been sampled before. All but nine of the main-body measurements and all but sixteen of the head/skirt measurements had been made previously. 
Table 2a. Cylinder Thickness Data Chronology: Data Collected FY92-95

\begin{tabular}{|c|c|c|c|c|c|c|c|c|}
\hline $\begin{array}{l}\text { Year } \\
\text { Measured }\end{array}$ & Site & $\begin{array}{c}\text { Thickness } \\
\text { Class } \\
\end{array}$ & $\begin{array}{c}\text { Skirt } \\
\text { Data? }\end{array}$ & Method & $\begin{array}{c}\text { Current } \\
\text { T/B } \\
\end{array}$ & $\begin{array}{c}\text { Number } \\
\text { Measured }\end{array}$ & $\begin{array}{c}\text { Current } \\
\text { Yard }\end{array}$ & Subgroups \\
\hline 1992 & ETTP & Thin & No & Visual & B & 2 & $\mathrm{~K}$ & 2 from $\mathrm{K}$ bottom \\
\hline \multirow[t]{6}{*}{1994} & ETTP & Thin & No & P-Scan & B & 8 & $\mathrm{E}$ & 3 from $\mathrm{K}$ bottom \\
\hline & & & & & & 41 & $\mathrm{~K}$ & 37 from $\mathrm{K}$ bottom \\
\hline & & & & & & 49 & All & 40 from $\mathrm{K}$ bottom \\
\hline & & & & & $\mathrm{T}$ & 8 & $\mathrm{E}$ & 3 from $\mathrm{K}$ bottom \\
\hline & & & & & & 58 & $\mathrm{~K}$ & 3 from $\mathrm{K}$ bottom \\
\hline & & & & & & 66 & All & 6 from $\mathrm{K}$ bottom \\
\hline \multirow[t]{16}{*}{1995} & PGDP & Thin & No & $\mathrm{P}-$ Scan & $\mathrm{B}$ & 3 & $\mathrm{C}$ & \\
\hline & & & & & & 16 & $\mathrm{~F}$ & 6 from old $\mathrm{F}$ bottom \\
\hline & & & & & & 13 & G & 7 from old $\mathrm{G}$ bottom \\
\hline & & & & & & 3 & $\mathrm{~K}$ & 1 from old $\mathrm{F}$ bottom \\
\hline & & & & & & 11 & $\mathrm{~L}$ & \\
\hline & & & & & & 1 & M & \\
\hline & & & & & & 2 & $\mathrm{~T}$ & \\
\hline & & & & & & 49 & All & 7 from old F bottom, 7 from old G bottom \\
\hline & & & & & $\mathrm{T}$ & 3 & $\mathrm{C}$ & \\
\hline & & & & & & 14 & $\mathrm{~F}$ & 4 from old $\mathrm{F}$ bottom \\
\hline & & & & & & 19 & G & 9 from old $\mathrm{G}$ bottom \\
\hline & & & & & & 1 & $\mathrm{~K}$ & \\
\hline & & & & & & 9 & $\mathrm{~L}$ & \\
\hline & & & & & & 4 & M & 2 from old $\mathrm{G}$ bottom \\
\hline & & & & & & 1 & $\mathrm{~T}$ & \\
\hline & & & & & & 51 & All & 4 from old $\mathrm{F}$ bottom, 11 from old $\mathrm{G}$ bottom \\
\hline
\end{tabular}


Table 2b. Cylinder Thickness Data Chronology: Data Collected FY96

\begin{tabular}{|c|c|c|c|c|c|c|c|}
\hline & Thickness & Skirt & & Current & Number of & Current & \\
\hline Site & Class & Data? & Method & T/B & Cylinders & Yard & Subgroups \\
\hline \multirow[t]{14}{*}{ PGDP } & Thin & $\mathrm{N}$ & P-Scan & B & 49 & G & 1 from old $\mathrm{F}$ bottom, 11 from old $\mathrm{G}$ bottom \\
\hline & & & & & 37 & $\mathrm{~K}$ & 10 from old $\mathrm{G}$ bottom \\
\hline & & & & & 4 & $\mathrm{~L}$ & \\
\hline & & & & & 18 & M & 6 from old $\mathrm{G}$ bottom \\
\hline & & & & & 3 & S & 2 from old $\mathrm{G}$ bottom \\
\hline & & & & & 27 & $\mathrm{~T}$ & 20 from old $\mathrm{G}$ bottom \\
\hline & & & & & 138 & All & 1 from old $\mathrm{F}$ bottom, 49 from old $\mathrm{G}$ bottom \\
\hline & & & & $\mathrm{T}$ & 33 & G & 10 from old $\mathrm{G}$ bottom \\
\hline & & & & & 36 & K & 1 from old $\mathrm{F}$ bottom, 12 from old $\mathrm{G}$ bottom \\
\hline & & & & & 2 & $\mathrm{~L}$ & \\
\hline & & & & & 19 & M & 5 from old $\mathrm{G}$ bottom \\
\hline & & & & & 4 & S & \\
\hline & & & & & 17 & $\mathrm{~T}$ & 14 from old $\mathrm{G}$ bottom \\
\hline & & & & & 111 & All & 1 from old $\mathrm{F}$ bottom, 41 from old $\mathrm{G}$ bottom \\
\hline \multirow[t]{8}{*}{ PORTS } & Thick & $\mathrm{N}$ & P-Scan & B & 1 & $\mathrm{C}$ & \\
\hline & & & & & 60 & $\mathrm{E}$ & 60 from $E$ \\
\hline & & & & & 61 & All & 60 from $\mathrm{E}$ \\
\hline & & & & $\mathrm{T}$ & 54 & E & 54 from $\mathrm{E}$ \\
\hline & Thin & $\mathrm{N}$ & P-Scan & B & 239 & E & 239 from $E$ \\
\hline & & & & $\mathrm{T}$ & 1 & $\mathrm{C}$ & \\
\hline & & & & & 232 & $\mathrm{E}$ & 232 from $E$ \\
\hline & & & & & 233 & All & 232 from $E$ \\
\hline
\end{tabular}


Table 2c. Cylinder Thickness Data Chronology: Data Collected FY97

\begin{tabular}{|c|c|c|c|c|c|c|c|}
\hline & Thicknes & Skirt & & Curren & Number of & Current & \\
\hline Site & Class & Data? & Method & T/B & Cylinders & Yard & Subgroups \\
\hline PGDP & Thin & $\mathrm{N}$ & P-Scan & B & 3 & $\mathrm{G}$ & 2 from old $\mathrm{G}$ bottom \\
\hline \multirow[t]{6}{*}{ PORTS } & Thick & Y & Manual UT & B & 29 & $\mathrm{E}$ & 29 from $\mathrm{E}$ \\
\hline & & & & $\mathrm{T}$ & 85 & $\mathrm{E}$ & 85 from $\mathrm{E}$ \\
\hline & Thin & $\mathrm{N}$ & P-Scan & B & 40 & $\mathrm{E}$ & 40 from $\mathrm{E}$ \\
\hline & & & & $\mathrm{T}$ & 47 & $\mathrm{E}$ & 47 from $E$ \\
\hline & & Y & Manual UT & B & 113 & $\mathrm{E}$ & 113 from $\mathrm{E}$ \\
\hline & & & & $\mathrm{T}$ & 117 & $\mathrm{E}$ & 117 from $\mathrm{E}$ \\
\hline
\end{tabular}


Table 2d. Cylinder Thickness Data Chronology: Data Collected FY98

\begin{tabular}{|c|c|c|c|c|c|c|c|}
\hline & Thickness & Skirt & & CurreI & Number of & Curren & \\
\hline Site & Class & Data? & Method & $\mathbf{T} / \mathbf{B}$ & Cylinders & Yard & Subgroups \\
\hline \multirow[t]{2}{*}{ ETTP } & Thin & $\mathrm{N}$ & Manual UT & B & 21 & $\mathrm{E}$ & 9 from $\mathrm{K}$ bottom \\
\hline & & & & $\mathrm{T}$ & 19 & $\mathrm{E}$ & 8 from $\mathrm{K}$ bottom \\
\hline \multirow[t]{9}{*}{ PORTS } & $1 / 2 "$ & $\mathrm{~N}$ & Manual UT & B & 12 & E & 12 from $E$ \\
\hline & Thick & $\mathrm{N}$ & Manual UT & B & 1 & E & 1 from $E$ \\
\hline & & & & $\mathrm{T}$ & 1 & $\mathrm{E}$ & 1 from $E$ \\
\hline & Thin & $\mathrm{N}$ & Manual UT & B & 63 & $\mathrm{C}$ & \\
\hline & & & & & 5 & E & 5 from $E$ \\
\hline & & & & & 68 & All & 5 from $\mathrm{E}$ \\
\hline & & & & $\mathrm{T}$ & 57 & $\mathrm{C}$ & \\
\hline & & & & & 4 & E & 4 from $E$ \\
\hline & & & & & 61 & All & 4 from $E$ \\
\hline
\end{tabular}


Table 2e. Cylinder Thickness Data Chronology: Data Collected FY99

\begin{tabular}{|c|c|c|c|c|c|c|c|}
\hline \multirow[b]{2}{*}{ Site } & \multirow{2}{*}{$\begin{array}{c}\text { Thickness } \\
\text { Class }\end{array}$} & Skirt & \multicolumn{4}{|c|}{ Current Number of Current } & \multirow[b]{2}{*}{ Subgroups } \\
\hline & & Data? & Method & T/B & Cylinders & Yard & \\
\hline \multirow[t]{6}{*}{ ETTP } & Thin & $\mathrm{N}$ & Manual UT & B & 9 & $\mathrm{E}$ & 8 from $\mathrm{K}$ bottom \\
\hline & & & & & 5 & $\mathrm{~K}$ & 3 from $\mathrm{K}$ bottom \\
\hline & & & & & 14 & All & 11 from K bottom \\
\hline & & & & $\mathrm{T}$ & 10 & E & 2 from $\mathrm{K}$ bottom \\
\hline & & & & & 6 & $\mathrm{~K}$ & 3 from $\mathrm{K}$ bottom \\
\hline & & & & & 16 & All & 5 from $\mathrm{K}$ bottom \\
\hline \multirow[t]{10}{*}{ PGDP } & $1 / 2^{\prime \prime}$ & $\mathrm{N}$ & Manual UT & B & 50 & $\mathrm{~T}$ & \\
\hline & & & & $\mathrm{T}$ & 50 & $\mathrm{~T}$ & \\
\hline & Thin & $\mathrm{N}$ & Manual UT & B & 5 & $\mathrm{C}$ & \\
\hline & & & & & 4 & $\mathrm{~F}$ & \\
\hline & & & & & 34 & G & 5 from old $\mathrm{F}$ bottom, 15 from old $\mathrm{G}$ bottom \\
\hline & & & & & 8 & $\mathrm{~K}$ & 3 from old $\mathrm{F}$ bottom \\
\hline & & & & & 16 & $\mathrm{~L}$ & \\
\hline & & & & & 7 & M & 1 from old $\mathrm{F}$ bottom, 2 from old $\mathrm{G}$ bottom \\
\hline & & & & & 36 & $\mathrm{~T}$ & 21 from old $\mathrm{G}$ bottom \\
\hline & & & & & 110 & All & 9 from old $\mathrm{F}$ bottom, 38 from old $\mathrm{G}$ bottom \\
\hline
\end{tabular}


Table 2e-cont'd. Cylinder Thickness Data Chronology: Data Collected FY99

\begin{tabular}{|c|c|c|c|c|c|c|c|}
\hline \multirow[b]{2}{*}{ Site } & \multicolumn{2}{|c|}{ Thickness Skirt } & \multicolumn{4}{|c|}{ Current Number of Current } & \multirow[b]{2}{*}{ Subgroups } \\
\hline & Class & Data? & Method & T/B & Cylinders & Yard & \\
\hline \multirow[t]{11}{*}{ PGDP } & Thin & $\mathrm{N}$ & Manual UT & $\mathrm{T}$ & 4 & $\mathrm{C}$ & \\
\hline & & & & & 9 & $\mathrm{~F}$ & 7 from old $\mathrm{F}$ bottom \\
\hline & & & & & 37 & $\mathrm{G}$ & 2 from old $\mathrm{F}$ bottom, 20 from old $\mathrm{G}$ bottom \\
\hline & & & & & 1 & $\mathrm{~K}$ & \\
\hline & & & & & 6 & $\mathrm{~L}$ & \\
\hline & & & & & 4 & M & 3 from old $\mathrm{F}$ bottom, 1 from old $\mathrm{G}$ bottom \\
\hline & & & & & 1 & $\mathrm{~N}$ & \\
\hline & & & & & 1 & $\mathrm{P}$ & \\
\hline & & & & & 1 & $\mathrm{~S}$ & 1 from old $\mathrm{G}$ bottom \\
\hline & & & & & 25 & $\mathrm{~T}$ & 18 from old $\mathrm{G}$ bottom \\
\hline & & & & & 89 & All & 12 from old $\mathrm{F}$ bottom, 40 from old $\mathrm{G}$ bottom \\
\hline \multirow[t]{2}{*}{ PORTS } & Thin & $\mathrm{N}$ & Manual UT & B & 53 & $\mathrm{E}$ & 53 from $E$ \\
\hline & & & & $\mathrm{T}$ & 88 & $\mathrm{E}$ & 88 from $\mathrm{E}$ \\
\hline
\end{tabular}


Table 2f. Cylinder Thickness Data Chronology: Data Collected FY2000

\begin{tabular}{|c|c|c|c|c|c|c|c|}
\hline \multirow[b]{2}{*}{ Site } & \multicolumn{2}{|c|}{ Thickness Skirt } & \multicolumn{4}{|c|}{ Current Number of Current } & \multirow[b]{2}{*}{ Subgroups } \\
\hline & Class & Data? & Method & T/B & Cylinders & Yard & \\
\hline \multirow[t]{6}{*}{ ETTP } & Thin & $\mathrm{N}$ & Manual UT & $\mathrm{B}$ & 5 & $\mathrm{E}$ & 4 from $\mathrm{K}$ bottom \\
\hline & & & & & 25 & $\mathrm{~K}$ & 20 from $\mathrm{K}$ bottom \\
\hline & & & & & 30 & All & 24 from $\mathrm{K}$ bottom \\
\hline & & & & $\mathrm{T}$ & 5 & $\mathrm{E}$ & \\
\hline & & & & & 23 & $\mathrm{~K}$ & 9 from $\mathrm{K}$ bottom \\
\hline & & & & & 28 & All & 9 from $\mathrm{K}$ bottom \\
\hline \multirow[t]{16}{*}{ PGDP } & Thin & $\mathrm{N}$ & Manual UT & B & 1 & $\mathrm{D}$ & \\
\hline & & & & & 5 & $\mathrm{~F}$ & 2 from old $\mathrm{F}$ bottom \\
\hline & & & & & 31 & $\mathrm{G}$ & 19 from old $\mathrm{G}$ bottom \\
\hline & & & & & 4 & $\mathrm{~K}$ & 2 from old $\mathrm{F}$ bottom, 1 from old $\mathrm{G}$ bottom \\
\hline & & & & & 4 & $\mathrm{~L}$ & \\
\hline & & & & & 6 & M & 3 from old $\mathrm{F}$ bottom, 2 from old $\mathrm{G}$ bottom \\
\hline & & & & & 1 & $\mathrm{~N}$ & \\
\hline & & & & & 1 & $\mathrm{~T}$ & 1 from old $\mathrm{G}$ bottom \\
\hline & & & & & 53 & All & 7 from old $\mathrm{F}$ bottom, 23 from old $\mathrm{G}$ bottom \\
\hline & & & & $\mathrm{T}$ & 1 & $\mathrm{D}$ & \\
\hline & & & & & 3 & $\mathrm{~F}$ & 2 from old $\mathrm{F}$ bottom \\
\hline & & & & & 33 & G & 2 from old $\mathrm{F}$ bottom, 15 from old $\mathrm{G}$ bottom \\
\hline & & & & & 2 & $\mathrm{~K}$ & 1 from old $\mathrm{F}$ bottom, 1 from old $\mathrm{G}$ bottom \\
\hline & & & & & 2 & $\mathrm{~L}$ & \\
\hline & & & & & 5 & M & 3 from old $\mathrm{F}$ bottom, 1 from old $\mathrm{G}$ bottom \\
\hline & & & & & 2 & $\mathrm{~N}$ & \\
\hline
\end{tabular}


Table 2f-cont'd. Cylinder Thickness Data Chronology: Data Collected FY2000

\begin{tabular}{|c|c|c|c|c|c|c|c|}
\hline & Thickness & Skirt & & Current & Number of & Current & \\
\hline Site & Class & Data? & Method & T/B & Cylinders & Yard & Subgroups \\
\hline PGDP & Thin & $\mathrm{N}$ & Manual UT & $\mathrm{T}$ & 48 & All & 8 from old $\mathrm{F}$ bottom, 17 from old $\mathrm{G}$ bottom \\
\hline \multirow[t]{12}{*}{ PORTS } & Thick & $\mathrm{N}$ & Manual UT & B & 8 & $\mathrm{E}$ & 8 from $\mathrm{E}$ \\
\hline & & & & $\mathrm{T}$ & 15 & $\mathrm{E}$ & 15 from $\mathrm{E}$ \\
\hline & & $\mathrm{Y}$ & Manual UT & B & 8 & $\mathrm{E}$ & 8 from $\mathrm{E}$ \\
\hline & & & & $\mathrm{T}$ & 15 & $\mathrm{E}$ & 15 from $\mathrm{E}$ \\
\hline & Thin & $\mathrm{N}$ & Manual UT & B & 10 & $\mathrm{C}$ & \\
\hline & & & & & 45 & E & 45 from $E$ \\
\hline & & & & & 55 & All & 45 from $E$ \\
\hline & & & & $\mathrm{T}$ & 15 & $\mathrm{C}$ & \\
\hline & & & & & 59 & E & 59 from $E$ \\
\hline & & & & & 74 & All & 59 from $E$ \\
\hline & & Y & Manual UT & B & 39 & $\mathrm{E}$ & 39 from $E$ \\
\hline & & & & $\mathrm{T}$ & 48 & $\mathrm{E}$ & 48 from $\mathrm{E}$ \\
\hline
\end{tabular}


Table 2g. Cylinder Thickness Data Chronology: Data Collected FY01

\begin{tabular}{|c|c|c|c|c|c|c|c|}
\hline \multirow[b]{2}{*}{ Site } & \multicolumn{2}{|c|}{ Thickness Skirt } & \multicolumn{4}{|c|}{ Current Number of Current } & \multirow[b]{2}{*}{ Subgroups } \\
\hline & Class & Data? & Method & $\mathbf{T} / \mathbf{B}$ & Cylinders & Yard & \\
\hline \multirow[t]{4}{*}{ ETTP } & Thin & $\mathrm{N}$ & Manual UT & B & 21 & $\mathrm{E}$ & 11 from $\mathrm{K}$ bottom \\
\hline & & & & & 76 & $\mathrm{~K}$ & 53 from $\mathrm{K}$ bottom \\
\hline & & & & & 97 & All & 64 from $\mathrm{K}$ bottom \\
\hline & & & & $\mathrm{T}$ & 3 & $\mathrm{E}$ & 2 from $\mathrm{K}$ bottom \\
\hline \multirow[t]{12}{*}{ PGDP } & $1 / 2 "$ & $\mathrm{~N}$ & Manual UT & B & 2 & $\mathrm{D}$ & \\
\hline & & & & & 49 & $\mathrm{~T}$ & \\
\hline & & & & & 51 & All & \\
\hline & & & & $\mathrm{T}$ & 48 & $\mathrm{~T}$ & \\
\hline & Thin & $\mathrm{N}$ & Manual UT & B & 102 & $\mathrm{C}$ & \\
\hline & & & & & 16 & $\mathrm{~F}$ & 3 from old $\mathrm{F}$ bottom \\
\hline & & & & & 7 & $\mathrm{G}$ & 6 from old $\mathrm{F}$ bottom \\
\hline & & & & & 2 & $\mathrm{~K}$ & 1 from old $\mathrm{F}$ bottom \\
\hline & & & & & 18 & M & 10 from old $\mathrm{F}$ bottom \\
\hline & & & & & 1 & $S$ & 1 from old $\mathrm{F}$ bottom \\
\hline & & & & & 1 & $\mathrm{~T}$ & 1 from old $\mathrm{F}$ bottom \\
\hline & & & & & 147 & All & 22 from old $\mathrm{F}$ bottom \\
\hline
\end{tabular}


Table 2g-cont'd. Cylinder Thickness Data Chronology: Data Collected FY01

\begin{tabular}{|c|c|c|c|c|c|c|c|}
\hline & Thicknes & Skirt & & Currer & Number of & Current & \\
\hline Site & Class & Data? & Method & T/B & Cylinders & Yard & Subgroups \\
\hline \multirow[t]{9}{*}{ PGDP } & Thin & $\mathrm{N}$ & Manual UT & $\mathrm{T}$ & 99 & $\mathrm{C}$ & \\
\hline & & & & & 24 & $\mathrm{~F}$ & 23 from old $\mathrm{F}$ bottom \\
\hline & & & & & 5 & G & 4 from old $\mathrm{F}$ bottom \\
\hline & & & & & 5 & $\mathrm{~K}$ & 4 from old $\mathrm{F}$ bottom \\
\hline & & & & & 2 & $\mathrm{~L}$ & \\
\hline & & & & & 15 & M & 11 from old $\mathrm{F}$ bottom \\
\hline & & & & & 2 & $S$ & 2 from old $\mathrm{F}$ bottom \\
\hline & & & & & 2 & $\mathrm{~T}$ & 2 from old $\mathrm{F}$ bottom \\
\hline & & & & & 154 & All & 46 from old $\mathrm{F}$ bottom \\
\hline \multirow[t]{8}{*}{ PORTS } & Thick & $\mathrm{N}$ & Manual UT & B & 6 & $\mathrm{E}$ & 6 from $\mathrm{E}$ \\
\hline & & & & $\mathrm{T}$ & 8 & $\mathrm{E}$ & 8 from $\mathrm{E}$ \\
\hline & & $\mathrm{Y}$ & Manual UT & B & 6 & $\mathrm{E}$ & 6 from $\mathrm{E}$ \\
\hline & & & & $\mathrm{T}$ & 8 & $\mathrm{E}$ & 8 from $\mathrm{E}$ \\
\hline & Thin & $\mathrm{N}$ & Manual UT & B & 58 & $\mathrm{E}$ & 58 from $\mathrm{E}$ \\
\hline & & & & $\mathrm{T}$ & 81 & $\mathrm{E}$ & 81 from $\mathrm{E}$ \\
\hline & & $\mathrm{Y}$ & Manual UT & B & 49 & $\mathrm{E}$ & 49 from $E$ \\
\hline & & & & $\mathrm{T}$ & 50 & $\mathrm{E}$ & 50 from $\mathrm{E}$ \\
\hline
\end{tabular}


Table 2h. Cylinder Thickness Data Chronology: Data Collected FY02

\begin{tabular}{|c|c|c|c|c|c|c|c|}
\hline \multirow[b]{2}{*}{ Site } & \multicolumn{2}{|c|}{ Thickness Skirt } & \multicolumn{4}{|c|}{ Current Number of Current } & \multirow[b]{2}{*}{ Subgroups } \\
\hline & Class & Data? & Method & $\mathbf{T} / \mathbf{B}$ & Cylinders & Yard & \\
\hline \multirow[t]{4}{*}{ ETTP } & Thin & $\mathrm{N}$ & Manual UT & $\mathrm{B}$ & 43 & $\mathrm{E}$ & 29 from $\mathrm{K}$ bottom \\
\hline & & & & & 53 & $\mathrm{~K}$ & 28 from $\mathrm{K}$ bottom \\
\hline & & & & & 96 & All & 57 from $\mathrm{K}$ bottom \\
\hline & & & & $\mathrm{T}$ & 7 & $\mathrm{E}$ & 3 from $\mathrm{K}$ bottom \\
\hline \multirow[t]{14}{*}{ PGDP } & $1 / 2^{\prime \prime}$ & $\mathrm{N}$ & Manual UT & B & 14 & $\mathrm{~T}$ & \\
\hline & & & & $\mathrm{T}$ & 11 & $\mathrm{~T}$ & \\
\hline & Thin & $\mathrm{N}$ & Manual UT & B & 3 & $\mathrm{D}$ & 3 from old $\mathrm{F}$ bottom \\
\hline & & & & & 8 & $\mathrm{~F}$ & 1 from old $\mathrm{F}$ bottom \\
\hline & & & & & 24 & $\mathrm{G}$ & 5 from old $\mathrm{F}$ bottom, 8 from old $\mathrm{G}$ bottom \\
\hline & & & & & 5 & $\mathrm{~K}$ & \\
\hline & & & & & 4 & $\mathrm{~L}$ & \\
\hline & & & & & 3 & M & 1 from old $\mathrm{G}$ bottom \\
\hline & & & & & 2 & $\mathrm{~T}$ & \\
\hline & & & & & 49 & All & 9 from old $\mathrm{F}$ bottom, 9 from old $\mathrm{G}$ bottom \\
\hline & & & & $\mathrm{T}$ & 2 & $\mathrm{C}$ & \\
\hline & & & & & 1 & $\mathrm{~F}$ & 1 from old $\mathrm{F}$ bottom \\
\hline & & & & & 17 & $\mathrm{G}$ & 2 from old $\mathrm{F}$ bottom, 6 from old $\mathrm{G}$ bottom \\
\hline & & & & & 7 & $\mathrm{~K}$ & \\
\hline
\end{tabular}


Table 2h-cont'd. Cylinder Thickness Data Chronology: Data Collected FY02

\begin{tabular}{|c|c|c|c|c|c|c|c|}
\hline & Thickness & Skirt & & Curren & Number of & Current & \\
\hline Site & Class & Data? & Method & $\mathbf{T} / \mathbf{B}$ & Cylinders & Yard & Subgroups \\
\hline \multirow[t]{2}{*}{ PGDP } & Thin & $\mathrm{N}$ & Manual UT & $\mathrm{T}$ & 1 & M & \\
\hline & & & & & 28 & All & 3 from old $\mathrm{F}$ bottom, 6 from old $\mathrm{G}$ bottom \\
\hline \multirow[t]{8}{*}{ PORTS } & Thick & $\mathrm{N}$ & Manual UT & B & 18 & $\mathrm{E}$ & 18 from $\mathrm{E}$ \\
\hline & & & & $\mathrm{T}$ & 18 & $\mathrm{E}$ & 18 from $\mathrm{E}$ \\
\hline & & Y & Manual UT & B & 18 & $\mathrm{E}$ & 18 from $\mathrm{E}$ \\
\hline & & & & $\mathrm{T}$ & 18 & $\mathrm{E}$ & 18 from $\mathrm{E}$ \\
\hline & Thin & $\mathrm{N}$ & Manual UT & $\mathrm{B}$ & 54 & $\mathrm{E}$ & 54 from $\mathrm{E}$ \\
\hline & & & & $\mathrm{T}$ & 63 & $\mathrm{E}$ & 63 from $E$ \\
\hline & & $\mathrm{Y}$ & Manual UT & B & 33 & $\mathrm{E}$ & 33 from $E$ \\
\hline & & & & $\mathrm{T}$ & 42 & $\mathrm{E}$ & 42 from $E$ \\
\hline
\end{tabular}


Table 2i. Cylinder Thickness Data Chronology: Data Collected FY03

\begin{tabular}{|c|c|c|c|c|c|c|c|}
\hline \multirow[b]{2}{*}{ Site } & \multicolumn{2}{|c|}{ Thickness Skirt } & \multicolumn{4}{|c|}{ Current Number of Current } & \multirow[b]{2}{*}{ Subgroups } \\
\hline & Class & Data? & Method & $\mathbf{T} / \mathbf{B}$ & Cylinders & Yard & \\
\hline \multirow[t]{18}{*}{ PGDP } & $1 / 2 "$ & $\mathrm{~N}$ & Manual UT & $\mathrm{B}$ & 11 & $\mathrm{~T}$ & \\
\hline & & & & $\mathrm{T}$ & 9 & $\mathrm{~T}$ & \\
\hline & Thin & $\mathrm{N}$ & Manual UT & B & 4 & $\mathrm{C}$ & \\
\hline & & & & & 1 & $\mathrm{~F}$ & \\
\hline & & & & & 6 & $\mathrm{G}$ & 2 from old $\mathrm{G}$ bottom \\
\hline & & & & & 5 & $\mathrm{~K}$ & 1 from old $\mathrm{G}$ bottom \\
\hline & & & & & 6 & $\mathrm{~L}$ & \\
\hline & & & & & 4 & M & 2 from old $\mathrm{F}$ bottom, 1 from old $\mathrm{G}$ bottom \\
\hline & & & & & 14 & $\mathrm{~T}$ & 1 from old $\mathrm{F}$ bottom, 1 from old $\mathrm{G}$ bottom \\
\hline & & & & & 40 & All & 3 from old $F$ bottom, 5 from old $\mathrm{G}$ bottom \\
\hline & & & & $\mathrm{T}$ & 2 & $\mathrm{C}$ & \\
\hline & & & & & 2 & $\mathrm{~F}$ & 2 from old $\mathrm{F}$ bottom \\
\hline & & & & & 11 & G & 5 from old $\mathrm{G}$ bottom \\
\hline & & & & & 4 & $\mathrm{~K}$ & \\
\hline & & & & & 3 & $\mathrm{~L}$ & \\
\hline & & & & & 5 & M & 1 from old $\mathrm{F}$ bottom, 1 from old $\mathrm{G}$ bottom \\
\hline & & & & & 13 & $\mathrm{~T}$ & 3 from old $\mathrm{F}$ bottom \\
\hline & & & & & 40 & All & 6 from old $\mathrm{F}$ bottom, 6 from old $\mathrm{G}$ bottom \\
\hline \multirow[t]{4}{*}{ PORTS } & Thick & $\mathrm{N}$ & Manual UT & $\mathrm{B}$ & 20 & $\mathrm{E}$ & 20 from $\mathrm{E}$ \\
\hline & & & & $\mathrm{T}$ & 26 & $\mathrm{E}$ & 26 from $\mathrm{E}$ \\
\hline & & $\mathrm{Y}$ & Manual UT & $\mathrm{B}$ & 20 & $\mathrm{E}$ & 20 from $\mathrm{E}$ \\
\hline & & & & $\mathrm{T}$ & 26 & $\mathrm{E}$ & 26 from $\mathrm{E}$ \\
\hline
\end{tabular}


Table 2i-cont'd. Cylinder Thickness Data Chronology: Data Collected FY03

\begin{tabular}{|c|c|c|c|c|c|c|c|}
\hline & Thickness & Skirt & & Curren & Number of & Curren & \\
\hline Site & Class & Data? & Method & T/B & Cylinders & Yard & Subgroups \\
\hline \multirow[t]{4}{*}{ PORTS } & Thin & $\mathrm{N}$ & Manual UT & B & 46 & E & 46 from $\mathrm{E}$ \\
\hline & & & & $\mathrm{T}$ & 63 & $\mathrm{E}$ & 63 from $E$ \\
\hline & & $\mathrm{Y}$ & Manual UT & B & 26 & E & 26 from $\mathrm{E}$ \\
\hline & & & & $\mathrm{T}$ & 42 & E & 42 from $E$ \\
\hline
\end{tabular}




\subsection{Summary of Data by Subpopulation}

Like Section 3.2, this section also summarizes UT measurements. However, in this section the data is classified into seventeen subpopulations, rather than by year of data collection. This classification is used in Section 4 in fitting the corrosion regression models. The subpopulations are defined on the basis of cylinder type (thin-wall, thick-wall, 1/2"), location histories (site, yard, top/bottom status), positions of thickness measurements (main body or head/skirt interface), measurement method (manual UT or P-scan), and the amount of thickness data that has been collected for potential subpopulations. Tables 3a-d categorizes cylinders and gives subpopulation counts and counts by fiscal year of the thickness measurements. This categorization is refined into the seventeen subpopulations (Table 4).

Tables 3a-c are for cylinder subpopulations at ETTP, PGDP, and PORTS, respectively, for which one or more wall-thickness measurements have been made. Table $3 \mathrm{~d}$ lists other cylinder subpopulations for which no wall-thickness measurements have (as yet) been made. For projections about numbers of cylinders that will fail the various thickness criteria, these subpopulations are grouped with subpopulations that do have data and are thus used to fit the indirect or direct corrosion models. Total population counts are also listed in the tables for cylinders of known age and for cylinders not painted in the last ten years, which are considered "at risk" in the cylinder corrosion models. (Cylinders painted in the last ten years are assumed to be not at risk.) Cylinders of unknown age cannot be used in the (age-based) corrosion models. Thus projections of numbers of cylinders failing various thickness criteria are ultimately based on population counts for unpainted cylinders of known age.

In reckoning bounds, it is often useful to focus on worst cases. Estimates of corrosion performance for worst-case cylinder groups are lower bounds for the performance expected from other cylinders. Bottomrow storage conditions are generally worse than top. Various cylinder yards, such as the former (unrefurbished) G-yard at Paducah, are generally considered to be or to have been worst-case yards. Kyard is considered worst at ETTP, and E-yard is considered worst at Portsmouth, though there is probably less of a difference between yards at Portsmouth than at the other sites. ${ }^{5}$ The worst cases are used in defining the classifications for thin-wall cylinders.

Most of the wall-thickness data available for this report is for thin-wall cylinders. Also, most of the wallthickness data is for wall areas on the main cylinder body as opposed to the head/skirt interface. Some data, though considerably less, is available for $1 / 2 "$ and thick-wall cylinders and for the head/skirt interface. Therefore, although statistics for $1 / 2$ " and thick-wall cylinders and the head/skirt interface area are broken down by site in Tables 3a-d, single classes for all three sites are used for this data in the corrosion modeling. These cylinders are classified by top/bottom status in the corrosion models, however, except for the thick-wall head/skirt data, which is combined even for the top and bottom cylinders.

For thin-wall cylinders, PGDP former G-yard bottom (worst case) cylinders are taken as a separate class, as are ETTP K-yard bottom cylinders. PGDP bottom-row thin-wall cylinders not from former G-yard are taken as a separate class, as are PGDP top-row thin-wall cylinders. Because of limits on data availability, all (both top and bottom) ETTP thin-wall cylinders other than K-yard bottom cylinders are taken as a separate class.

Determination of Location. Cylinders at Portsmouth are stored in one of two yards, C and E-yards. Although C-yard has more cylinders, most of the Portsmouth wall thickness data is for cylinders from Eyard, which is considered the worst case. C and E-yard thin-wall cylinders are classified separately in Tables $3 \mathrm{c}$ and $3 \mathrm{~d}$, but for the corrosion and wall-thickness modeling, $\mathrm{C}$ and E-yard cylinders are grouped

${ }^{5}$ Roger McDermott, Theta Technologies, Inc., personal communication. 
together, and only the top/bottom status is used to classify Portsmouth thin-wall cylinders, with the bottom cylinders representing the worst-case.

The best way to classify cylinders can change over time. Previously all ETTP cylinders were classed together. With additional data collected in recent years, ETTP, K-yard bottom cylinders are now treated as a separate class. Former F-yard at PGDP is considered to represent the second-worst case at PGDP, next to former G-yard, ${ }^{6}$ and former F-yard cylinders may be separately classified in a future edition of this report. For now, however, there does not seem to be sufficient data or reason to warrant modeling $F$ yard separately.

Of course an individual cylinder's location (site, yard, top/bottom status) can also change over time. Complete location histories of cylinders are not generally available in the CID or in any other electronic format, and even if electronic histories were available, incorporating them into a corrosion model would be difficult. For many cylinders, even when former locations have been recorded, the corresponding old top/bottom statuses have not. Thus some guesswork and approximations are used in classifying cylinders on the basis of their location histories. In this report, "location" of a cylinder refers in theory to where the cylinder was stored longest, but because the longest-storage locations are not determinable exactly for every cylinder, "location" is in practice a best guess of where the cylinder was stored longest. Sometimes current top/bottom statuses are substituted for missing former top/bottom statuses. Thus the cylinder locations used in this report are rough approximations to a more ideal classification.

P-Scan and Manual UT Data. Although P-scanning was originally the primary method used to measure cylinder wall thicknesses, manual UT data has become preponderant over the last few years. For the data in this report, except for head/skirt interface data, all UT measurements made before FY98 were by automatic P-scanning and all UT measurements in FY98 and later were manual. All of the head/skirt UT measurements were manual.

Sampling methods in the earlier years tended to be more purposive (e.g., to deliberately examine suspect cylinders). Subsequent sampling has been closer to random. Furthermore, manual UT and P-scan measurements have appeared to be somewhat inconsistent. Measurements made by manual UT in FY98 are significantly different from the measurements of the same cylinders made in FY94 with P-scan equipment (see Lyon 2000, p 23). The manually collected data shows a larger minimum thickness (mean difference: 49.8 mils; standard error: 8.8 mils; significance level of difference: .002). Similarly, Schmidt et al (1996) found that P-scan measurements under-predicted minimum wall thickness by an average of 1020 mils. An analysis of Portsmouth cylinders measured in FY96 and again in FY98-01 shows P-scan minimum wall thicknesses 20-30 mils smaller. Assuming that this trend holds in general, because the Pscan method predates the manual UT measurements, P-scanned cylinders tend to have lower ages, and the systematic difference between manual and P-scan UT results would skew corrosion rate estimates, if the Pscan and manual UT data were combined into a single (uncorrected) analysis.

For these reasons, over the past few years, the P-scan data has been deprecated in the corrosion analyses. This has been accomplished in steps as the manual UT data has gone from predominant to secondary in the UT database:

1. For thin-wall cylinders, P-scan data is incorporated into the corrosion modeling, but as separate data classes, and conclusions from the P-scan data are deprecated in the interpretation.

\footnotetext{
${ }^{6}$ The top and bottom rows of PGDP F-yard were interchanged in FY92 when all bottom row cylinder chocks were replaced, concrete chocks replacing wood. Each row was also relocated south one row. It is likely that some of these bottom row cylinders were in water contact for extended periods of time, although none are now, and conditions in the F-yard are considered to have been better than G-yard conditions.
} 
2. P-scan data was originally but is no longer used to model corrosion in thick-wall cylinders.

3. For the direct model, P-scan data is dropped for any cylinder for which more recent manual UT measurements have been made.

Note that none of the UT measurements of $1 \frac{1}{2}$ " cylinders has been by P-scanning. Steps 2 and 3 are new for this (2004) edition of the corrosion report. There is not enough P-scan data for thick-wall cylinders to warrant a separate group for it, so that data is not used at all in the analysis. The advantage of step 3 is that it makes data for separate cylinders statistically independent (except for head/skirt data; see below), which is an assumption in the direct model regression. This is not a requirement for the indirect models, which are fit separately for each cylinder group, and so (3) is imposed only for the direct model. Step (3) was not taken for the direct model in previous editions of this report, because it reduces the net sample size. Additional data collected in the last few years now mitigates that reduction.

ETTP Thin-Wall Cylinders. Table 3 a inventories the P-scan and manual UT cylinder thickness data available for ETTP. There are 4,718 thin-wall cylinders at ETTP. Of these 4,034 have not been painted in the last ten years and are of known age ranging (in 2004) from 12 to 48 years. The bottom-rows of ETTP K-1066-K yard are considered to represent worst-case storage conditions at ETTP. A large portion of these K-yard cylinders were previously stored in ground contact at K-1066-G yard, starting about 1966. They were relocated to K-yard in 1983 (Barber et al. 1994), where they are stored either in top or bottom rows. According to CID records (as of January 2004), 1,506 ETTP cylinders are classified as having spent the substantial part of their lifetimes at K-yard bottom. Of these, 1,261 are currently stored in top rows, and 245 are currently stored in bottom rows. Of the 1,506, 1,166 are unpainted and of known age. There are 3,212 (1,314 bottom and 1,898 top) other currently unpainted cylinders at ETTP, of which 2,868 are of known age. In the corrosion modeling, these cylinders are handled as three subpopulations, those with P-scan data (group \#1), and separate top and bottom-row subpopulations (groups \#2 and 3) for cylinders with more recent manual UT measurements.

Paducah Thin-Wall Cylinders. Table $3 \mathrm{~b}$ inventories the thin-wall cylinder thickness data collected for PGDP cylinders. According to the CID, there are 35,599 thin-wall cylinders at Paducah of which 32,231 are of known age and have not been painted in the last ten years. The ages range from 5 to 48 years. The following three populations of Paducah thin-wall cylinders were defined for the purpose of corrosion modeling: (1) PGDP G-yard (i.e., C-745-G yard), bottom-row, thin-wall cylinders, (2) all other PGDP bottom-row, thin-wall cylinders, and (3) all PGDP, top-row, thin-wall cylinders (including G yard cylinders). The subpopulation of cylinders classified as coming from $\mathrm{G}$ yard actually consists of those cylinders that were originally in $\mathrm{C}-745-\mathrm{G}$ yard prior to construction of the new yard. A painting program was initiated for cylinders moved from C-745-G to C-745-S yard in FY96. All 2,168 cylinders in C-745-S were painted during FY96-97. There are currently 3,907 cylinder classified as from former G-yard bottom, but only 1,983 are unpainted (all of known age). Of these 1,983, 1,047 are currently stored in bottom rows, and 936 are currently stored in top rows. There are 16,079 other (i.e, not from former G-yard) bottom-row cylinders at Paducah, of which 15,337 are unpainted and of known age. There are 15,613 toprow cylinders, of which 14,911 are unpainted and of known age.

PGDP P-scan data is handled separately in the corrosion modeling, as one data group (\#4), regardless of yard or top/bottom row. Former G-yard bottom-row cylinders are singled out as a separate subpopulation (group \#5). Otherwise top and bottom-row PGDP thin-wall cylinders are treated as separate subpopulations (groups \#6 and 7). 
Table 3a. ETTP Cylinder Population and Thickness Data Inventory

\begin{tabular}{|c|c|c|c|c|c|c|c|c|c|c|c|c|}
\hline $\begin{array}{c}\text { Thickness } \\
\text { Class }\end{array}$ & $\begin{array}{l}\text { Skirt } \\
\text { Data? }\end{array}$ & $\begin{array}{c}\text { Current } \\
\text { T/B }\end{array}$ & Subgroups & $\begin{array}{l}\text { Pop. } \\
\text { Count }\end{array}$ & Unpainted & $\begin{array}{l}\text { Unpainted, } \\
\text { Age Known }\end{array}$ & $\begin{array}{c}\text { Min } \\
\text { Age } \\
(\mathbf{2 0 0 4})\end{array}$ & $\begin{array}{c}\text { Mean } \\
\text { Age } \\
(\mathbf{2 0 0 4})\end{array}$ & $\begin{array}{c}\text { Max } \\
\text { Age } \\
(2004)\end{array}$ & $\begin{array}{c}\text { FY } \\
\text { Measured }\end{array}$ & $\begin{array}{l}\text { Number } \\
\text { Measured }\end{array}$ & $\begin{array}{c}\text { Current } \\
\text { Yards }\end{array}$ \\
\hline \multirow[t]{25}{*}{ Thin } & No & B & - & 1,314 & 1,186 & 1,186 & 12 & 32.3 & 48 & 1994 & 9 & E, K \\
\hline & & & & & & & & & & 1998 & 12 & E \\
\hline & & & & & & & & & & 1999 & 3 & E, K \\
\hline & & & & & & & & & & 2000 & 6 & $\mathrm{E}, \mathrm{K}$ \\
\hline & & & & & & & & & & 2001 & 33 & $\mathrm{E}, \mathrm{K}$ \\
\hline & & & & & & & & & & 2002 & 39 & $\mathrm{E}, \mathrm{K}$ \\
\hline & & & K-bottom & 1,261 & 1,033 & 1,033 & 13 & 43.1 & 48 & 1992 & 2 & K \\
\hline & & & & & & & & & & 1994 & 40 & $\mathrm{E}, \mathrm{K}$ \\
\hline & & & & & & & & & & 1998 & 9 & E \\
\hline & & & & & & & & & & 1999 & 11 & $\mathrm{E}, \mathrm{K}$ \\
\hline & & & & & & & & & & 2000 & 24 & $\mathrm{E}, \mathrm{K}$ \\
\hline & & & & & & & & & & 2001 & 64 & $\mathrm{E}, \mathrm{K}$ \\
\hline & & & & & & & & & & 2002 & 57 & $\mathrm{E}, \mathrm{K}$ \\
\hline & & $\mathrm{T}$ & - & 1,898 & 1,682 & 1,682 & 22 & 36.3 & 48 & 1994 & 60 & $\mathrm{E}, \mathrm{K}$ \\
\hline & & & & & & & & & & 1998 & 11 & E \\
\hline & & & & & & & & & & 1999 & 11 & $\mathrm{E}, \mathrm{K}$ \\
\hline & & & & & & & & & & 2000 & 19 & $\mathrm{E}, \mathrm{K}$ \\
\hline & & & & & & & & & & 2001 & 1 & $\mathrm{E}$ \\
\hline & & & & & & & & & & 2002 & 4 & E \\
\hline & & & K-bottom & 245 & 133 & 133 & 41 & 46.1 & 47 & 1994 & 6 & $\mathrm{E}, \mathrm{K}$ \\
\hline & & & & & & & & & & 1998 & 8 & $\mathrm{E}$ \\
\hline & & & & & & & & & & 1999 & 5 & $\mathrm{E}, \mathrm{K}$ \\
\hline & & & & & & & & & & 2000 & 9 & $\mathrm{~K}$ \\
\hline & & & & & & & & & & 2001 & 2 & $\mathrm{E}$ \\
\hline & & & & & & & & & & 2002 & 3 & $\mathrm{E}$ \\
\hline
\end{tabular}


Table 3b. PGDP Cylinder Population and Thickness Data Inventory

\begin{tabular}{|c|c|c|c|c|c|c|c|c|c|c|c|c|}
\hline $\begin{array}{c}\text { Thickness } \\
\text { Class }\end{array}$ & $\begin{array}{l}\text { Skirt } \\
\text { Data? }\end{array}$ & $\begin{array}{c}\text { Current } \\
\text { T/B }\end{array}$ & Subgroups & $\begin{array}{l}\text { Pop. } \\
\text { Count }\end{array}$ & Unpainted & $\begin{array}{l}\text { Unpainted, } \\
\text { Age Known }\end{array}$ & $\begin{array}{c}\text { Min } \\
\text { Age } \\
(2004)\end{array}$ & $\begin{array}{c}\text { Mean } \\
\text { Age } \\
(2004)\end{array}$ & $\begin{array}{c}\text { Max } \\
\text { Age } \\
(2004)\end{array}$ & $\begin{array}{c}\text { FY } \\
\text { Measured }\end{array}$ & $\begin{array}{l}\text { Number } \\
\text { Measured }\end{array}$ & $\begin{array}{c}\text { Current } \\
\text { Yards }\end{array}$ \\
\hline \multirow[t]{8}{*}{$1 / 2^{\prime \prime}$} & No & B & - & 926 & 926 & 926 & 50 & 50.0 & 50 & 1999 & 50 & $\mathrm{~T}$ \\
\hline & & & & & & & & & & 2001 & 51 & $\mathrm{~T}, \mathrm{D}$ \\
\hline & & & & & & & & & & 2002 & 14 & $\mathrm{~T}$ \\
\hline & & & & & & & & & & 2003 & 11 & $\mathrm{~T}$ \\
\hline & & $\mathrm{T}$ & - & 899 & 899 & 899 & 50 & 50.0 & 50 & 1999 & 50 & $\mathrm{~T}$ \\
\hline & & & & & & & & & & 2001 & 48 & $\mathrm{~T}$ \\
\hline & & & & & & & & & & 2002 & 11 & $\mathrm{~T}$ \\
\hline & & & & & & & & & & 2003 & 9 & $\mathrm{~T}$ \\
\hline \multirow[t]{15}{*}{ Thin } & No & B & - & 16,079 & 15,337 & 15,337 & 5 & 21.4 & 48 & 1995 & 42 & $\mathrm{~K}, \mathrm{~T}, \mathrm{C}, \mathrm{F}, \mathrm{G}, \mathrm{L}, \mathrm{M}$ \\
\hline & & & & & & & & & & 1996 & 89 & $\mathrm{~K}, \mathrm{~T}, \mathrm{G}, \mathrm{L}, \mathrm{M}, \mathrm{S}$ \\
\hline & & & & & & & & & & 1997 & 1 & $\mathrm{G}$ \\
\hline & & & & & & & & & & 1999 & 72 & $\mathrm{~K}, \mathrm{~T}, \mathrm{C}, \mathrm{F}, \mathrm{G}, \mathrm{L}, \mathrm{M}$ \\
\hline & & & & & & & & & & 2000 & 30 & $\mathrm{~K}, \mathrm{D}, \mathrm{F}, \mathrm{G}, \mathrm{L}, \mathrm{M}, \mathrm{N}$ \\
\hline & & & & & & & & & & 2001 & 147 & $\mathrm{~K}, \mathrm{~T}, \mathrm{C}, \mathrm{F}, \mathrm{G}, \mathrm{M}, \mathrm{S}$ \\
\hline & & & & & & & & & & 2002 & 40 & $\mathrm{~K}, \mathrm{~T}, \mathrm{D}, \mathrm{F}, \mathrm{G}, \mathrm{L}, \mathrm{M}$ \\
\hline & & & & & & & & & & 2003 & 35 & $\mathrm{~K}, \mathrm{~T}, \mathrm{C}, \mathrm{F}, \mathrm{G}, \mathrm{L}, \mathrm{M}$ \\
\hline & & & Old G-Btm. & 2,015 & 1,046 & 1,046 & 12 & 37.1 & 45 & 1995 & 7 & $\mathrm{G}$ \\
\hline & & & & & & & & & & 1996 & 49 & $\mathrm{~K}, \mathrm{~T}, \mathrm{G}, \mathrm{M}, \mathrm{S}$ \\
\hline & & & & & & & & & & 1997 & 2 & $\mathrm{G}$ \\
\hline & & & & & & & & & & 1999 & 38 & $\mathrm{~T}, \mathrm{G}, \mathrm{M}$ \\
\hline & & & & & & & & & & 2000 & 23 & $\mathrm{~K}, \mathrm{~T}, \mathrm{G}, \mathrm{M}$ \\
\hline & & & & & & & & & & 2002 & 9 & $\mathrm{G}, \mathrm{M}$ \\
\hline & & & & & & & & & & 2003 & 5 & $\mathrm{~K}, \mathrm{~T}, \mathrm{G}, \mathrm{M}$ \\
\hline
\end{tabular}


Table 3b-cont'd. PGDP Cylinder Population and Thickness Data Inventory

\begin{tabular}{|c|c|c|c|c|c|c|c|c|c|c|c|c|}
\hline $\begin{array}{c}\text { Thickness } \\
\text { Class }\end{array}$ & $\begin{array}{l}\text { Skirt } \\
\text { Data? }\end{array}$ & $\begin{array}{c}\text { Current } \\
\text { T/B }\end{array}$ & Subgroups & $\begin{array}{l}\text { Pop. } \\
\text { Count }\end{array}$ & Unpainted & $\begin{array}{l}\text { Unpainted, } \\
\text { Age Known }\end{array}$ & $\begin{array}{c}\text { Min } \\
\text { Age } \\
(2004)\end{array}$ & $\begin{array}{c}\text { Mean } \\
\text { Age } \\
(2004)\end{array}$ & $\begin{array}{c}\text { Max } \\
\text { Age } \\
(2004)\end{array}$ & $\begin{array}{c}\text { FY } \\
\text { Measured }\end{array}$ & $\begin{array}{l}\text { Number } \\
\text { Measured }\end{array}$ & $\begin{array}{c}\text { Current } \\
\text { Yards }\end{array}$ \\
\hline \multirow[t]{13}{*}{ Thin } & No & $\mathrm{T}$ & - & 15,613 & 14,911 & 14,911 & 5 & 22.1 & 48 & 1995 & 40 & $\mathrm{~K}, \mathrm{~T}, \mathrm{C}, \mathrm{F}, \mathrm{G}, \mathrm{L}, \mathrm{M}$ \\
\hline & & & & & & & & & & 1996 & 70 & $\mathrm{~K}, \mathrm{~T}, \mathrm{G}, \mathrm{L}, \mathrm{M}, \mathrm{S}$ \\
\hline & & & & & & & & & & 1999 & 49 & $\mathrm{~K}, \mathrm{~T}, \mathrm{C}, \mathrm{F}, \mathrm{G}, \mathrm{L}, \mathrm{M}, \mathrm{N}, \mathrm{P}$ \\
\hline & & & & & & & & & & 2000 & 31 & $\mathrm{~K}, \mathrm{D}, \mathrm{F}, \mathrm{G}, \mathrm{L}, \mathrm{M}, \mathrm{N}$ \\
\hline & & & & & & & & & & 2001 & 154 & $\mathrm{~K}, \mathrm{~T}, \mathrm{C}, \mathrm{F}, \mathrm{G}, \mathrm{L}, \mathrm{M}, \mathrm{S}$ \\
\hline & & & & & & & & & & 2002 & 22 & $\mathrm{~K}, \mathrm{C}, \mathrm{F}, \mathrm{G}, \mathrm{M}$ \\
\hline & & & & & & & & & & 2003 & 34 & $\mathrm{~K}, \mathrm{~T}, \mathrm{C}, \mathrm{F}, \mathrm{G}, \mathrm{L}, \mathrm{M}$ \\
\hline & & & Old G-Btm. & 1,892 & 937 & 937 & 13 & 39.4 & 45 & 1995 & 11 & $\mathrm{G}, \mathrm{M}$ \\
\hline & & & & & & & & & & 1996 & 41 & $\mathrm{~K}, \mathrm{~T}, \mathrm{G}, \mathrm{M}$ \\
\hline & & & & & & & & & & 1999 & 40 & $\mathrm{~T}, \mathrm{G}, \mathrm{M}, \mathrm{S}$ \\
\hline & & & & & & & & & & 2000 & 17 & $\mathrm{~K}, \mathrm{G}, \mathrm{M}$ \\
\hline & & & & & & & & & & 2002 & 6 & G \\
\hline & & & & & & & & & & 2003 & 6 & $\mathrm{G}, \mathrm{M}$ \\
\hline
\end{tabular}


Table 3c. Portsmouth Cylinder Population and Thickness Data Inventory

\begin{tabular}{|c|c|c|c|c|c|c|c|c|c|c|c|c|}
\hline $\begin{array}{c}\text { Thickness } \\
\text { Class } \\
\end{array}$ & $\begin{array}{r}\text { Skirt } \\
\text { Data? }\end{array}$ & $\begin{array}{c}\text { Current } \\
\text { T/B } \\
\end{array}$ & Subgroups & $\begin{array}{c}\text { Pop. } \\
\text { Count }\end{array}$ & Unpainted & $\begin{array}{c}\text { Unpainted, } \\
\text { Age Known }\end{array}$ & $\begin{array}{c}\text { Min } \\
\text { Age } \\
(\mathbf{2 0 0 4 )}) \\
\end{array}$ & $\begin{array}{c}\text { Mean } \\
\text { Age } \\
(\mathbf{2 0 0 4 )}) \\
\end{array}$ & $\begin{array}{c}\text { Max } \\
\text { Age } \\
(\mathbf{2 0 0 4 )}) \\
\end{array}$ & $\begin{array}{c}\text { FY } \\
\text { Measured } \\
\end{array}$ & $\begin{array}{c}\text { Number } \\
\text { Measured }\end{array}$ & $\begin{array}{c}\text { Current } \\
\text { Yards }\end{array}$ \\
\hline $1 / 2 "$ & No & B & E & 252 & 252 & 252 & 4 & 49.6 & 50 & 1998 & 12 & E \\
\hline \multirow[t]{23}{*}{ Thick } & No & B & - & 1 & 1 & 1 & 50 & 50.0 & 50 & 1996 & 1 & $\mathrm{C}$ \\
\hline & & & E & 649 & 649 & 649 & 24 & 50.3 & 53 & 1996 & 60 & E \\
\hline & & & & & & & & & & 1998 & 1 & E \\
\hline & & & & & & & & & & 2000 & 8 & E \\
\hline & & & & & & & & & & 2001 & 6 & E \\
\hline & & & & & & & & & & 2002 & 18 & E \\
\hline & & & & & & & & & & 2003 & 20 & E \\
\hline & & $\mathrm{T}$ & E & 615 & 615 & 615 & 24 & 50.3 & 53 & 1996 & 54 & E \\
\hline & & & & & & & & & & 1998 & 1 & E \\
\hline & & & & & & & & & & 2000 & 15 & E \\
\hline & & & & & & & & & & 2001 & 8 & E \\
\hline & & & & & & & & & & 2002 & 18 & E \\
\hline & & & & & & & & & & 2003 & 26 & E \\
\hline & Yes & B & E & 649 & 649 & 649 & 24 & 50.3 & 53 & 1997 & 29 & E \\
\hline & & & & & & & & & & 2000 & 8 & E \\
\hline & & & & & & & & & & 2001 & 6 & E \\
\hline & & & & & & & & & & 2002 & 18 & E \\
\hline & & & & & & & & & & 2003 & 20 & E \\
\hline & & $\mathrm{T}$ & E & 615 & 615 & 615 & 24 & 50.3 & 53 & 1997 & 85 & E \\
\hline & & & & & & & & & & 2000 & 15 & E \\
\hline & & & & & & & & & & 2001 & 8 & E \\
\hline & & & & & & & & & & 2002 & 18 & E \\
\hline & & & & & & & & & & 2003 & 26 & E \\
\hline
\end{tabular}


Table 3c-cont'd. Portsmouth Cylinder Population and Thickness Data Inventory

\begin{tabular}{|c|c|c|c|c|c|c|c|c|c|c|c|c|}
\hline $\begin{array}{c}\text { Thickness } \\
\text { Class }\end{array}$ & $\begin{array}{l}\text { Skirt } \\
\text { Data? }\end{array}$ & $\begin{array}{c}\text { Current } \\
\text { T/B }\end{array}$ & Subgroups & $\begin{array}{c}\text { Pop. } \\
\text { Count }\end{array}$ & Unpainted & $\begin{array}{l}\text { Unpainted, } \\
\text { Age Known }\end{array}$ & $\begin{array}{c}\text { Min } \\
\text { Age } \\
(\mathbf{2 0 0 4 )}\end{array}$ & $\begin{array}{c}\text { Mean } \\
\text { Age } \\
(2004)\end{array}$ & $\begin{array}{c}\text { Max } \\
\text { Age } \\
(\mathbf{2 0 0 4 )}\end{array}$ & $\begin{array}{c}\text { FY } \\
\text { Measured }\end{array}$ & $\begin{array}{c}\text { Number } \\
\text { Measured }\end{array}$ & $\begin{array}{c}\text { Current } \\
\text { Yards }\end{array}$ \\
\hline \multirow[t]{5}{*}{ Thin } & No & B & - & 7,345 & 7,345 & 7,345 & 8 & 19.9 & 45 & $\begin{array}{l}1998 \\
2000\end{array}$ & $\begin{array}{l}63 \\
10\end{array}$ & $\begin{array}{l}\mathrm{C} \\
\mathrm{C}\end{array}$ \\
\hline & & & $\mathrm{E}$ & 1,423 & 1,423 & 1,423 & 14 & 40.9 & 48 & $\begin{array}{l}1996 \\
1997 \\
1998 \\
1999 \\
2000 \\
2001 \\
2002 \\
2003\end{array}$ & $\begin{array}{c}239 \\
40 \\
5 \\
53 \\
45 \\
58 \\
54 \\
46\end{array}$ & $\begin{array}{l}\mathrm{E} \\
\mathrm{E} \\
\mathrm{E} \\
\mathrm{E} \\
\mathrm{E} \\
\mathrm{E} \\
\mathrm{E} \\
\mathrm{E}\end{array}$ \\
\hline & & $\mathrm{T}$ & - & 7,118 & 7,118 & 7,118 & 8 & 20.0 & 42 & $\begin{array}{l}1996 \\
1998 \\
2000\end{array}$ & $\begin{array}{c}1 \\
57 \\
15\end{array}$ & $\begin{array}{l}\mathrm{C} \\
\mathrm{C} \\
\mathrm{C}\end{array}$ \\
\hline & & & $\mathrm{E}$ & 1,383 & 1,383 & 1,383 & 14 & 42.2 & 48 & $\begin{array}{l}1996 \\
1997 \\
1998 \\
1999 \\
2000 \\
2001 \\
2002 \\
2003\end{array}$ & $\begin{array}{c}232 \\
47 \\
4 \\
88 \\
59 \\
81 \\
63 \\
63\end{array}$ & $\begin{array}{l}\mathrm{E} \\
\mathrm{E} \\
\mathrm{E} \\
\mathrm{E} \\
\mathrm{E} \\
\mathrm{E} \\
\mathrm{E} \\
\mathrm{E}\end{array}$ \\
\hline & Yes & B & $\mathrm{E}$ & 1,063 & 1,063 & 1,063 & 47 & 47.1 & 48 & $\begin{array}{l}1997 \\
2000 \\
2001 \\
2002 \\
2003\end{array}$ & $\begin{array}{c}113 \\
39 \\
49 \\
33 \\
26\end{array}$ & $\begin{array}{l}\mathrm{E} \\
\mathrm{E} \\
\mathrm{E} \\
\mathrm{E} \\
\mathrm{E}\end{array}$ \\
\hline
\end{tabular}


Table 3c-cont'd. Portsmouth Cylinder Population and Thickness Data Inventory

\begin{tabular}{|c|c|c|c|c|c|c|c|c|c|c|c|c|}
\hline $\begin{array}{c}\text { Thickness } \\
\text { Class }\end{array}$ & $\begin{array}{l}\text { Skirt } \\
\text { Data? }\end{array}$ & $\begin{array}{c}\text { Current } \\
\text { T/B }\end{array}$ & Subgroups & $\begin{array}{l}\text { Pop. } \\
\text { Count }\end{array}$ & Unpainted & $\begin{array}{l}\text { Unpainted, } \\
\text { Age Known }\end{array}$ & $\begin{array}{c}\text { Min } \\
\text { Age } \\
(\mathbf{2 0 0 4})\end{array}$ & $\begin{array}{c}\text { Mean } \\
\text { Age } \\
(\mathbf{2 0 0 4})\end{array}$ & $\begin{array}{c}\text { Max } \\
\text { Age } \\
(\mathbf{2 0 0 4})\end{array}$ & $\begin{array}{c}\text { FY } \\
\text { Measured }\end{array}$ & $\begin{array}{l}\text { Number } \\
\text { Measured }\end{array}$ & $\begin{array}{c}\text { Current } \\
\text { Yards }\end{array}$ \\
\hline \multirow[t]{5}{*}{ Thin } & Yes & $\mathrm{T}$ & E & 1,063 & 1,063 & 1,063 & 47 & 47.1 & 48 & 1997 & 117 & $\mathrm{E}$ \\
\hline & & & & & & & & & & 2000 & 48 & $\mathrm{E}$ \\
\hline & & & & & & & & & & 2001 & 50 & $\mathrm{E}$ \\
\hline & & & & & & & & & & 2002 & 42 & E \\
\hline & & & & & & & & & & 2003 & 42 & $\mathrm{E}$ \\
\hline
\end{tabular}


Table 3d. Site-Specific Cylinder Groupings Without Thickness Data

\begin{tabular}{|c|c|c|c|c|c|c|c|c|c|c|}
\hline Site & $\begin{array}{c}\text { Thickness } \\
\text { Class } \\
\end{array}$ & $\begin{array}{c}\text { Skirt } \\
\text { Data? }\end{array}$ & $\begin{array}{c}\text { Current } \\
\text { T/B } \\
\end{array}$ & Subgroups & $\begin{array}{c}\text { Pop. } \\
\text { Count }\end{array}$ & Unpainted & $\begin{array}{l}\text { Unpainted, } \\
\text { Age Known }\end{array}$ & $\begin{array}{c}\text { Min } \\
\text { Age } \\
(\mathbf{2 0 0 4 )} \\
\end{array}$ & $\begin{array}{c}\text { Mean } \\
\text { Age } \\
(2004) \\
\end{array}$ & $\begin{array}{c}\text { Max } \\
\text { Age } \\
(2004) \\
\end{array}$ \\
\hline \multirow[t]{10}{*}{ ETTP } & $1 / 2^{\prime \prime}$ & No & B & - & 198 & 198 & 175 & 50 & 50 & 50 \\
\hline & & & $\mathrm{T}$ & - & 141 & 141 & 135 & 50 & 50 & 50 \\
\hline & Thick & No & B & - & 193 & 193 & 191 & 42 & 49 & 53 \\
\hline & & & $\mathrm{T}$ & - & 199 & 199 & 199 & 42 & 50 & 53 \\
\hline & & Yes & B & - & 193 & 193 & 191 & 42 & 49 & 53 \\
\hline & & & $\mathrm{T}$ & - & 199 & 199 & 199 & 42 & 50 & 53 \\
\hline & Thin & Yes & B & - & 327 & 201 & 201 & 22 & 46 & 48 \\
\hline & & & & $\mathrm{K}$-bottom & 506 & 279 & 279 & 47 & 47 & 48 \\
\hline & & & $\mathrm{T}$ & - & 436 & 220 & 220 & 25 & 47 & 48 \\
\hline & & & & K-bottom & 222 & 110 & 110 & 47 & 47 & 47 \\
\hline \multirow[t]{6}{*}{ PGDP } & Thick & No & B & - & 223 & 223 & 215 & 11 & 43 & 53 \\
\hline & & & $\mathrm{T}$ & - & 143 & 143 & 132 & 11 & 39 & 53 \\
\hline & & Yes & B & - & 223 & 223 & 215 & 11 & 43 & 53 \\
\hline & & & $\mathrm{T}$ & - & 143 & 143 & 132 & 11 & 39 & 53 \\
\hline & Thin & Yes & B & - & 344 & 344 & 344 & 7 & 46 & 48 \\
\hline & & & $\mathrm{T}$ & - & 317 & 317 & 317 & 23 & 46 & 48 \\
\hline \multirow[t]{6}{*}{ PORTS } & $1 / 2^{\prime \prime}$ & No & B & - & 81 & 81 & 80 & 4 & 49 & 50 \\
\hline & & & $\mathrm{T}$ & - & 78 & 78 & 77 & 4 & 49 & 50 \\
\hline & & & & $\mathrm{E}$ & 1 & 1 & 1 & 50 & 50 & 50 \\
\hline & Thick & Yes & B & - & 1 & 1 & 1 & 50 & 50 & 50 \\
\hline & Thin & Yes & B & - & 598 & 598 & 598 & 22 & 24 & 25 \\
\hline & & & $\mathrm{T}$ & - & 575 & 575 & 575 & 22 & 24 & 25 \\
\hline
\end{tabular}


Portsmouth Thin-Wall Cylinders. P-scan and manual UT measurements for Portsmouth thin-wall cylinders (main body measurements) are inventoried in Table 3c. According to the CID, there are 17,269 thin-wall cylinders at Portsmouth, all of which are of known age and have not been painted in the last ten years. Their ages range from 8 to 48 years. The CID classifies Portsmouth cylinders as coming from two yards, $\mathrm{C}$ or E. Cylinders in both yards are stacked in two tiers. Prior to FY96, there were four cylinder yards at Portsmouth, designated as X-745-A, X-745-C, X-745-E, and X-745-F. The X-745-A and X-745$\mathrm{C}$ yards were essentially the same yard, C-yard, but were separated into different sections.

Cylinders at Portsmouth were moved from single row storage to a two-tiered arrangement around 1976. Prior to that, there were no top row cylinders at Portsmouth. Thus, current "top" row cylinders at Portsmouth have been in a top row for at most about $28(=2004-1976)$ years. The X-745-E yard, which had been a compacted gravel area, was reconstructed during FY95-96 to a reinforced concrete yard. In FY96, 5,708 cylinders were relocated to meet new storage requirements.

In FY96, wall thickness UT measurements were made on $10 \%$ of the cylinders that were relocated, randomly selected (using a random number generator). The $10 \%$ evaluation criterion was required according to a 1989 DOE Consent Decree with the State of Ohio. These cylinders, as well as other cylinders with handling or storage damage, were evaluated using the automated scanner P-scan system and manual UT measurements for head/skirt areas. During subsequent years many of these same cylinders have been remeasured. Many of the measurements are thus duplicates-measurements made on the same cylinders over multiple FY's. In FY03, for example, 155 cylinders were measured on the main cylinder body, but all but nine had been measured previously. In these cases, only the most recent measurements were used in the corrosion modeling, which, because of statistical independence requirements, assumes that all UT measurements on any given cylinder were made at essentially the same time. Although there are advantages to measuring the same cylinders multiple times, the payoff decreases over time, and opportunities for measuring previously unsampled cylinders are thereby foregone.

Although the E-yard cylinders at Portsmouth are, considered on the whole to be in worse shape than C-yard cylinders, because most of the Portsmouth UT data is for E-yard cylinders, all (E and C-yard) thin-wall, top-row cylinders are treated as one group, and all thin-wall, bottom-row cylinders are treated as one group in the regression modeling (Section 4). The bottom-row cylinders thus represent the worst-case of two for thin-wall cylinders at Portsmouth. The Portsmouth thin-wall cylinders with P-scan measurements are modeled as a separate group (\#8). Otherwise Portsmouth thin-wall cylinders are modeled as separate top and bottom-row subpopulations (groups \#9 and 10). There are 8,768 unpainted, age-known, bottom-row cylinders, and 8,501 unpainted, age-known, top-row cylinders.

Thick-Wall Cylinders. UT measurements for thick-wall cylinders (main body) are inventoried in Table 3c. There are 2,023 thick-wall cylinders (nominal wall thickness 625 mils) at the three sites: 1,264 at Portsmouth, 366 at PGDP, and 392 at ETTP, but all of the UT measurements for thick-wall cylinders have been made at Portsmouth. No thick-wall cylinders are designated in the CID as painted. The ages of two cylinders at ETTP and 19 at PGDP are unknown; otherwise the ages are known. The age ranges for thickwall cylinders are 24-53 years at Portsmouth, 11-53 years at PGDP, and 42-53 years at ETTP. Of the thick-wall cylinders that are of known age (and unpainted), 946 are top-row cylinders and 1,056 are bottom-row cylinders. These cylinders are modeled as separate top and bottom-row subpopulations (groups \#11 and 12). The bottom-row cylinders are the "worst case," though with their thick walls, corrosion problems are less of a risk for thick-wall than for thin-wall cylinders. 
Virtually all UT measurements of thick-wall cylinders have been made at Portsmouth (see Table 3c). During FY96, 115 thick-wall cylinders were measured with the P-scanner during a cylinder relocation. Those 115 cylinders were selected because of ease of accessibility (Lykins and Pawel 1997). Because of limitations on the total number of measurements, this P-scan data had been combined with later manual UT measurements in corrosion modeling for thick-wall cylinders. With additional thick-wall measurements made in FY02 and FY03, the thick-wall P-scan data is no longer used.

Thin-Wall Skirted Cylinders. The head/skirt UT data for thin-wall cylinders is inventoried in Table 3c. The CID lists 5,451 thin-wall cylinders as having skirts, 3,299 at PORTS, 1,491 at ETTP, and 661 at PGDP. Of the 5,451, 4,770 are unpainted and of known age: all of the cylinders at Portsmouth and PGPD and 810 at ETTP. The ages of these skirted cylinders range from 18 to 48 years. Of the 4,770 cylinders that are unpainted and of known age, 2,485 are stored in bottom rows and 2,285 are in top rows. In the corrosion model, these cylinders are divided only by the top/bottom status (groups \#13 and 14), with the bottom cylinders assumed to represent the worst case.

Because of a combination of extended time-of-wetness and differential aeration (Lykins and Pawel 1997), there is a concern about the possibility of accelerated corrosion in the head/skirt interface crevice. In order to comply with the Ohio EPA Director's Findings and Orders for Portsmouth cylinder movements performed in FY96, wall thickness measurements at Portsmouth were made during FY97 at the head/skirt interface of 230 thin-wall cylinders. Many of these cylinders were also measured again during subsequent years (see above comments about remeasurements for thin-wall cylinders).

Thick-Wall Skirted Cylinders. The head/skirt UT data for thick-wall cylinders is inventoried in Table 3c. All of the 2,023 thick-wall cylinders discussed above are skirted. As with the thin-wall skirted cylinders, concerns about corrosion vulnerability at the head/skirt interface also apply, though to a lesser extent, to thick-wall cylinders. As part of the compliance with the Ohio EPA Director's Findings and Orders for cylinder movements performed in FY96, wall thickness measurements at Portsmouth were made during FY97 at the head/skirt interface of 114 thick-wall cylinders. Some of these cylinders were measured again during subsequent years, with the more recent data replacing the earlier in the corrosion analysis. These cylinders are modeled as one subpopulation (group \#15).

$1 / 2$ " Thick (30" diameter) Cylinders. UT data for $1 / 2$ " thick 30 " diameter cylinders is inventoried in Tables 3b, 3c, and 3d. There are 1,825 30", 1/2" nominal thickness, cylinders at Paducah, 412 at Portsmouth, and 339 at ETTP. All of the 1/2" cylinders at Paducah, 410 at Portsmouth, and 310 at ETTP are unpainted and of known age. Precise historical information is not available on each cylinder, but it is known that nearly all of them were manufactured around 1954. Except for twelve 30" cylinders measured at Portsmouth in FY98, all 30" cylinder thickness data is for Paducah cylinders. The $1 / 2$ " cylinders are modeled as separate top and bottom populations (groups \#16 an 17). 
Cylinder Subpopulations. The seventeen cylinder subpopulations are summarized in Table 4.

Table 4. The Seventeen Subpopulation Classification System Used for the Regression Modeling

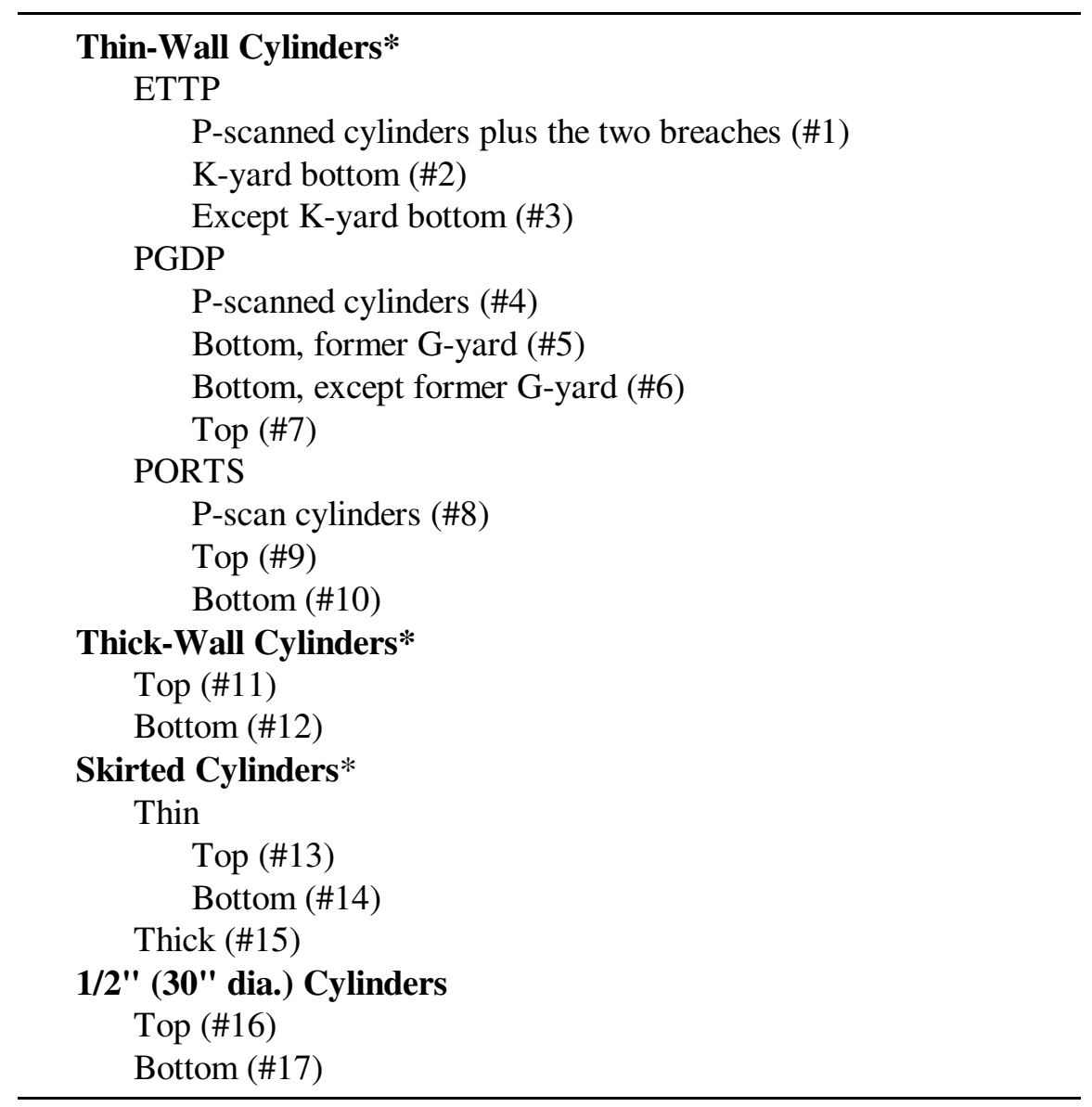

*Main body measurements and head/skirt interface measurements may be on the same cylinders (i.e., the populations overlap). 


\section{DATA ANALYSIS}

This section details regression modeling with the indirect and direct corrosion models discussed in Section 2 and the cylinder corrosion data discussed in Section 3. The indirect model is considered in Section 4.1; the direct model, in Section 4.2. The cylinder classification developed in Section 3.3 and summarized in Table 4 is used for both the direct and indirect models. The classification is intended to strike a balance between model and statistical precision, and it was chosen only after considering the regression modeling results.

Figures 4-20 in Appendix A are scatter plots of maximum pit depth estimates for each of the seventeen cylinder groups. Figures 21-37 in Appendix A are scatter plots of the minimum thickness measurements for each cylinder group. Figures 4-37 also illustrate the indirect or direct model fitted to the maximum pit depth or minimum thickness data. Figures 21-37 also contain charts of the distributions of cylinder ages in underlying subpopulations from which the data is sampled. Projections based on both the direct and indirect fitted regression models are discussed in Section 5, and the direct and indirect models are compared in Section 6.

Several of Figures 4-37 contain points that are highlighted. These points, which are statistical outliers, are discussed in Section 4.3. Reanalyses with both the direct and indirect model are performed without the outliers, and the results are the basis for an alternative set of projections discussed in Section 5.

\subsection{Indirect Model Regressions}

Table 5 summarizes the indirect model results for the seventeen cylinder subpopulations. The indirect model (2.2) is fit to the data for each subpopulation listed in Table 4. For each subpopulation, if the fitted log-scale slope is between 0 and 1, then the fitted model is used per se. If, however, the fitted slope is outside this range, then, according to the indirect model prescription, the "slope $=1$ " model (log pit depth $=$ constant + time, or equivalently, pit depth $\propto$ time) is used instead. Table 5 indicates whether the "slope $=1$ " is model is used, sample sizes, intercept and slope estimates, regression standard deviation, initial thickness estimates, and population sizes. All of this information is used in computing indirect-model wall thickness projections (Section 5).

Table 5 shows that the log-scale slope $=1$ model was used for ten of the seventeen subpopulations. Without setting the slope to one, the indirect corrosion model would fail in ten of the seventeen cases. Examination of Figures 4-20 (Appendix A) and regression output shows that the failures occur in some cases because the fitted slope exceeds 1 and in other cases because the fitted slope is less than 0 .

The failures may be due to a variety of reasons: (1) The maximum pit depth estimates computed from maximum thickness measurements as a proxy for initial thickness are statistically variable and sometimes inconsistent. (2) The logs of the maximum pit depths might not be normally distributed. In particular, there are outliers. (3) The model might not fit, because of changed maintenance and storage conditions, or because the power-law model is based on corrosion physics that might apply to small objects such as metal coupons under ideal conditions, but not necessarily to thermally massive storage cylinders that are abraded, nicked, and cut during one or more use cycles. 
Table 5. Summary of Indirect-Model Populations and Modeling Assumptions

\begin{tabular}{|c|c|c|c|c|c|c|c|c|c|c|c|}
\hline $\begin{array}{l}\text { Cylinder } \\
\text { Grouping }\end{array}$ & Population & Model & $\begin{array}{l}\text { Sample } \\
\text { Size }\end{array}$ & $\begin{array}{c}\text { Inter- } \\
\text { cept }\end{array}$ & Slope & $\begin{array}{l}\text { Std. } \\
\text { Dev. }\end{array}$ & $\begin{array}{c}\text { Initial } \\
\text { Thick- } \\
\text { ness } \\
\text { Sample } \\
\text { Size }\end{array}$ & $\begin{array}{l}\text { Initial } \\
\text { Mean }\end{array}$ & $\begin{array}{l}\text { Initial } \\
\text { Std }\end{array}$ & $\begin{array}{l}\text { Initial } \\
\text { Thick- } \\
\text { ness } \\
\text { Inter- } \\
\text { val }\end{array}$ & $\begin{array}{l}\text { Total } \\
\text { in } \\
\text { Popu- } \\
\text { lation }\end{array}$ \\
\hline \multirow[t]{10}{*}{ Thin-Walled } & ETTP thin (P-scan data) & Slope $=1$ & 117 & 0.532 & 1.000 & 0.456 & 117 & 315.1 & 9.8 & {$[302.5,340]$} & 4,034 \\
\hline & $\begin{array}{r}\text { ETTP thin, } \begin{array}{r}\mathrm{K}-\mathrm{yard} \\
\text { bottom }\end{array}\end{array}$ & Slope $=1$ & 191 & -.567 & 1.000 & 0.788 & 191 & 332.1 & 11.7 & {$[302.5,379]$} & 1,166 \\
\hline & $\begin{array}{l}\text { ETTP thin, except } \\
\text { K-yard bottom }\end{array}$ & Slope $=1$ & 139 & -.629 & 1.000 & 0.903 & 139 & 331.3 & 9.7 & {$[302.5,368]$} & 2,868 \\
\hline & $\begin{array}{r}\text { PGDP thin (P-scan } \\
\text { data })\end{array}$ & Slope Fit & 350 & 1.507 & 0.715 & 0.390 & 350 & 333.8 & 9.3 & {$[302.5,363]$} & 32,231 \\
\hline & $\begin{array}{l}\text { PGDP thin bottom, } \\
\text { former G-yard }\end{array}$ & Slope Fit & 141 & 0.838 & 0.488 & 0.736 & 141 & 323.3 & 13.6 & {$[302.5,350]$} & 1,983 \\
\hline & $\begin{array}{l}\text { PGDP thin btm, excpt } \\
\text { fmr G-yard }\end{array}$ & Slope Fit & 356 & 0.906 & 0.487 & 0.679 & 356 & 327.9 & 13.0 & {$[302.5,395]$} & 15,337 \\
\hline & PGDP thin top & Slope Fit & 248 & 1.414 & 0.286 & 0.640 & 248 & 328.4 & 12.1 & {$[302.5,376]$} & 14,911 \\
\hline & $\begin{array}{r}\text { PORTS thin }\left(\begin{array}{r}P-\text { scan } \\
\text { data })\end{array}\right.\end{array}$ & Slope Fit & 556 & 2.565 & 0.395 & 0.273 & 556 & 332.6 & 13.5 & {$[302.5,378]$} & 17,269 \\
\hline & PORTS thin top & Slope Fit & 206 & 2.644 & 0.199 & 0.448 & 206 & 357.8 & 12.3 & {$[302.5,396]$} & 8,501 \\
\hline & PORTS thin bottom & Slope Fit & 194 & 2.335 & 0.257 & 0.441 & 194 & 355.0 & 13.1 & {$[302.5,430]$} & 8,768 \\
\hline
\end{tabular}


Table 5-cont'd. Summary of Indirect-Model Populations and Modeling Assumptions

\begin{tabular}{|c|c|c|c|c|c|c|c|c|c|c|c|}
\hline $\begin{array}{l}\text { Cylinder } \\
\text { Grouping }\end{array}$ & Population & Model & $\begin{array}{l}\text { Sample } \\
\text { Size }\end{array}$ & $\begin{array}{l}\text { Inter- } \\
\text { cept }\end{array}$ & Slope & $\begin{array}{l}\text { Std. } \\
\text { Dev. }\end{array}$ & $\begin{array}{c}\text { Initial } \\
\text { Thick- } \\
\text { ness } \\
\text { Sample } \\
\text { Size }\end{array}$ & $\begin{array}{l}\text { Initial } \\
\text { Mean }\end{array}$ & $\begin{array}{l}\text { Initial } \\
\text { Std }\end{array}$ & $\begin{array}{c}\text { Initial } \\
\text { Thick- } \\
\text { ness } \\
\text { Inter- } \\
\text { val }\end{array}$ & $\begin{array}{l}\text { Total } \\
\text { in } \\
\text { Popu- } \\
\text { lation }\end{array}$ \\
\hline \multirow[t]{5}{*}{ Thick-Walled } & $\begin{array}{r}\text { ETTP/PGDP/PORTS } \\
\text { thick top }\end{array}$ & Slope $=1$ & 292 & -.096 & 1.000 & 0.700 & 51 & 674.1 & 31.5 & {$[615,749]$} & 957 \\
\hline & $\begin{array}{r}\text { ETTP/PGDP/PORTS } \\
\text { thick bottom }\end{array}$ & Slope $=1$ & 273 & -.052 & 1.000 & 0.771 & 49 & 673.5 & 30.0 & {$[615,727]$} & 1,066 \\
\hline & $\begin{array}{r}\text { ETTP/PGDP/PORTS } \\
\text { thin skirted top }\end{array}$ & Slope $=1$ & 122 & -1.10 & 1.000 & 0.484 & 122 & 364.3 & 14.6 & {$[302.5,435]$} & 2,285 \\
\hline & $\begin{array}{r}\text { ETTP/PGDP/PORTS } \\
\text { thin skirted btm }\end{array}$ & Slope $=1$ & 116 & -1.33 & 1.000 & 0.538 & 116 & 360.4 & 11.5 & {$[302.5,390]$} & 2,485 \\
\hline & $\begin{array}{r}\text { ETTP/PGDP/PORTS } \\
\text { thick skirted }\end{array}$ & Slope $=1$ & 147 & -.321 & 1.000 & 0.709 & 147 & 779.7 & 23.4 & {$[615,849]$} & 2,023 \\
\hline \multirow[t]{2}{*}{$1 / 2^{\prime \prime}(30 "$ dia. $)$} & $\begin{array}{l}\text { ETTP/PGDP/PORTS } \\
1 / 2 " \text { (30" dia.) top }\end{array}$ & Slope $=1$ & 126 & -.128 & 1.000 & 0.751 & 126 & 521.7 & 33.8 & {$[490,595]$} & 1,119 \\
\hline & $\begin{array}{l}\text { ETTP/PGDP/PORTS } \\
1 / 2 " \text { (30" dia.) btm }\end{array}$ & Slope $=1$ & 117 & 0.130 & 1.000 & 0.770 & 117 & 518.1 & 32.5 & {$[490,587]$} & 1,457 \\
\hline
\end{tabular}




\subsection{Direct Model Regressions}

Whether for theoretical reasons or because of practical data limitations, the failure of the fitted-slope power law model in ten of seventeen cases suggests trying an alternative approach that does not require the estimation of pit-depth maxima, and that smooths out data anomalies by imposing more structure than the structure in the indirect approach's seventeen separately-fitted regressions. The direct model is such an approach. The direct model has been fit to UT data since the 2002 report and has generally been more satisfactory than the indirect model in the sense of not leading to inconsistent model fits.

FY03 Cylinders Remeasurements. However, although the direct model was originally considered as an alternative to the indirect model that might lead to tighter wall thickness projections, both models have led to projections that seem too conservative. Possible explanations for why the direct model would be conservative include (1) outliers, and (2) incorrect weighting in the regression model for the different groups. Both of these issues are related to variability in minimum thickness estimates. Variability must be accounted for in wall thickness projections, and, if it is overestimated, projections will be tend to be conservative. In particular, if the $30 \mathrm{~A} 1 / 2$ " cylinders are statistically more variable than the other cylinder groups, then in a combined (e.g. direct-model) analysis, variance estimates for the other groups will be too big, and variance estimates for the 30As will be too small. Inflated variances estimates are a particular problem for thin-wall cylinders, because they are thinner than the other cylinder types to begin with.

A conclusion of the 2003 edition of this report was that certain outlier cylinders should be remeasured to verify or reject their UT measurements. Ten of those cylinders were 30As and five were thin-wall cylinders. All fifteen cylinders are at Paducah. The differences between the remeasurements and original measurements are shown in Figure 1.

The results for the thin-wall cylinders (first five in Figure 1) are as expected. All five minimum thickness remeasurements are at least 100 mils higher than their previous values. Because these cylinders were identified as outliers having unusually low minimum thicknesses, it is not surprising that their remeasurement minimum thicknesses are considerably higher.

The story is different for the ten 30A cylinders. Remeasured minimum thicknesses were substantially higher for two cylinders, but substantially lower for three cylinders. Of the remaining five cylinders, four of the minimum thickness remeasurements were lower than the original values. Because all ten were selected for remeasuring because their minimum thickness seemed to low, these results seem more to substantiate than refute the original $30 \mathrm{~A}$ measurements.

To better understand these minimum thickness differences, they can be referenced to the distribution of minimum thickness differences for Portsmouth cylinders, which have been remeasured as part of the sampling protocol specified in the Consent Decree with the Ohio Environmental Protection Agency. Remeasurement differences for Portsmouth cylinders are plotted in Figure 2. (Note that one 157 mil difference has been excluded in Figure 2 to improve the scaling.) These results suggest that 100 mil differences in minimum thickness measurements are rare. Even 50 mil differences are unusual. Figure 2 suggests that all of the differences for thin-wall cylinders in Figure 1 are unusually large. For the 30A cylinders, two of the positive differences and three or four of the negative differences are unusually large. The unusually large negative differences are particularly surprising. 


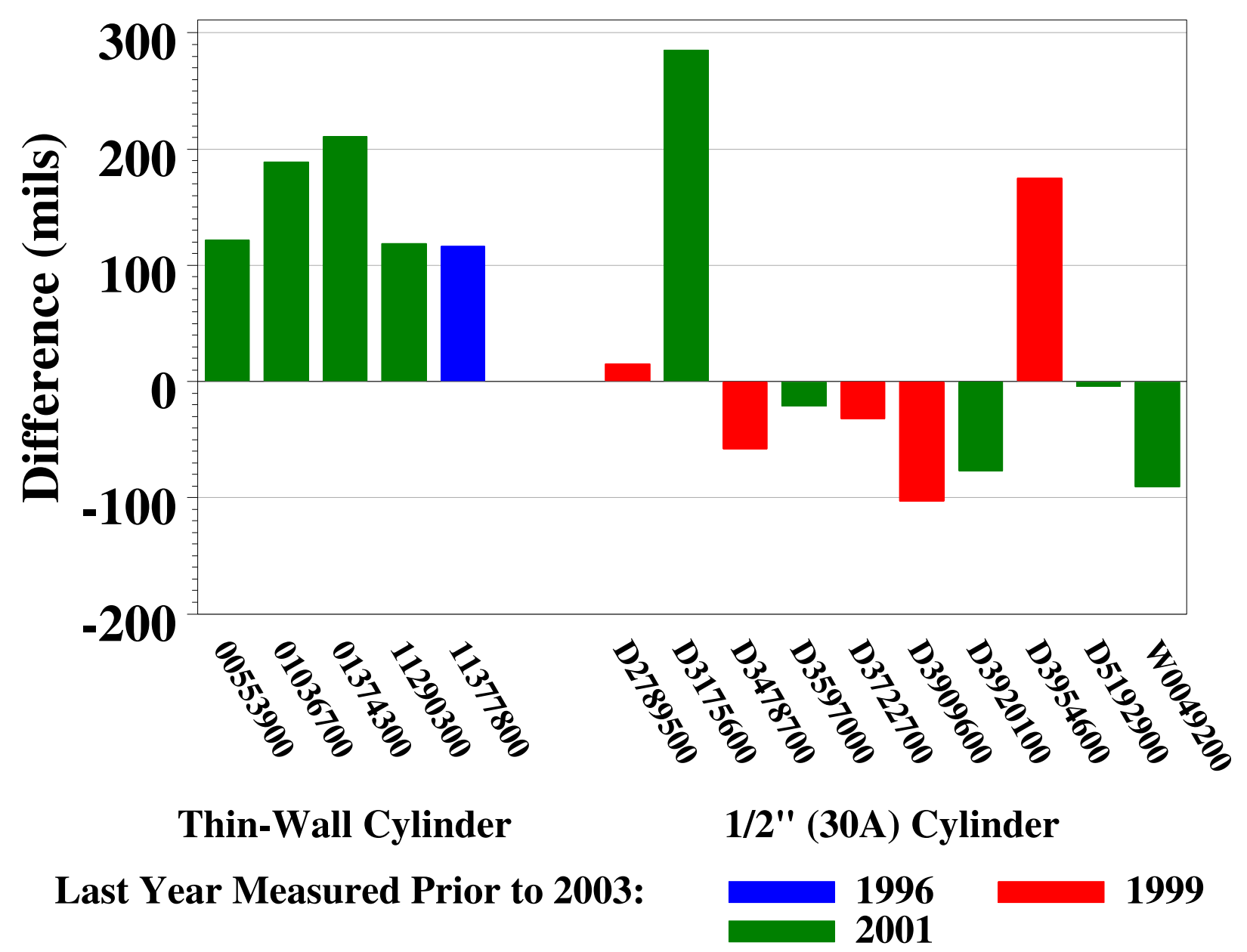

Figure 1. Differences between FY03 and earlier UT measurements for fifteen cylinders selected because the earlier thickness measurements were low-side statistical outliers.

Cylinder minimum thickness measurement error is due to instrument error and error associated with finding the area of minimum thickness. Instrument error is probably quite small, perhaps just a few mils (see for example Fowler et al 2003). Larger errors (on average) are more likely due to not finding the area of minimum thickness. The measurements are a compromise between sampling at predetermined locations and, as a natural part of the inspection process, "gravitation" toward worst areas. However, the analysis of duplicates shows that the difference between actual and observed minimum thickness rarely exceed 30 mils.

On the other hand, the relative consistency across the years of the Portsmouth minimum thickness data suggests that better UT data might be obtained at Portsmouth by measuring new cylinders, rather than remeasuring cylinders measured in the past. Because every UT measurement is an inspection as well as a characterization, remeasurement forgoes possible discoveries.

Thus the remeasurement results for the five thin-wall cylinders support the idea that some unusually low minimum thickness measurements are bad values and should be replaced or excluded. At the same time, however, the remeasurements for the 30As suggest that minimum thicknesses for 30As are statistically more variable than for the other subpopulations. 


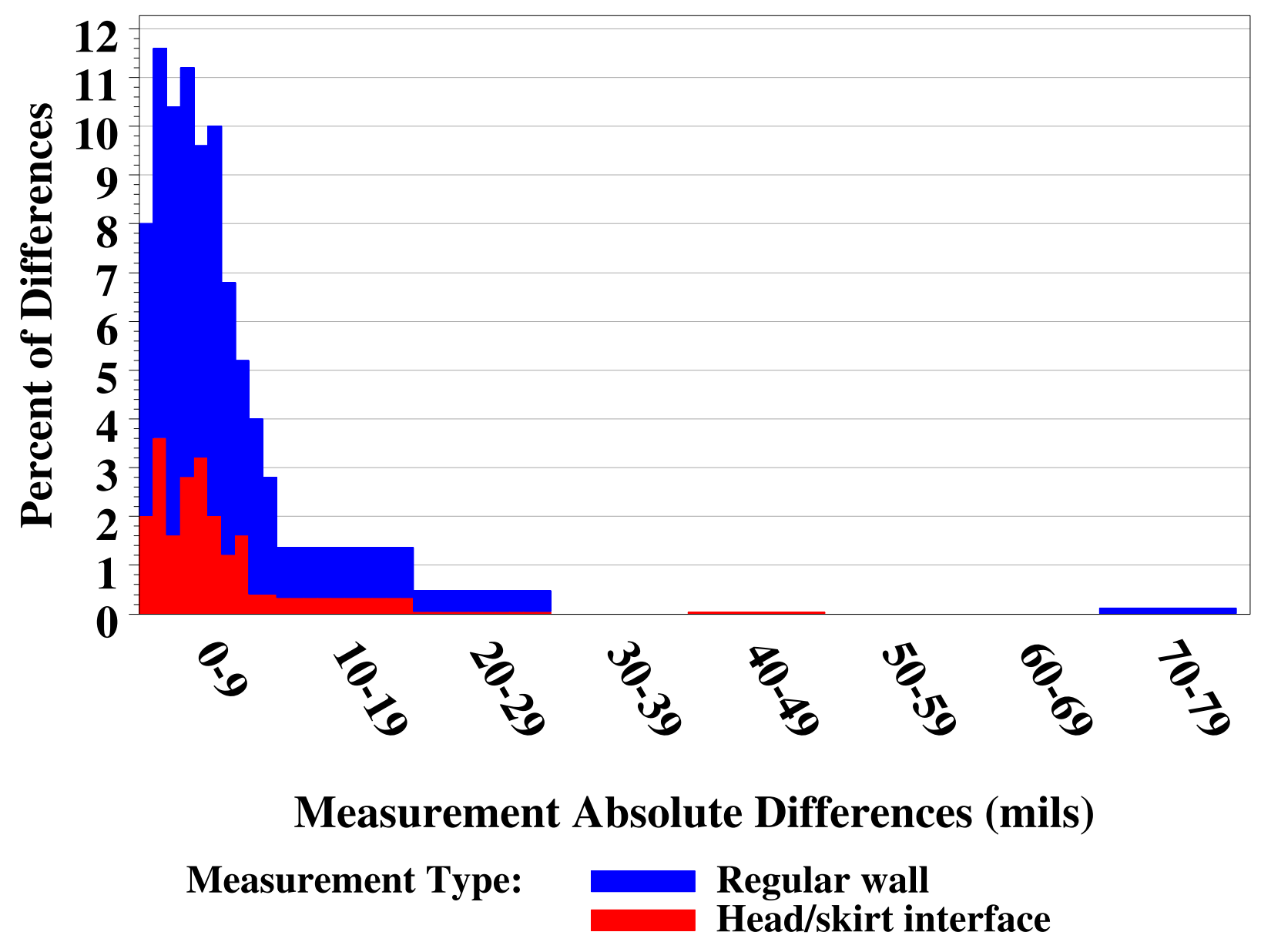

Figure 2. Differences between later and earlier UT measurements made on 90 randomly sampled Portsmouth cylinders, excluding one cylinder, which had a 157 mil difference.

Original Thickness Estimates. The direct model requires estimates of the initial cylinder thickness. For initial thickness estimates, design-sheet specifications are a good starting point, but, as Table 6 suggests, design-sheet specifications can be refined. For each of the seventeen cylinder groups developed in Section 3, Table 6 contains $97.5 \%$ one-side lower and upper confidence limits (which together compose a 95\% confidence interval) for the mean maximum thickness. The confidence limits are computed from wall maximum thickness measurements for each cylinder group. The table also contains the nominal lower and upper design limits, from the design sheets. In the final column, the table contains an original thickness estimate, which combines the nominal and confidence limits. These original thickness estimates are used in the direct-model regressions.

The original thickness estimates in Table 6 are computed as follows. As can be seen from the table, except for the skirted groups and the $1 / 2$ " cylinders, the confidence limit ranges are not far from the nominal ranges and in most cases overlap them. Because of metal forming in manufacturing, the nominal wall thickness is probably not a good measure of the original thickness of walls at the head/skirt interface. For the 30A cylinders, the maximum thickness measurements are so far from the nominal that the nominal values are not reasonable. So, for the skirted and the $1 / 2$ " groups, the $97.5 \%$ LCL was taken as the original thickness estimate. The $97.5 \% \mathrm{LCL}$ is the point in the $95 \%$ confidence range closest to the nominal thickness range.

For the other cylinder groups, the confidence intervals and design ranges are closer. For these other groups, when the confidence and nominal ranges overlap, the original thickness estimate was taken as the 
midpoint of the range of overlap. When the confidence and nominal ranges do not overlap, the nominal range endpoint nearest to the confidence interval was taken as the original thickness estimate. Thus, except for skirted and $1 / 2 "$ cylinders, the original thickness estimate is defined as follows:

If Nominal Upper < LCL, then Original Estimate = Nominal Upper;

Otherwise, if UCL < Nominal Lower, then Original Estimate = Nominal Lower;

Otherwise, Original Estimate $=[\min (U C L$, Nominal Upper $)+\max (L C L$, Nominal Lower $)] / 2$.

The original thickness estimates in Table 6 all exceed their corresponding nominal thicknesses $(312.5,625$, or 500 mils). The original thickness estimates were used in the direct model regression, as a predictor variable, the effect of which was adjusted in fitting the direct regression model (2.3). Thus a source of information for refining the original minimum thickness estimates is the UT minimum thickness data itself. Although each original thickness estimate in the direct regression model is assumed only to be an estimate (not the original thickness itself), the $\alpha \times$ (Original Thickness Estimate) term in the direct model (2.3) actually represents the mean thickness at one year of age (i.e., when $\log ($ age $)=0$ ). Thus we would expect $\alpha$ to be close to 1 and smaller than 1, though a departure from this is possible because of error in the original thickness estimates.

\section{Table 6. Original Thickness Estimates}

\begin{tabular}{|c|c|c|c|c|c|}
\hline Cylinder Group & $\begin{array}{c}97.5 \% \\
\text { LCL }\end{array}$ & $\begin{array}{c}97.5 \% \\
\text { UCL }\end{array}$ & $\begin{array}{c}\text { Nominal } \\
\text { Lower }\end{array}$ & $\begin{array}{c}\text { Nominal } \\
\text { Upper }\end{array}$ & $\begin{array}{c}\text { Orginal } \\
\text { Thickness } \\
\text { Estimate }\end{array}$ \\
\hline ETTP thin (P-scan data) & 313.3 & 316.9 & 302.5 & 345.5 & 315.1 \\
\hline ETTP thin, $\mathrm{K}$-yard bottom & 330.5 & 333.8 & 302.5 & 345.5 & 332.1 \\
\hline ETTP thin, except K-yard bottom & 329.6 & 332.9 & 302.5 & 345.5 & 331.3 \\
\hline PGDP thin (P-scan data) & 332.8 & 334.8 & 302.5 & 345.5 & 333.8 \\
\hline PGDP thin bottom, former G-yard & 321.1 & 325.6 & 302.5 & 345.5 & 323.3 \\
\hline PGDP thin btm, excpt fmr G-yard & 326.5 & 329.2 & 302.5 & 345.5 & 327.9 \\
\hline PGDP thin top & 326.9 & 329.9 & 302.5 & 345.5 & 328.4 \\
\hline PORTS thin (P-scan data) & 331.5 & 333.8 & 302.5 & 345.5 & 332.6 \\
\hline PORTS thin top & 356.1 & 359.5 & 302.5 & 345.5 & 345.5 \\
\hline PORTS thin bottom & 353.1 & 356.8 & 302.5 & 345.5 & 345.5 \\
\hline ETTP/PGDP/PORTS thick top & 665.3 & 683.0 & 615.0 & 655.0 & 655.0 \\
\hline ETTP/PGDP/PORTS thick bottom & 664.9 & 682.1 & 615.0 & 655.0 & 655.0 \\
\hline ETTP/PGDP/PORTS thin skirted top & 361.6 & 366.9 & 302.5 & 345.5 & 361.6 \\
\hline ETTP/PGDP/PORTS thin skirted btm & 358.2 & 362.5 & 302.5 & 345.5 & 358.2 \\
\hline ETTP/PGDP/PORTS thick skirted & 775.9 & 783.6 & 615.0 & 655.0 & 775.9 \\
\hline ETTP/PGDP/PORTS 1/2" (30" dia.) top & 515.8 & 527.7 & 343.8 & 468.8 & 515.8 \\
\hline ETTP/PGDP/PORTS 1/2" (30" dia.) btm & 512.2 & 524.1 & 343.8 & 468.8 & 512.2 \\
\hline
\end{tabular}


Because a nominal range endpoint is used when the confidence and nominal ranges do not overlap, this algorithm for estimating the initial thickness favors the nominal specification. The rationale for preferring the nominal specification is that (1) if the original thickness of a cylinder was not uniform, then the maximum thickness (at any time) is likely to be a poor estimate of the original minimum thickness of the cylinder, and (2) the original estimates, so defined, seem to work well in the minimum thickness regression discussed below. For the skirted groups or the $1 / 2$ " cylinders, the discrepancy between the confidence limits and the nominal specification is so great that the nominal specification does not seem reasonable, and the confidence limit closest to the nominal range is used instead.

Weighting. Whether and how the fit of the regression model in one region of the space of predictor variables (e.g., subpopulation, original thickness, and age) should be used to make inferences (e.g., predictions) for another region depends on the statistical distribution of the underlying regression errors. For example, the variance of the distribution of minimum thickness measurements likely increases with cylinder age. This should be accounted for, because projections about minimum thicknesses at a target age in the future are based on measurements for cylinders at ages less than the target age. In the direct-model regression, the dependency of the variance on age is accounted for by weighting. Three weighting strategies were investigated for the direct-model regressions: constant-variance (i.e., unweighted), varianceproportional-to-age, and variance-proportional-to-age-squared. The variance-proportional-to-age weighting was chosen on the basis of residual plots and judgment about data quality. (Regression residuals are the differences between the observed (dependent variable) values and their corresponding fitted values.)

The regression weighted by age is easily implemented by dividing cylinder minimum thicknesses, original thickness estimates, and the $\log ($ age $)$ terms by the square root of age. The indirect model in equation (2.3) becomes

$$
\frac{M(\text { age })}{\sqrt{\text { age }}}=\alpha \frac{\text { Initial Thickness Estimate }}{\sqrt{\text { age }}}+\beta(\text { group }) \frac{\log (\text { age })}{\sqrt{\text { age }}}+\frac{\text { random error }}{\sqrt{\text { age }}}
$$

for age $>1$. By dividing by $\sqrt{\text { age }}$ the original random error term is transformed to a new random error with variance that is homogeneous across ages.

The results for 30A cylinders remeasured in FY03 suggest that an adjustment should be applied to account for greater variability in minimum thickness measurements for the 30As-even after variably weighting for age. This can be checked by fitting regression models, weighted by the square root of age, separately for the 30A cylinders and the other cylinders groups. Table 7 shows age-weighted regression root mean squared errors (RMSEs) for the direct model fit first for all cylinder groups except the 30As $(1 / 2$ " thick cylinders) and second for the 30 As only.

Table 7. Root Mean Squared Errors (RMSEs) for Age-Weighted Regressions

\begin{tabular}{cccc}
\hline Case & $\begin{array}{c}\text { RMSE for All } \\
\text { Groups Except } \\
\text { 30As }\end{array}$ & $\begin{array}{c}\text { RMSE for 30As (1/2" } \\
\text { Thick Cylinders) Only }\end{array}$ & $\begin{array}{c}\text { Ratio of RMSE for } \\
\text { 30As to RMSE for } \\
\text { Other Groups }\end{array}$ \\
\hline All data & 4.008734 & 11.23712 & 2.803159 \\
$\begin{array}{c}\text { Outliers Excluded } \\
\text { (See Section 4.3) }\end{array}$ & 3.617425 & 11.23712 & 3.106386 \\
\hline
\end{tabular}


Table 7 shows that the age-weighted MSE for 30As is about three times higher than the MSE for other groups, and that the ratio is slightly higher after excluding outliers (see Section 4.3; none of the outliers turn out to be 30As). The ordinary, unweighted direct regression model (2.3) is thus transformed to an age and group-weighted direct-model regression

$$
\frac{M(\text { age })}{w \sqrt{\text { age }}}=\alpha \frac{\text { Initial Thickness Estimate }}{w \sqrt{\text { age }}}+\beta(\text { group }) \frac{\log (\text { age })}{w \sqrt{\text { age }}}+\frac{\text { random error }}{w \sqrt{\text { age }}}
$$

where $w=2.803159$ for $30 \mathrm{~A}$ cylinders and $w=1$ for all other cylinders. For the outliers-excluded case, the ratio 3.106386 replaces the 2.803159 .

Direct-Model Regression Results. Table 8 shows the $\alpha$ and $\beta$ (group) regression parameter estimates for the direct model (4.1). The $\mathrm{R}^{2}$ value for the regression is $92.0 \%{ }^{7}$ The $\alpha$ coefficient for the original thickness estimate, .96 , is in the range reasonably close to but less than 1 . The $\beta$ (group) parameters should all be negative, because, according to the model $d M(t) / d t=\beta$ (group) $/ t$. Although the direct model imposes no constraints on the $\beta$ (group) parameter estimates, all of the estimates do turn out to be negative.

Figures 21-37 in Appendix A show the fitted, direct-model, age-weighted regressions for the seventeen cylinder subpopulations. In addition to plots of regression results, these figures also contain charts of the cylinder age distributions for the seventeen groups. These age distribution are for all cylinders in the subpopulation, not just for cylinders that were sampled. The age distribution charts show, in particular, the ages and counts for the oldest cylinders in each group, which, on average, are the cylinders at greatest risk. Estimates that are averages for entire groups can obscure risks for the oldest cylinders, for example, if the oldest cylinders are exceptions relative to the population in general (see for example Figures 26-39, Appendix A).

In addition to minimum thickness measurements, the regression plots in Figures 21-37 (Appendix A) show the direct-model fitted regression curves and approximate 99\% lower confidence limits (LCLs) for minimum thicknesses for individual cylinders over the age ranges in the plots. The LCL curves are approximations:

$$
\text { Probability ( Actual Minimum Thickness at age } \mathrm{t} \geq \mathrm{LCL} \text { at } \mathrm{t} \text { ) } \approx .99
$$

for any particular age t. Two different sets of LCL curves are shown. One set is based on a large-sample approximation that does not assume any particular underlying distribution (e.g., normal) for the regression errors. Schmoyer (1992) has shown that the error in this approximation goes to zero (so that (4.2) holds exactly) as the sample size increases. The other set of LCLs are the usual LCLs for individual predicted values, which are based on the approximation or assumption that regression errors have normal distributions. The normal-theory confidence limits are generally though not necessarily closer to the regression fitted curve than the large-sample limits. Both the normal-theory and large-sample LCLs suggest that although there are slight declines over time in average minimum wall thicknesses, there is considerable uncertainty about individual cylinders, and the uncertainty about individual cylinders increases as predictions extend farther ahead in time.

\footnotetext{
${ }^{7} \mathrm{R}^{2}$ is the squared multiple correlation coefficient or proportion of explained variance (see Draper and Smith, 1981). Although $\mathrm{R}^{2}$ statistics for the direct and indirect models are not directly comparable, for reference, the $\mathrm{R}^{2}$ values for the indirect models were less than .10 for all but three of the seventeen indirect model regressions and never exceeded .30. These are actually the $\mathrm{R}^{2}$ for the unconstrained two-parameter power law model, even when the slope-set-to-one model is used instead. The $\mathrm{R}^{2}$ statistic for the slope-set-to-one model, which is an intercept-only model, is by definition always zero.
} 
Figures 38 and 39 (Appendix A) are plots of the regression residuals from the age-weighted regression. The plots can be used to determine (1) whether the statistical distribution of the regression errors is normal or otherwise, (2) whether the regression errors are approximately uniform (e.g., across ages), and (3) whether the variance-proportional-to-age weighting or some other weighting is appropriate. A uniform distribution in the weighted residuals is the objective of the weighting, because a uniform weighted error distribution is an assumption in statistical inferences (e.g., confidence bounds) based on the regression. Figure 38 shows that, except perhaps for about six outlier residuals (of over 2,800 residuals), the variance of the regression residuals is approximately the same for different ages and cylinder thickness types. This suggests that the age and group weighting is appropriate. If the regression is computed without the special weighting for $1 / 2$ " cylinders, the residual variance is not nearly as uniform. (See also the corresponding figure in the 2003 edition of this report.) Cylinders with unusually large negative residuals (highlighted in the figures) are considered as outliers in the discussion below.

Figure 39 shows the regression residuals in a normal probability plot. This figure shows that the distribution of residuals, and by extension the distribution of regression errors, is not normal, particularly for the lower (left) side of the distribution, where the residuals are smaller (more negative) than would be expected under normal theory. This suggests that the normal-theory LCLs for individual minimum thickness predictions are likely to be inaccurate, and that the large-sample confidence limits (which are lower than the normal-based limits) are probably better. Because the use of the normal-theory confidence limits is much more common in regression modeling, they were included in the figures as points of comparison for the large-sample limits.

\section{Table 8. Direct-Model Parameter Estimates and Standard Errors}

\begin{tabular}{lrc}
\hline & & Standard \\
Parameter & Estimate & Error \\
\hline Initial Thickness & 1.00 & 0.01 \\
ETTP thin (P-scan data) & -16.3 & 1.10 \\
ETTP thin, K-yard bottom & -9.03 & 1.00 \\
ETTP thin, except K-yard bottom & -9.54 & 1.05 \\
PGDP thin (P-scan data) & -16.1 & 1.07 \\
PGDP thin bottom, former G-yard & -4.98 & 1.06 \\
PGDP thin btm, excpt fmr G-yard & -4.86 & 1.05 \\
PGDP thin top & -4.01 & 1.08 \\
PORTS thin (P-scan data) & -15.3 & 1.20 \\
PORTS thin top & -5.88 & 1.08 \\
PORTS thin bottom & -5.84 & 1.10 \\
ETTP/PGDP/PORTS thick top & -5.45 & 1.92 \\
ETTP/PGDP/PORTS thick bottom & -5.17 & 1.94 \\
ETTP/PGDP/PORTS thin skirted top & -3.88 & 1.12 \\
ETTP/PGDP/PORTS thin skirted btm & -3.15 & 1.13 \\
ETTP/PGDP/PORTS thick skirted & -11.0 & 2.08 \\
ETTP/PGDP/PORTS 1/2" (30" dia.) top & -13.5 & 2.15 \\
ETTP/PGDP/PORTS 1/2" (30" dia.) btm & -17.6 & 2.19 \\
\hline
\end{tabular}




\subsection{Reanalyses After Dropping Outliers}

Data points plotted in Figures 4-39 were considered outliers if they met the following criteria:

For the indirect model (Figures 4-20): maximum pit depth $>160$ mils

For the direct model (Figures 21-39): corresponding regression residual $<-20$ mils

Outliers (points failing the above criteria) are highlighted in yellow in the figures (though not every figure shows outliers). Examination of the figures shows that there do not seem to be any statistical outliers associated with small pit depths or large minimum thicknesses (large positive residuals). This is not surprising, because the pit depth distribution is right-skewed and the residual distribution (or minimum thickness distribution) is left-skewed.

Outliers are suspicious statistically, but that alone does not justify excluding them from an analysis. If they represent bad data, then they should be excluded, but if they are good, they are of great concern.

Nevertheless, the UT remeasurements performed in FY03 suggest that at least for thin-wall cylinders, some of the outlier data points probably are, in fact, bad.

Data meeting the above outlier criteria are listed in Table 9. For the direct model, only six points are so identified. The maximum pit depth and minimum thickness data were re-analyzed with the outliers dropped. Sections 5 and 6 show that projections based on the analyses without the outliers are in fact more consistent with experience than projections based on the analyses with the outliers included. Although being a statistical outlier does not automatically imply that anything is wrong with a data point, the more realistic projections computed without the outliers together with the evidence that some of the outlier data is in fact bad, suggests that projections computed without the outliers are likely to be better than the projections computed with them. Cylinders flagged as outliers should be remeasured to either validate or correct their measurements. 
Table 9. Cylinders Excluded from Tables 10B (Indirect Model) or 11B (Direct Model)

\begin{tabular}{|c|c|c|c|c|c|c|}
\hline Cylinder Grouping & $\begin{array}{c}\text { Max. } \\
\text { Pit } \\
\text { Depth }\end{array}$ & $\begin{array}{c}\text { Min. } \\
\text { Thick- } \\
\text { ness }\end{array}$ & $\begin{array}{c}\text { Year } \\
\text { Meas- } \\
\text { ured }\end{array}$ & $\begin{array}{l}\text { Measure- } \\
\text { ment } \\
\text { Method }\end{array}$ & Cylinder & $\begin{array}{c}\text { Model(s) } \\
\text { Excluded } \\
\text { For }\end{array}$ \\
\hline \multirow[t]{3}{*}{ ETTP thin (P-scan data) } & 180 & 140 & 1994 & P-Scan & 00734000 & Indirect \\
\hline & 315 & 0 & 1992 & Visual & 00795300 & Indirect \\
\hline & 315 & 0 & 1992 & Visual & 10124400 & Indirect \\
\hline \multirow[t]{3}{*}{ ETTP thin, except K-yard bottom } & 205 & 134 & 2001 & Man-UT & 01202700 & Both \\
\hline & 249 & 100 & 2001 & Man-UT & 11495100 & Both \\
\hline & 182 & 161 & 2001 & Man-UT & 11679700 & Both \\
\hline PORTS thin bottom & 176 & 170 & 2003 & Man-UT & 11431000 & Both \\
\hline \multirow[t]{2}{*}{ ETTP/PGDP/PORTS thick bottom } & 34 & 464 & 1998 & Man-UT & 00238000 & Direct \\
\hline & 176 & 170 & 2003 & Man-UT & 11431000 & Indirect \\
\hline ETTP/PGDP/PORTS thick skirted & 160 & 595 & 1997 & Hand-held & 00084800 & Direct \\
\hline \multirow[t]{8}{*}{ ETTP/PGDP/PORTS 1/2" (30" dia.) top } & 168 & 332 & 1999 & Man-UT & D2364600 & Indirect \\
\hline & 440 & 112 & 2003 & Man-UT & D2789500 & Indirect \\
\hline & 181 & 353 & 1999 & Man-UT & D3472600 & Indirect \\
\hline & 241 & 255 & 2002 & Man-UT & D3472900 & Indirect \\
\hline & 278 & 111 & 2003 & Man-UT & D3597000 & Indirect \\
\hline & 249 & 111 & 2003 & Man-UT & D5192900 & Indirect \\
\hline & 167 & 376 & 2001 & Man-UT & D7784700 & Indirect \\
\hline & 341 & 118 & 2003 & Man-UT & W0049200 & Indirect \\
\hline \multirow[t]{11}{*}{ ETTP/PGDP/PORTS 1/2" (30" dia.) btm } & 263 & 263 & 2003 & Man-UT & D2693300 & Indirect \\
\hline & 173 & 317 & 2002 & Man-UT & D3124900 & Indirect \\
\hline & 350 & 129 & 2003 & Man-UT & D3478700 & Indirect \\
\hline & 209 & 277 & 2003 & Man-UT & D3720600 & Indirect \\
\hline & 354 & 132 & 2003 & Man-UT & D3722700 & Indirect \\
\hline & 196 & 284 & 1999 & Man-UT & D3870400 & Indirect \\
\hline & 353 & 133 & 2003 & Man-UT & D3909600 & Indirect \\
\hline & 213 & 94 & 2003 & Man-UT & D3920100 & Indirect \\
\hline & 271 & 234 & 2002 & Man-UT & D3952000 & Indirect \\
\hline & 234 & 305 & 2002 & Man-UT & D4260300 & Indirect \\
\hline & 290 & 215 & 2003 & Man-UT & D7680600 & Indirect \\
\hline
\end{tabular}




\section{WALL THICKNESS PROJECTIONS}

This section contains projections of the numbers or proportions of cylinders expected to fail various thickness criteria, as a function of extended storage time. The projections are based on the fitted indirect and direct corrosion models. Projections based on the indirect model are in Tables 10a-c; projections based on the direct model are in Tables 11a-c. Tables 10a and 11a are computed without excluding outliers; Tables $10 \mathrm{~b}$ and $11 \mathrm{~b}$ are computed after excluding outliers; Tables $10 \mathrm{c}$ and $11 \mathrm{c}$ are of proportions rather than absolute cylinder counts. The projections in Tables 10 and 11 are broken down by subpopulation. Table 12 contains projections broken downs by both subpopulation and age.

The projections are computed for the following minimum wall thickness criteria:

1. 0 mils (i.e., a breach), which indicates a possible loss of contained material

2. 62.5 mils, below which ordinary safe handling and stacking is considered to be impaired

3. 250 mils for thin-wall cylinders and 500 mils for thick-wall cylinders, which represent applicable standards for off-site transport and contents transfer (based on ANSI 14.1 1995).

For $1 / 2$ " (30" diameter) cylinders, there are no published criteria for minimum thicknesses. However, in addition to the zero (breach) and 62.5 mil criteria, 100 mils, the minimum thickness for regular hot feeding ${ }^{8}$ is also used for $1 / 2$ " cylinders.

These criteria are actually for on an area of wall thinning, as opposed to a point. Minimum thicknesses predictions calculated for this report are for a tiny area of only about 0.01 square inches, essentially a point. For thickness criteria greater than zero (breach), the calculations may therefore be conservative. For the breach criteria, consider the following from DNFSB (1995):

A breach in a cylinder allows the external atmosphere to react slowly with the $\mathrm{UF}_{6}$. The solid reaction product tends to plug the breach; however, the HF formed releases slowly, attacks the metal cylinder, and enlarges the breach over time. The hole diameter is estimated to increase at a rate of approximately one inch per year.

Therefore, because of the interaction of $\mathrm{UF}_{6}$ with atmospheric moisture and the substrate steel, the approximation of a small-area breach with a point breach is appropriate. ${ }^{9}$

Cylinder Count Projections. Table 10A shows numbers of cylinders projected on the basis of the indirect regression model (equation 2.2) to have minimum wall thickness below the various thickness criteria. Table 11A shows projections based on the direct model (equation 4.1). These projections are computed using equation (2.1) with cylinder counts from the CID and either the indirect or direct-model estimates of the probability $\operatorname{Prob}(M(t)<l)$ for the various ages $t$ and thickness criteria $l$. Thus the numbers in the tables are estimates of the numbers of cylinders expected to fail the various thickness criteria. Even if the estimates of $\operatorname{Prob}(M(t)<l)$ were exact (and the estimates of the numbers of cylinders expected to fail were thus also exact), the actual numbers of cylinders observed in practice to violate the various thickness criteria would still depart randomly from the estimates.

${ }^{8}$ S. J. Pawel, ORNL Corrosion Science \& Technology Group, personal communication.

${ }^{9}$ However, note also page 4 of the SRD (LMES 1997a): "Reaction deposits formed when UF $_{6}$ is exposed to the atmosphere in the presence of the mild steel containers have a self-sealing nature." 


\section{Table 10A. Summary of Indirect-Model Projections for Target Years and Minimum Thickness Criteria}

\begin{tabular}{|c|c|c|c|c|c|c|c|c|c|c|c|c|c|}
\hline \multirow[b]{3}{*}{ Cylinder Population } & \multirow[b]{3}{*}{$\begin{array}{l}\text { Pop. } \\
\text { Total }\end{array}$} & \multirow[b]{3}{*}{ Model } & \multirow{3}{*}{$\begin{array}{l}\text { Thick. } \\
\text { Spec } \\
\text { (mils) }\end{array}$} & \multicolumn{10}{|c|}{ Projected Number of Cylinders Below Thickness Criterion } \\
\hline & & & & \multicolumn{2}{|c|}{2005} & \multicolumn{2}{|c|}{2010} & \multicolumn{2}{|c|}{2015} & \multicolumn{2}{|c|}{2020} & \multicolumn{2}{|c|}{2025} \\
\hline & & & & $\begin{array}{l}\text { Esti- } \\
\text { mate }\end{array}$ & $\begin{array}{l}95 \% \\
\text { UCB } \\
\end{array}$ & $\begin{array}{l}\text { Esti- } \\
\text { mate }\end{array}$ & $\begin{array}{l}95 \% \\
\text { UCB }\end{array}$ & $\begin{array}{l}\text { Esti- } \\
\text { mate }\end{array}$ & $\begin{array}{l}95 \% \\
\text { UCB } \\
\end{array}$ & $\begin{array}{l}\text { Esti- } \\
\text { mate }\end{array}$ & $\begin{array}{l}95 \% \\
\text { UCB } \\
\end{array}$ & $\begin{array}{l}\text { Esti- } \\
\text { mate }\end{array}$ & $\begin{array}{l}95 \% \\
\text { UCB }\end{array}$ \\
\hline \multirow[t]{3}{*}{ ETTP thin (P-scan data) } & 4,034 & Slope $=1$ & 250 & 1,894 & 2,168 & 2,292 & 2,606 & 2,643 & 2,970 & 2,938 & 3,258 & 3,178 & 3,476 \\
\hline & & & 62.5 & 10 & 45 & 20 & 75 & 36 & 116 & 59 & 168 & 92 & 233 \\
\hline & & & 0 & 2 & 15 & 5 & 27 & 9 & 44 & 17 & 67 & 27 & 97 \\
\hline \multirow[t]{3}{*}{ ETTP thin, K-yard bottom } & 1,166 & Slope $=1$ & 250 & 83 & 139 & 106 & 168 & 131 & 198 & 157 & 228 & 184 & 258 \\
\hline & & & 62.5 & 2 & 7 & 2 & 9 & 4 & 12 & 5 & 16 & 7 & 20 \\
\hline & & & 0 & 1 & 3 & 1 & 5 & 2 & 6 & 2 & 8 & 3 & 11 \\
\hline \multirow[t]{3}{*}{ ETTP thin, except K-yard bottom } & 2,868 & Slope $=1$ & 250 & 167 & 314 & 218 & 385 & 273 & 457 & 332 & 528 & 392 & 599 \\
\hline & & & 62.5 & 6 & 26 & 9 & 35 & 12 & 46 & 17 & 59 & 22 & 72 \\
\hline & & & 0 & 3 & 15 & 4 & 21 & 6 & 28 & 9 & 36 & 12 & 45 \\
\hline \multirow[t]{3}{*}{ PGDP thin (P-scan data) } & 32,231 & Slope Fit & 250 & 2,931 & 4,793 & 4,189 & 6,486 & 5,750 & 8,351 & 7,561 & 10,321 & 9,533 & 12,395 \\
\hline & & & 62.5 & 1 & 10 & 3 & 20 & 6 & 36 & 10 & 60 & 18 & 96 \\
\hline & & & 0 & 0 & 2 & 0 & 4 & 1 & 7 & 2 & 13 & 3 & 22 \\
\hline \multirow[t]{3}{*}{ PGDP thin bottom, former G-yard } & 1,983 & Slope Fit & 250 & 27 & 101 & 32 & 122 & 38 & 144 & 44 & 169 & 51 & 196 \\
\hline & & & 62.5 & 0 & 2 & 0 & 2 & 0 & 3 & 0 & 4 & 0 & 5 \\
\hline & & & 0 & 0 & 1 & 0 & 1 & 0 & 1 & 0 & 2 & 0 & 2 \\
\hline \multirow[t]{3}{*}{ PGDP thin btm, excpt fmr G-yard } & 15,337 & Slope Fit & 250 & 53 & 181 & 74 & 229 & 99 & 280 & 127 & 336 & 158 & 399 \\
\hline & & & 62.5 & 0 & 1 & 0 & 1 & 0 & 1 & 0 & 2 & 0 & 2 \\
\hline & & & 0 & 0 & 0 & 0 & 0 & 0 & 0 & 0 & 1 & 0 & 1 \\
\hline \multirow[t]{3}{*}{ PGDP thin top } & 14,911 & Slope Fit & 250 & 15 & 88 & 19 & 99 & 24 & 111 & 29 & 124 & 34 & 140 \\
\hline & & & 62.5 & 0 & 0 & 0 & 0 & 0 & 0 & 0 & 0 & 0 & 0 \\
\hline & & & 0 & 0 & 0 & 0 & 0 & 0 & 0 & 0 & 0 & 0 & 0 \\
\hline
\end{tabular}


Table 10A-cont'd. Summary of Indirect-Model Projections for Target Years and Minimum Thickness Criteria

\begin{tabular}{|c|c|c|c|c|c|c|c|c|c|c|c|c|c|}
\hline \multirow[b]{3}{*}{ Cylinder Population } & \multirow[b]{3}{*}{$\begin{array}{l}\text { Pop. } \\
\text { Total }\end{array}$} & \multirow[b]{3}{*}{ Model } & \multirow{3}{*}{$\begin{array}{l}\text { Thick. } \\
\text { Spec } \\
\text { (mils) }\end{array}$} & \multicolumn{10}{|c|}{ Projected Number of Cylinders Below Thickness Criterion } \\
\hline & & & & \multicolumn{2}{|c|}{2005} & \multicolumn{2}{|c|}{2010} & \multicolumn{2}{|c|}{2015} & \multicolumn{2}{|c|}{2020} & \multicolumn{2}{|c|}{2025} \\
\hline & & & & $\begin{array}{l}\text { Esti- } \\
\text { mate }\end{array}$ & $\begin{array}{l}95 \% \\
\text { UCB } \\
\end{array}$ & $\begin{array}{l}\text { Esti- } \\
\text { mate }\end{array}$ & $\begin{array}{l}95 \% \\
\text { UCB } \\
\end{array}$ & $\begin{array}{l}\text { Esti- } \\
\text { mate }\end{array}$ & $\begin{array}{l}95 \% \\
\text { UCB } \\
\end{array}$ & $\begin{array}{l}\text { Esti- } \\
\text { mate }\end{array}$ & $\begin{array}{l}95 \% \\
\text { UCB }\end{array}$ & $\begin{array}{l}\text { Esti- } \\
\text { mate }\end{array}$ & $\begin{array}{l}95 \% \\
\text { UCB } \\
\end{array}$ \\
\hline \multirow[t]{3}{*}{ PORTS thin (P-scan data) } & 17,269 & Slope Fit & 250 & 784 & 1,160 & 1,112 & 1,583 & 1,506 & 2,064 & 1,955 & 2,596 & 2,443 & 3,175 \\
\hline & & & 62.5 & 0 & 0 & 0 & 0 & 0 & 0 & 0 & 0 & 0 & 0 \\
\hline & & & 0 & 0 & 0 & 0 & 0 & 0 & 0 & 0 & 0 & 0 & 0 \\
\hline \multirow[t]{3}{*}{ PORTS thin top } & 8,501 & Slope Fit & 250 & 12 & 74 & 15 & 81 & 19 & 88 & 22 & 96 & 26 & 106 \\
\hline & & & 62.5 & 0 & 0 & 0 & 0 & 0 & 0 & 0 & 0 & 0 & 0 \\
\hline & & & 0 & 0 & 0 & 0 & 0 & 0 & 0 & 0 & 0 & 0 & 0 \\
\hline \multirow[t]{3}{*}{ PORTS thin bottom } & 8,768 & Slope Fit & 250 & 6 & 44 & 8 & 51 & 11 & 59 & 14 & 68 & 17 & 79 \\
\hline & & & 62.5 & 0 & 0 & 0 & 0 & 0 & 0 & 0 & 0 & 0 & 0 \\
\hline & & & 0 & 0 & 0 & 0 & 0 & 0 & 0 & 0 & 0 & 0 & 0 \\
\hline \multirow[t]{3}{*}{ ETTP/PGDP/PORTS thick top } & 957 & Slope $=1$ & 500 & 31 & 53 & 41 & 67 & 52 & 82 & 64 & 98 & 78 & 114 \\
\hline & & & 62.5 & 0 & 1 & 0 & 1 & 0 & 1 & 0 & 2 & 1 & 2 \\
\hline & & & 0 & 0 & 0 & 0 & 1 & 0 & 1 & 0 & 1 & 0 & 2 \\
\hline \multirow[t]{3}{*}{ ETTP/PGDP/PORTS thick bottom } & 1,066 & Slope $=1$ & 500 & 56 & 90 & 70 & 109 & 86 & 129 & 103 & 149 & 121 & 170 \\
\hline & & & 62.5 & 1 & 2 & 1 & 3 & 1 & 4 & 2 & 5 & 2 & 7 \\
\hline & & & 0 & 0 & 2 & 1 & 2 & 1 & 3 & 1 & 4 & 1 & 5 \\
\hline \multirow[t]{3}{*}{ ETTP/PGDP/PORTS thin skirted top } & 2,285 & Slope $=1$ & 250 & 0 & 1 & 0 & 2 & 0 & 3 & 1 & 5 & 1 & 8 \\
\hline & & & 62.5 & 0 & 0 & 0 & 0 & 0 & 0 & 0 & 0 & 0 & 0 \\
\hline & & & 0 & 0 & 0 & 0 & 0 & 0 & 0 & 0 & 0 & 0 & 0 \\
\hline \multirow[t]{3}{*}{ ETTP/PGDP/PORTS thin skirted btm } & 2,485 & Slope $=1$ & 250 & 0 & 1 & 0 & 2 & 0 & 3 & 1 & 5 & 1 & 8 \\
\hline & & & 62.5 & 0 & 0 & 0 & 0 & 0 & 0 & 0 & 0 & 0 & 0 \\
\hline & & & 0 & 0 & 0 & 0 & 0 & 0 & 0 & 0 & 0 & 0 & 0 \\
\hline
\end{tabular}


Table 10A-cont'd. Summary of Indirect-Model Projections for Target Years and Minimum Thickness Criteria

\begin{tabular}{|c|c|c|c|c|c|c|c|c|c|c|c|c|c|}
\hline \multirow[b]{3}{*}{ Cylinder Population } & \multirow[b]{3}{*}{$\begin{array}{l}\text { Pop. } \\
\text { Total } \\
\end{array}$} & \multirow[b]{3}{*}{ Model } & \multirow{3}{*}{$\begin{array}{l}\text { Thick. } \\
\text { Spec } \\
\text { (mils) }\end{array}$} & \multicolumn{10}{|c|}{ Projected Number of Cylinders Below Thickness Criterion } \\
\hline & & & & \multicolumn{2}{|c|}{2005} & \multicolumn{2}{|c|}{2010} & \multicolumn{2}{|c|}{2015} & \multicolumn{2}{|c|}{2020} & \multicolumn{2}{|c|}{2025} \\
\hline & & & & $\begin{array}{l}\text { Esti- } \\
\text { mate }\end{array}$ & $\begin{array}{l}95 \% \\
\text { UCB }\end{array}$ & $\begin{array}{l}\text { Esti- } \\
\text { mate }\end{array}$ & $\begin{array}{l}95 \% \\
\text { UCB }\end{array}$ & $\begin{array}{l}\text { Esti- } \\
\text { mate }\end{array}$ & $\begin{array}{l}95 \% \\
\text { UCB }\end{array}$ & $\begin{array}{l}\text { Esti- } \\
\text { mate }\end{array}$ & $\begin{array}{l}95 \% \\
\text { UCB } \\
\end{array}$ & $\begin{array}{l}\text { Esti- } \\
\text { mate }\end{array}$ & $\begin{array}{l}95 \% \\
\text { UCB }\end{array}$ \\
\hline \multirow[t]{3}{*}{ ETTP/PGDP/PORTS thick skirted } & 2,023 & Slope $=1$ & 500 & 5 & 20 & 7 & 27 & 10 & 35 & 13 & 44 & 18 & 54 \\
\hline & & & 62.5 & 0 & 0 & 0 & 1 & 0 & 1 & 0 & 1 & 0 & 2 \\
\hline & & & 0 & 0 & 0 & 0 & 1 & 0 & 1 & 0 & 1 & 0 & 1 \\
\hline \multirow[t]{3}{*}{ ETTP/PGDP/PORTS 1/2" (30" dia.) top } & 1,119 & Slope $=1$ & 100 & 1 & 8 & 2 & 11 & 3 & 14 & 4 & 18 & 6 & 22 \\
\hline & & & 62.5 & 1 & 6 & 2 & 9 & 2 & 11 & 3 & 14 & 4 & 18 \\
\hline & & & 0 & 1 & 4 & 1 & 6 & 1 & 8 & 2 & 10 & 2 & 12 \\
\hline \multirow[t]{3}{*}{ ETTP/PGDP/PORTS 1/2" (30" dia.) btm } & 1,457 & Slope $=1$ & 100 & 7 & 29 & 10 & 37 & 13 & 46 & 17 & 55 & 22 & 66 \\
\hline & & & 62.5 & 5 & 23 & 7 & 29 & 10 & 37 & 13 & 45 & 17 & 54 \\
\hline & & & 0 & 3 & 16 & 4 & 21 & 6 & 26 & 8 & 32 & 11 & 39 \\
\hline
\end{tabular}


Table 10B. Summary of Indirect-Model Projections for Data with Outlier Exclusions

\begin{tabular}{|c|c|c|c|c|c|c|c|c|c|c|c|c|c|}
\hline \multirow[b]{3}{*}{ Population } & \multirow[b]{3}{*}{$\begin{array}{l}\text { Pop. } \\
\text { Total }\end{array}$} & \multirow[b]{3}{*}{ Model } & \multirow{3}{*}{$\begin{array}{l}\text { Thick. } \\
\text { Spec } \\
\text { (mils) }\end{array}$} & \multicolumn{10}{|c|}{ Projected Number of Cylinders Below Thickness Criterion } \\
\hline & & & & \multicolumn{2}{|c|}{2005} & \multicolumn{2}{|c|}{2010} & \multicolumn{2}{|c|}{2015} & \multicolumn{2}{|c|}{2020} & \multicolumn{2}{|c|}{2025} \\
\hline & & & & $\begin{array}{l}\text { Esti- } \\
\text { mate }\end{array}$ & $\begin{array}{l}95 \% \\
\text { UCB } \\
\end{array}$ & $\begin{array}{l}\text { Esti- } \\
\text { mate }\end{array}$ & $\begin{array}{l}95 \% \\
\text { UCB }\end{array}$ & $\begin{array}{l}\text { Esti- } \\
\text { mate }\end{array}$ & $\begin{array}{l}95 \% \\
\text { UCB } \\
\end{array}$ & $\begin{array}{l}\text { Esti- } \\
\text { mate }\end{array}$ & $\begin{array}{l}95 \% \\
\text { UCB } \\
\end{array}$ & $\begin{array}{l}\text { Esti- } \\
\text { mate }\end{array}$ & $\begin{array}{l}95 \% \\
\text { UCB }\end{array}$ \\
\hline \multirow[t]{3}{*}{ ETTP thin (P-scan data) } & 4,034 & Slope $=1$ & 250 & 1,737 & 1,986 & 2,187 & 2,482 & 2,594 & 2,909 & 2,937 & 3,247 & 3,214 & 3,497 \\
\hline & & & 62.5 & 1 & 11 & 4 & 22 & 8 & 39 & 16 & 64 & 28 & 99 \\
\hline & & & 0 & 0 & 2 & 0 & 5 & 1 & 10 & 3 & 18 & 5 & 29 \\
\hline \multirow[t]{3}{*}{ ETTP thin, K-yard bottom } & 1,166 & Slope $=1$ & 250 & 83 & 139 & 106 & 168 & 131 & 198 & 157 & 228 & 184 & 258 \\
\hline & & & 62.5 & 2 & 7 & 2 & 9 & 4 & 12 & 5 & 16 & 7 & 20 \\
\hline & & & 0 & 1 & 3 & 1 & 5 & 2 & 6 & 2 & 8 & 3 & 11 \\
\hline \multirow[t]{3}{*}{ ETTP thin, except K-yard bottom } & 2,868 & Slope $=1$ & 250 & 111 & 231 & 151 & 293 & 196 & 358 & 246 & 424 & 299 & 491 \\
\hline & & & 62.5 & 2 & 12 & 3 & 17 & 5 & 23 & 7 & 31 & 10 & 40 \\
\hline & & & 0 & 1 & 6 & 1 & 9 & 2 & 13 & 3 & 17 & 4 & 22 \\
\hline \multirow[t]{3}{*}{ PGDP thin (P-scan data) } & 32,231 & Slope Fit & 250 & 2,931 & 4,793 & 4,189 & 6,486 & 5,750 & 8,351 & 7,561 & 10,321 & 9,533 & 12,395 \\
\hline & & & 62.5 & 1 & 10 & 3 & 20 & 6 & 36 & 10 & 60 & 18 & 96 \\
\hline & & & 0 & 0 & 2 & 0 & 4 & 1 & 7 & 2 & 13 & 3 & 22 \\
\hline \multirow[t]{3}{*}{ PGDP thin bottom, former G-yard } & 1,983 & Slope Fit & 250 & 27 & 101 & 32 & 122 & 38 & 144 & 44 & 169 & 51 & 196 \\
\hline & & & 62.5 & 0 & 2 & 0 & 2 & 0 & 3 & 0 & 4 & 0 & 5 \\
\hline & & & 0 & 0 & 1 & 0 & 1 & 0 & 1 & 0 & 2 & 0 & 2 \\
\hline \multirow[t]{3}{*}{ PGDP thin btm, excpt fmr G-yard } & 15,337 & Slope Fit & 250 & 53 & 181 & 74 & 229 & 99 & 280 & 127 & 336 & 158 & 399 \\
\hline & & & 62.5 & 0 & 1 & 0 & 1 & 0 & 1 & 0 & 2 & 0 & 2 \\
\hline & & & 0 & 0 & 0 & 0 & 0 & 0 & 0 & 0 & 1 & 0 & 1 \\
\hline \multirow[t]{3}{*}{ PGDP thin top } & 14,911 & Slope Fit & 250 & 15 & 88 & 19 & 99 & 24 & 111 & 29 & 124 & 34 & 140 \\
\hline & & & 62.5 & 0 & 0 & 0 & 0 & 0 & 0 & 0 & 0 & 0 & 0 \\
\hline & & & 0 & 0 & 0 & 0 & 0 & 0 & 0 & 0 & 0 & 0 & 0 \\
\hline
\end{tabular}


Table 10B-cont'd. Summary of Indirect-Model Projections for Data with Outlier Exclusions

\begin{tabular}{|c|c|c|c|c|c|c|c|c|c|c|c|c|c|}
\hline \multirow[b]{3}{*}{ Population } & \multirow[b]{3}{*}{$\begin{array}{l}\text { Pop. } \\
\text { Total }\end{array}$} & \multirow[b]{3}{*}{ Model } & \multirow{3}{*}{$\begin{array}{l}\text { Thick. } \\
\text { Spec } \\
\text { (mils) }\end{array}$} & \multicolumn{10}{|c|}{ Projected Number of Cylinders Below Thickness Criterion } \\
\hline & & & & \multicolumn{2}{|c|}{2005} & \multicolumn{2}{|c|}{2010} & \multicolumn{2}{|c|}{2015} & \multicolumn{2}{|c|}{2020} & \multicolumn{2}{|c|}{2025} \\
\hline & & & & $\begin{array}{l}\text { Esti- } \\
\text { mate }\end{array}$ & $\begin{array}{l}95 \% \\
\text { UCB } \\
\end{array}$ & $\begin{array}{l}\text { Esti- } \\
\text { mate }\end{array}$ & $\begin{array}{l}95 \% \\
\text { UCB } \\
\end{array}$ & $\begin{array}{l}\text { Esti- } \\
\text { mate }\end{array}$ & $\begin{array}{l}95 \% \\
\text { UCB } \\
\end{array}$ & $\begin{array}{l}\text { Esti- } \\
\text { mate }\end{array}$ & $\begin{array}{l}95 \% \\
\text { UCB }\end{array}$ & $\begin{array}{l}\text { Esti- } \\
\text { mate }\end{array}$ & $\begin{array}{l}95 \% \\
\text { UCB } \\
\end{array}$ \\
\hline \multirow[t]{3}{*}{ PORTS thin (P-scan data) } & 17,269 & Slope Fit & 250 & 784 & 1,160 & 1,112 & 1,583 & 1,506 & 2,064 & 1,955 & 2,596 & 2,443 & 3,175 \\
\hline & & & 62.5 & 0 & 0 & 0 & 0 & 0 & 0 & 0 & 0 & 0 & 0 \\
\hline & & & 0 & 0 & 0 & 0 & 0 & 0 & 0 & 0 & 0 & 0 & 0 \\
\hline \multirow[t]{3}{*}{ PORTS thin top } & 8,501 & Slope Fit & 250 & 12 & 74 & 15 & 81 & 19 & 88 & 22 & 96 & 26 & 106 \\
\hline & & & 62.5 & 0 & 0 & 0 & 0 & 0 & 0 & 0 & 0 & 0 & 0 \\
\hline & & & 0 & 0 & 0 & 0 & 0 & 0 & 0 & 0 & 0 & 0 & 0 \\
\hline \multirow[t]{3}{*}{ PORTS thin bottom } & 8,768 & Slope Fit & 250 & 3 & 26 & 5 & 32 & 6 & 38 & 8 & 45 & 10 & 54 \\
\hline & & & 62.5 & 0 & 0 & 0 & 0 & 0 & 0 & 0 & 0 & 0 & 0 \\
\hline & & & 0 & 0 & 0 & 0 & 0 & 0 & 0 & 0 & 0 & 0 & 0 \\
\hline \multirow[t]{3}{*}{ ETTP/PGDP/PORTS thick top } & 957 & Slope $=1$ & 500 & 31 & 53 & 41 & 67 & 52 & 82 & 64 & 98 & 78 & 114 \\
\hline & & & 62.5 & 0 & 1 & 0 & 1 & 0 & 1 & 0 & 2 & 1 & 2 \\
\hline & & & 0 & 0 & 0 & 0 & 1 & 0 & 1 & 0 & 1 & 0 & 2 \\
\hline \multirow[t]{3}{*}{ ETTP/PGDP/PORTS thick bottom } & 1,066 & Slope $=1$ & 500 & 53 & 87 & 67 & 106 & 83 & 125 & 100 & 145 & 117 & 166 \\
\hline & & & 62.5 & 0 & 2 & 1 & 3 & 1 & 4 & 1 & 5 & 2 & 6 \\
\hline & & & 0 & 0 & 1 & 0 & 2 & 1 & 3 & 1 & 4 & 1 & 5 \\
\hline \multirow[t]{3}{*}{ ETTP/PGDP/PORTS thin skirted top } & 2,285 & Slope $=1$ & 250 & 0 & 1 & 0 & 2 & 0 & 3 & 1 & 5 & 1 & 8 \\
\hline & & & 62.5 & 0 & 0 & 0 & 0 & 0 & 0 & 0 & 0 & 0 & 0 \\
\hline & & & 0 & 0 & 0 & 0 & 0 & 0 & 0 & 0 & 0 & 0 & 0 \\
\hline \multirow[t]{3}{*}{ ETTP/PGDP/PORTS thin skirted btm } & 2,485 & Slope $=1$ & 250 & 0 & 1 & 0 & 2 & 0 & 3 & 1 & 5 & 1 & 8 \\
\hline & & & 62.5 & 0 & 0 & 0 & 0 & 0 & 0 & 0 & 0 & 0 & 0 \\
\hline & & & 0 & 0 & 0 & 0 & 0 & 0 & 0 & 0 & 0 & 0 & 0 \\
\hline
\end{tabular}


Table 10B-cont'd. Summary of Indirect-Model Projections for Data with Outlier Exclusions

\begin{tabular}{|c|c|c|c|c|c|c|c|c|c|c|c|c|c|}
\hline \multirow[b]{3}{*}{ Population } & \multirow[b]{3}{*}{$\begin{array}{l}\text { Pop. } \\
\text { Total }\end{array}$} & \multirow[b]{3}{*}{ Model } & \multirow{3}{*}{$\begin{array}{l}\text { Thick. } \\
\text { Spec } \\
\text { (mils) }\end{array}$} & \multicolumn{10}{|c|}{ Projected Number of Cylinders Below Thickness Criterion } \\
\hline & & & & 20 & 05 & 20 & 10 & 20 & 15 & & 20 & & 25 \\
\hline & & & & $\begin{array}{l}\text { Esti- } \\
\text { mate }\end{array}$ & $\begin{array}{l}95 \% \\
\text { UCB } \\
\end{array}$ & $\begin{array}{l}\text { Esti- } \\
\text { mate }\end{array}$ & $\begin{array}{l}95 \% \\
\text { UCB } \\
\end{array}$ & $\begin{array}{l}\text { Esti- } \\
\text { mate }\end{array}$ & $\begin{array}{l}95 \% \\
\text { UCB } \\
\end{array}$ & $\begin{array}{l}\text { Esti- } \\
\text { mate }\end{array}$ & $\begin{array}{l}95 \% \\
\text { UCB } \\
\end{array}$ & $\begin{array}{l}\text { Esti- } \\
\text { mate }\end{array}$ & $\begin{array}{l}95 \% \\
\text { UCB } \\
\end{array}$ \\
\hline \multirow[t]{3}{*}{ ETTP/PGDP/PORTS thick skirted } & 2,023 & Slope $=1$ & 500 & 5 & 20 & 7 & 27 & 10 & 35 & 13 & 44 & 18 & 5 \\
\hline & & & 62.5 & 0 & 0 & 0 & 1 & 0 & 1 & 0 & 1 & 0 & 2 \\
\hline & & & 0 & 0 & 0 & 0 & 1 & 0 & 1 & 0 & 1 & 0 & \\
\hline \multirow[t]{3}{*}{ ETTP/PGDP/PORTS 1/2" (30" dia.) top } & 1,119 & Slope $=1$ & 100 & 0 & 1 & 0 & 1 & 0 & 2 & 0 & 3 & 0 & 2 \\
\hline & & & 62.5 & 0 & 1 & 0 & 1 & 0 & 1 & 0 & 2 & 0 & 3 \\
\hline & & & 0 & 0 & 0 & 0 & 0 & 0 & 1 & 0 & 1 & 0 & \\
\hline \multirow[t]{3}{*}{ ETTP/PGDP/PORTS 1/2" (30" dia.) btm } & 1,457 & Slope $=1$ & 100 & 0 & 4 & 1 & 5 & 1 & 8 & 1 & 10 & 2 & 12 \\
\hline & & & 62.5 & 0 & 2 & 0 & 4 & 1 & 5 & 1 & 7 & 1 & 10 \\
\hline & & & 0 & 0 & 1 & 0 & 2 & 0 & 3 & 0 & 4 & 1 & 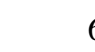 \\
\hline
\end{tabular}


Table 10C. Indirect-Model Projected Proportions for Target Years and Minimum Thickness Criteria

\begin{tabular}{|c|c|c|c|c|c|c|c|c|c|c|c|c|c|}
\hline \multirow[b]{3}{*}{ Population } & \multirow[b]{3}{*}{$\begin{array}{l}\text { Pop. } \\
\text { Total }\end{array}$} & \multirow[b]{3}{*}{ Model } & \multirow{3}{*}{$\begin{array}{c}\text { Thick. } \\
\text { Spec } \\
\text { (mils) }\end{array}$} & \multicolumn{10}{|c|}{ Projected Proportion of Cylinders Below Thickness Criterion } \\
\hline & & & & \multicolumn{2}{|c|}{2005} & \multicolumn{2}{|c|}{2010} & \multicolumn{2}{|c|}{2015} & \multicolumn{2}{|c|}{2020} & \multicolumn{2}{|c|}{2025} \\
\hline & & & & $\begin{array}{l}\text { Esti- } \\
\text { mate }\end{array}$ & $\begin{array}{l}95 \% \\
\text { UCB }\end{array}$ & $\begin{array}{l}\text { Esti- } \\
\text { mate }\end{array}$ & $\begin{array}{l}95 \% \\
\text { UCB }\end{array}$ & $\begin{array}{l}\text { Esti- } \\
\text { mate }\end{array}$ & $\begin{array}{l}95 \% \\
\text { UCB }\end{array}$ & $\begin{array}{l}\text { Esti- } \\
\text { mate }\end{array}$ & $\begin{array}{l}95 \% \\
\text { UCB }\end{array}$ & $\begin{array}{l}\text { Esti- } \\
\text { mate }\end{array}$ & $\begin{array}{l}95 \% \\
\text { UCB }\end{array}$ \\
\hline \multirow[t]{3}{*}{ ETTP thin $(\mathrm{P}-$ scan data $)$} & 4,034 & Slope $=1$ & 250 & .4695 & .5375 & .5683 & 6459 & .6551 & .7363 & .7282 & .8076 & .7878 & .8616 \\
\hline & & & 62.5 & .0025 & .0113 & .0050 & .0186 & .0089 & .0287 & .0147 & .0418 & .0227 & .0577 \\
\hline & & & 0 & .0006 & .0037 & .0012 & .0066 & .0023 & .0108 & .0041 & .0166 & .0068 & .0241 \\
\hline \multirow[t]{3}{*}{ ETTP thin, K-yard bottom } & 1,166 & Slope $=1$ & 250 & .0714 & .1192 & .0913 & .1444 & .1125 & .1700 & .1349 & .1958 & .1579 & .2215 \\
\hline & & & 62.5 & .0014 & .0057 & .0021 & .0079 & .0030 & .0106 & .0042 & .0136 & .0057 & .0171 \\
\hline & & & 0 & .0005 & .0028 & .0009 & .0040 & .0013 & .0055 & .0019 & .0073 & .0026 & .0093 \\
\hline \multirow[t]{3}{*}{ ETTP thin, except K-yard bottom } & 2,868 & Slope $=1$ & 250 & .0584 & 1096 & .0761 & .1342 & .0954 & .1592 & .1156 & .1842 & .1366 & .2088 \\
\hline & & & 62.5 & .0020 & .0090 & .0030 & .0123 & .0043 & .0161 & .0059 & .0204 & .0078 & .0252 \\
\hline & & & 0 & .0010 & .0052 & .0015 & .0073 & .0022 & .0097 & .0030 & .0124 & .0040 & .0155 \\
\hline \multirow[t]{3}{*}{ PGDP thin (P-scan data) } & 32,231 & Slope Fit & 250 & .0909 & .1487 & .1300 & .2012 & .1784 & .2591 & .2346 & .3202 & .2958 & .3846 \\
\hline & & & 62.5 & .0000 & .0003 & .0001 & .0006 & .0002 & .0011 & .0003 & .0019 & .0005 & .0030 \\
\hline & & & 0 & .0000 & .0001 & .0000 & .0001 & .0000 & .0002 & .0000 & .0004 & .0001 & .0007 \\
\hline \multirow[t]{3}{*}{ PGDP thin bottom, former G-yard } & 1,983 & Slope Fit & 250 & .0134 & .0511 & .0163 & .0615 & .0193 & .0729 & .0224 & .0853 & .0256 & .0990 \\
\hline & & & 62.5 & .0000 & .0008 & .0000 & .0011 & .0001 & .0015 & .0001 & .0020 & .0001 & .0026 \\
\hline & & & 0 & .0000 & .0003 & .0000 & .0005 & .0000 & .0007 & .0000 & .0009 & .0000 & .0012 \\
\hline \multirow[t]{3}{*}{ PGDP thin btm, excpt fmr G-yard } & 15,337 & Slope Fit & 250 & .0035 & .0118 & .0048 & .0149 & .0064 & .0183 & .0083 & .0219 & .0103 & .0260 \\
\hline & & & 62.5 & .0000 & .0000 & .0000 & .0001 & .0000 & .0001 & .0000 & .0001 & .0000 & .0002 \\
\hline & & & 0 & .0000 & .0000 & .0000 & .0000 & .0000 & .0000 & .0000 & .0000 & .0000 & .0001 \\
\hline \multirow[t]{3}{*}{ PGDP thin top } & 14,911 & Slope Fit & 250 & .0010 & .0059 & .0013 & .0066 & .0016 & .0074 & .0020 & .0083 & .0023 & .0094 \\
\hline & & & 62.5 & .0000 & .0000 & .0000 & .0000 & .0000 & .0000 & .0000 & .0000 & .0000 & .0000 \\
\hline & & & 0 & .0000 & .0000 & .0000 & .0000 & .0000 & .0000 & .0000 & .0000 & .0000 & .0000 \\
\hline
\end{tabular}


Table 10C-cont'd. Indirect-Model Projected Proportions for Target Years and Minimum Thickness Criteria

\begin{tabular}{|c|c|c|c|c|c|c|c|c|c|c|c|c|c|}
\hline \multirow[b]{3}{*}{ Population } & \multirow[b]{3}{*}{$\begin{array}{c}\text { Pop. } \\
\text { Total }\end{array}$} & \multirow[b]{3}{*}{ Model } & \multicolumn{11}{|c|}{ Projected Proportion of Cylinders Below Thickness Criterion } \\
\hline & & & \multirow{2}{*}{$\begin{array}{c}\text { Thick. } \\
\text { Spec } \\
\text { (mils) }\end{array}$} & \multicolumn{2}{|c|}{2005} & \multicolumn{2}{|c|}{2010} & \multicolumn{2}{|c|}{2015} & \multicolumn{2}{|c|}{2020} & \multicolumn{2}{|c|}{2025} \\
\hline & & & & $\begin{array}{l}\text { Esti- } \\
\text { mate }\end{array}$ & $\begin{array}{l}95 \% \\
\text { UCB }\end{array}$ & $\begin{array}{l}\text { Esti- } \\
\text { mate }\end{array}$ & $\begin{array}{l}95 \% \\
\text { UCB }\end{array}$ & $\begin{array}{l}\text { Esti- } \\
\text { mate }\end{array}$ & $\begin{array}{l}95 \% \\
\text { UCB }\end{array}$ & $\begin{array}{l}\text { Esti- } \\
\text { mate }\end{array}$ & $\begin{array}{l}95 \% \\
\text { UCB }\end{array}$ & $\begin{array}{l}\text { Esti- } \\
\text { mate }\end{array}$ & $\begin{array}{l}95 \% \\
\text { UCB }\end{array}$ \\
\hline \multirow[t]{3}{*}{ PORTS thin (P-scan data) } & 17,269 & Slope Fit & 250 & .0454 & .0672 & .0644 & .0917 & .0872 & .1195 & .1132 & .1503 & .1415 & .1839 \\
\hline & & & 62.5 & .0000 & .0000 & .0000 & .0000 & .0000 & .0000 & .0000 & .0000 & .0000 & .0000 \\
\hline & & & 0 & .0000 & .0000 & .0000 & .0000 & .0000 & .0000 & .0000 & .0000 & .0000 & .0000 \\
\hline \multirow[t]{3}{*}{ PORTS thin top } & 8,501 & Slope Fit & 250 & .0014 & .0087 & .0018 & .0095 & .0022 & .0104 & .0026 & .0113 & .0030 & .0125 \\
\hline & & & 62.5 & .0000 & .0000 & .0000 & .0000 & .0000 & .0000 & .0000 & .0000 & .0000 & .0000 \\
\hline & & & 0 & .0000 & .0000 & .0000 & .0000 & .0000 & .0000 & .0000 & .0000 & .0000 & .0000 \\
\hline \multirow[t]{3}{*}{ PORTS thin bottom } & 8,768 & Slope Fit & 250 & .0007 & .0050 & .0010 & .0058 & .0012 & .0068 & .0016 & .0078 & .0019 & .0090 \\
\hline & & & 62.5 & .0000 & .0000 & .0000 & .0000 & .0000 & .0000 & .0000 & .0000 & .0000 & .0000 \\
\hline & & & 0 & .0000 & .0000 & .0000 & .0000 & .0000 & .0000 & .0000 & .0000 & .0000 & .0000 \\
\hline \multirow[t]{3}{*}{ ETTP/PGDP/PORTS thick top } & 957 & Slope $=1$ & 500 & .0322 & .0558 & .0425 & .0701 & .0541 & .0856 & .0670 & .1021 & .0810 & .1195 \\
\hline & & & 62.5 & .0001 & .0006 & .0002 & .0009 & .0003 & .0013 & .0005 & .0018 & .0007 & .0024 \\
\hline & & & 0 & .0001 & .0004 & .0001 & .0006 & .0002 & .0008 & .0003 & .0012 & .0004 & .0016 \\
\hline \multirow[t]{3}{*}{ ETTP/PGDP/PORTS thick bottom } & 1,066 & Slope $=1$ & 500 & .0523 & .0847 & .0659 & .1025 & .0808 & .1210 & .0967 & .1402 & .1134 & .1598 \\
\hline & & & 62.5 & .0005 & .0021 & .0008 & .0029 & .0011 & .0039 & .0016 & .0051 & .0021 & .0065 \\
\hline & & & 0 & .0003 & .0014 & .0005 & .0020 & .0007 & .0028 & .0010 & .0036 & .0014 & .0047 \\
\hline \multirow[t]{3}{*}{ ETTP/PGDP/PORTS thin skirted top } & 2,285 & Slope $=1$ & 250 & .0000 & .0005 & .0001 & .0009 & .0002 & .0015 & .0003 & .0023 & .0005 & .0034 \\
\hline & & & 62.5 & .0000 & .0000 & .0000 & .0000 & .0000 & .0000 & .0000 & .0000 & .0000 & .0000 \\
\hline & & & 0 & .0000 & .0000 & .0000 & .0000 & .0000 & .0000 & .0000 & .0000 & .0000 & .0000 \\
\hline \multirow[t]{3}{*}{ ETTP/PGDP/PORTS thin skirted btm } & 2,485 & Slope $=1$ & 250 & .0000 & .0005 & .0001 & .0009 & .0001 & .0014 & .0002 & .0021 & .0004 & .0030 \\
\hline & & & 62.5 & .0000 & .0000 & .0000 & .0000 & .0000 & .0000 & .0000 & .0000 & .0000 & .0000 \\
\hline & & & 0 & .0000 & .0000 & .0000 & .0000 & .0000 & .0000 & .0000 & .0000 & .0000 & .0000 \\
\hline
\end{tabular}


Table 10C-cont'd. Indirect-Model Projected Proportions for Target Years and Minimum Thickness Criteria

\begin{tabular}{|c|c|c|c|c|c|c|c|c|c|c|c|c|c|}
\hline \multirow[b]{3}{*}{ Population } & \multirow[b]{3}{*}{$\begin{array}{l}\text { Pop. } \\
\text { Total }\end{array}$} & \multirow[b]{3}{*}{ Model } & \multicolumn{11}{|c|}{ Projected Proportion of Cylinders Below Thickness Criterion } \\
\hline & & & \multirow{2}{*}{$\begin{array}{l}\text { Thick. } \\
\text { Spec } \\
\text { (mils) }\end{array}$} & \multicolumn{2}{|c|}{2005} & \multicolumn{2}{|c|}{2010} & \multicolumn{2}{|c|}{2015} & \multicolumn{2}{|c|}{2020} & \multicolumn{2}{|c|}{2025} \\
\hline & & & & $\begin{array}{l}\text { Esti- } \\
\text { mate }\end{array}$ & $\begin{array}{l}95 \% \\
\text { UCB }\end{array}$ & $\begin{array}{l}\text { Esti- } \\
\text { mate }\end{array}$ & $\begin{array}{l}95 \% \\
\text { UCB }\end{array}$ & $\begin{array}{l}\text { Esti- } \\
\text { mate }\end{array}$ & $\begin{array}{l}95 \% \\
\text { UCB }\end{array}$ & $\begin{array}{l}\text { Esti- } \\
\text { mate }\end{array}$ & $\begin{array}{l}95 \% \\
\text { UCB }\end{array}$ & $\begin{array}{l}\text { Esti- } \\
\text { mate }\end{array}$ & $\begin{array}{l}95 \% \\
\text { UCB } \\
\end{array}$ \\
\hline \multirow[t]{3}{*}{ ETTP/PGDP/PORTS thick skirted } & 2,023 & Slope $=1$ & 500 & .0023 & .0099 & .0035 & .0132 & .0049 & .0171 & .0066 & .0215 & .0088 & .0265 \\
\hline & & & 62.5 & .0000 & .0002 & .0000 & .0004 & .0000 & .0005 & .0001 & .0007 & .0001 & .0010 \\
\hline & & & 0 & .0000 & .0002 & .0000 & .0003 & .0000 & .0004 & .0000 & .0005 & .0001 & .0007 \\
\hline \multirow[t]{3}{*}{ ETTP/PGDP/PORTS 1/2" (30" dia.) top } & 1,119 & Slope $=1$ & 100 & .0013 & .0075 & .0020 & .0100 & .0028 & .0129 & .0039 & .0162 & .0052 & .0199 \\
\hline & & & 62.5 & .0009 & .0057 & .0014 & .0077 & .0020 & .0101 & .0028 & .0127 & .0037 & .0157 \\
\hline & & & 0 & .0005 & .0038 & .0008 & .0051 & .0012 & .0068 & .0016 & .0087 & .0022 & .0109 \\
\hline \multirow[t]{3}{*}{ ETTP/PGDP/PORTS 1/2" (30" dia.) btm } & 1,457 & Slope $=1$ & 100 & .0048 & .0197 & .0068 & .0252 & .0092 & .0313 & .0120 & .0379 & .0153 & .0451 \\
\hline & & & 62.5 & .0035 & .0157 & .0049 & .0202 & .0068 & .0253 & .0090 & .0309 & .0115 & .0369 \\
\hline & & & 0 & .0021 & .0109 & .0030 & .0143 & .0042 & .0181 & .0057 & .0223 & .0074 & .0269 \\
\hline
\end{tabular}


Table 11A. Summary of Direct-Model Projections for Target Years and Thickness Criteria

\begin{tabular}{|c|c|c|c|c|c|c|c|}
\hline \multirow[b]{2}{*}{ Cylinder Population } & \multirow[b]{2}{*}{$\begin{array}{l}\text { Pop. } \\
\text { Total }\end{array}$} & \multirow[b]{2}{*}{$\begin{array}{l}\text { Thick. } \\
\text { Spec } \\
\text { (mils) }\end{array}$} & \multicolumn{5}{|c|}{ Projected Number of Cylinders Below Minimum Thickness Criteria } \\
\hline & & & $\begin{array}{l}2005 \\
\text { Esti- } \\
\text { mate }\end{array}$ & $\begin{array}{l}2010 \\
\text { Esti- } \\
\text { mate }\end{array}$ & $\begin{array}{l}2015 \\
\text { Esti- } \\
\text { mate }\end{array}$ & $\begin{array}{l}2020 \\
\text { Esti- } \\
\text { mate }\end{array}$ & $\begin{array}{l}2025 \\
\text { Esti- } \\
\text { mate }\end{array}$ \\
\hline \multirow[t]{3}{*}{ ETTP thin (P-scan data) } & 4,034 & 250 & 1,038 & 1,214 & 1,380 & 1,529 & 1,660 \\
\hline & & 62.5 & 3 & 4 & 5 & 6 & 7 \\
\hline & & 0 & 1 & 2 & 2 & 2 & 2 \\
\hline \multirow[t]{3}{*}{ ETTP thin, K-yard bottom } & 1,166 & 250 & 57 & 64 & 68 & 71 & 75 \\
\hline & & 62.5 & 1 & 1 & 1 & 1 & 1 \\
\hline & & 0 & 0 & 0 & 0 & 1 & 1 \\
\hline \multirow[t]{3}{*}{ ETTP thin, except K-yard bottom } & 2,868 & 250 & 120 & 137 & 153 & 168 & 180 \\
\hline & & 62.5 & 1 & 1 & 2 & 2 & 2 \\
\hline & & 0 & {$[0-1]$} & 1 & 1 & 1 & 1 \\
\hline \multirow[t]{3}{*}{ PGDP thin (P-scan data) } & 32,231 & 250 & 1,578 & 2,020 & 2,476 & 2,906 & 3,325 \\
\hline & & 62.5 & 8 & 11 & 15 & 18 & 23 \\
\hline & & 0 & 6 & 8 & 8 & 8 & 9 \\
\hline \multirow[t]{3}{*}{ PGDP thin bottom, former G-yard } & 1,983 & 250 & 69 & 78 & 88 & 96 & 103 \\
\hline & & 62.5 & 1 & 1 & 1 & 1 & 1 \\
\hline & & 0 & 0 & 0 & 0 & 1 & 1 \\
\hline \multirow[t]{3}{*}{ PGDP thin btm, excpt fmr G-yard } & 15,337 & 250 & 201 & 269 & 343 & 415 & 488 \\
\hline & & 62.5 & 3 & 4 & 4 & 5 & 6 \\
\hline & & 0 & {$[0-3]$} & {$[0-3]$} & 3 & 3 & 3 \\
\hline \multirow[t]{3}{*}{ PGDP thin top } & 14,911 & 250 & 178 & 237 & 300 & 364 & 424 \\
\hline & & 62.5 & 4 & 4 & 4 & 5 & 5 \\
\hline & & 0 & {$[0-3]$} & {$[0-3]$} & {$[0-3]$} & 3 & 3 \\
\hline
\end{tabular}


Table 11A-cont'd. Summary of Direct-Model Projections for Target Years and Thickness Criteria

\begin{tabular}{|c|c|c|c|c|c|c|c|}
\hline \multirow[b]{2}{*}{ Cylinder Population } & \multirow[b]{2}{*}{$\begin{array}{c}\text { Pop. } \\
\text { Total }\end{array}$} & \multirow[b]{2}{*}{$\begin{array}{c}\text { Thick. } \\
\text { Spec } \\
\text { (mils) }\end{array}$} & \multicolumn{5}{|c|}{ Projected Number of Cylinders Below Minimum Thickness Criteria } \\
\hline & & & $\begin{array}{l}2005 \\
\text { Esti- } \\
\text { mate }\end{array}$ & $\begin{array}{l}2010 \\
\text { Esti- } \\
\text { mate }\end{array}$ & $\begin{array}{l}2015 \\
\text { Esti- } \\
\text { mate }\end{array}$ & $\begin{array}{l}2020 \\
\text { Esti- } \\
\text { mate }\end{array}$ & $\begin{array}{l}2025 \\
\text { Esti- } \\
\text { mate }\end{array}$ \\
\hline \multirow[t]{3}{*}{ PORTS thin (P-scan data) } & 17,269 & 250 & 1,106 & 1,406 & 1,679 & 1,954 & 2,247 \\
\hline & & 62.5 & 5 & 7 & 8 & 11 & 14 \\
\hline & & 0 & 4 & 4 & 4 & 4 & 6 \\
\hline \multirow[t]{3}{*}{ PORTS thin top } & 8,501 & 250 & 71 & 95 & 124 & 152 & 182 \\
\hline & & 62.5 & 2 & 2 & 2 & 2 & 3 \\
\hline & & 0 & {$[0-2]$} & {$[0-2]$} & {$[0-2]$} & 2 & 2 \\
\hline \multirow[t]{3}{*}{ PORTS thin bottom } & 8,768 & 250 & 71 & 96 & 125 & 154 & 185 \\
\hline & & 62.5 & 2 & 2 & 2 & 2 & 3 \\
\hline & & 0 & {$[0-2]$} & {$[0-2]$} & {$[0-2]$} & 2 & 2 \\
\hline \multirow[t]{3}{*}{ ETTP/PGDP/PORTS thick top } & 957 & 500 & 3 & 4 & 5 & 5 & 7 \\
\hline & & 62.5 & 0 & 0 & 0 & 0 & 0 \\
\hline & & 0 & 0 & 0 & 0 & 0 & 0 \\
\hline \multirow[t]{3}{*}{ ETTP/PGDP/PORTS thick bottom } & 1,066 & 500 & 3 & 4 & 5 & 6 & 7 \\
\hline & & 62.5 & 0 & 0 & 0 & 0 & 0 \\
\hline & & 0 & 0 & 0 & 0 & 0 & 0 \\
\hline \multirow[t]{3}{*}{ ETTP/PGDP/PORTS thin skirted top } & 2,285 & 250 & 20 & 24 & 29 & 34 & 38 \\
\hline & & 62.5 & 0 & 1 & 1 & 1 & 1 \\
\hline & & 0 & 0 & 0 & 0 & 0 & 0 \\
\hline \multirow[t]{3}{*}{ ETTP/PGDP/PORTS thin skirted btm } & 2,485 & 250 & 22 & 26 & 32 & 37 & 42 \\
\hline & & 62.5 & 0 & 1 & 1 & 1 & 1 \\
\hline & & 0 & 0 & 0 & 0 & 0 & 0 \\
\hline
\end{tabular}


Table 11A-cont'd. Summary of Direct-Model Projections for Target Years and Thickness Criteria

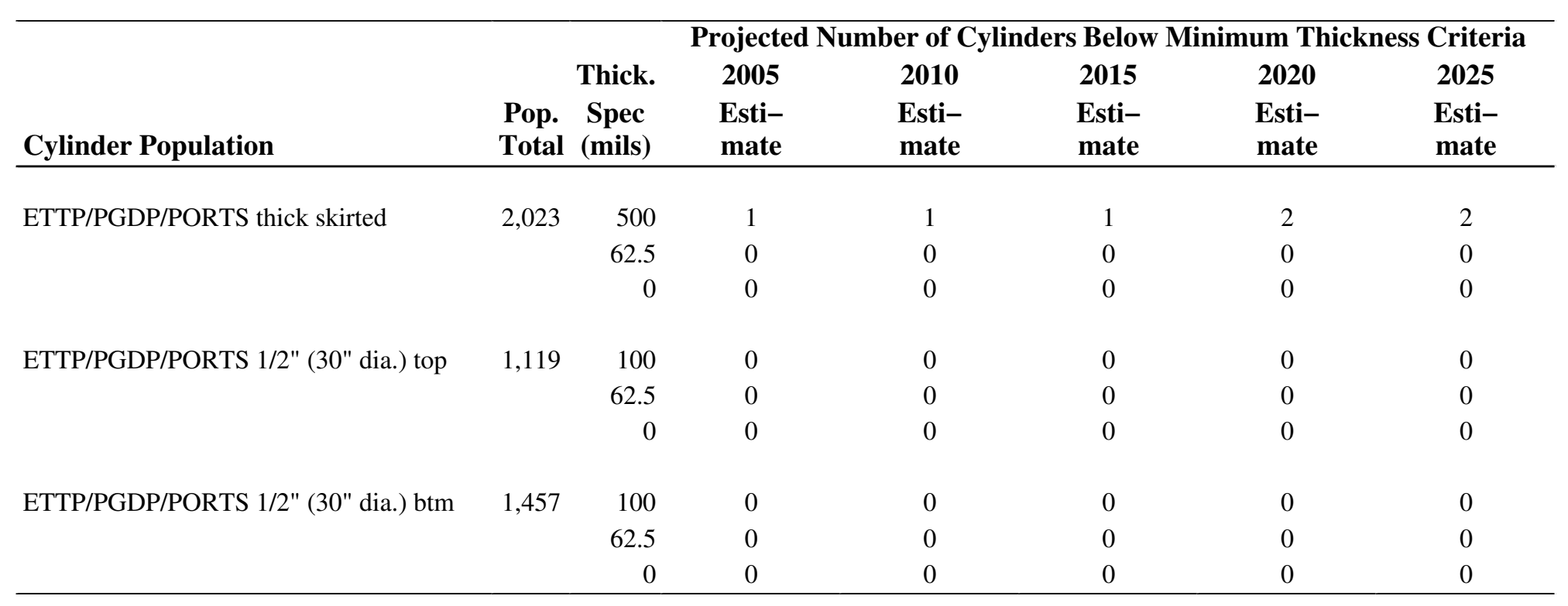


Table 11B. Summary of Direct-Model Projections for Data with Outlier Exclusions

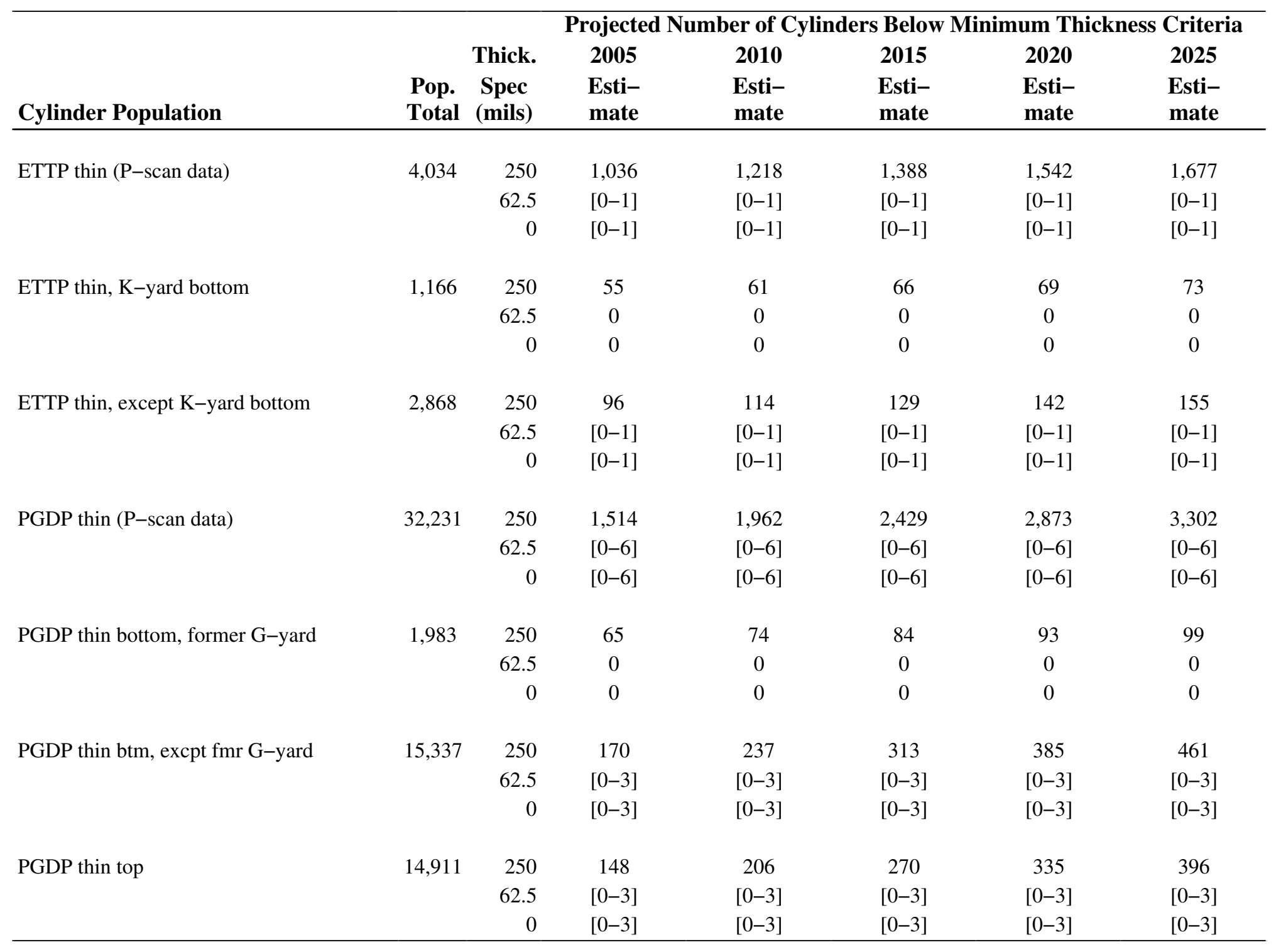


Table 11B-cont'd. Summary of Direct-Model Projections for Data with Outlier Exclusions

\begin{tabular}{|c|c|c|c|c|c|c|c|}
\hline \multirow[b]{2}{*}{ Cylinder Population } & \multirow[b]{2}{*}{$\begin{array}{c}\text { Pop. } \\
\text { Total }\end{array}$} & \multirow[b]{2}{*}{$\begin{array}{l}\text { Thick. } \\
\text { Spec } \\
\text { (mils) }\end{array}$} & \multicolumn{5}{|c|}{ Projected Number of Cylinders Below Minimum Thickness Criteria } \\
\hline & & & $\begin{array}{l}2005 \\
\text { Esti- } \\
\text { mate }\end{array}$ & $\begin{array}{l}2010 \\
\text { Esti- } \\
\text { mate }\end{array}$ & $\begin{array}{l}2015 \\
\text { Esti- } \\
\text { mate } \\
\end{array}$ & $\begin{array}{l}2020 \\
\text { Esti- } \\
\text { mate }\end{array}$ & $\begin{array}{l}2025 \\
\text { Esti- } \\
\text { mate }\end{array}$ \\
\hline PORTS thin (P-scan data) & 17,269 & $\begin{array}{r}250 \\
62.5 \\
0\end{array}$ & $\begin{array}{l}1,085 \\
{[0-3]} \\
{[0-3]}\end{array}$ & $\begin{array}{l}1,395 \\
{[0-3]} \\
{[0-3]}\end{array}$ & $\begin{array}{l}1,677 \\
{[0-3]} \\
{[0-3]}\end{array}$ & $\begin{array}{l}1,965 \\
{[0-3]} \\
{[0-3]}\end{array}$ & $\begin{array}{l}2,275 \\
{[0-3]} \\
{[0-3]}\end{array}$ \\
\hline PORTS thin top & 8,501 & $\begin{array}{r}250 \\
62.5 \\
0\end{array}$ & $\begin{array}{c}54 \\
{[0-2]} \\
{[0-2]}\end{array}$ & $\begin{array}{c}77 \\
{[0-2]} \\
{[0-2]}\end{array}$ & $\begin{array}{c}106 \\
{[0-2]} \\
{[0-2]}\end{array}$ & $\begin{array}{c}135 \\
{[0-2]} \\
{[0-2]}\end{array}$ & $\begin{array}{c}166 \\
{[0-2]} \\
{[0-2]}\end{array}$ \\
\hline PORTS thin bottom & 8,768 & $\begin{array}{r}250 \\
62.5 \\
0\end{array}$ & $\begin{array}{c}50 \\
{[0-2]} \\
{[0-2]}\end{array}$ & $\begin{array}{c}74 \\
{[0-2]} \\
{[0-2]}\end{array}$ & $\begin{array}{c}103 \\
{[0-2]} \\
{[0-2]}\end{array}$ & $\begin{array}{c}131 \\
{[0-2]} \\
{[0-2]}\end{array}$ & $\begin{array}{c}162 \\
{[0-2]} \\
{[0-2]}\end{array}$ \\
\hline ETTP/PGDP/PORTS thick top & 957 & $\begin{array}{r}500 \\
62.5 \\
0\end{array}$ & $\begin{array}{l}1 \\
0 \\
0\end{array}$ & $\begin{array}{l}2 \\
0 \\
0\end{array}$ & $\begin{array}{l}3 \\
0 \\
0\end{array}$ & $\begin{array}{l}4 \\
0 \\
0\end{array}$ & $\begin{array}{l}5 \\
0 \\
0\end{array}$ \\
\hline ETTP/PGDP/PORTS thick bottom & 1,066 & $\begin{array}{r}500 \\
62.5 \\
0\end{array}$ & $\begin{array}{l}1 \\
0 \\
0\end{array}$ & $\begin{array}{l}1 \\
0 \\
0\end{array}$ & $\begin{array}{l}2 \\
0 \\
0\end{array}$ & $\begin{array}{l}3 \\
0 \\
0\end{array}$ & $\begin{array}{l}4 \\
0 \\
0\end{array}$ \\
\hline ETTP/PGDP/PORTS thin skirted top & 2,285 & $\begin{array}{r}250 \\
62.5 \\
0\end{array}$ & $\begin{array}{c}15 \\
0 \\
0\end{array}$ & $\begin{array}{c}19 \\
0 \\
0\end{array}$ & $\begin{array}{c}24 \\
0 \\
0\end{array}$ & $\begin{array}{c}29 \\
0 \\
0\end{array}$ & $\begin{array}{c}33 \\
0 \\
0\end{array}$ \\
\hline ETTP/PGDP/PORTS thin skirted btm & 2,485 & $\begin{array}{r}250 \\
62.5 \\
0\end{array}$ & $\begin{array}{c}17 \\
0 \\
0\end{array}$ & $\begin{array}{c}21 \\
0 \\
0\end{array}$ & $\begin{array}{c}27 \\
0 \\
0\end{array}$ & $\begin{array}{c}32 \\
0 \\
0\end{array}$ & $\begin{array}{c}37 \\
0 \\
0\end{array}$ \\
\hline
\end{tabular}


Table 11B-cont'd. Summary of Direct-Model Projections for Data with Outlier Exclusions

\begin{tabular}{|c|c|c|c|c|c|c|c|}
\hline \multirow[b]{2}{*}{ Cylinder Population } & \multirow[b]{2}{*}{$\begin{array}{l}\text { Pop. } \\
\text { Total }\end{array}$} & \multirow[b]{2}{*}{$\begin{array}{l}\text { Thick. } \\
\text { Spec } \\
\text { (mils) }\end{array}$} & \multicolumn{5}{|c|}{ Projected Number of Cylinders Below Minimum Thickness Criteria } \\
\hline & & & $\begin{array}{l}2005 \\
\text { Esti- } \\
\text { mate }\end{array}$ & $\begin{array}{l}2010 \\
\text { Esti- } \\
\text { mate }\end{array}$ & $\begin{array}{l}2015 \\
\text { Esti- } \\
\text { mate }\end{array}$ & $\begin{array}{l}2020 \\
\text { Esti- } \\
\text { mate }\end{array}$ & $\begin{array}{l}2025 \\
\text { Esti- } \\
\text { mate }\end{array}$ \\
\hline \multirow[t]{3}{*}{ ETTP/PGDP/PORTS thick skirted } & 2,023 & 500 & 0 & 0 & 0 & 0 & 0 \\
\hline & & 62.5 & 0 & 0 & 0 & 0 & 0 \\
\hline & & 0 & 0 & 0 & 0 & 0 & 0 \\
\hline \multirow[t]{3}{*}{ ETTP/PGDP/PORTS 1/2" (30" dia.) top } & 1,119 & 100 & 0 & 0 & 0 & 0 & 0 \\
\hline & & 62.5 & 0 & 0 & 0 & 0 & 0 \\
\hline & & 0 & 0 & 0 & 0 & 0 & 0 \\
\hline \multirow{3}{*}{ ETTP/PGDP/PORTS 1/2" (30" dia.) btm } & 1,457 & 100 & 0 & 0 & 0 & 0 & 0 \\
\hline & & 62.5 & 0 & 0 & 0 & 0 & 0 \\
\hline & & 0 & 0 & 0 & 0 & 0 & 0 \\
\hline
\end{tabular}


Table 11C. Direct-Model Projected Proportions for Target Years and Thickness Criteria

\begin{tabular}{|c|c|c|c|c|c|c|c|}
\hline \multirow[b]{2}{*}{ Cylinder Grouping } & \multirow[b]{2}{*}{$\begin{array}{l}\text { Pop. } \\
\text { Total }\end{array}$} & & \multicolumn{5}{|c|}{ Projected Proportion of Cylinders Below Minimum Thickness Criteria } \\
\hline & & $\begin{array}{c}\text { Thick. } \\
\text { Spec } \\
\text { (mils) }\end{array}$ & $\begin{array}{l}2005 \\
\text { Esti- } \\
\text { mate }\end{array}$ & $\begin{array}{l}2010 \\
\text { Esti- } \\
\text { mate }\end{array}$ & $\begin{array}{l}2015 \\
\text { Esti- } \\
\text { mate }\end{array}$ & $\begin{array}{l}2020 \\
\text { Esti- } \\
\text { mate }\end{array}$ & $\begin{array}{l}2025 \\
\text { Esti- } \\
\text { mate }\end{array}$ \\
\hline \multirow[t]{3}{*}{ ETTP thin (P-scan data) } & 4,034 & 250 & .2572 & .3011 & .3420 & .3790 & .4116 \\
\hline & & 62.5 & .0007 & .0010 & .0011 & .0015 & .0017 \\
\hline & & 0 & .0003 & .0004 & .0004 & .0005 & .0005 \\
\hline \multirow[t]{3}{*}{ ETTP thin, K-yard bottom } & 1,166 & 250 & .0490 & .0545 & .0581 & .0612 & .0645 \\
\hline & & 62.5 & .0005 & .0005 & .0005 & .0006 & .0007 \\
\hline & & 0 & {$[.0002]$} & .0002 & .0003 & .0005 & .0005 \\
\hline \multirow[t]{3}{*}{ ETTP thin, except K-yard bottom } & 2,868 & 250 & .0418 & .0479 & .0532 & .0585 & .0627 \\
\hline & & 62.5 & .0003 & .0004 & .0005 & .0006 & .0007 \\
\hline & & 0 & {$[.0002]$} & .0002 & .0002 & .0003 & .0003 \\
\hline \multirow[t]{3}{*}{ PGDP thin (P-scan data) } & 32,231 & 250 & .0489 & .0627 & .0768 & .0902 & .1032 \\
\hline & & 62.5 & .0003 & .0003 & .0005 & .0006 & .0007 \\
\hline & & 0 & .0002 & .0002 & .0002 & .0002 & .0003 \\
\hline \multirow[t]{3}{*}{ PGDP thin bottom, former G-yard } & 1,983 & 250 & .0348 & .0394 & .0442 & .0486 & .0519 \\
\hline & & 62.5 & .0004 & .0004 & .0005 & .0005 & .0005 \\
\hline & & 0 & [.0002] & [.0002] & .0002 & .0003 & .0004 \\
\hline \multirow[t]{3}{*}{ PGDP thin btm, excpt fmr G-yard } & 15,337 & 250 & .0131 & .0175 & .0224 & .0270 & .0318 \\
\hline & & 62.5 & .0002 & .0002 & .0002 & .0003 & .0004 \\
\hline & & 0 & {$[.0002]$} & [.0002] & .0002 & .0002 & .0002 \\
\hline \multirow[t]{3}{*}{ PGDP thin top } & 14,911 & 250 & .0119 & .0159 & .0201 & .0244 & .0284 \\
\hline & & 62.5 & .0002 & .0002 & .0003 & .0003 & .0004 \\
\hline & & 0 & {$[.0002]$} & [.0002] & [.0002] & .0002 & .0002 \\
\hline
\end{tabular}


Table 11C-cont'd. Direct-Model Projected Proportions for Target Years and Thickness Criteria

\begin{tabular}{|c|c|c|c|c|c|c|c|}
\hline \multirow[b]{2}{*}{ Cylinder Grouping } & \multirow[b]{2}{*}{$\begin{array}{l}\text { Pop. } \\
\text { Total }\end{array}$} & \multirow[b]{2}{*}{$\begin{array}{l}\text { Thick. } \\
\text { Spec } \\
\text { (mils) }\end{array}$} & \multicolumn{5}{|c|}{ Projected Proportion of Cylinders Below Minimum Thickness Criteria } \\
\hline & & & $\begin{array}{l}2005 \\
\text { Esti- } \\
\text { mate }\end{array}$ & $\begin{array}{l}2010 \\
\text { Esti- } \\
\text { mate }\end{array}$ & $\begin{array}{l}2015 \\
\text { Esti- } \\
\text { mate }\end{array}$ & $\begin{array}{l}2020 \\
\text { Esti- } \\
\text { mate }\end{array}$ & $\begin{array}{l}2025 \\
\text { Esti- } \\
\text { mate }\end{array}$ \\
\hline \multirow[t]{3}{*}{ PORTS thin (P-scan data) } & 17,269 & 250 & .0640 & .0814 & .0973 & .1131 & 1301 \\
\hline & & 62.5 & .0003 & .0004 & .0005 & .0006 & .0008 \\
\hline & & 0 & .0002 & .0002 & .0002 & .0003 & .0003 \\
\hline \multirow[t]{3}{*}{ PORTS thin top } & 8,501 & 250 & .0083 & .0112 & .0146 & .0179 & .0215 \\
\hline & & 62.5 & .0002 & .0002 & .0002 & .0003 & .0003 \\
\hline & & 0 & [.0002] & {$[.0002]$} & {$[.0002]$} & .0002 & .0002 \\
\hline \multirow[t]{3}{*}{ PORTS thin bottom } & 8,768 & 250 & .0081 & .0109 & .0143 & .0176 & .0211 \\
\hline & & 62.5 & .0002 & .0002 & .0002 & .0003 & .0003 \\
\hline & & 0 & {$[.0002]$} & {$[.0002]$} & {$[.0002]$} & .0002 & .0002 \\
\hline \multirow[t]{3}{*}{ ETTP/PGDP/PORTS thick top } & 957 & 500 & .0029 & .0039 & .0048 & .0057 & .0069 \\
\hline & & 62.5 & .0002 & .0002 & .0002 & .0002 & .0002 \\
\hline & & 0 & .0002 & .0002 & .0002 & .0002 & .0002 \\
\hline \multirow[t]{3}{*}{ ETTP/PGDP/PORTS thick bottom } & 1,066 & 500 & .0028 & .0037 & .0046 & .0055 & .0067 \\
\hline & & 62.5 & .0002 & .0002 & .0002 & .0002 & .0002 \\
\hline & & 0 & .0002 & .0002 & .0002 & .0002 & .0002 \\
\hline \multirow[t]{3}{*}{ ETTP/PGDP/PORTS thin skirted top } & 2,285 & 250 & .0087 & .0104 & .0125 & .0148 & .0167 \\
\hline & & 62.5 & .0002 & .0004 & .0004 & .0004 & .0004 \\
\hline & & 0 & {$[.0002]$} & {$[.0002]$} & {$[.0002]$} & {$[.0002]$} & {$[.0002]$} \\
\hline \multirow[t]{3}{*}{ ETTP/PGDP/PORTS thin skirted btm } & 2,485 & 250 & .0089 & .0106 & .0128 & .0151 & .0169 \\
\hline & & 62.5 & .0002 & .0004 & .0004 & .0004 & .0004 \\
\hline & & 0 & [.0002] & [.0002] & [.0002] & [.0002] & [.0002] \\
\hline
\end{tabular}


Table 11C-cont'd. Direct-Model Projected Proportions for Target Years and Thickness Criteria

\begin{tabular}{|c|c|c|c|c|c|c|c|}
\hline \multirow[b]{2}{*}{ Cylinder Grouping } & \multirow[b]{2}{*}{$\begin{array}{l}\text { Pop. } \\
\text { Total }\end{array}$} & \multirow[b]{2}{*}{$\begin{array}{c}\text { Thick. } \\
\text { Spec } \\
\text { (mils) }\end{array}$} & \multicolumn{5}{|c|}{ Projected Proportion of Cylinders Below Minimum Thickness Criteria } \\
\hline & & & $\begin{array}{l}2005 \\
\text { Esti- } \\
\text { mate }\end{array}$ & $\begin{array}{l}2010 \\
\text { Esti- } \\
\text { mate }\end{array}$ & $\begin{array}{l}2015 \\
\text { Esti- } \\
\text { mate }\end{array}$ & $\begin{array}{l}2020 \\
\text { Esti- } \\
\text { mate }\end{array}$ & $\begin{array}{l}2025 \\
\text { Esti- } \\
\text { mate }\end{array}$ \\
\hline \multirow[t]{3}{*}{ ETTP/PGDP/PORTS thick skirted } & 2,023 & 500 & .0005 & .0005 & .0006 & .0009 & .0011 \\
\hline & & 62.5 & .0002 & .0002 & .0002 & .0002 & .0002 \\
\hline & & 0 & .0002 & .0002 & .0002 & .0002 & .0002 \\
\hline \multirow[t]{3}{*}{ ETTP/PGDP/PORTS 1/2" (30" dia.) top } & 1,119 & 100 & .0002 & .0002 & .0002 & .0002 & .0002 \\
\hline & & 62.5 & .0002 & .0002 & .0002 & .0002 & .0002 \\
\hline & & 0 & .0002 & .0002 & .0002 & .0002 & .0002 \\
\hline \multirow[t]{3}{*}{ ETTP/PGDP/PORTS 1/2" (30" dia.) btm } & 1,457 & 100 & .0002 & .0002 & .0002 & .0002 & .0002 \\
\hline & & 62.5 & .0002 & .0002 & .0002 & .0002 & .0002 \\
\hline & & 0 & .0002 & .0002 & .0002 & .0002 & .0002 \\
\hline
\end{tabular}


In the indirect model approach, for the various cylinder subpopulations, the statistical distributions of $M(t)$ are assumed to be lognormal, and regression is used to estimate the parameters of the respective lognormal distributions. These estimates and therefore the corresponding projections do not incorporate adjustments to account for statistical variability in model parameter estimates. The projections may be conservative for other reasons but not because of statistical adjustments to account for error in the parameter estimates. However, in addition to the projections, Table 10A also contains upper confidence limits (UCLs) for the projections. The numbers in the columns of Table 10A labeled "Estimate" are point estimates computed from the regression estimates; the numbers labeled "95\% UCL" are approximate upper 95\% confidence limits computed using the method developed by Lyon (2000) and refined by Schmoyer and Lyon (2003). The confidence limits take into account variability in the regression parameter estimates, though the mathematics underlying them is based on conservative approximations.

The direct-model projections in Table 11A are based on the same large-sample approximation that is used to derive the nonparametric LCLs plotted in Figures 21-37 for individual predicted values. Those LCLs are nonparametric analogs of the usual normal-theory LCLs for individual predicted values, which are also plotted in the figures. For given $\gamma$, a level $\gamma$ lower prediction bound $L$ for a minimum thickness $M$ satisfies $\operatorname{Prob}(M>L)=\gamma$. By inverting $L$ as a function of $\gamma$, a probability $\gamma(l)$ can also be computed for any specified $L=l$ (e.g. $l=0$ or $l=62.5$ ). Further, $\gamma(l)$ converges to $\operatorname{Prob}(M>l)$ by the same argument (Schmoyer 1992) that shows that $\operatorname{Prob}(M>L)$ converges to $\gamma$ as the sample size increases. The probability estimate $\gamma(l)$ thus reflects estimation error in the direct-model regression parameters, just as $L(\gamma)$ does. As the regression mean squared error increases, $L(\gamma)$ decreases for given $\gamma$, and $\gamma(l)$ decreases for given $l$.

The probability $1-\gamma(l)$ is an estimate of the tail probability $\operatorname{Prob}(M \leq l)$. A limitation of this nonparametric approach is that because it is not premised on a distribution with functional form that is known (up to unspecified parameters), not much can be extrapolated beyond the sample about the lower (or upper) tail of the distribution. An implication of this is that the prediction bounds are not appropriate for values of $\gamma$ less than $1 /(2(n+1)$ ) (or perhaps $1 /(n+1))$, where $n$ is the number of observations in the regression used to compute them. A consequence of this limitation is that direct model probability estimates are never smaller than $1 /(2(n+1)$. Smaller values are in this sense below the resolution of the sample. Details about the resolution limitation are in Schmoyer (1992), but we note here it is related to the problem of predicting, on the basis of $n$ observations $X_{1} \ldots, X_{n}$, a new $(n+1)^{\text {st }}$ observation $X^{*}$. The probability is $1 /(n+1)$ that $X^{*}$ is less than the smallest of $X_{1}, \ldots, X_{n}$. However, without further assumptions about the distribution of the $\mathrm{X}_{1}, \ldots, \mathrm{X}_{\mathrm{n}}$, and $\mathrm{X}^{*}$ (e.g., that it is lognormal), stronger statements about how small $X^{*}$ is likely to be are difficult to justify. When assumptions about the form of the distribution are true, they are refinements, but they can be very misleading when they are false, particularly when making inferences about the lower (or upper) tail of a probability distribution.

For the direct model, there are $n=2,809$ observations. The resolution limit is thus $1 /(2(n+1)=.000178$. Without further assumptions (e.g., that the thickness distribution is normal), the only way to reduce this limit is to increase the sample size $\mathrm{n}$. For a subpopulation of say 2,000 cylinders, the limit translates to $.000178 \times 2,000=.36$ or, essentially, $\mathrm{N}=0$ cylinders. But for a subpopulation of 10,000 cylinders the limit translates to 1.78 cylinders or about $\mathrm{N}=2$ cylinders. When projections like this are at the limit of resolution of the sample, they are presented as bracketed ranges " $[0-\mathrm{N}]$ " in the tables to differentiate them from projections that are above this limit.

The direct model projections incorporate adjustments that account for statistical error in the regression parameter estimates. In that sense they are more like the confidence bounds for the indirect-model projections than the indirect-model projections themselves. However, although the direct-model projections are likely to be more conservative than the indirect-model projections, they are not as conservative as the confidence limits for the indirect-model projections. 
Tables $10 \mathrm{~A}$ and $11 \mathrm{~A}$ show clearly that projections of the numbers of noncompliant cylinders are much higher for the P-scan groups than for the manual UT groups. As discussed earlier, however, the P-scan results are deprecated in favor of the more recent manual UT data and are disregarded in the conclusions of this report.

Tables 10A and 11A both show that many cylinders are projected to fail the upper (e.g., 250 or 500 mil) thickness specifications, though (except of the P-scanned groups) the proportions projected to fail are small. The validation analysis in Section 6 is consistent with these results, though it is somewhat inconclusive, because relatively few of the sampled cylinders failed even the upper criteria in the UT inspection. Therefore an even higher "pseudo" thickness criteria is used in the validation, and observed and projected results are consistent for that criteria.

However, Tables 10A and 11A also show that numerous breaches are projected for 2005 and later years. The number of breaches projected by the indirect model (point estimate) is eight for 2005 and considerably more for later years. Ten breaches were predicted by the indirect model for 2005 in the 2003 edition of this report.

For the direct model, no 2005 breaches are explicitly predicted for 2005, though in some cases, because of the sample size resolution limit, breaches are not ruled out. (These are indicated by the [0-N] notation.) This is a substantial change from the 2003 edition of this report, in which seventeen breaches were predicted by the direct model. This change reflects the outlier remeasurements, the modification to the $30 \mathrm{~A}$ weighting, as well as the new UT measurements made in FY03.

The direct model does explicitly predict breaches by 2010 and later. Although breaches have occurred in the past, and despite random variations, the numbers of breaches predicted in the tables seem too high-it is unlikely that breaches of this frequency would go unnoticed, even if they were not detected in the UT scanning itself.

Possible reasons for high projections include:

- Not all cylinders were sampled randomly (e.g., using a random number generator), but were selected "quasi-randomly" or, as is natural in inspections, with purposive focus on groups thought to be at higher risk.

- The cylinder groupings (subpopulations) only roughly approximate the complete storage location history of cylinders. Because cylinders are typically moved from time to time, the "locations" associated with the cylinder groupings would be better represented as combinations of locations. When cylinders are moved, they are usually moved to improved storage locations.

- Outliers. Low minimum thickness outliers have occurred in the past and can substantially effect the projections.

There is no straightforward way to account for bias induced by purposive sampling. Similarly, an accurate accounting for storage location history would be very difficult to implement. On the other hand, excluding outliers from the analysis is straightforward, at least to implement. Tables 10B and 11B are recomputed versions of Tables 10A and 11A, computed after excluding outliers identified in Table 9.

Projections with Outlier Exclusions. Table 10B is the analog of Table 10A for the indirect model, computed after excluding observations (cylinders) for which the minimum pit depth exceeds 160 mils. Table 11B is the analog of Table 11A for the direct model, computed after excluding observations for which the regression residual is less than -20 mils. The 160 mil and -20 mil thresholds are subjective; different cutoffs could also be considered. However, they are same thresholds that were used for the 2003 
edition of this report. For the 2003 report, 27 cylinders were excluded for the indirect model, 24 cylinders were excluded for the direct model, with 23 of the excluded cylinders common to both models. For 2004, with the remeasurement of cylinders identified as outliers, and with the modified weighting of 30As in the direct model regression, the number of cylinders excluded for the direct model is only six. The number of cylinders excluded from the indirect-model analysis is again 27 , four of which are also dropped for the direct model.

When the outliers are dropped (and again disregarding the P-scan groups), the number of breaches (point estimate not confidence limit) predicted for 2005 drops from 8 to 2 for the indirect model. Again, more breaches are predicted in later years, however. On the other hand, for the direct model, with six outliers excluded, no breaches are explicitly predicted for any year in the table. Breaches are not ruled out in many cases, but that is because of the resolution limit. This is the first year that no breaches were explicitly predicted by the direct model (or either model).

Proportions Projections. The projections in Tables 10A and 11A (or 10B and 11B) can also be used on a relative basis, for example, to prioritize cylinder groups. Because biases tend to cancel out in comparisons, comparisons tend to be more robust than absolute estimates. For such comparisons, rather than counts of cylinders expected to fail the various thickness criteria, it is convenient to examine rates (proportions) of cylinders projected to fail the various thickness criteria.

Tables $10 \mathrm{C}$ and $11 \mathrm{C}$ are the analogs of Tables $10 \mathrm{~A}$ and $11 \mathrm{~A}$ with proportions of cylinders rather than absolute counts. The tables show the cylinder groups where individual cylinders are projected to be most likely to fail either the breach or 62.5 mil criteria. In decreasing order (and disregarding the P-scan results) the first four groups for the indirect model (Table 10C) are 1/2" bottom-row cylinders, ETTP thin-wall cylinders, except K-yard bottom; $1 / 2$ " top-row cylinders, and ETTP thin-wall, K-yard bottom cylinders. These results pertain for all years listed in the table, for either the breach or 62.5 mil criteria.

For the direct model, some of the subpopulation comparisons based on the breach criteria are ties, because, as with the count projections in Table 11A, some of the direct-model rate projections in Table 11C are at the resolution limit $.5 /(2,809+1)=.0001779$ (and listed in brackets as [.0002] in the table). But the 62.5 mil criteria can be used in all cases. According to the direct-model projections the cylinders most likely to fail either the breach or 62.5 mil criteria are the ETTP thin-wall K-yard bottom cylinders, followed by the PGDP thin-wall former G-yard bottom cylinders, followed by the ETTP thin-wall cylinders other than Kyard bottom. This holds for all years listed in the table.

Projections by Cylinder Group and Age. Because the likelihood that a cylinder will fail a particular thickness criteria depends on both the cylinder's subpopulation and age, and because the cylinder subpopulations have different cylinder age distributions, focusing on subpopulations in general can be misleading. For example, a cylinder of average age in a large subpopulation composed of many new cylinders and a few very old ones may have only a tiny chance of failing a particular criteria. Yet the oldest cylinders in the same population might nevertheless be likely to fail. Therefore it is useful to examine cylinders grouped by both subpopulation and age.

Table 12 lists, for each subpopulation and age, the direct and indirect-model estimates of the failure rate for the 62.5 mil thickness criteria. Because these rates are very small, they are expressed as percentages. The groups are listed in descending order of the direct-model estimates. Many of the rate estimates are the same for different ages and subpopulations. That is because of the discreteness of the distribution of the 2,809 regression residuals, and because the rate estimates are computed from the extreme lower tail of that distribution. Most of the estimates are in fact $100 /(2(2,809+1))=.01779$, which is the lower limit of the distribution (limit of resolution). More refined tail probability estimates are difficult, because they require additional assumptions (for example, that the underlying distribution is normal) which generally have no physical basis. 
Table 12 shows that it is the combination of both age and subpopulation together that leads to the highest percentage risks. Of course the table shows that cylinders in thin-wall subpopulations tend to be more likely to fail than thick-wall or $1 / 2$ " cylinders. However, the table also shows that subpopulation is otherwise less of a determinant of corrosion than age. Consider, for example, the direct-model risk percentage estimates for age-48 ETTP, thin-wall, K-yard bottom cylinders and for age-48 thin-wall Portsmouth bottom cylinders, which are the same, .0005338 (.05338\%). The estimates in Table 10C of the overall probabilities of failing the 62.5 mil criterion are .0005 for the ETTP, thin-wall, K-yard bottom cylinders, which is 2.5 times the overall probability (.0002) for the Portsmouth, thin-wall, bottom cylinders. However, the two subpopulations differ in cylinder age distributions. Figure 3 shows that the ETTP, Kyard bottom cylinders are much older on average than the Portsmouth cylinders. The overall risk is higher for the older cylinders in ETTP K-yard, though the risk for age 48 cylinders is about the same.

Table 12 is for the 62.5 mil thickness criterion, but tables for other criteria are similar. The direct and indirect models are evaluated and compared further in the next section.

\section{ETTP Thin-Wall K-yard Bottom Cylinders}

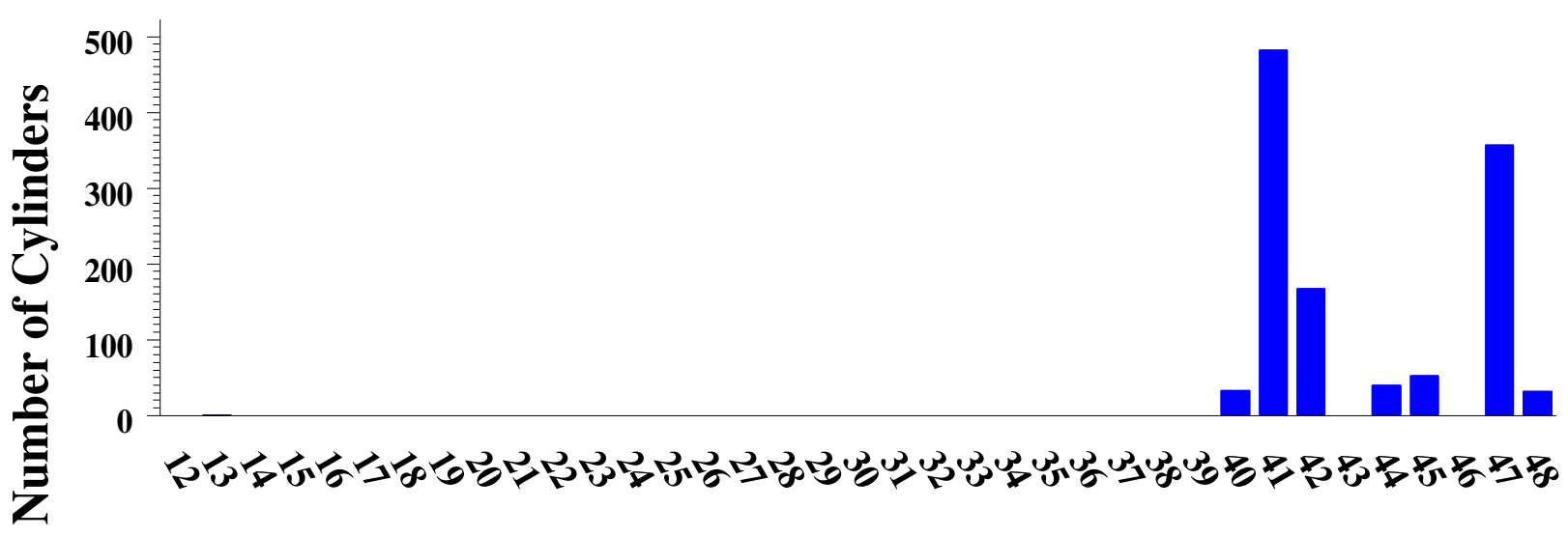

Age in 2004

\section{Portsmouth Thin-Wall Bottom Cylinders}

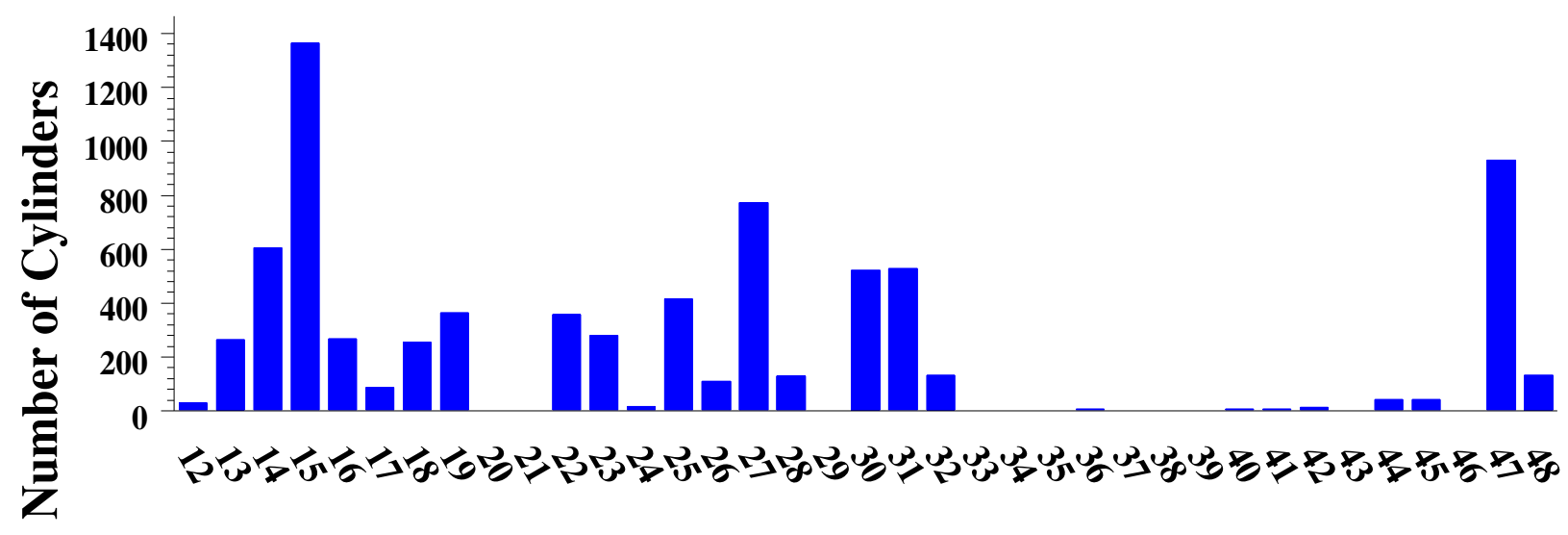

Age in 2004

Figure 3. A comparison of the cylinder age distributions for two thin-wall, bottom-row cylinder subpopulations (ETTP K-yard and Portsmouth). 
Table 12. Cylinder Subpopulation/Age Groups With Year 2005 Projections of the Percentage Failing the 62.5 Mil Thickness Criteria (By Descending Direct-Model Percentage Estimate)

\begin{tabular}{|c|c|c|c|c|c|}
\hline Cylinder Subpopulation & Age & $\mathbf{N}$ & $\begin{array}{l}\text { Ind. Model } \\
\text { Estimated } \\
\text { Percentage } \\
\text { Out of Spec* }\end{array}$ & $\begin{array}{c}\text { Ind. } \\
\text { Model } \\
\text { Rank }\end{array}$ & $\begin{array}{c}\text { Dir. Model } \\
\text { Estimated } \\
\text { Percentage } \\
\text { Out of Spec* }\end{array}$ \\
\hline ETTP thin, except K-yard bottom & 43 & 168 & .32493 & 6 & .05338 \\
\hline ETTP thin, except K-yard bottom & 41 & 29 & .27671 & 8 & .05338 \\
\hline ETTP thin, $\mathrm{K}$-yard bottom & 49 & 32 & .19818 & 9 & .05338 \\
\hline ETTP thin, $\mathrm{K}$-yard bottom & 48 & 357 & .18235 & 11 & .05338 \\
\hline ETTP thin, $\mathrm{K}$-yard bottom & 45 & 40 & .13994 & 13 & .05338 \\
\hline ETTP thin, $\mathrm{K}$-yard bottom & 43 & 168 & .11570 & 15 & .05338 \\
\hline ETTP thin, $\mathrm{K}$-yard bottom & 42 & 482 & .10473 & 17 & .05338 \\
\hline ETTP thin, $\mathrm{K}$-yard bottom & 41 & 33 & .09449 & 19 & .05338 \\
\hline PGDP thin bottom, former G-yard & 46 & 336 & .00524 & 37 & .05338 \\
\hline PGDP thin btm, excpt fmr G-yard & 48 & 32 & .00203 & 49 & .05338 \\
\hline PGDP thin btm, excpt fmr G-yard & 47 & 1 & .00190 & 50 & .05338 \\
\hline PGDP thin btm, excpt fmr G-yard & 46 & 782 & .00178 & 53 & .05338 \\
\hline PGDP thin top & 49 & 257 & .00010 & 87 & .05338 \\
\hline PGDP thin top & 48 & 37 & .00009 & 89 & .05338 \\
\hline PGDP thin top & 46 & 351 & .00008 & 91 & .05338 \\
\hline PORTS thin top & 49 & 152 & .00002 & 109 & .05338 \\
\hline ETTP thin, except K-yard bottom & 49 & 36 & .49824 & 1 & .05338 \\
\hline ETTP thin, except K-yard bottom & 48 & 373 & .46632 & 2 & .05338 \\
\hline ETTP thin, except K-yard bottom & 46 & 45 & .40614 & 3 & .05338 \\
\hline ETTP thin, except K-yard bottom & 45 & 34 & .37787 & 4 & .05338 \\
\hline ETTP thin, except $\mathrm{K}$-yard bottom & 42 & 472 & .30023 & 7 & .05338 \\
\hline ETTP thin, $\mathrm{K}$-yard bottom & 46 & 53 & .15325 & 12 & .05338 \\
\hline PGDP thin bottom, former G-yard & 45 & 548 & .00494 & 38 & .05338 \\
\hline PGDP thin btm, excpt fmr G-yard & 49 & 280 & .00216 & 46 & .05338 \\
\hline PGDP thin btm, excpt fmr G-yard & 45 & 616 & .00166 & 56 & .05338 \\
\hline PGDP thin btm, excpt fmr G-yard & 43 & 158 & .00144 & 59 & .05338 \\
\hline PGDP thin top & 45 & 1000 & .00008 & 92 & .05338 \\
\hline PORTS thin bottom & 49 & 134 & .00001 & 134 & .05338 \\
\hline PGDP thin bottom, former G-yard & 43 & 250 & .00436 & 39 & .05338 \\
\hline
\end{tabular}


Table 12-cont'd. Cylinder Subpopulation/Age Groups

\begin{tabular}{|c|c|c|c|c|c|}
\hline Cylinder Subpopulation & Age & $\mathbf{N}$ & $\begin{array}{l}\text { Ind. Model } \\
\text { Estimated } \\
\text { Percentage } \\
\text { Out of Spec }\end{array}$ & $\begin{array}{l}\text { Ind. } \\
\text { Model } \\
\text { Rank }\end{array}$ & $\begin{array}{l}\text { Dir. Model } \\
\text { Estimated } \\
\text { Percentage } \\
\text { Out of Spec }\end{array}$ \\
\hline PORTS thin top & 48 & 911 & .00002 & 110 & .05338 \\
\hline PORTS thin bottom & 48 & 929 & .00001 & 137 & .05338 \\
\hline PGDP thin bottom, former G-yard & 42 & 138 & .00408 & 41 & .05338 \\
\hline PGDP thin btm, excpt fmr G-yard & 42 & 194 & .00134 & 61 & .05338 \\
\hline PGDP thin bottom, former G-yard & 41 & 8 & .00382 & 42 & .05338 \\
\hline PGDP thin top & 43 & 671 & .00007 & 93 & .05338 \\
\hline PGDP thin btm, excpt fmr G-yard & 41 & 32 & .00124 & 64 & .05336 \\
\hline PORTS thin bottom & 46 & 41 & .00001 & 141 & .05336 \\
\hline PGDP thin top & 42 & 302 & .00007 & 94 & .05313 \\
\hline ETTP thin, except $\mathrm{K}$-yard bottom & 37 & 10 & .19403 & 10 & .05300 \\
\hline PORTS thin bottom & 45 & 44 & .00000 & 143 & .05137 \\
\hline PGDP thin top & 41 & 47 & .00006 & 95 & .04108 \\
\hline PORTS thin top & 43 & 163 & .00002 & 115 & .01875 \\
\hline PORTS thin bottom & 43 & 13 & .00000 & 147 & .01867 \\
\hline PGDP thin bottom, former G-yard & 37 & 13 & .00287 & 44 & .01857 \\
\hline ETTP/PGDP/PORTS thin skirted btm & 49 & 455 & .00000 & 185 & .01780 \\
\hline PORTS thin bottom & 42 & 7 & .00000 & 149 & .01780 \\
\hline PORTS thin top & 42 & 64 & .00002 & 116 & .01780 \\
\hline ETTP/PGDP/PORTS thin skirted top & 49 & 436 & .00000 & 194 & .01779 \\
\hline ETTP/PGDP/PORTS thin skirted btm & 48 & 1392 & .00000 & 189 & .01779 \\
\hline ETTP thin, except $\mathrm{K}$-yard bottom & 33 & 10 & .12881 & 14 & .01779 \\
\hline ETTP/PGDP/PORTS thin skirted top & 48 & 1246 & .00000 & 196 & .01779 \\
\hline PORTS thin bottom & 41 & 7 & .00000 & 152 & .01779 \\
\hline PORTS thin top & 41 & 40 & .00002 & 117 & .01779 \\
\hline ETTP thin, except K-yard bottom & 32 & 20 & .11508 & 16 & .01779 \\
\hline PGDP thin btm, excpt fmr G-yard & 37 & 162 & .00089 & 66 & .01779 \\
\hline ETTP/PGDP/PORTS 1/2" (30" dia.) btm & 51 & 1430 & .35283 & 5 & .01779 \\
\hline ETTP/PGDP/PORTS 1/2" (30" dia.) top & 51 & 1111 & .09212 & 20 & .01779 \\
\hline ETTP/PGDP/PORTS thick bottom & 53 & 267 & .06138 & 24 & .01779 \\
\hline ETTP thin, except K-yard bottom & 27 & 175 & .06057 & 25 & .01779 \\
\hline ETTP/PGDP/PORTS thick bottom & 52 & 95 & .05629 & 26 & .01779 \\
\hline
\end{tabular}


Table 12-cont'd. Cylinder Subpopulation/Age Groups

\begin{tabular}{|c|c|c|c|c|c|}
\hline Cylinder Subpopulation & Age & $\mathbf{N}$ & $\begin{array}{l}\text { Ind. Model } \\
\text { Estimated } \\
\text { Percentage } \\
\text { Out of Spec }\end{array}$ & $\begin{array}{c}\text { Ind. } \\
\text { Model } \\
\text { Rank }\end{array}$ & $\begin{array}{l}\text { Dir. Model } \\
\text { Estimated } \\
\text { Percentage } \\
\text { Out of Spec }\end{array}$ \\
\hline ETTP thin, except K-yard bottom & 24 & 3 & .03807 & 30 & .01779 \\
\hline ETTP thin, except K-yard bottom & 23 & 6 & .03207 & 31 & .01779 \\
\hline ETTP/PGDP/PORTS thick bottom & 43 & 48 & .02298 & 32 & .01779 \\
\hline ETTP/PGDP/PORTS thick top & 51 & 319 & .01151 & 36 & .01779 \\
\hline ETTP/PGDP/PORTS thick top & 43 & 39 & .00431 & 40 & .01779 \\
\hline ETTP thin, except K-yard bottom & 14 & 1 & .00371 & 43 & .01779 \\
\hline ETTP thin, except K-yard bottom & 13 & 1 & .00262 & 45 & .01779 \\
\hline PGDP thin bottom, former G-yard & 31 & 95 & .00173 & 54 & .01779 \\
\hline ETTP/PGDP/PORTS thick skirted & 52 & 178 & .00167 & 55 & .01779 \\
\hline PGDP thin bottom, former G-yard & 29 & 39 & .00143 & 60 & .01779 \\
\hline PGDP thin bottom, former G-yard & 28 & 275 & .00129 & 63 & .01779 \\
\hline PGDP thin btm, excpt fmr G-yard & 36 & 1 & .00082 & 67 & .01779 \\
\hline ETTP/PGDP/PORTS thick skirted & 43 & 87 & .00050 & 71 & .01779 \\
\hline ETTP thin, $\mathrm{K}$-yard bottom & 14 & 1 & .00039 & 73 & .01779 \\
\hline PGDP thin btm, excpt fmr G-yard & 27 & 1252 & .00032 & 75 & .01779 \\
\hline PGDP thin btm, excpt fmr G-yard & 26 & 25 & .00028 & 76 & .01779 \\
\hline PGDP thin bottom, former G-yard & 16 & 1 & .00023 & 78 & .01779 \\
\hline PGDP thin btm, excpt fmr G-yard & 22 & 1 & .00016 & 82 & .01779 \\
\hline PGDP thin bottom, former G-yard & 14 & 3 & .00015 & 83 & .01779 \\
\hline PGDP thin bottom, former G-yard & 13 & 1 & .00012 & 85 & .01779 \\
\hline ETTP/PGDP/PORTS thick bottom & 16 & 23 & .00009 & 90 & .01779 \\
\hline PGDP thin top & 37 & 143 & .00005 & 97 & .01779 \\
\hline PGDP thin top & 33 & 29 & .00004 & 100 & .01779 \\
\hline PGDP thin top & 32 & 172 & .00004 & 101 & .01779 \\
\hline PGDP thin top & 31 & 87 & .00003 & 102 & .01779 \\
\hline PGDP thin top & 29 & 146 & .00003 & 104 & .01779 \\
\hline PGDP thin top & 26 & 15 & .00002 & 108 & .01779 \\
\hline PGDP thin top & 25 & 290 & .00002 & 111 & .01779 \\
\hline ETTP/PGDP/PORTS thick skirted & 26 & 75 & .00001 & 118 & .01779 \\
\hline ETTP/PGDP/PORTS thick bottom & 12 & 3 & .00001 & 119 & .01779 \\
\hline PGDP thin top & 20 & 64 & .00001 & 121 & .01779 \\
\hline
\end{tabular}


Table 12-cont'd. Cylinder Subpopulation/Age Groups

\begin{tabular}{|c|c|c|c|c|c|}
\hline Cylinder Subpopulation & Age & $\mathbf{N}$ & $\begin{array}{l}\text { Ind. Model } \\
\text { Estimated } \\
\text { Percentage } \\
\text { Out of Spec }\end{array}$ & $\begin{array}{l}\text { Ind. } \\
\text { Model } \\
\text { Rank }\end{array}$ & $\begin{array}{l}\text { Dir. Model } \\
\text { Estimated } \\
\text { Percentage } \\
\text { Out of Spec }\end{array}$ \\
\hline PORTS thin top & 37 & 50 & .00001 & 122 & .01779 \\
\hline PGDP thin top & 19 & 350 & .00001 & 124 & .01779 \\
\hline PGDP thin top & 18 & 1 & .00001 & 125 & .01779 \\
\hline PORTS thin top & 33 & 119 & .00001 & 126 & .01779 \\
\hline PORTS thin top & 30 & 1 & .00001 & 132 & .01779 \\
\hline PORTS thin top & 29 & 127 & .00001 & 133 & .01779 \\
\hline PORTS thin top & 28 & 638 & .00001 & 136 & .01779 \\
\hline PGDP thin btm, excpt fmr G-yard & 9 & 860 & .00001 & 138 & .01779 \\
\hline PGDP thin top & 14 & 823 & .00001 & 140 & .01779 \\
\hline PORTS thin top & 26 & 400 & .00001 & 142 & .01779 \\
\hline ETTP/PGDP/PORTS thick top & 16 & 19 & .00000 & 144 & .01779 \\
\hline PORTS thin top & 25 & 16 & .00000 & 145 & .01779 \\
\hline PGDP thin top & 13 & 591 & .00000 & 146 & .01779 \\
\hline PORTS thin top & 24 & 257 & .00000 & 148 & .01779 \\
\hline PORTS thin top & 23 & 343 & .00000 & 150 & .01779 \\
\hline PGDP thin top & 12 & 588 & .00000 & 153 & .01779 \\
\hline PORTS thin top & 20 & 348 & .00000 & 155 & .01779 \\
\hline PORTS thin bottom & 37 & 8 & .00000 & 156 & .01779 \\
\hline PORTS thin top & 19 & 232 & .00000 & 157 & .01779 \\
\hline PORTS thin top & 18 & 88 & .00000 & 159 & .01779 \\
\hline PORTS thin top & 17 & 275 & .00000 & 161 & .01779 \\
\hline PGDP thin top & 9 & 836 & .00000 & 162 & .01779 \\
\hline PORTS thin bottom & 32 & 529 & .00000 & 163 & .01779 \\
\hline PORTS thin bottom & 31 & 522 & .00000 & 165 & .01779 \\
\hline PGDP thin top & 8 & 438 & .00000 & 167 & .01779 \\
\hline PORTS thin bottom & 29 & 128 & .00000 & 168 & .01779 \\
\hline PORTS thin top & 12 & 148 & .00000 & 175 & .01779 \\
\hline ETTP/PGDP/PORTS 1/2" (30" dia.) btm & 5 & 3 & .00000 & 179 & .01779 \\
\hline PORTS thin top & 11 & 430 & .00000 & 180 & .01779 \\
\hline PORTS thin bottom & 23 & 359 & .00000 & 181 & .01779 \\
\hline ETTP/PGDP/PORTS thick top & 12 & 2 & .00000 & 182 & .01779 \\
\hline
\end{tabular}


Table 12-cont'd. Cylinder Subpopulation/Age Groups

\begin{tabular}{|c|c|c|c|c|c|}
\hline Cylinder Subpopulation & Age & $\mathbf{N}$ & $\begin{array}{l}\text { Ind. Model } \\
\text { Estimated } \\
\text { Percentage } \\
\text { Out of Spec }\end{array}$ & $\begin{array}{l}\text { Ind. } \\
\text { Model } \\
\text { Rank }\end{array}$ & $\begin{array}{c}\text { Dir. Model } \\
\text { Estimated } \\
\text { Percentage } \\
\text { Out of Spec }\end{array}$ \\
\hline PORTS thin bottom & 20 & 363 & .00000 & 186 & .01779 \\
\hline PORTS thin bottom & 19 & 254 & .00000 & 188 & .01779 \\
\hline PORTS thin bottom & 18 & 88 & .00000 & 190 & .01779 \\
\hline PORTS thin bottom & 17 & 269 & .00000 & 191 & .01779 \\
\hline PORTS thin bottom & 16 & 1366 & .00000 & 192 & .01779 \\
\hline PORTS thin bottom & 15 & 605 & .00000 & 193 & .01779 \\
\hline PORTS thin bottom & 13 & 31 & .00000 & 197 & .01779 \\
\hline PORTS thin bottom & 12 & 157 & .00000 & 198 & .01779 \\
\hline PORTS thin bottom & 11 & 447 & .00000 & 199 & .01779 \\
\hline ETTP/PGDP/PORTS 1/2" (30" dia.) top & 5 & 1 & .00000 & 200 & .01779 \\
\hline PORTS thin bottom & 9 & 372 & .00000 & 203 & .01779 \\
\hline ETTP/PGDP/PORTS thin skirted btm & 26 & 446 & .00000 & 204 & .01779 \\
\hline ETTP/PGDP/PORTS thin skirted top & 24 & 8 & .00000 & 208 & .01779 \\
\hline ETTP/PGDP/PORTS thin skirted top & 23 & 175 & .00000 & 209 & .01779 \\
\hline ETTP/PGDP/PORTS thin skirted btm & 19 & 1 & .00000 & 210 & .01779 \\
\hline ETTP/PGDP/PORTS thin skirted btm & 8 & 1 & .00000 & 211 & .01779 \\
\hline ETTP thin, except K-yard bottom & 31 & 903 & .10233 & 18 & .01779 \\
\hline ETTP thin, except $\mathrm{K}$-yard bottom & 29 & 239 & .07966 & 21 & .01779 \\
\hline ETTP thin, except K-yard bottom & 28 & 316 & .06969 & 22 & .01779 \\
\hline ETTP/PGDP/PORTS thick bottom & 54 & 235 & .06680 & 23 & .01779 \\
\hline ETTP thin, except K-yard bottom & 26 & 10 & .05229 & 27 & .01779 \\
\hline ETTP/PGDP/PORTS thick bottom & 51 & 324 & .05150 & 28 & .01779 \\
\hline ETTP thin, except K-yard bottom & 25 & 17 & .04480 & 29 & .01779 \\
\hline ETTP/PGDP/PORTS thick top & 54 & 222 & .01580 & 33 & .01779 \\
\hline ETTP/PGDP/PORTS thick top & 53 & 206 & .01426 & 34 & .01779 \\
\hline ETTP/PGDP/PORTS thick top & 52 & 83 & .01283 & 35 & .01779 \\
\hline ETTP/PGDP/PORTS thick skirted & 54 & 457 & .00210 & 47 & .01779 \\
\hline PGDP thin bottom, former G-yard & 33 & 13 & .00207 & 48 & .01779 \\
\hline PGDP thin bottom, former G-yard & 32 & 179 & .00190 & 51 & .01779 \\
\hline ETTP/PGDP/PORTS thick skirted & 53 & 473 & .00187 & 52 & .01779 \\
\hline ETTP/PGDP/PORTS thick bottom & 26 & 40 & .00163 & 57 & .01779 \\
\hline
\end{tabular}


Table 12-cont'd. Cylinder Subpopulation/Age Groups

\begin{tabular}{|c|c|c|c|c|c|}
\hline Cylinder Subpopulation & Age & $\mathbf{N}$ & $\begin{array}{l}\text { Ind. Model } \\
\text { Estimated } \\
\text { Percentage } \\
\text { Out of Spec }\end{array}$ & $\begin{array}{c}\text { Ind. } \\
\text { Model } \\
\text { Rank }\end{array}$ & $\begin{array}{l}\text { Dir. Model } \\
\text { Estimated } \\
\text { Percentage } \\
\text { Out of Spec }\end{array}$ \\
\hline ETTP/PGDP/PORTS thick skirted & 51 & 643 & .00148 & 58 & .01779 \\
\hline ETTP/PGDP/PORTS thick bottom & 25 & 21 & .00130 & 62 & .01779 \\
\hline PGDP thin bottom, former G-yard & 27 & 84 & .00116 & 65 & .01779 \\
\hline PGDP thin btm, excpt fmr G-yard & 33 & 27 & .00062 & 68 & .01779 \\
\hline PGDP thin btm, excpt fmr G-yard & 32 & 311 & .00056 & 69 & .01779 \\
\hline PGDP thin btm, excpt fmr G-yard & 31 & 141 & .00050 & 70 & .01779 \\
\hline PGDP thin btm, excpt fmr G-yard & 29 & 185 & .00040 & 72 & .01779 \\
\hline PGDP thin btm, excpt fmr G-yard & 28 & 1017 & .00036 & 74 & .01779 \\
\hline PGDP thin btm, excpt fmr G-yard & 25 & 336 & .00024 & 77 & .01779 \\
\hline PGDP thin btm, excpt fmr G-yard & 24 & 1307 & .00021 & 79 & .01779 \\
\hline PGDP thin btm, excpt fmr G-yard & 23 & 969 & .00018 & 80 & .01779 \\
\hline ETTP/PGDP/PORTS thick top & 26 & 35 & .00017 & 81 & .01779 \\
\hline ETTP/PGDP/PORTS thick top & 25 & 21 & .00013 & 84 & .01779 \\
\hline PGDP thin btm, excpt fmr G-yard & 20 & 56 & .00011 & 86 & .01779 \\
\hline PGDP thin btm, excpt fmr G-yard & 19 & 365 & .00009 & 88 & .01779 \\
\hline PGDP thin btm, excpt fmr G-yard & 17 & 461 & .00006 & 96 & .01779 \\
\hline PGDP thin btm, excpt fmr G-yard & 16 & 1096 & .00005 & 98 & .01779 \\
\hline PGDP thin btm, excpt fmr G-yard & 15 & 639 & .00004 & 99 & .01779 \\
\hline PGDP thin btm, excpt fmr G-yard & 14 & 903 & .00003 & 103 & .01779 \\
\hline PGDP thin top & 28 & 993 & .00003 & 105 & .01779 \\
\hline PGDP thin top & 27 & 1125 & .00002 & 106 & .01779 \\
\hline PGDP thin btm, excpt fmr G-yard & 13 & 593 & .00002 & 107 & .01779 \\
\hline PGDP thin top & 24 & 1061 & .00002 & 112 & .01779 \\
\hline PGDP thin btm, excpt fmr G-yard & 12 & 607 & .00002 & 113 & .01779 \\
\hline PGDP thin top & 23 & 906 & .00002 & 114 & .01779 \\
\hline PGDP thin btm, excpt fmr G-yard & 11 & 444 & .00001 & 120 & .01779 \\
\hline ETTP/PGDP/PORTS thick skirted & 25 & 42 & .00001 & 123 & .01779 \\
\hline PGDP thin btm, excpt fmr G-yard & 10 & 1025 & .00001 & 127 & .01779 \\
\hline PORTS thin top & 32 & 423 & .00001 & 128 & .01779 \\
\hline PGDP thin top & 17 & 452 & .00001 & 129 & .01779 \\
\hline PORTS thin top & 31 & 490 & .00001 & 130 & .01779 \\
\hline
\end{tabular}


Table 12-cont'd. Cylinder Subpopulation/Age Groups

\begin{tabular}{|c|c|c|c|c|c|}
\hline Cylinder Subpopulation & Age & $\mathbf{N}$ & $\begin{array}{l}\text { Ind. Model } \\
\text { Estimated } \\
\text { Percentage } \\
\text { Out of Spec }\end{array}$ & $\begin{array}{l}\text { Ind. } \\
\text { Model } \\
\text { Rank }\end{array}$ & $\begin{array}{l}\text { Dir. Model } \\
\text { Estimated } \\
\text { Percentage } \\
\text { Out of Spec }\end{array}$ \\
\hline PGDP thin top & 16 & 1041 & .00001 & 131 & .01779 \\
\hline PGDP thin top & 15 & 648 & .00001 & 135 & .01779 \\
\hline PORTS thin top & 27 & 112 & .00001 & 139 & .01779 \\
\hline PGDP thin btm, excpt fmr G-yard & 8 & 404 & .00000 & 151 & .01779 \\
\hline PGDP thin top & 11 & 411 & .00000 & 154 & .01779 \\
\hline PGDP thin top & 10 & 980 & .00000 & 158 & .01779 \\
\hline PORTS thin bottom & 33 & 133 & .00000 & 160 & .01779 \\
\hline PORTS thin top & 16 & 1293 & .00000 & 164 & .01779 \\
\hline PORTS thin top & 15 & 607 & .00000 & 166 & .01779 \\
\hline PGDP thin btm, excpt fmr G-yard & 6 & 55 & .00000 & 169 & .01779 \\
\hline PORTS thin top & 14 & 280 & .00000 & 170 & .01779 \\
\hline PORTS thin bottom & 28 & 772 & .00000 & 171 & .01779 \\
\hline PORTS thin bottom & 27 & 111 & .00000 & 172 & .01779 \\
\hline PORTS thin top & 13 & 33 & .00000 & 173 & .01779 \\
\hline PORTS thin bottom & 26 & 416 & .00000 & 174 & .01779 \\
\hline PORTS thin bottom & 25 & 17 & .00000 & 176 & .01779 \\
\hline PORTS thin bottom & 24 & 280 & .00000 & 177 & .01779 \\
\hline PGDP thin top & 6 & 56 & .00000 & 178 & .01779 \\
\hline PORTS thin top & 10 & 110 & .00000 & 183 & .01779 \\
\hline PORTS thin top & 9 & 351 & .00000 & 184 & .01779 \\
\hline ETTP/PGDP/PORTS thick skirted & 16 & 42 & .00000 & 187 & .01779 \\
\hline PORTS thin bottom & 14 & 264 & .00000 & 195 & .01779 \\
\hline PORTS thin bottom & 10 & 102 & .00000 & 201 & .01779 \\
\hline ETTP/PGDP/PORTS thick skirted & 12 & 5 & .00000 & 202 & .01779 \\
\hline ETTP/PGDP/PORTS thin skirted btm & 24 & 5 & .00000 & 205 & .01779 \\
\hline ETTP/PGDP/PORTS thin skirted btm & 23 & 185 & .00000 & 206 & .01779 \\
\hline ETTP/PGDP/PORTS thin skirted top & 26 & 420 & .00000 & 207 & .01779 \\
\hline
\end{tabular}




\section{MODEL EVALUATION AND COMPARISON}

In this section, the direct and indirect models are evaluated by comparing FY03 UT measurements with projections computed only from UT measurements made prior to FY03. This evaluation shows that the projected and observed results are consistent, though the evaluation is somewhat inconclusive in the sense that for the relatively few cylinders for which UT measurements were made in FY03, very few are either projected or observed to have failed the lower thickness specifications.

The FY03 projections based on pre-FY03 data are discussed in Section 6.1. Because these projections are similar for the direct and indirect models, they also neither confirm nor refute the conclusion of Section 4 that the direct model leads to more sensible fits than the indirect model. This conclusion was based on the observations that the indirect model slope estimate fails to stay within its 0-to-1 theoretical range for ten of seventeen subpopulations, that the direct model parameter estimates are all in the range expected for them, and that the indirect model "seems" even more conservative in its projections than the direct model. Therefore, a further comparison of the two models, based on the Akaike information criterion (AIC, Akaike 1974), is discussed in Section 6.2.

\subsection{FY03 Projected vs Observed}

Table 13 shows counts of cylinders whose actual FY03 UT measurements were below various thickness specifications, and projections of these counts based on the direct and indirect models. Cylinders previously identified as outliers and remeasured in FY03 were excluded from these results, but the outliers identified in the analysis in Section 5 were not excluded. The projections are computed only from UT measurements made before FY03. P-scan data was used to fit the models, but is not considered at all in this Table 13. Because the FY03 sampled results are statistically independent of the data used to fit the models, these comparisons independently support or refute the corrosion models. However, several factors complicate this evaluation. For example, the model-based minimum thickness projections are estimates, about which actual measured minimum thicknesses are expected to vary randomly. At most general agreement, not exact agreement, should ever be expected between the projected and observed counts.

Another complication is the low probabilities with which cylinders fail the various thickness criteria This has been the case in previous editions of this report for the breach or 62.5 mil thickness specification, but for this report, it is also true for the upper $(250,500$, or 100 mil) thickness criteria. In FY03 only three cylinders were observed by direct UT measurement to have failed the upper criteria. In FY02, thirteen cylinders failed the upper criteria. Nine of those FY02 measurements were of were ETTP cylinders, and no UT measurements of ETTP cylinders were made in FY03. Thus none of the thickness criteria has provided much resolution between the observed and projected numbers of noncompliant cylinders. Therefore, for this report, an additional $300 \mathrm{mil}$ "spec" has been added to the table. Although adequacy in forecasting numbers of cylinders with thickness below a value in the central part (e.g., around 300 mils) of a thickness distribution does not imply adequacy in forecasting numbers of cylinders with thickness below a value in the lower tail of the distribution, the 300 mil specification does provide a richer comparison.

The table shows that for the thickness specifications other than 300 mils, both the direct and indirect model projections are consistent with FY03 observed results. For the $300 \mathrm{mil} \mathrm{spec}$, the FY03 results suggest that the projections may be conservative, in the vicinity of 300 mils. This suggests that the projections for the lower criteria may also be conservative. 
Table 13. FY03 Indirect and Direct-Model Projected and Observed Counts for Sampled Cylinders

\begin{tabular}{|c|c|c|c|c|c|c|}
\hline Cylinder Population & $\begin{array}{c}\text { Number } \\
\text { in } \\
\text { Population }\end{array}$ & $\begin{array}{l}\text { Number } \\
\text { Sampled } \\
\text { from Pop. }\end{array}$ & $\begin{array}{c}\text { Thick. } \\
\text { Spec }\end{array}$ & $\begin{array}{c}\text { Observed } \\
\text { Number } \\
\text { Out of Spec }\end{array}$ & $\begin{array}{c}\text { Indirect Model } \\
\text { Projected } \\
\text { Number } \\
\text { Out of Spec }\end{array}$ & $\begin{array}{c}\text { Direct Mode } \\
\text { Projected } \\
\text { Number } \\
\text { Out of Spec }\end{array}$ \\
\hline \multirow[t]{4}{*}{ PGDP thin bottom, former G-yard } & 1,983 & 10 & 300 & 0 & 3 & 3 \\
\hline & & & 250 & 0 & 0 & 0 \\
\hline & & & 62.5 & 0 & 0 & 0 \\
\hline & & & 0 & 0 & 0 & 0 \\
\hline \multirow[t]{4}{*}{ PGDP thin btm, excpt fmr G-yard } & 15,337 & 33 & 300 & 0 & 5 & 4 \\
\hline & & & 250 & 0 & 0 & 0 \\
\hline & & & 62.5 & 0 & 0 & 0 \\
\hline & & & 0 & 0 & 0 & 0 \\
\hline \multirow[t]{4}{*}{ PGDP thin top } & 14,911 & 32 & 300 & 0 & 3 & 3 \\
\hline & & & 250 & 0 & 0 & 0 \\
\hline & & & 62.5 & 0 & 0 & 0 \\
\hline & & & 0 & 0 & 0 & 0 \\
\hline \multirow[t]{4}{*}{ PORTS thin top } & 8,501 & 63 & 300 & 0 & 3 & 4 \\
\hline & & & 250 & 0 & 0 & 1 \\
\hline & & & 62.5 & 0 & 0 & 0 \\
\hline & & & 0 & 0 & 0 & 0 \\
\hline \multirow[t]{4}{*}{ PORTS thin bottom } & 8,768 & 46 & 300 & 1 & 2 & 3 \\
\hline & & & 250 & 1 & 0 & 0 \\
\hline & & & 62.5 & 0 & 0 & 0 \\
\hline & & & 0 & 0 & 0 & 0 \\
\hline
\end{tabular}


Table 13-con't. FY03 Indirect and Direct-Model Projected and Observed Counts for Sampled Cylinders

\begin{tabular}{|c|c|c|c|c|c|c|}
\hline Cylinder Population & $\begin{array}{c}\text { Number } \\
\text { in } \\
\text { Population }\end{array}$ & $\begin{array}{c}\text { Number } \\
\text { Sampled } \\
\text { from Pop. }\end{array}$ & $\begin{array}{l}\text { Thick. } \\
\text { Spec }\end{array}$ & $\begin{array}{l}\text { Observed } \\
\text { Number } \\
\text { Out of Spec }\end{array}$ & $\begin{array}{l}\text { Indirect Model } \\
\text { Projected } \\
\text { Number } \\
\text { Out of Spec }\end{array}$ & $\begin{array}{l}\text { Direct Model } \\
\text { Projected } \\
\text { Number } \\
\text { Out of Spec }\end{array}$ \\
\hline \multirow[t]{4}{*}{ ETTP/PGDP/PORTS thick top } & 946 & 26 & 500 & 0 & 0 & 0 \\
\hline & & & 300 & 0 & 0 & 0 \\
\hline & & & 62.5 & 0 & 0 & 0 \\
\hline & & & 0 & 0 & 0 & 0 \\
\hline \multirow[t]{4}{*}{ ETTP/PGDP/PORTS thick bottom } & 1,056 & 20 & 500 & 0 & 0 & 0 \\
\hline & & & 300 & 0 & 0 & 0 \\
\hline & & & 62.5 & 0 & 0 & 0 \\
\hline & & & 0 & 0 & 0 & 0 \\
\hline \multirow[t]{4}{*}{ ETTP/PGDP/PORTS thin skirted top } & 2,285 & 42 & 300 & 0 & 4 & 2 \\
\hline & & & 250 & 0 & 0 & 0 \\
\hline & & & 62.5 & 0 & 0 & 0 \\
\hline & & & 0 & 0 & 0 & 0 \\
\hline \multirow[t]{4}{*}{ ETTP/PGDP/PORTS thin skirted btm } & 2,485 & 26 & 300 & 0 & 4 & 2 \\
\hline & & & 250 & 0 & 1 & 0 \\
\hline & & & 62.5 & 0 & 0 & 0 \\
\hline & & & 0 & 0 & 0 & 0 \\
\hline \multirow[t]{4}{*}{ ETTP/PGDP/PORTS thick skirted } & 2,002 & 46 & 500 & 0 & 0 & 0 \\
\hline & & & 300 & 0 & 0 & 0 \\
\hline & & & 62.5 & 0 & 0 & 0 \\
\hline & & & 0 & 0 & 0 & 0 \\
\hline
\end{tabular}


Table 13-con't. FY03 Indirect and Direct-Model Projected and Observed Counts for Sampled Cylinders

\begin{tabular}{|c|c|c|c|c|c|c|}
\hline Cylinder Population & $\begin{array}{c}\text { Number } \\
\text { in } \\
\text { Population }\end{array}$ & $\begin{array}{l}\text { Number } \\
\text { Sampled } \\
\text { from Pop. }\end{array}$ & $\begin{array}{l}\text { Thick. } \\
\text { Spec }\end{array}$ & $\begin{array}{c}\text { Observed } \\
\text { Number } \\
\text { Out of Spec }\end{array}$ & $\begin{array}{l}\text { Indirect Model } \\
\text { Projected } \\
\text { Number } \\
\text { Out of Spec }\end{array}$ & $\begin{array}{l}\text { Direct Model } \\
\text { Projected } \\
\text { Number } \\
\text { Out of Spec }\end{array}$ \\
\hline \multirow[t]{4}{*}{ ETTP/PGDP/PORTS 1/2" (30" dia.) top } & 1,112 & 4 & 300 & 0 & 0 & 0 \\
\hline & & & 100 & 0 & 0 & 0 \\
\hline & & & 62.5 & 0 & 0 & 0 \\
\hline & & & 0 & 0 & 0 & 0 \\
\hline \multirow[t]{4}{*}{ ETTP/PGDP/PORTS 1/2" (30" dia.) btm } & 1,433 & 6 & 300 & 1 & 0 & 0 \\
\hline & & & 100 & 0 & 0 & 0 \\
\hline & & & 62.5 & 0 & 0 & 0 \\
\hline & & & 0 & 0 & 0 & 0 \\
\hline
\end{tabular}




\subsection{Comparison by Akaike Information Criterion}

The direct and indirect model projections in Table 13 are consistent, excepting random variation, with each other, but they are also small. They do not provide substantial resolution between the two models, though the direct and indirect-model projections computed in Section 5 do in fact differ. In this section an attempt is made to more definitely decide which set of projections are likely to be better.

Comparing the direct and indirect models is difficult because the numbers of parameters in the two models differ substantially. For the seventeen cylinder groups, the direct model has nineteen parameters, including the standard deviation. The indirect model has, $3 \times 17=51$ parameters, including seventeen standard deviations, but not including parameters for the initial thickness distribution. Increasing the number of parameters in a model automatically improves model fitting criteria such as regression sum of squares (i.e., the sum of squared regression residuals).. However, having more parameters does not necessarily improve the statistical properties of projections, for example, their mean squared error (i.e., the variance plus the squared bias). Additional parameters tend to decreases the bias of projections, but they also increase the variance. If they decrease the bias only marginally, then their net effect can be to increase the mean squared error.

As an example, consider two sample means, $\bar{y}_{1}$ and $\bar{y}_{2}$, computed from two statistically independent samples of size $n$. Suppose the variance of the observations ( $y$ 's) in both samples is $\sigma^{2}$, but the means of the two samples are $\mu_{1}$ and $\mu_{2}$. Then for estimating $\mu_{1}$, the mean squared error of $\bar{y}_{1}$ (which is unbiased) is its variance, $\sigma^{2} / n$. However $\bar{y}=\left(\bar{y}_{1}+\bar{y}_{2}\right) / 2$, though biased, could also be used to estimate $\mu_{1}$. The mean squared error of $\bar{y}$ is $\left(\sigma^{2} / n\right) / 2+\left(\mu_{1}-\mu_{2}\right)^{2} / 4$. Therefore, if $\left(\mu_{1}-\mu_{2}\right)^{2} / 4$ is less than $\left(\sigma^{2} / n\right) / 2$, then in terms of mean squared error, $\bar{y}$ is better than $\bar{y}_{1}$ as an estimator of $\mu_{1}$. In that case, a model with only one mean rather than two would be better for estimating $\mu_{1}$. In regressions in general, the same kind of effects occur when small relatively insignificant parameters are included in the regression model, and the same logic also applies for loss functions other than the squared error, for example the difference between observed and projected numbers of cylinders below various thickness criteria.

Therefore, when the same data is used both to fit models and to evaluate their performance, comparisons of the models should be adjusted to account for differences in numbers of parameters. How to make such an adjustment is not an easy question, however. In this section, one such adjustment is considered. The point is not to consider the details of the adjustment itself, but rather simply to illustrate that after accounting for one such adjustment, the direct model seems clearly better than the indirect model.

Akaike (1974) considered the problem of comparing models with different numbers of parameters and developed a basis for model comparisons that has become known as the Akaike information criterion (AIC). The AIC is defined as

$$
\text { AIC }=-2 \text { (log-likelihood) }+2 \text { (number of model parameters })
$$

where "log-likelihood" denotes the maximized log-likelihood, and the method of maximum likelihood is the statistical method for estimating the parameters. The lower the AIC, the better the model fit. The second term in the AIC incorporates a penalty proportional to the number of model parameters, because having more parameters reduces the log-likelihood but does not necessarily improve model-based predictions of new measurements.

For a given thickness criterion $C$, and for any minimum thickness measurement $\mathrm{y}$, let the indicator function $I_{C}$ be defined as 


$$
I_{C}(\mathrm{y})= \begin{cases}1 & \text { if } \mathrm{y} \leq C \\ 0 & \text { if } \mathrm{y}>C\end{cases}
$$

For each measured cylinder $i$ with minimum thickness measurement $\mathrm{y}_{\mathrm{i}}, \mathrm{I}_{C}\left(\mathrm{y}_{\mathrm{i}}\right)$ is 1 if $\mathrm{y}_{\mathrm{i}}$ is at or below the thickness criterion $C$, and $\mathrm{I}_{C}\left(\mathrm{y}_{\mathrm{i}}\right)$ is 0 otherwise. For each cylinder $i$, let $\mathrm{p}_{i}$ denote the probability, under either the direct or indirect model, that the minimum thickness is below $C$. Then for all measured cylinders, the probability of the observed number of cylinders with minimum thickness below $C$ is

$$
\prod_{\text {All cylinders } i} \mathrm{p}_{i}^{I_{C}\left(\mathrm{y}_{\mathrm{i}}\right)}\left(1-\mathrm{p}_{i}\right)^{1-I_{C}\left(\mathrm{y}_{\mathrm{i}}\right)}
$$

Under either the direct or indirect (or other) model, each $\mathrm{p}_{i}$ can be estimated using the model's parameter estimates. Let $\hat{\mathrm{p}}_{i}$ denote such an estimate. If the model parameters are estimated by the method of maximum likelihood, then for all of the measured cylinders, the likelihood of the observed number with minimum thickness below $C$ is the probability of the observed number with minimum thickness evaluated at the $\hat{\mathrm{p}}_{i}$, and the log-likelihood is thus

$$
\sum_{\text {All cylinders } i} I_{C}\left(\mathrm{y}_{\mathrm{i}}\right) \log \left(\hat{p}_{i}\right)+\left(1-I_{C}\left(\mathrm{y}_{\mathrm{i}}\right)\right) \log \left(1-\hat{\mathrm{p}}_{i}\right)
$$

The indirect and direct model parameter estimation by least squares regression is not necessarily the same as maximum likelihood estimation, but the two estimation approaches lead to similar estimates. Thus the log-likelihoods can be evaluated approximately by plugging in the direct or indirect-model estimates.

Table 14 shows the direct and indirect-model approximate log-likelihood and AIC criteria for the 0, 62.5, and 250 mil criteria:

Table 14. Values of the Log-likelihood and Akaike Information Criterion (AIC)

\begin{tabular}{crrcr}
\hline $\begin{array}{c}\text { Thickness } \\
\text { Criterion }\end{array}$ & Log-likelihood & AIC & Log-likelihood & AIC \\
\hline 0 & -19.93 & 141.85 & -0.93 & 39.86 \\
62.5 & -16.19 & 134.37 & -1.39 & 40.77 \\
250 & $-10,844.05$ & $21,790.10$ & -461.26 & 960.52 \\
\hline
\end{tabular}

Table 14 shows that even without imposing the AIC penalty for the number of model parameters, the loglikelihood for the direct model is greater (less negative) than the log-likelihood for each thickness criteria. With the further adjustment for the number of parameters, the AIC difference between the two models is even greater. Although the likelihood is approximated here, these results suggest that the direct model is better, in this AIC adjusted sense. 


\section{LIMITATIONS, CONCLUSIONS, AND RECOMMENDATIONS}

Recap. $\mathrm{UF}_{6}$ storage cylinder corrosion models are developed in this report for projecting numbers of cylinders expected to fail various thickness criteria. UT measurements made in FY03 are combined with previously collected UT data to update the cylinder corrosion models. The CID is used for determining cylinder ages, to update cylinder subpopulation counts, and to discount cylinders painted during the last ten years from cylinders assumed, in the calculations, to be at risk of continuing degradation because of corrosion.

Fifteen of the cylinder UT measurements made in FY03 were of cylinders identified as statistical outliers in the 2003 corrosion report. Five of these were for thin-wall cylinders, and ten were for $1 / 2$ " thick $30 \mathrm{~A}$ cylinders. All of the outliers were selected because their minimum thicknesses were unusually low. Differences between the remeasured and original minimum thickness measurements were compared with differences between measurements made on the same cylinders (not selected as outliers) at Portsmouth. Relative to the Portsmouth differences, all five of the thin-wall cylinder remeasurements showed substantially higher minimum thicknesses than the previous measurements. This suggests that outliers in the thin-wall cylinder data may indeed reflect problems in the data. For the $30 \mathrm{~A}$ cylinders, some of the minimum thickness remeasurements were substantially higher and some were substantially lower. Because all ten cylinders were selected because their minimum thickness measurements were unusually low, this suggests that minimum thicknesses may be statistically more variable for 30As than for the other subpopulations. The consistency across the years of the Portsmouth minimum thickness data also suggests that better UT data might be obtained at Portsmouth by measuring new cylinders, rather than remeasuring cylinders measured in the past.

Two different corrosion modeling approaches are considered. An indirect model relates maximum pit depths to cylinder age and subpopulation. The maximum pit depths are related to age by a power-law. If the fitted exponent is not between 0 and 1 , however, it is set to 1 , and the model in which corrosion increases linearly in time is used instead. (The linear proportionality constant is still estimated.) The maximum pit depths are not measured directly, but rather are estimated as differences between maximum and minimum measured wall thicknesses. In order to estimate minimum wall thicknesses, the maximum pit depth model is combined with an initial thickness model using mathematics that assumes statistical independence of the distributions of the initial thicknesses and maximum pit depths. The independence assumption could fail, for example if steel quality and the initial thickness are correlated. The indirect model is then used to compute point estimates of the numbers of cylinders expected to fail the various thickness criteria. UCLs corresponding to the point estimates are also developed, but they seem too conservative to be useful. For various reasons, including perhaps a tendency in cylinder inspections to focus on deficient rather than good cylinder wall areas, minimum and maximum wall thickness measurements have sometimes been incompatible, and the power-law has not seemed to fit the maximum pit depth data very well. The power-law does not fit for ten of the seventeen subpopulations considered in this report, and the exponent-set-to-one model is used instead.

A second modeling approach is based on a direct model that relates measured minimum wall thickness directly to cylinder age, subpopulation, and initial thickness estimates. The initial thickness estimates are incorporated into the minimum thickness model, and the assumption that initial thickness and pit depth are statistically independent is thus avoided. The direct-model approach avoids problems with maximum pit depth estimates, which require good measurements of wall thicknesses maxima measured at relatively uncorroded areas of cylinder surfaces, assumed to be as new. The direct model also admits better incorporation of the information that there is zero corrosion at age zero. The indirect model does not make good use of this information, because it assumes that pit depths are lognormally distributed, and because zero-depth pits are inadmissable on the log scale. Because of the findings in the remeasurement of the ten 30A cylinders, the 30As are weighted differently than the other subpopulations in the direct model fit. 
The direct model projections of the numbers of noncompliant cylinders are computed by inverting nonparametric prediction bounds. They thus account for estimation error as well as variability in the regression errors. In that respect, direct-model projections should be more conservative than indirect-model projections, though, because they are based on fundamentally different approaches, the direct and indirectmodel projections are difficult to compare.

Although many of the projections based on the direct and indirect models are close, the direct model generally leads to fewer predicted failures of the breach or other thickness criteria. However, projections based on both models seem too conservative compared to actual experience (e.g., visual examination, inspection during painting or other maintenance). Therefore both models were fit a second time, after excluding various outliers - for the direct model, unusually low minimum thicknesses; for the indirect model, unusually large pit depths. Again the projections are less conservative for the direct model than for the indirect model, even though only six such points were excluded for the direct model, but 27 were excluded for the indirect model.

The same seventeen cylinder subpopulations are used in fitting both the direct and indirect models. The direct model also seems better in a comparison of the two approaches based on the Akaike Information Criterion. Because of this and the reasons cited above, direct model projections seem preferable to indirect model projections. Therefore the main conclusions of this report are based on the direct model.

According to the direct-model rate projections (Table 11c), the cylinders most likely to fail either the breach or 62.5 mil criteria are the ETTP thin-wall K-yard bottom cylinders, followed by the PGDP thin-wall former G-yard bottom cylinders, followed by the ETTP thin-wall cylinders other than K-yard bottom. This holds for all years 2005-2025. Before excluding outliers, the direct model predicts a few failures of the breach and 62.5 mil thickness criteria. After excluding six outliers, however, the direct model projections are all at the direct model's limit of resolution, which is the smallest number of thickness failures the direct model can predict. Thus, the direct-model projections are consistent with the hypothesis of zero failures of the two lower criteria, for all of the years 2005-2025. Because of the resolution limit, however, failures are not ruled out.

The substantial difference between the direct model projections before and after excluding outliers, together with the results of the outlier remeasurements made in FY03, suggest that (1) projections based on the direct-model analysis with the outliers excluded are likely to be better than the analysis with them, and (2) the six outliers should also be remeasured.

Limitations. Projecting cylinder conditions into the future on the basis of data collected at different times, with different goals, sampling schemes, and measurement methods is a difficult task, the limitations of which should be understood. Because the direct model is less flexible, and because data anomalies do not affect it as easily, the direct model seems to fit the cylinder thickness data better than the indirect model. Yet while less flexibility is an advantage in dealing with noisy or anomalous data, it can be a disadvantage in reflecting the underlying physics of the corrosion process. Many of the projections based on the direct and indirect models are similar. The evidence supporting the direct model over the indirect model is preponderant, but not absolute.

For both the direct and indirect approaches, relative to the variability of the data, corrosion appears to be only weakly related to cylinder age. That cylinder-to-cylinder variability is substantial, even for cylinders of the same age and grouping, is obvious from Figures 4-37. Age nevertheless does have an important and statistically significant effect on the corrosion process, and the oldest cylinders are of greatest concern. Tables 10A and 11A of subpopulation-wide numbers of cylinders projected to fall below the various thickness criteria can be misleading if careful attention is not also paid to the oldest and most vulnerable cylinders in each cylinder subpopulation, as indicated, for example, in Table 12. 
The following caveats and limitations should be kept in mind when considering this report:

- Implicit in either the direct or indirect models is an assumption of age invariance- that newer or older cylinders alike had similar corrosion when they were the same age. The distributions of pit depths or wall thicknesses for cylinders of a given age in a given population are assumed to be the same no matter when the cylinders were measured.

- Storage (e.g., ground contact) conditions have changed for many cylinders.

- Environmental changes such as acid rain are not accounted for.

- Cylinder sampling was not always random.

- Literature about the atmospheric corrosion of steel might not apply well to cylinder corrosion modeling, for example because of the thermal inertia of the cylinders.

- In the indirect model, the maximum pit depth data are only estimates, because initial wall thicknesses are estimates from maximum wall thicknesses.

- Age and population-specific projections should be considered in addition to projections by populations for all ages.

Conclusions and Recommendations. Corrosion projections made in this report are based on analyses that account for cylinder subpopulations, ages, and initial thicknesses. However, a myriad of other variables are not accounted. Examples include how many use cycles the cylinders went through, how many nicks and scrapes, and the nature of surface coatings, now perhaps long gone. There are variations in how the UT (or P-scan) measurements were made. The subpopulations themselves are only known approximately and in a few cases even the ages are approximate. Because of these extraneous sources of variation and other approximations, corrosion physics is blurred in the statistical noise. Thickness measurements vary widely about their model-based predictions. In this context, because there is not a definitive corrosion model based on chemistry and physics, it does not make sense to try to resolve fine differences between either the deterministic or stochastic components of plausible candidate models. The choice is not going to be clear. It is better to focus on general model behavior and on data quality and quantity, so that laws-oflarge numbers will allow a general corrosion signal to be resolved from the statistical noise.

The following are the main recommendations of this report:

- The projections in this report are based on the assumption that historical trends will continue. However, many of the yards are being improved. Cylinders are being painted. Cylinders are being shipped between sites (e.g., ETTP to Portsmouth). Whenever such changes can be quantified and accounted for, future analyses should incorporate them through adjustments to subpopulation definitions.

- As it appears unlikely that discrepancies between P-scan and manual UT results will ever be resolved, and as many new manual UT measurements have been made in recent years, P-scan data should be deprecated in favor of the manual UT data that has essentially superseded it. 
- Although the direct model appears to fit the UT cylinder thickness data better than the indirect model, support for that conclusion is not overwhelming. The indirect model, even its reduced proportional form (log-scale slope $=1)$, is still a reasonable approach. As additional UT measurements are made, computer programs for fitting the indirect model should still be rerun, and indirect model projections should be recomputed and compared with projections based on the direct model.

- Cylinder maintenance should be prioritized in terms of both cylinder age and subpopulation differences, as characterized in this report. Cylinder age is often more important than location or top/bottom status as a determinant of corrosion risk.

- As with cylinder maintenance, conversion/disposition schedules should also reflect age and subpopulation differences as characterized in this report.

- At Portsmouth, new cylinders should be sampled for UT measurement, rather than cylinders measured before

- Six cylinders with manual UT measurements identified in this report as direct-model outliers (Table 9) substantially influence the corrosion projections. Those cylinders should be measured again to confirm or correct their thickness measurements. 


\section{REFERENCES}

Akaike, H. (1974), "A New Look at Statistical Model Identification," IEEE Transactions on Automatic

Control, 19, 716-723.

American National Standards for Nuclear Materials-Uranium Hexafluoride-Packaging for Transport, ANSI N14.1, American National Standards Institute, New York, 1995 edition.

Barber, E. J., Butler, T. R., DeVan, J. H., Googin, J. M. and Taylor, M. S., Dyer, R. H., and Russell, J. R. (1994). Investigation of Breached Depleted UF ${ }_{6}$ Cylinders. ORNL/TM-11988, Oak Ridge, Tennessee, September1991.

Barber, E. J., Butler, T. R., DeVan, J. H., Googin, J. M. and Taylor, M. S. (1994). Investigation of Breached Depleted UF ${ }_{6}$ Cylinders at the K-25 Site. ORNL/TM-12840, Oak Ridge, Tennessee, October 1994.

Bechtel Jacobs (1998). "Functional System Design Document DOE UF6 Cylinder Information Database (CID)," https://www-internal1.bechteljacobs.org/scripts/CID/documentation/system_doc.cfm.

Blue, S. C. (1994). Facsimile from S.C. Blue to M. Taylor, October 27, 1994.

Blue, S. C. (1995). Memorandum from S.C. Blue to A.K. Balding, September 25, 1995.

Burden, R. L. and J. D. Faires (1989). Numerical Analysis, Fourth Edition, PWS-Kent Publishing Company, Boston.

David, H. A. (1981) Order Statistics, Second Edition, John Wiley \& Sons, New York.

Draper, N., and Smith, H. (1981) Applied Regression Analysis, 2nd ed., New York, John Wiley \& Sons.

DOE (2003) Draft Environmental Impact Statement for Construction and Operation of a Depleted Uranium Hexafluoride Conversion Facility at Portsmouth, Ohio, Site. DOE/EIS-0360 (December 2003), http://tis.eh.doe.gov/nepa/docs/deis/eis0360/.

DNFSB (1995) "Integrity of Uranium Hexafluoride Cylinders," Defense Nuclear Facilities Safety Board, DNFSB/TECH-4, May 5, 1995 (http://www.dnfsb.gov/techrpts/tech-4.html).

Felieu, S., M. Morcillo and S. Felieu, Jr. (1993a). The Prediction of Atmospheric Corrosion from Meteorological and Pollution Parameters--Ii. Annual Corrosion in Corrosion Science, Vol. 34, No.3, pp.403-414.

Felieu, S., M. Morcillo and S. Felieu, Jr. (1993b). The Prediction of Atmospheric Corrosion from Meteorological and Pollution Parameters--II. Long-term Forecasts in Corrosion Science, Vol. 34, No.3, pp.415-422.

Fowler, K. A., Elfbaum, G. M., Smith, K. A, Nelligan, T. J. (2003) "Theory and Application of Precision Ultrasonic Thickness Gaging Thickness Gaging," GE Panametrics NDT Division, http://www.checkline.com/wall_thickness_gauges/ultrasonic_theory.htm.

Horton, J. B. (1964). The Composition, Structure and Growth of the Atmospheric Rust on Various Steels. Thesis Lehigh University 1964, Bethlehem, PA. 
Johnson, N. L., and Kotz, S. (1970) Continuous Univariate Distributions-1, Houghton Mifflin Co., Boston.

Legault, R. A. and G. Preban (1975). Corrosion-NACE, Vol. 31, p.117.

Lockheed Martin Energy Systems, Inc. (LMES) (1997a). UF 6 Cylinder Project System Requirements Document (SRD). K/TSO-001, Rev.3. May 1997. U.S. Department of Energy.

Lockheed Martin Energy Systems, Inc. (LMES) (1997b). UF ${ }_{6}$ Cylinder Project System Engineering Management Plan (SEMP). K/TSO-017. July 1997. U.S. Department of Energy.

Lykins, M. L. and S. J. Pawel (1997). Evaluation of Wall Thickness in the Cylinder Head/Skirt Interface on Skirted Cylinders. Memorandum from M.L Lykins and S.J. Pawel to M.S. Taylor, ORNL/CST-SP-102297-1, October 22, 1997.

Lyon, B. F. (1995). Prediction of External Corrosion for UF ${ }_{6}$ Cylinders: Results of an Empirical Method, ORNL/TM-13012. June 1995. Oak Ridge National Laboratory, Oak Ridge, Tennessee.

Lyon, B. F. (1996). Prediction of External Corrosion for Steel Cylinders at the Paducah Gaseous Diffusion Plant: Application of an Empirical Method, ORNL/TM-13192. February 1996. Oak Ridge National Laboratory, Oak Ridge, Tennessee.

Lyon, B. F. and M. L. Lykins (1996). Ultrasonic Thickness Sampling Plan for the Depleted Uranium Hexafluoride Program, ORNL/TM-13280. July 1996. Oak Ridge National Laboratory, Oak Ridge, Tennessee.

Lyon, B. F. (1997). Prediction of External Corrosion for Steel Cylinders, ORNL/TM-13359. February 1997. Oak Ridge National Laboratory, Oak Ridge, Tennessee.

Lyon, B. F. (1298). Prediction of External Corrosion for Steel Cylinders - 1998 Report, ORNL/TM13568. February 1998. Oak Ridge National Laboratory, Oak Ridge, Tennessee.

Lyon, B. F. (2000). Prediction of External Corrosion for Steel Cylinders - 2000 Report, ORNL/TM2000/96. June 2000. Oak Ridge National Laboratory, Oak Ridge, Tennessee.

Mughabghab, S. F. and T. M. Sullivan (1989). Evaluation of the Pitting Corrosion of Carbon Steels and Other Ferrous Metals in Soil Systems. Waste Management, Vol. 9, pp. 239-251.

Philpot, H. E. (1995). Memorandum from Halen Philpot to Valerie Newman, February 17, 1995.

Pourbaix, M. (1982). The Linear Bilogarithmic Law for Atmospheric Corrosion, in Atmospheric Corrosion (W. H. Ailor, ed.). John Wiley and Sons, New York.

Romanoff, M. (1957). Underground Corrosion. NBS Circular 579, National Bureau of Standards, Washington, D.C.

Rosen, R. S. and R. E. Glaser (1995). Letter to C.E. Bradley from R.S. Rosen and R.E. Glaser, November $8,1995$.

Rosen, R. S. and R. E. Glaser (1996). Letter to B.F. Lyon from R.S. Rosen and R.E. Glaser, April, 10, 1996. 
Schmidt, M. A., J. K. Harper, and J. A. Broders (1996). A Comparison of Wall Thickness Measurements on UF ${ }_{6}$ Cylinders using Scanning vs Hand-held Ultrasonic Probes. K/TSO-019, November 1996. Oak Ridge National Laboratory, Oak Ridge, Tennessee.

Schmoyer, R. L. (1992), "Asymptotically Valid Prediction Intervals for Linear Models," Technometrics, 34, 399-408.

Schmoyer, R. L., and Lyon, B. F. (2001). Prediction of External Corrosion for Steel Cylinders - 2001 Report, ORNL/TM-2001/164. September 2001. Oak Ridge National Laboratory, Oak Ridge, Tennessee.

Schmoyer, R. L., and Lyon, B. F. (2002). Prediction of External Corrosion for Steel Cylinders - 2002 Report, ORNL/TM-2002/143. July 2002. Oak Ridge National Laboratory, Oak Ridge, Tennessee. 
APPENDIX A: FIGURES 


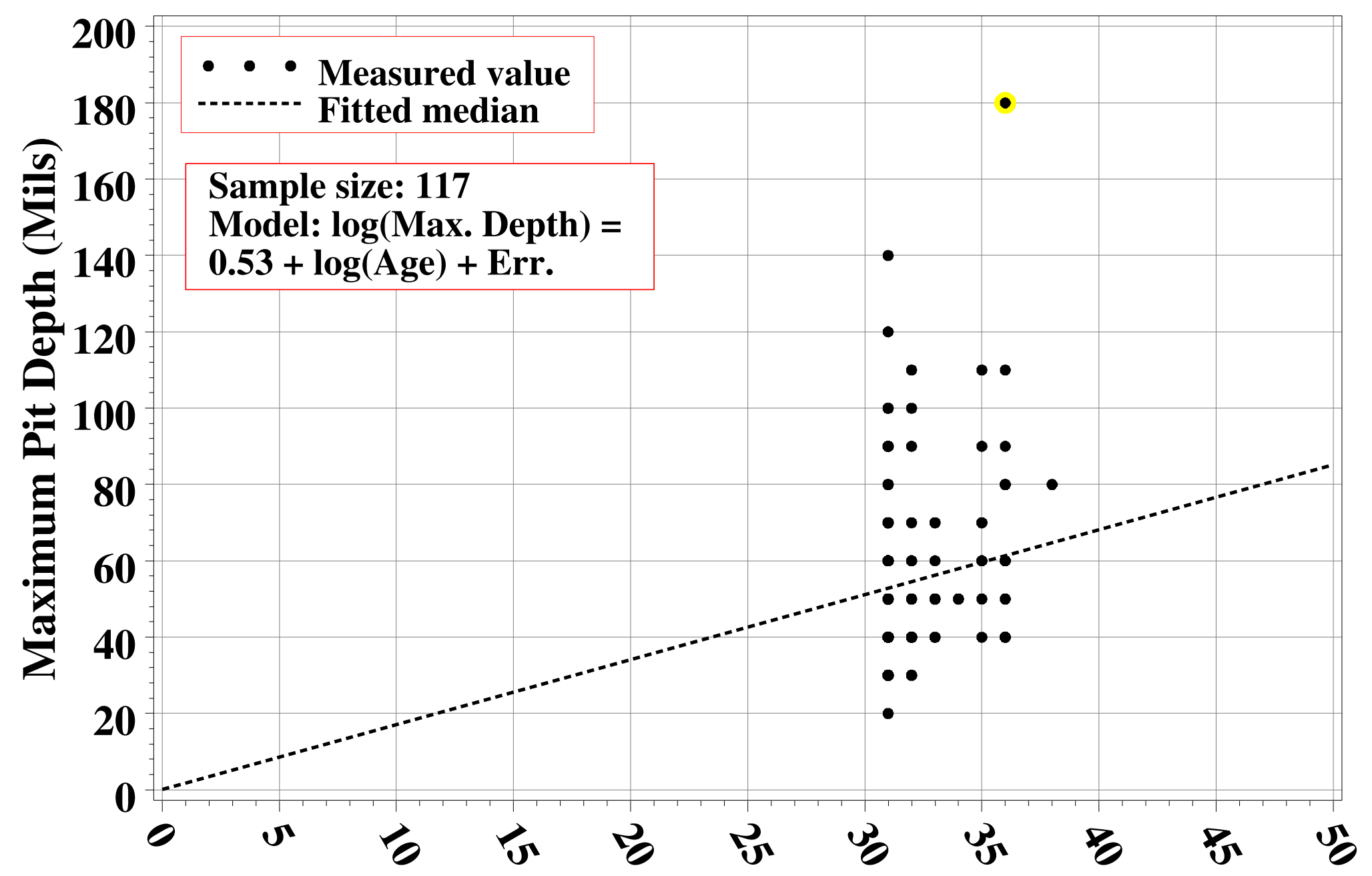

Age of Cylinder When Measured (Yrs)

Figure 4. Maximum pit depth estimates for ETTP thin (P-scan data) cylinders. In Figures 1-17, points above 160 mils are highlighted (yellow), and those points are excluded from Table 10B. 


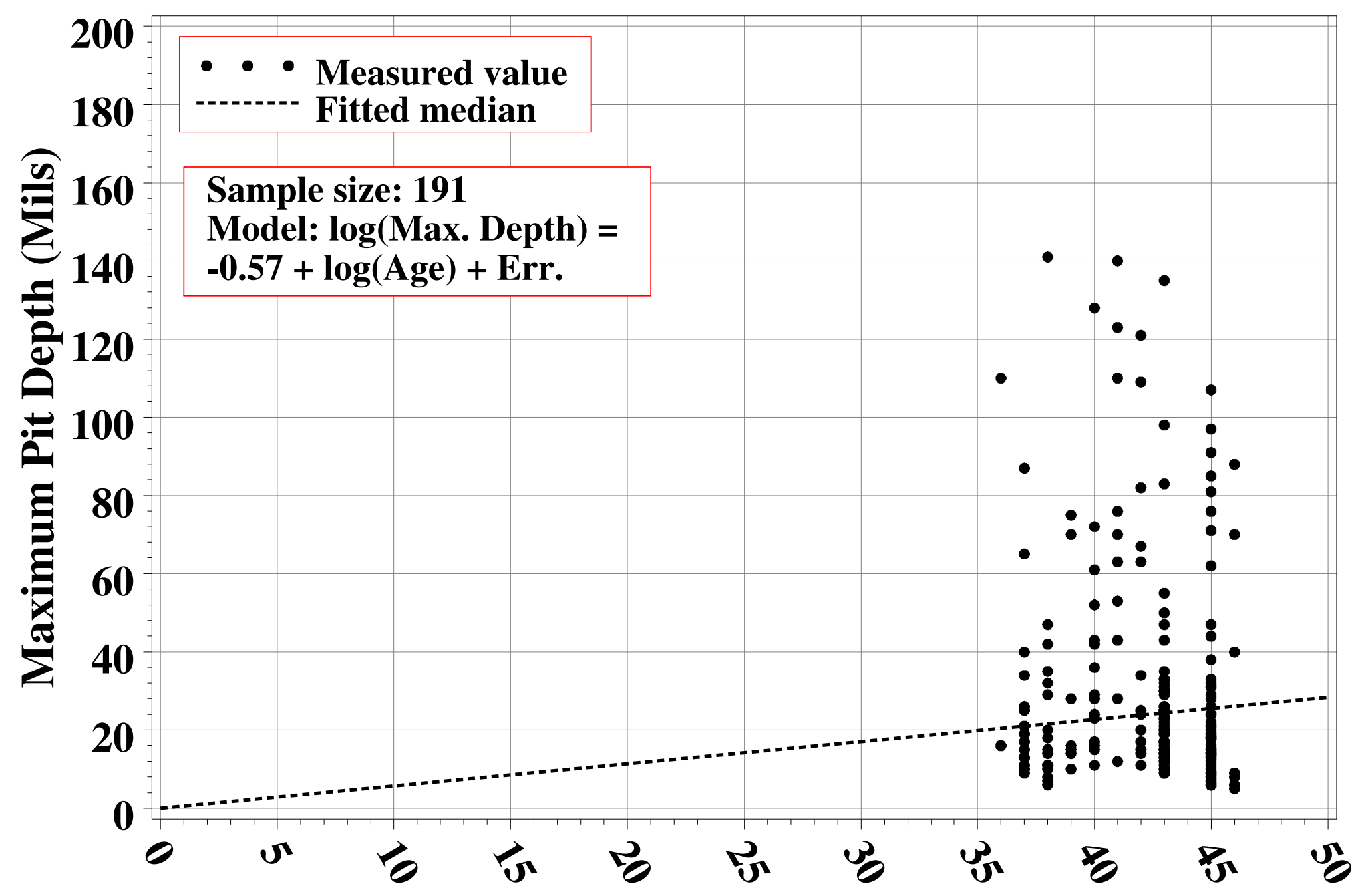

Age of Cylinder When Measured (Yrs)

Figure 5. Maximum pit depth estimates for ETTP thin, K-yard bottom cylinders. 


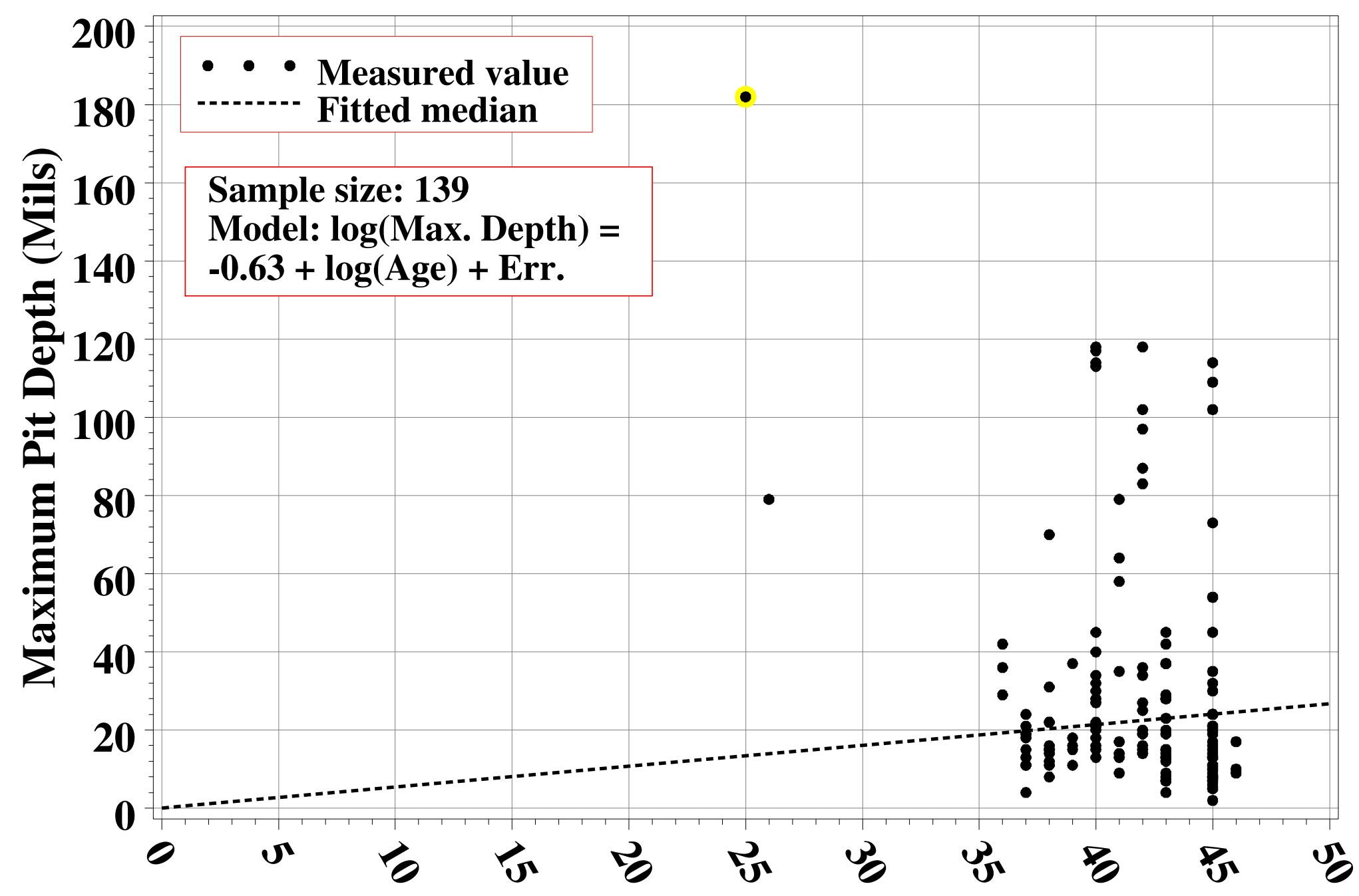

Age of Cylinder When Measured (Yrs)

Figure 6. Maximum pit depth estimates for ETTP thin, except K-yard bottom cylinders. 


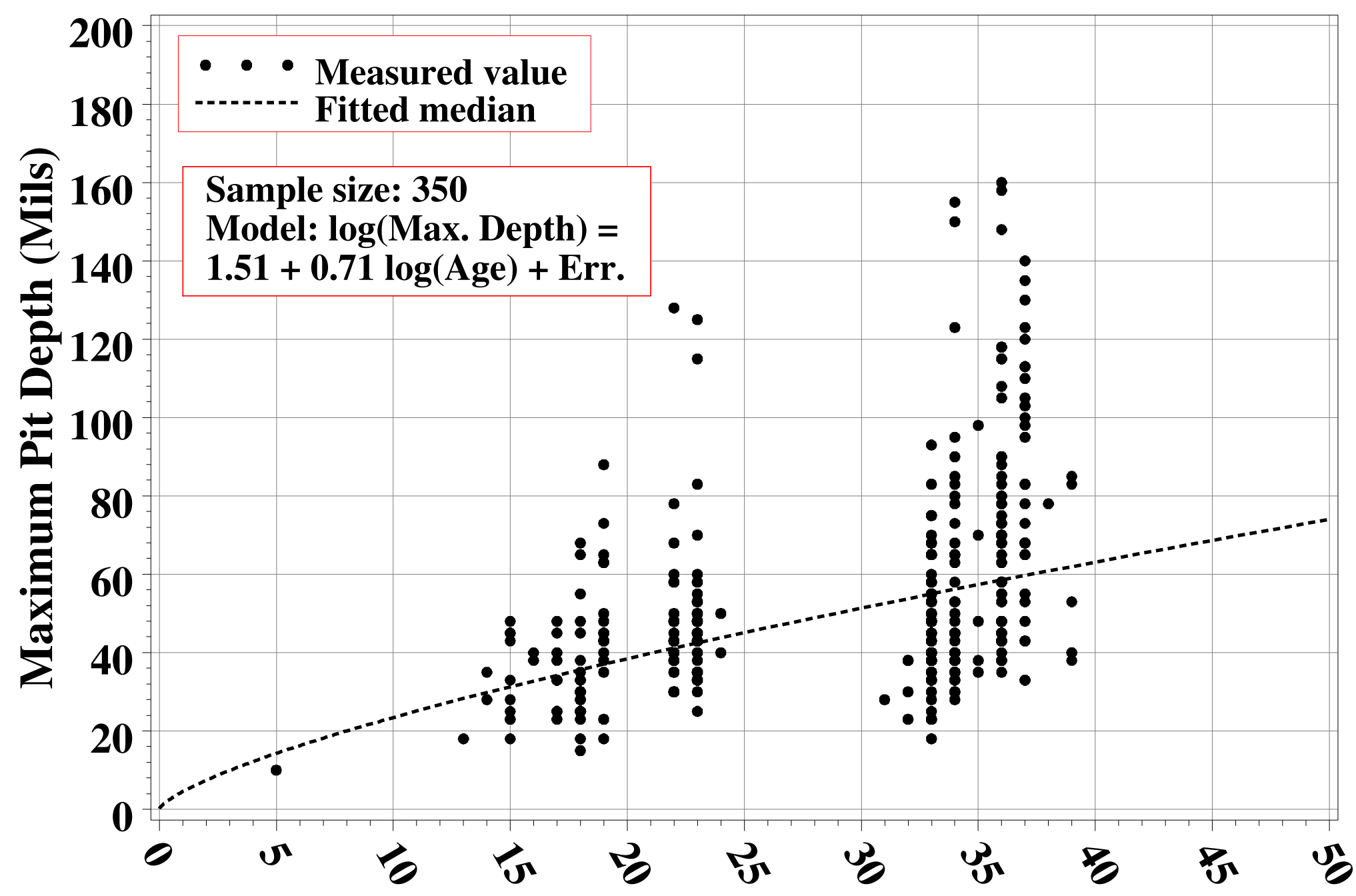

Age of Cylinder When Measured (Yrs)

Figure 7. Maximum pit depth estimates for PGDP thin (P-scan data) cylinders. 


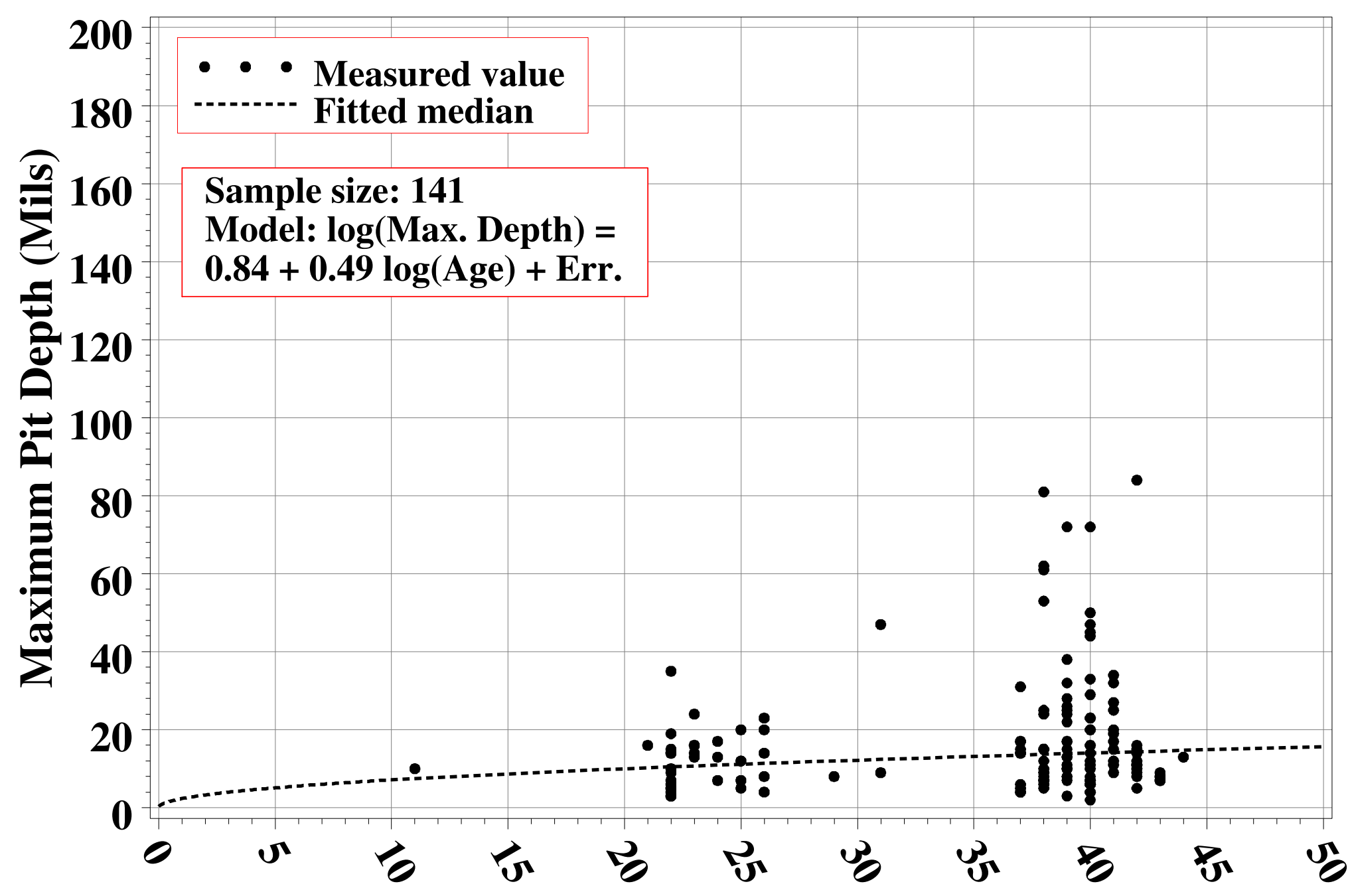

Age of Cylinder When Measured (Yrs)

Figure 8. Maximum pit depth estimates for PGDP thin bottom, former G-yard cylinders. 


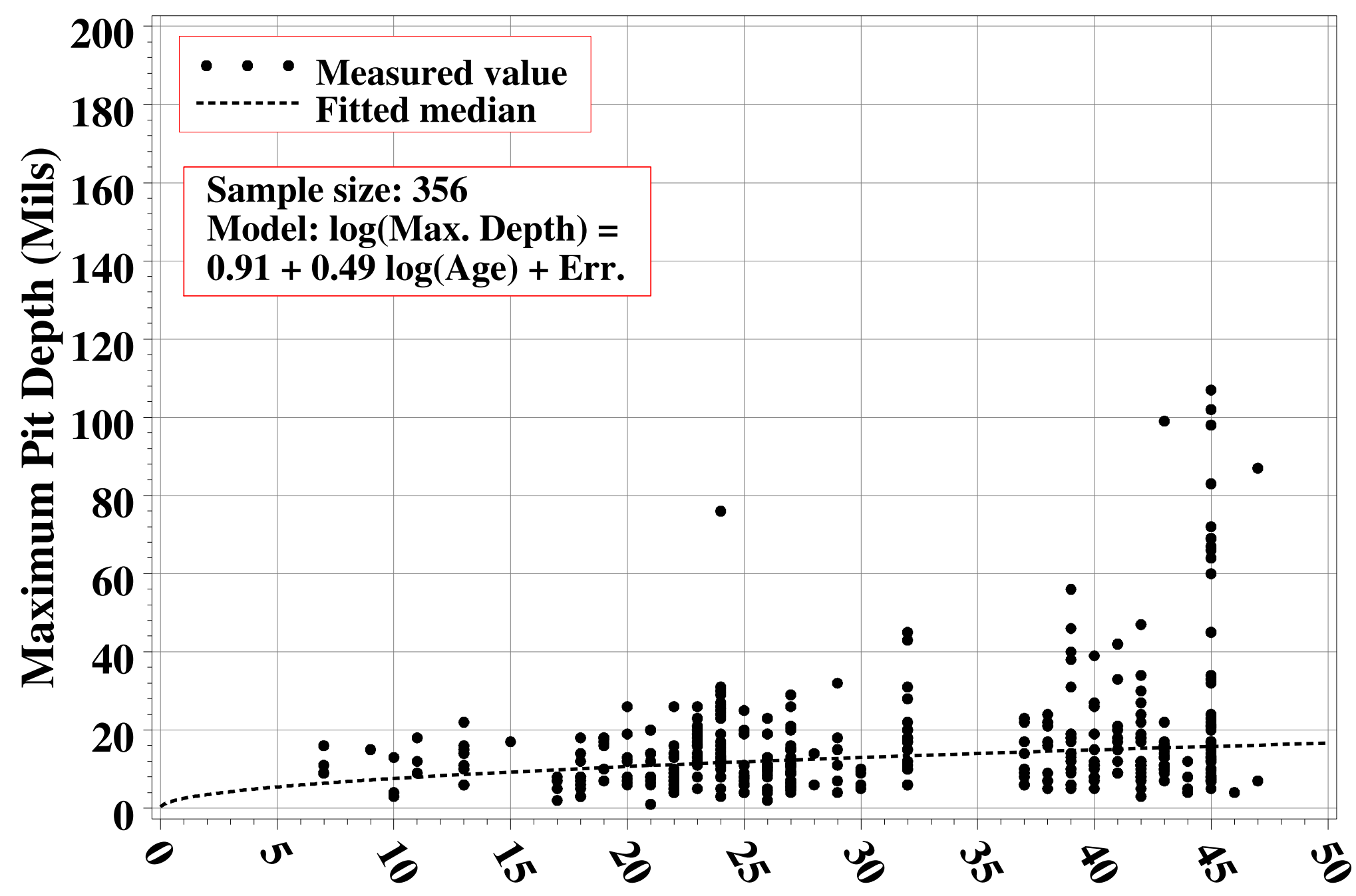

Age of Cylinder When Measured (Yrs)

Figure 9. Maximum pit depth estimates for PGDP thin btm, excpt fmr G-yard cylinders. 


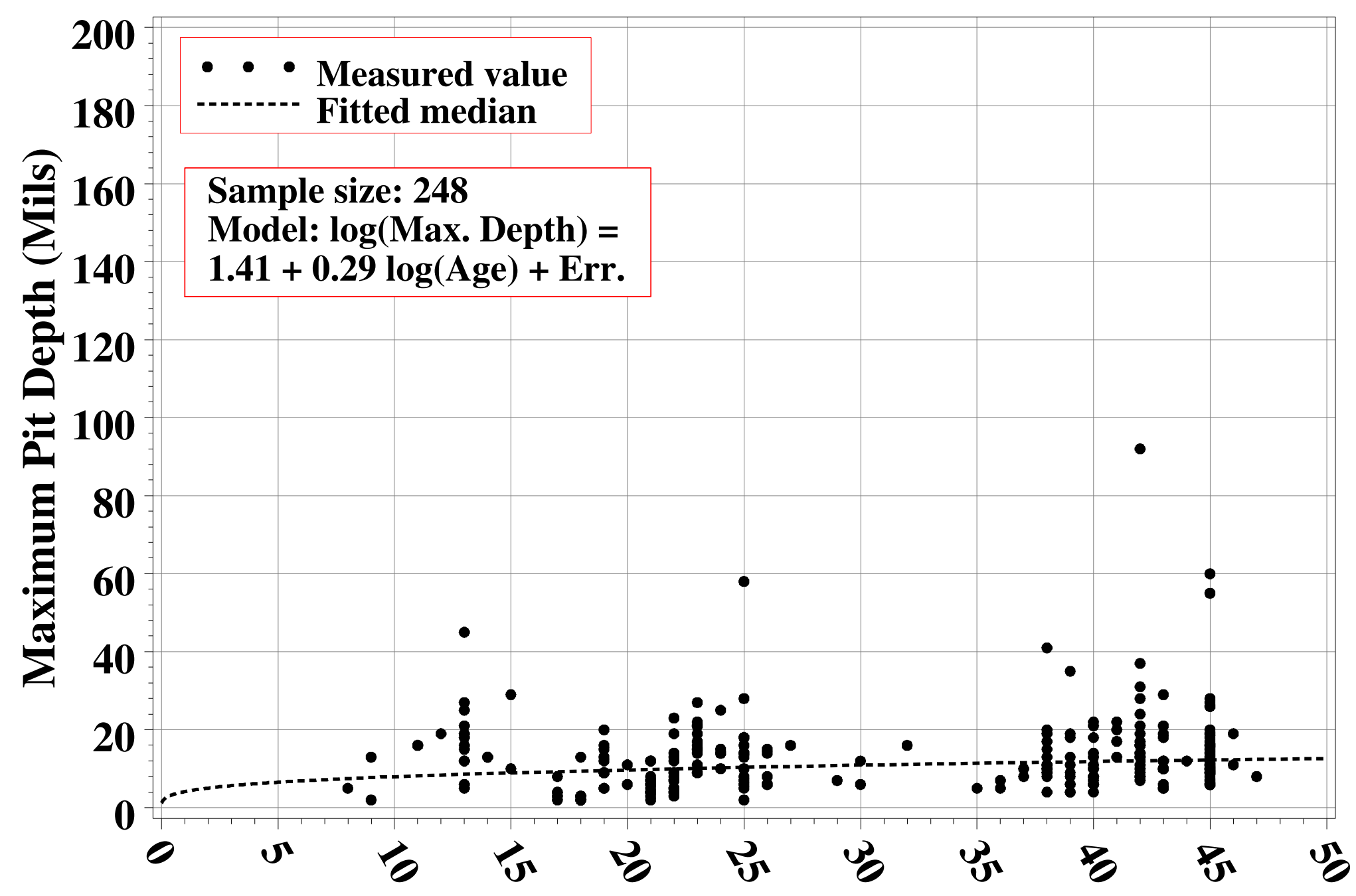

Age of Cylinder When Measured (Yrs)

Figure 10. Maximum pit depth estimates for PGDP thin top cylinders. 


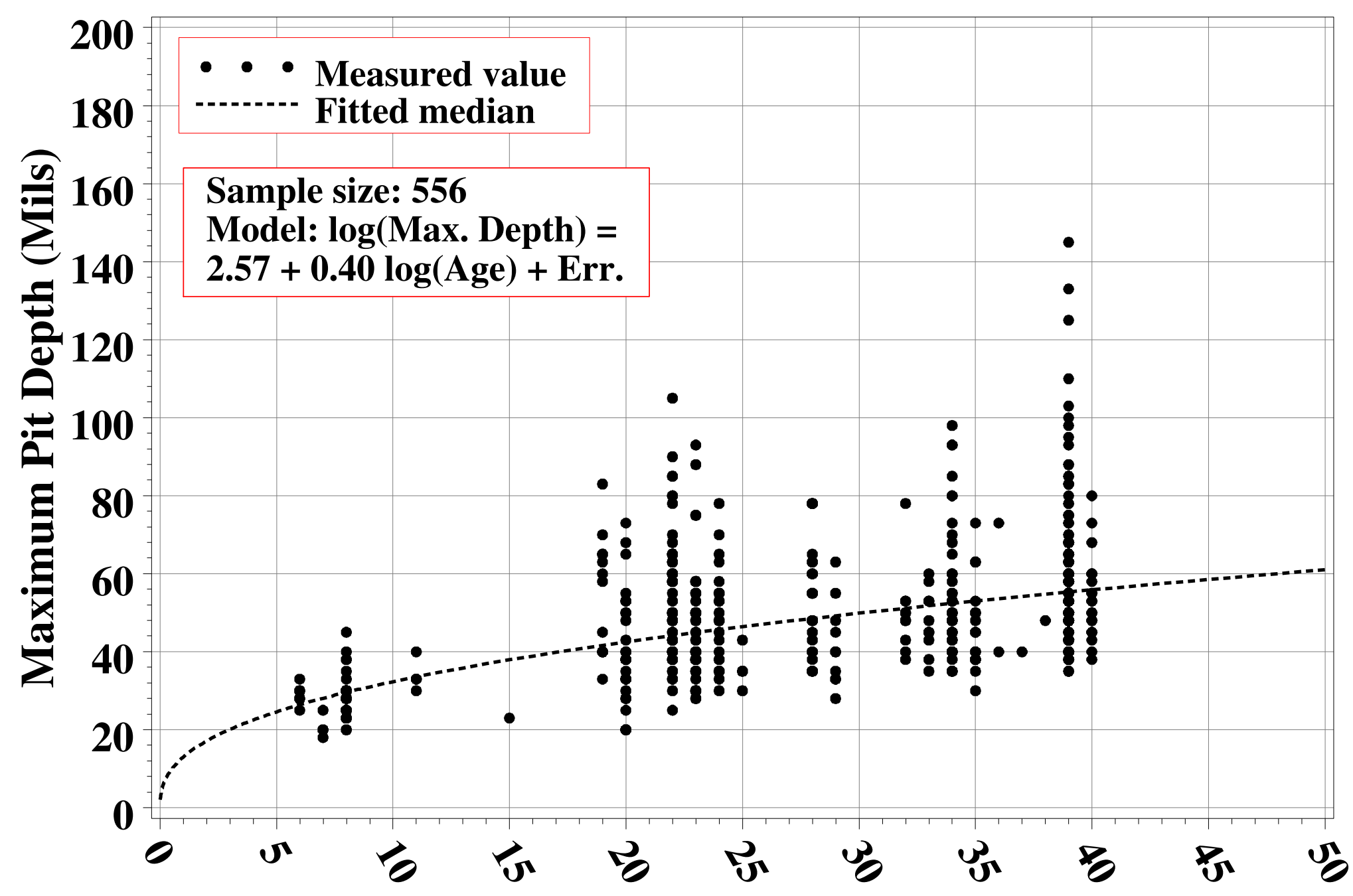

Age of Cylinder When Measured (Yrs)

Figure 11. Maximum pit depth estimates for PORTS thin (P-scan data) cylinders. 


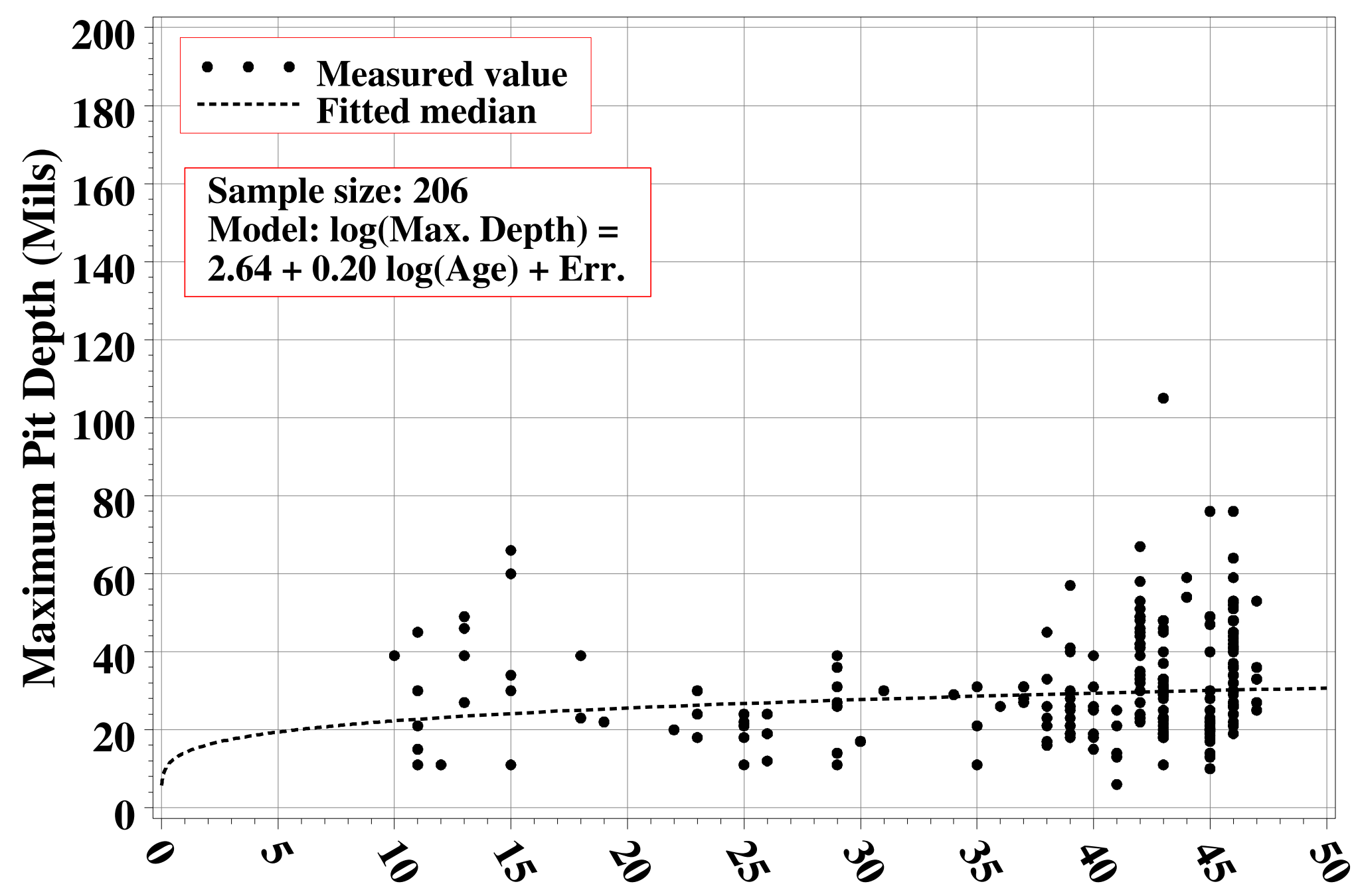

Age of Cylinder When Measured (Yrs)

Figure 12. Maximum pit depth estimates for PORTS thin top cylinders. 


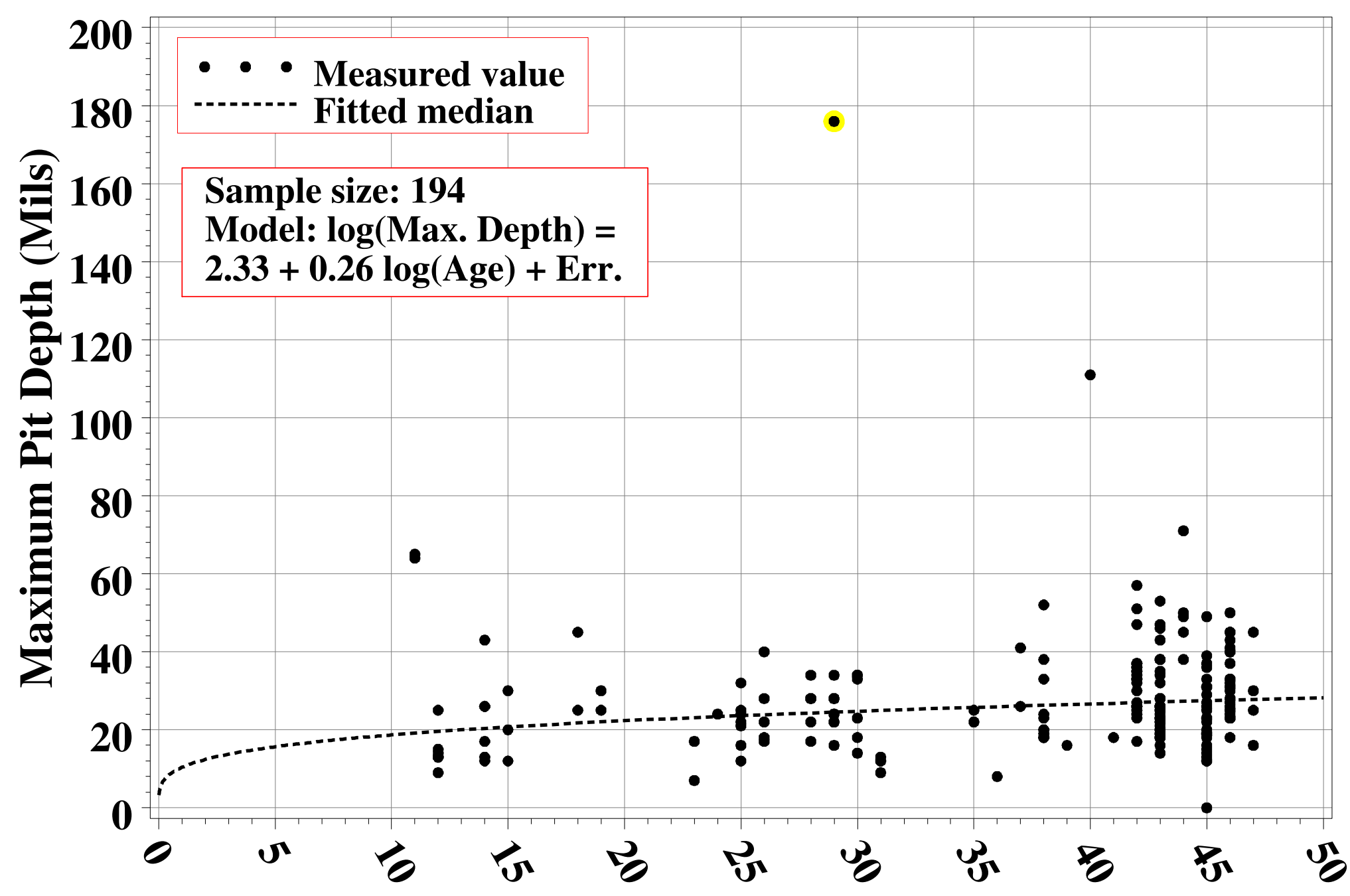

Age of Cylinder When Measured (Yrs)

Figure 13. Maximum pit depth estimates for PORTS thin bottom cylinders. 


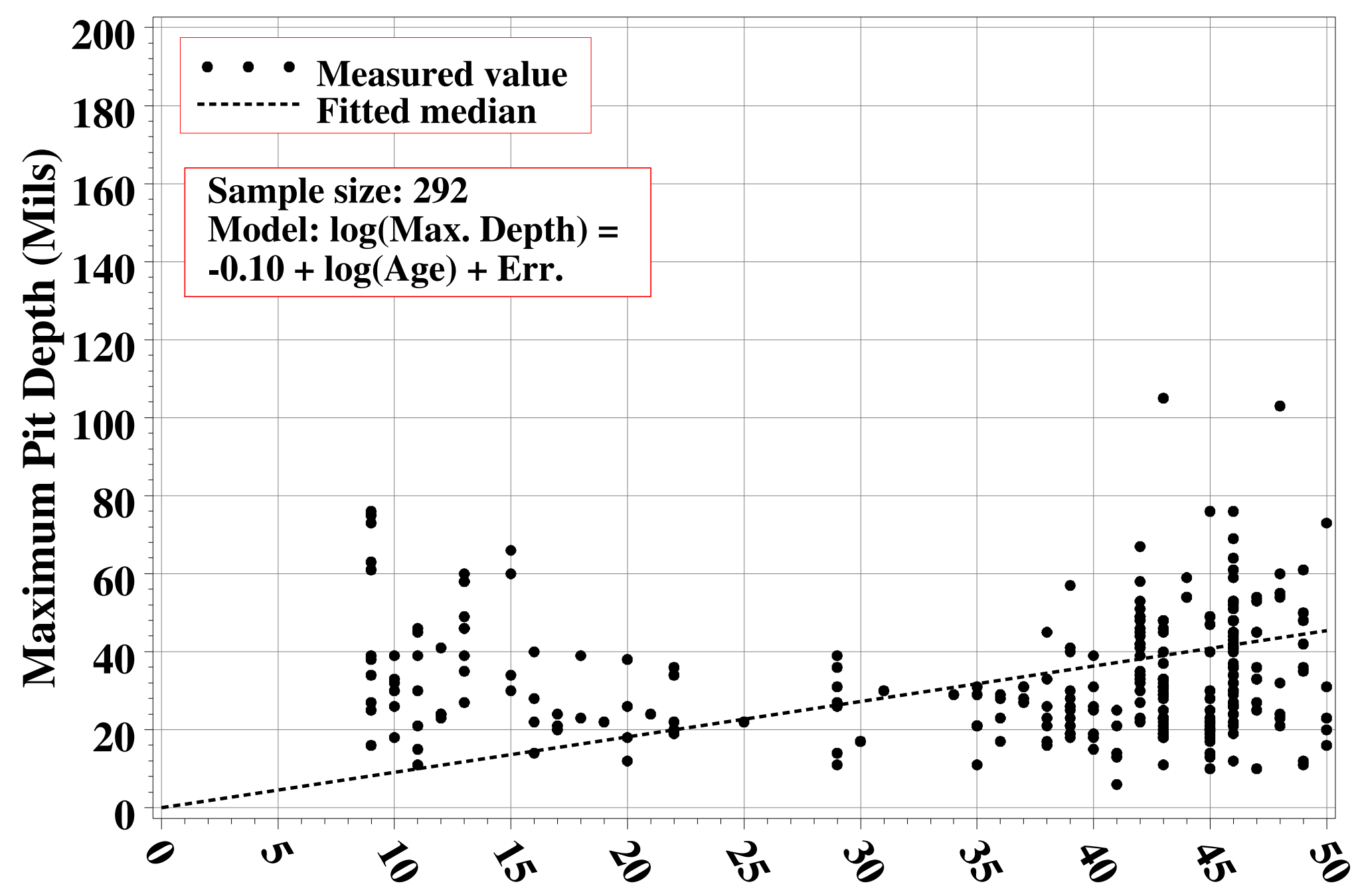

Age of Cylinder When Measured (Yrs)

Figure 14. Maximum pit depth estimates for ETTP/PGDP/PORTS thick top cylinders. 


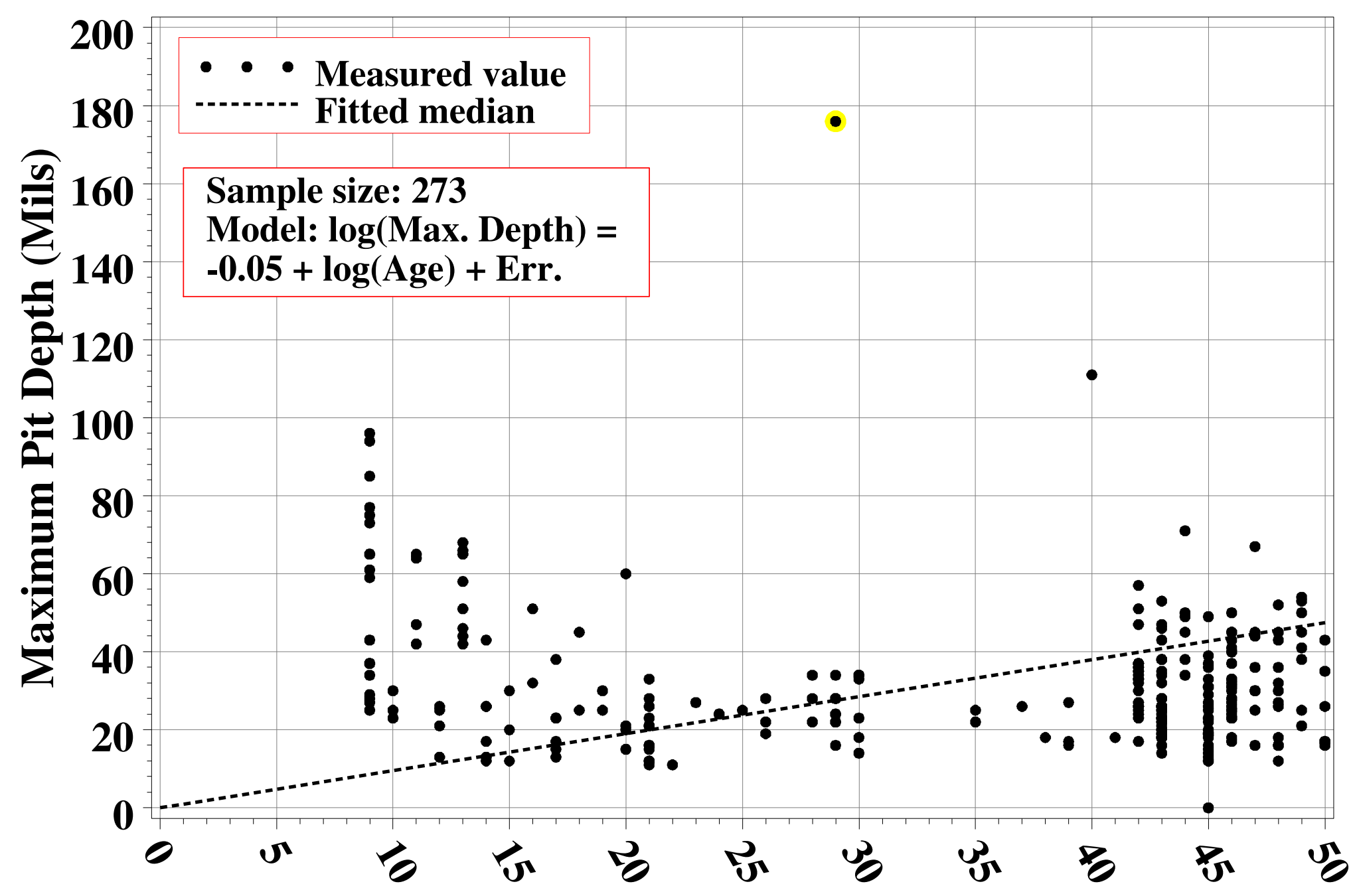

Age of Cylinder When Measured (Yrs)

Figure 15. Maximum pit depth estimates for ETTP/PGDP/PORTS thick bottom cylinders. 


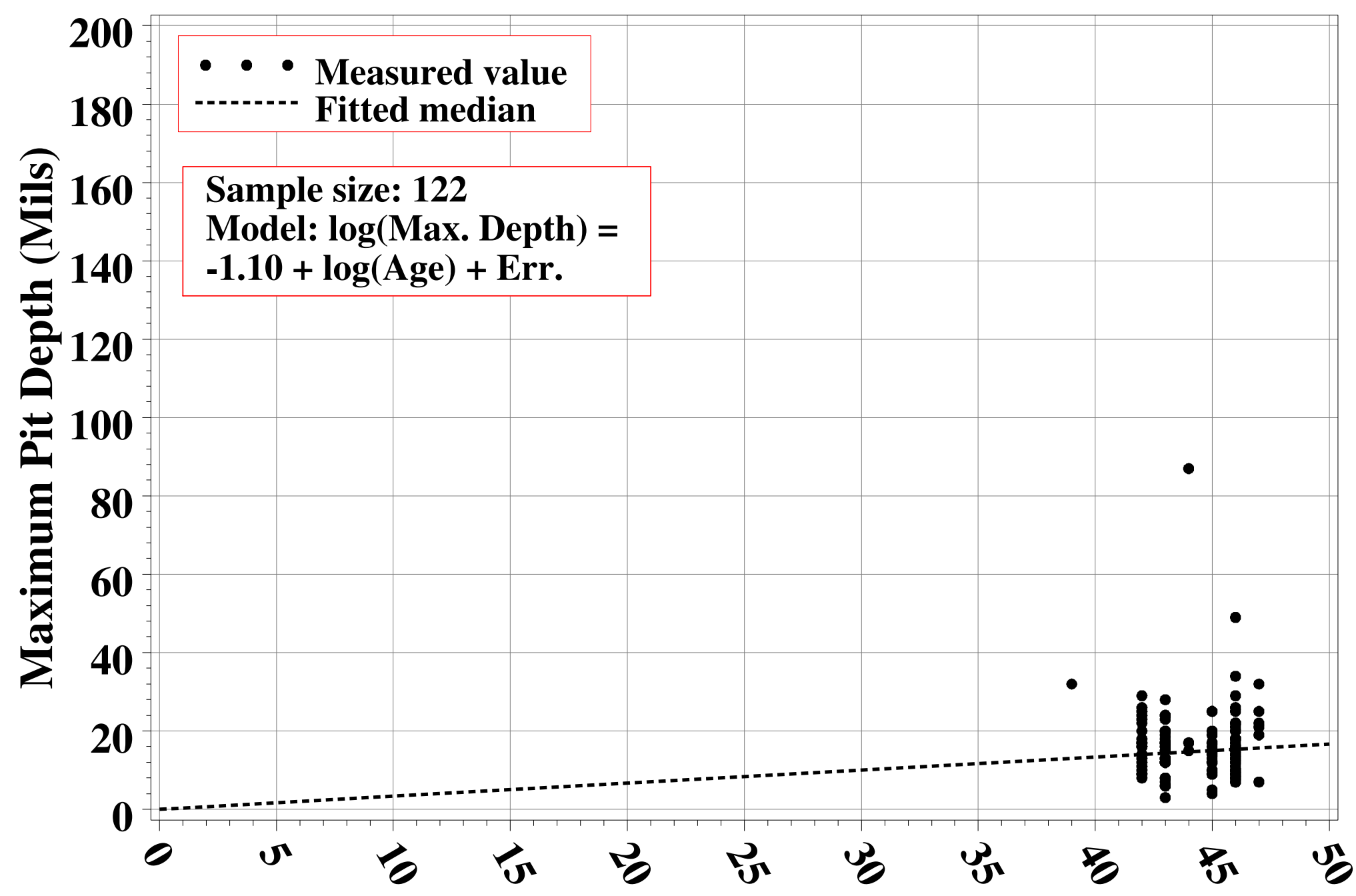

Age of Cylinder When Measured (Yrs)

Figure 16. Maximum pit depth estimates for ETTP/PGDP/PORTS thin skirted top cylinders. 


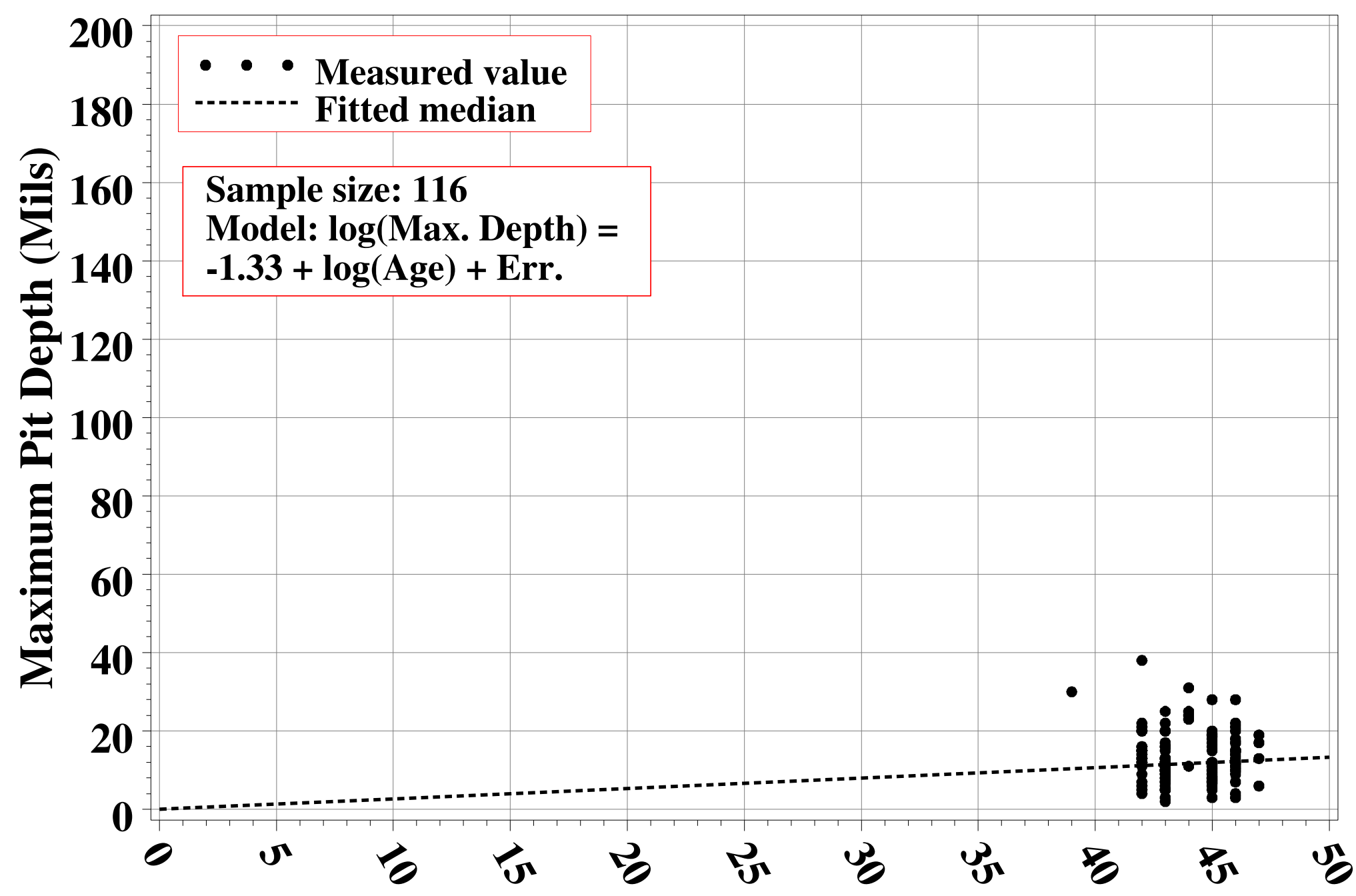

Age of Cylinder When Measured (Yrs)

Figure 17. Maximum pit depth estimates for ETTP/PGDP/PORTS thin skirted btm cylinders. 


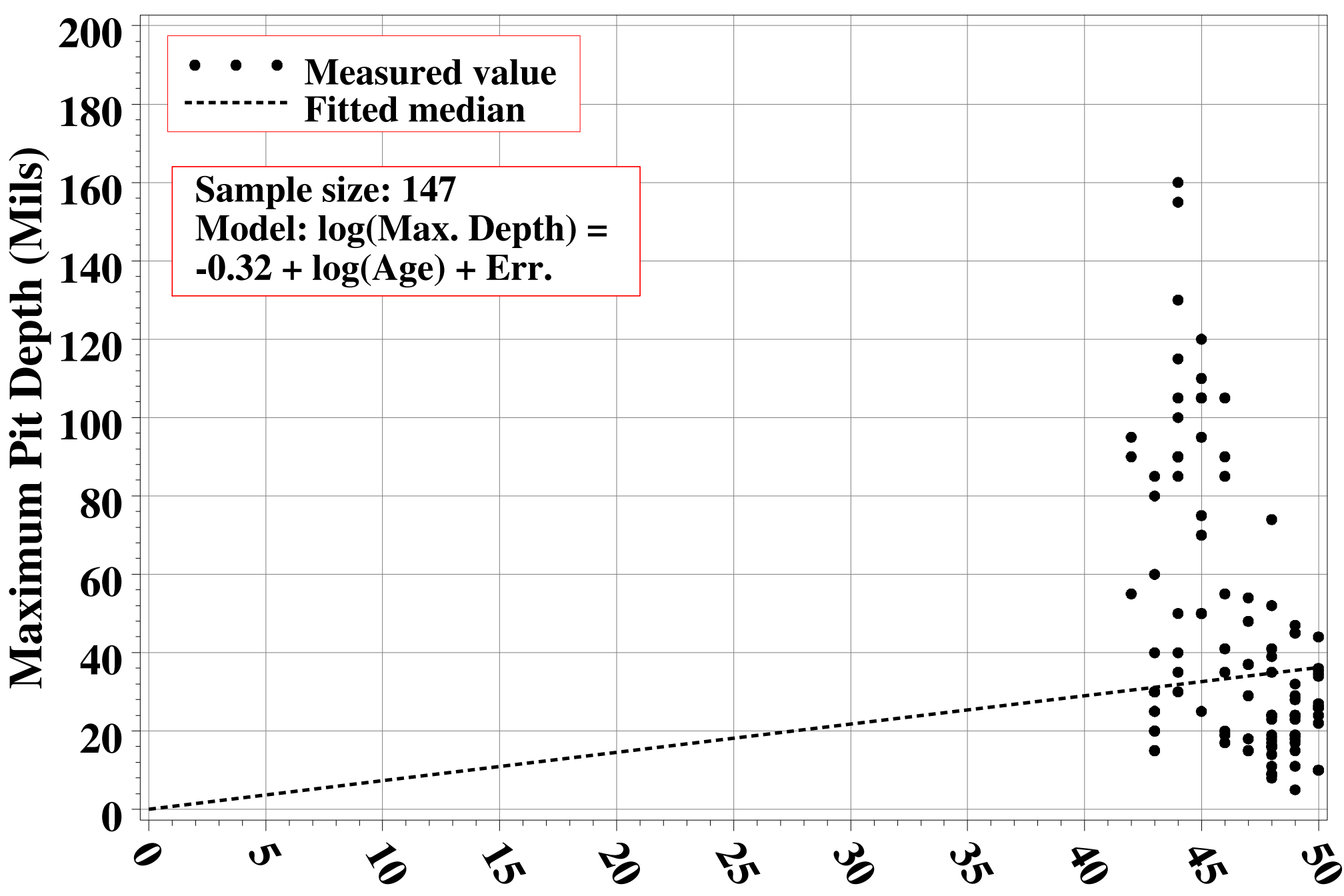

Age of Cylinder When Measured (Yrs)

Figure 18. Maximum pit depth estimates for ETTP/PGDP/PORTS thick skirted cylinders. 


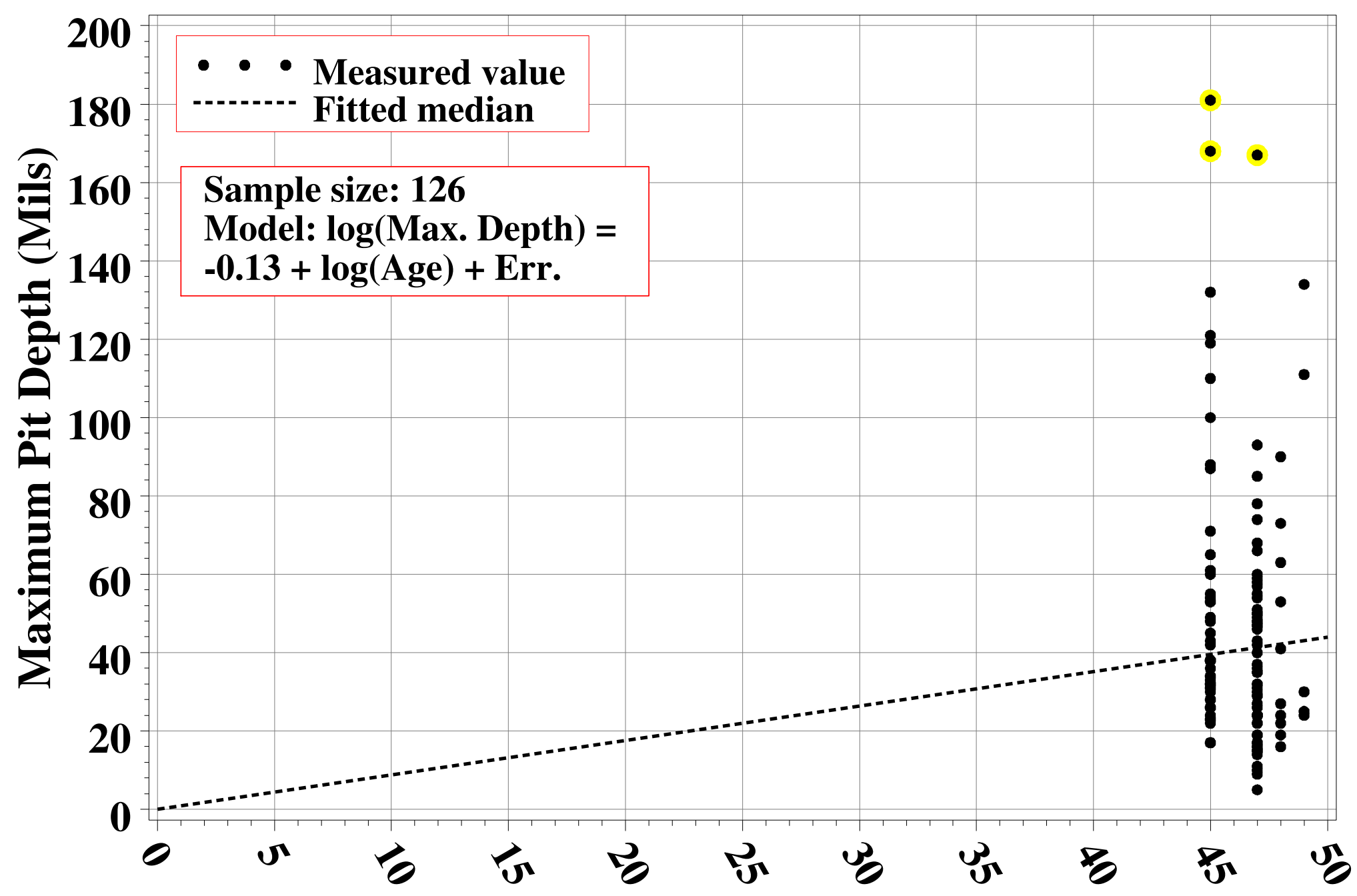

Age of Cylinder When Measured (Yrs)

Figure 19. Maximum pit depth estimates for ETTP/PGDP/PORTS 1/2" (30" dia.) top cylinders. 


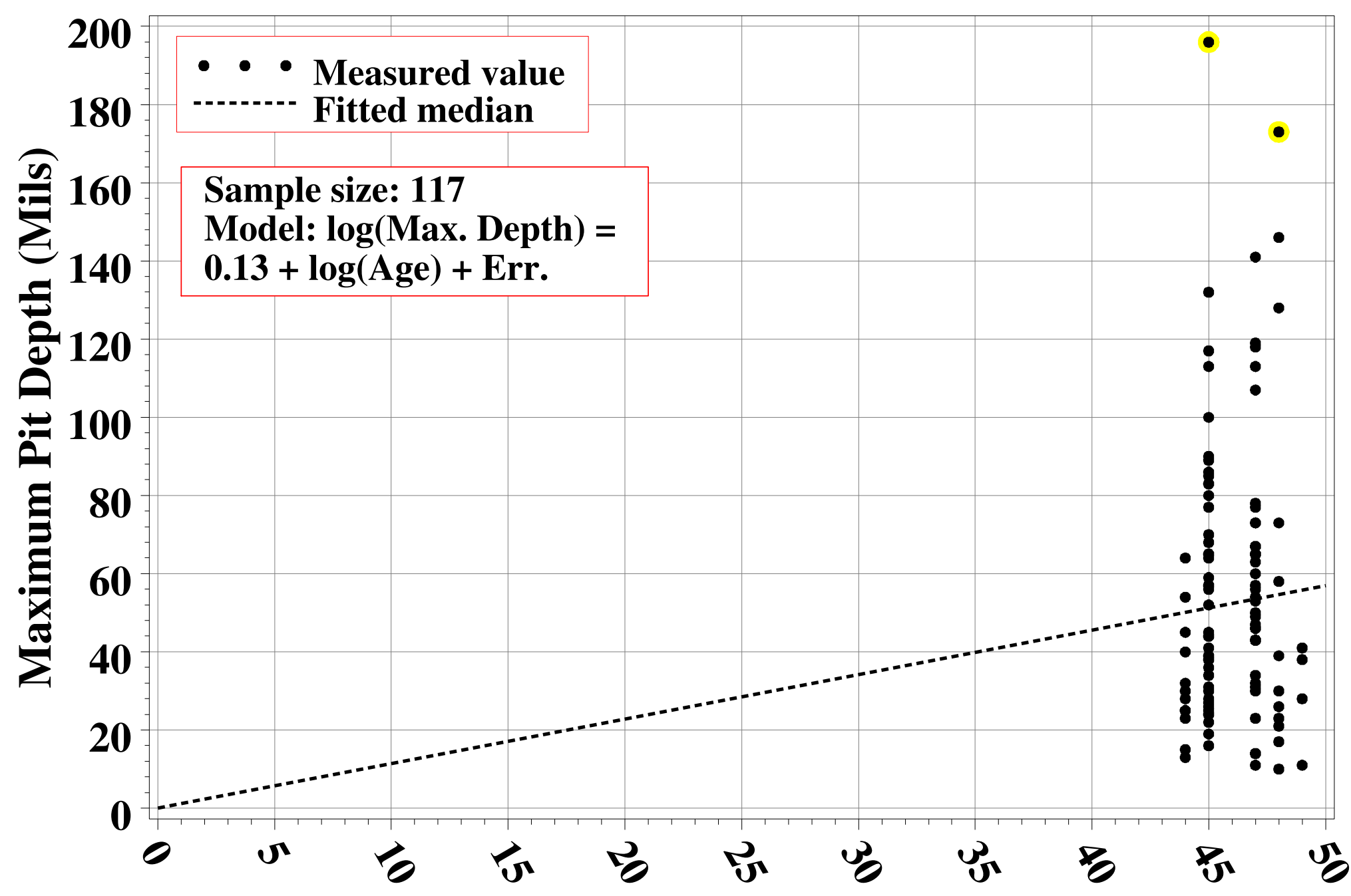

Age of Cylinder When Measured (Yrs)

Figure 20. Maximum pit depth estimates for ETTP/PGDP/PORTS 1/2" (30" dia.) btm cylinders. 

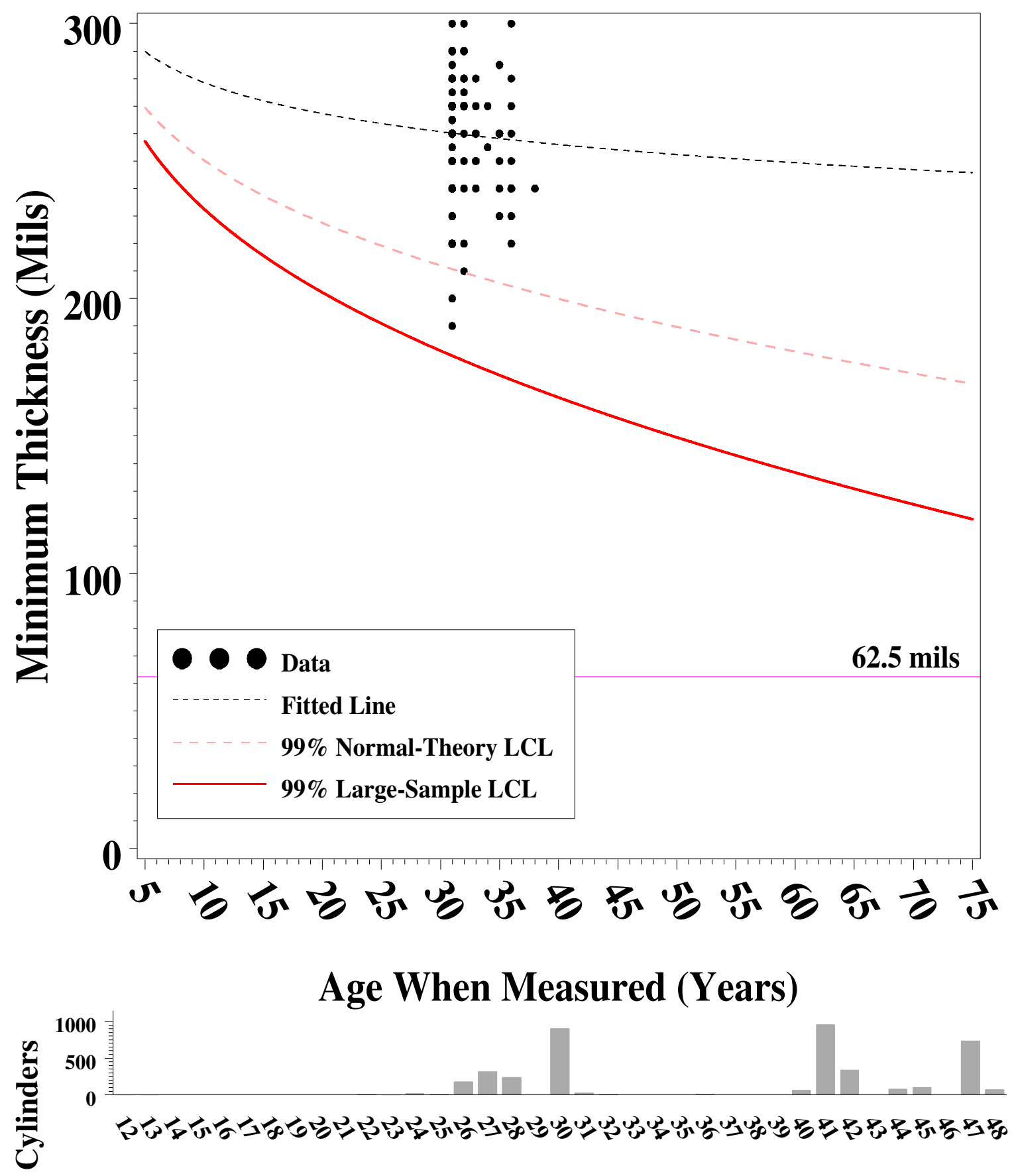

Age in 2004

Figure 21. Minimum thicknesses (top) and age distribution (below) for ETTP thin (P-scan data) cylinders. Points with corresponding regression residuals below $\mathbf{- 2 0}$ are highlighted (yellow) in Figures 18-36, and those points are excluded from Table 11B. 

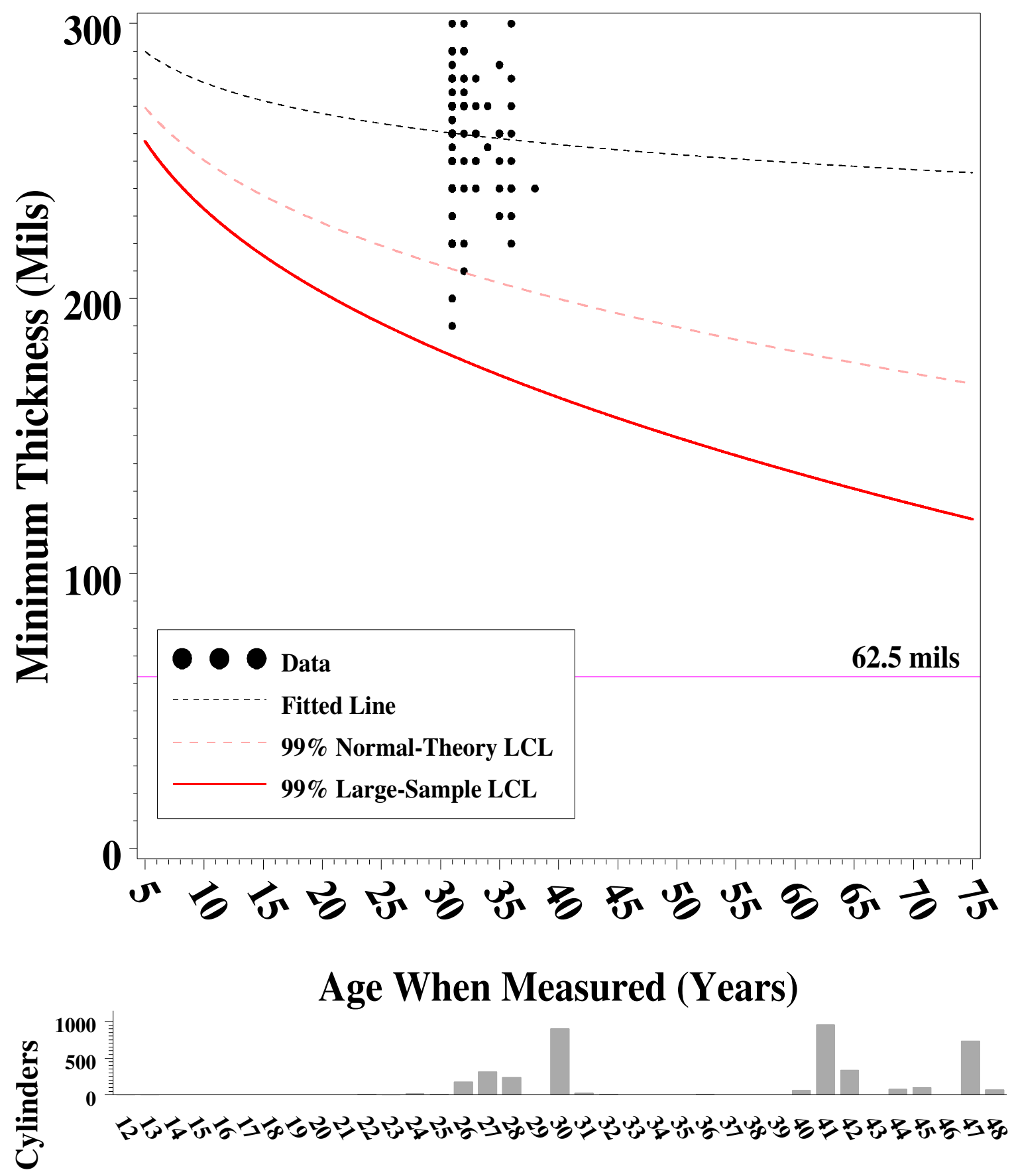

Age in 2004

Figure 21. Minimum thicknesses (top) and age distribution (below) for ETTP thin (P-scan data) cylinders. Points with corresponding regression residuals below $\mathbf{- 2 0}$ are highlighted (yellow) in Figures 18-36, and those points are excluded from Table 11B. 


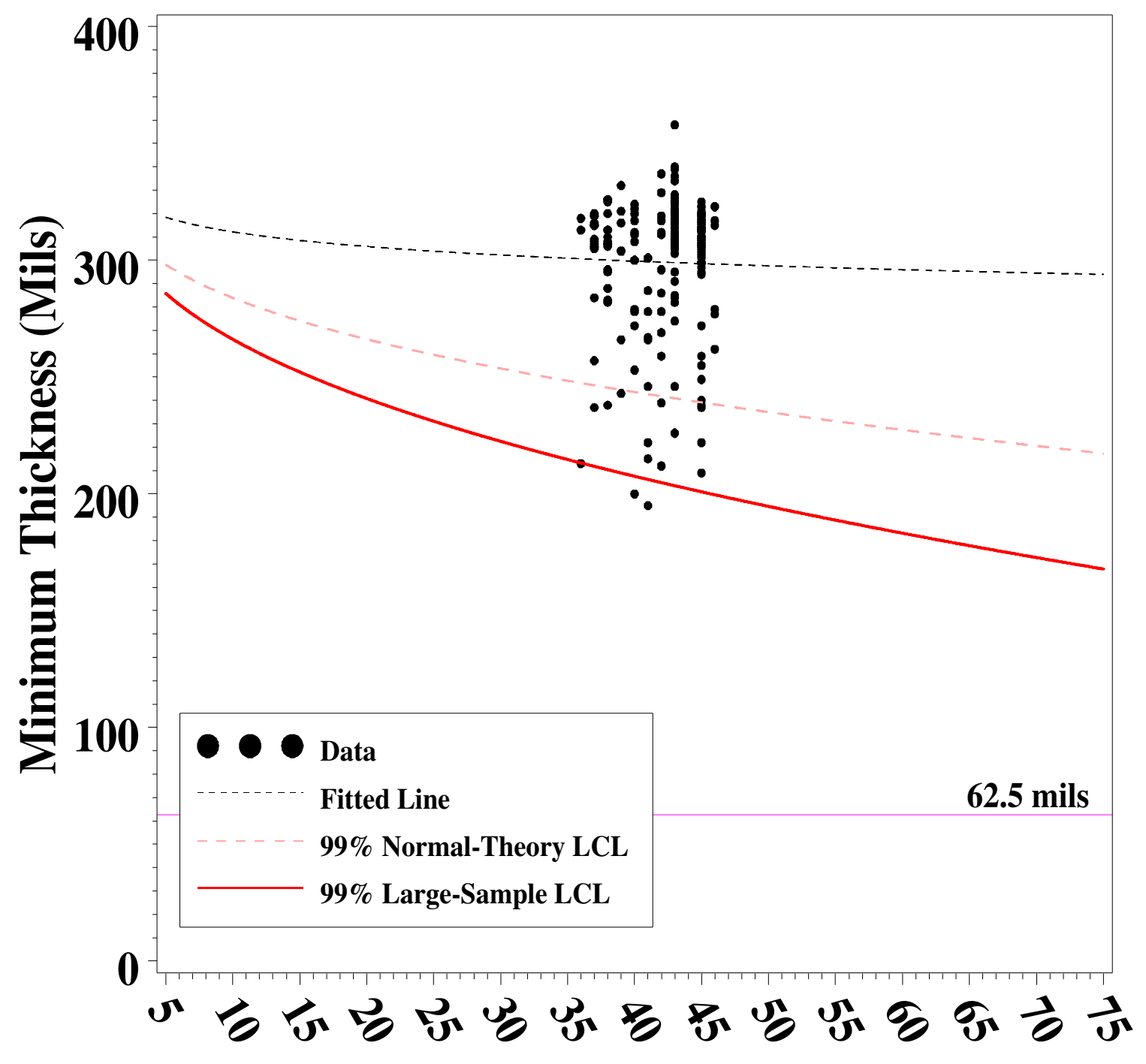

Age When Measured (Years)

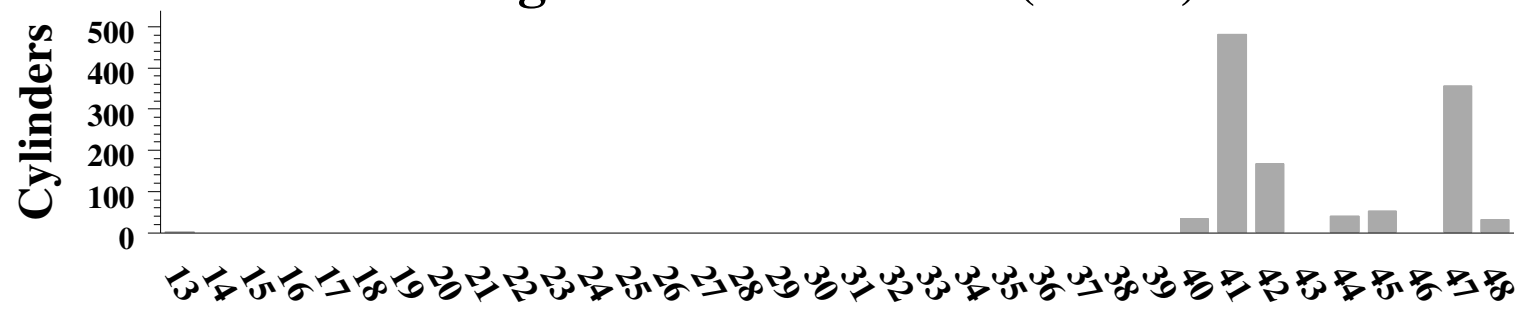

Age in 2004

Figure 22. Minimum thicknesses (top) and age distribution (below) for ETTP thin, K-yard bottom cylinders. 

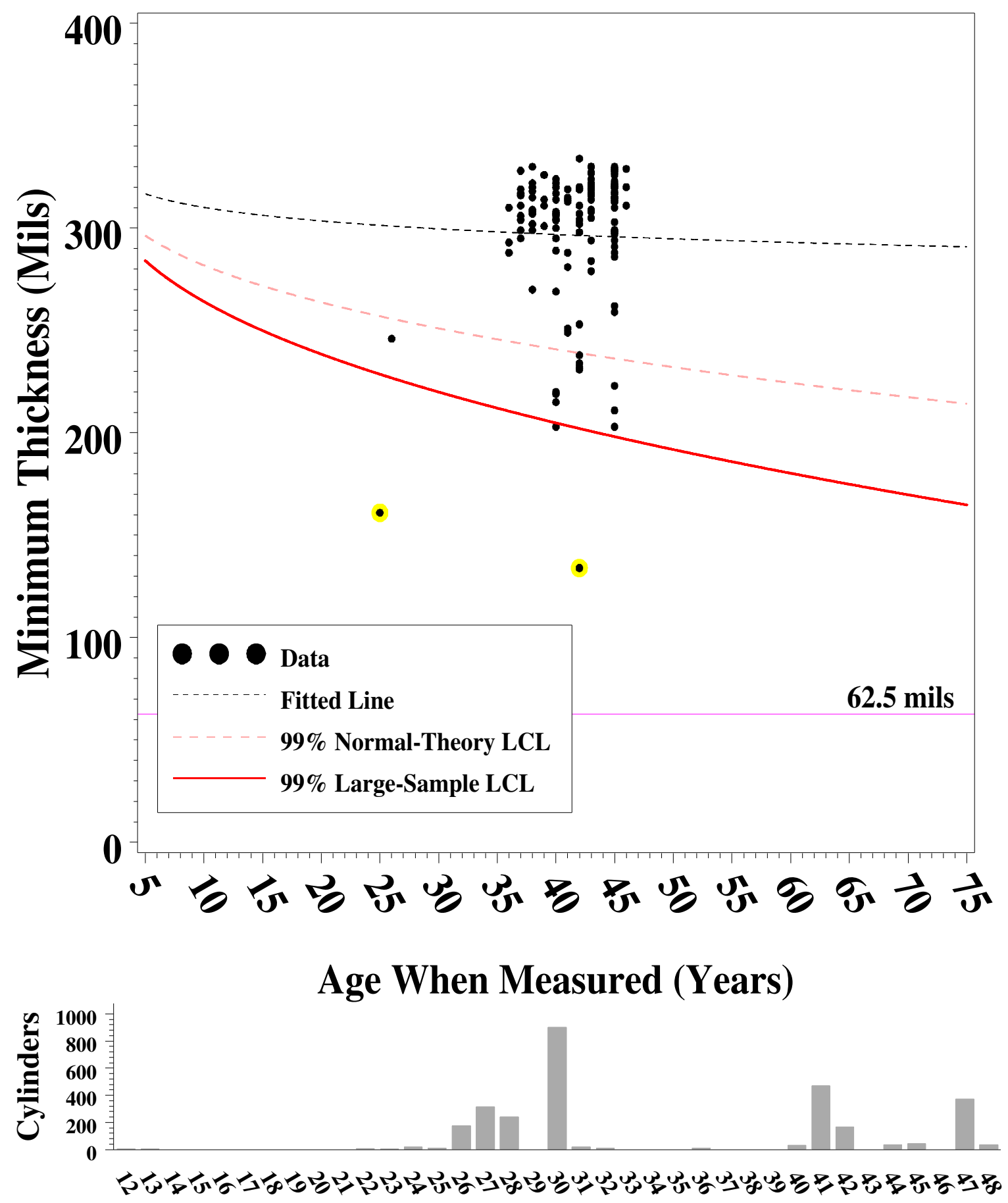

Age in 2004

Figure 23. Minimum thicknesses (top) and age distribution (below) for ETTP thin, except K-yard bottom cylinders. 

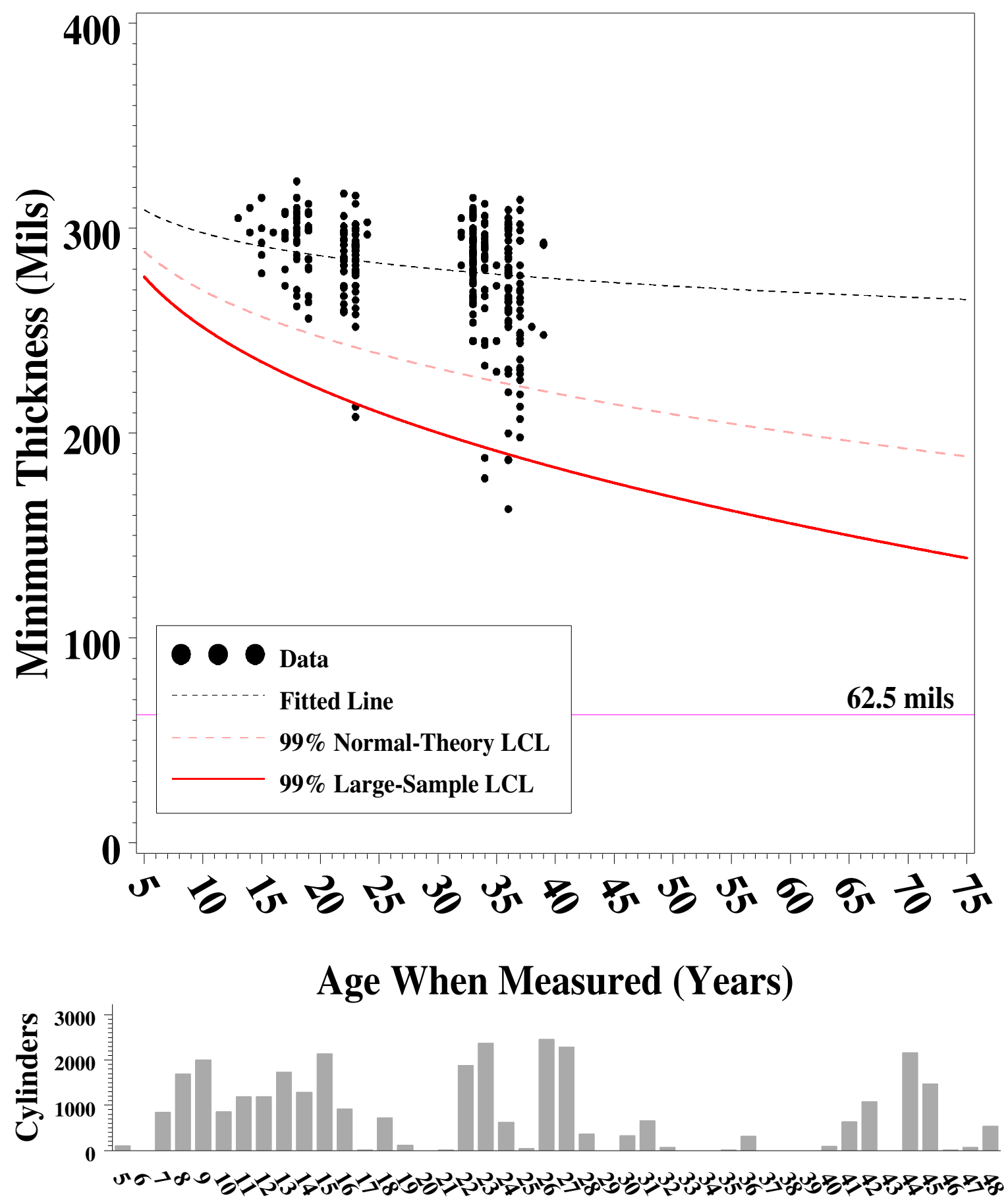

Age in 2004

Figure 24. Minimum thicknesses (top) and age distribution (below) for PGDP thin (P-scan data) cylinders. 

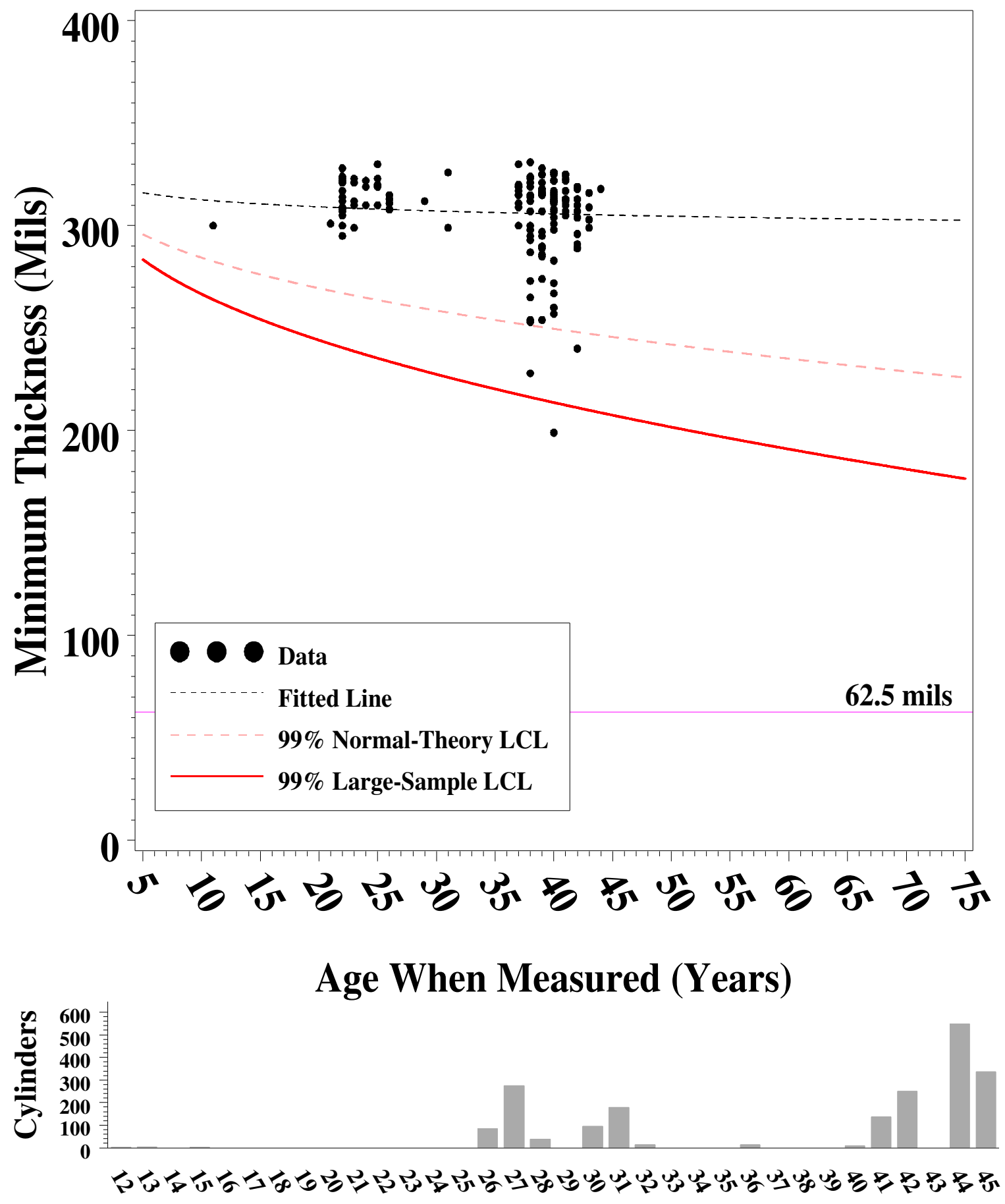

Age in 2004

Figure 25. Minimum thicknesses (top) and age distribution (below) for PGDP thin bottom, former G-yard cylinders. 

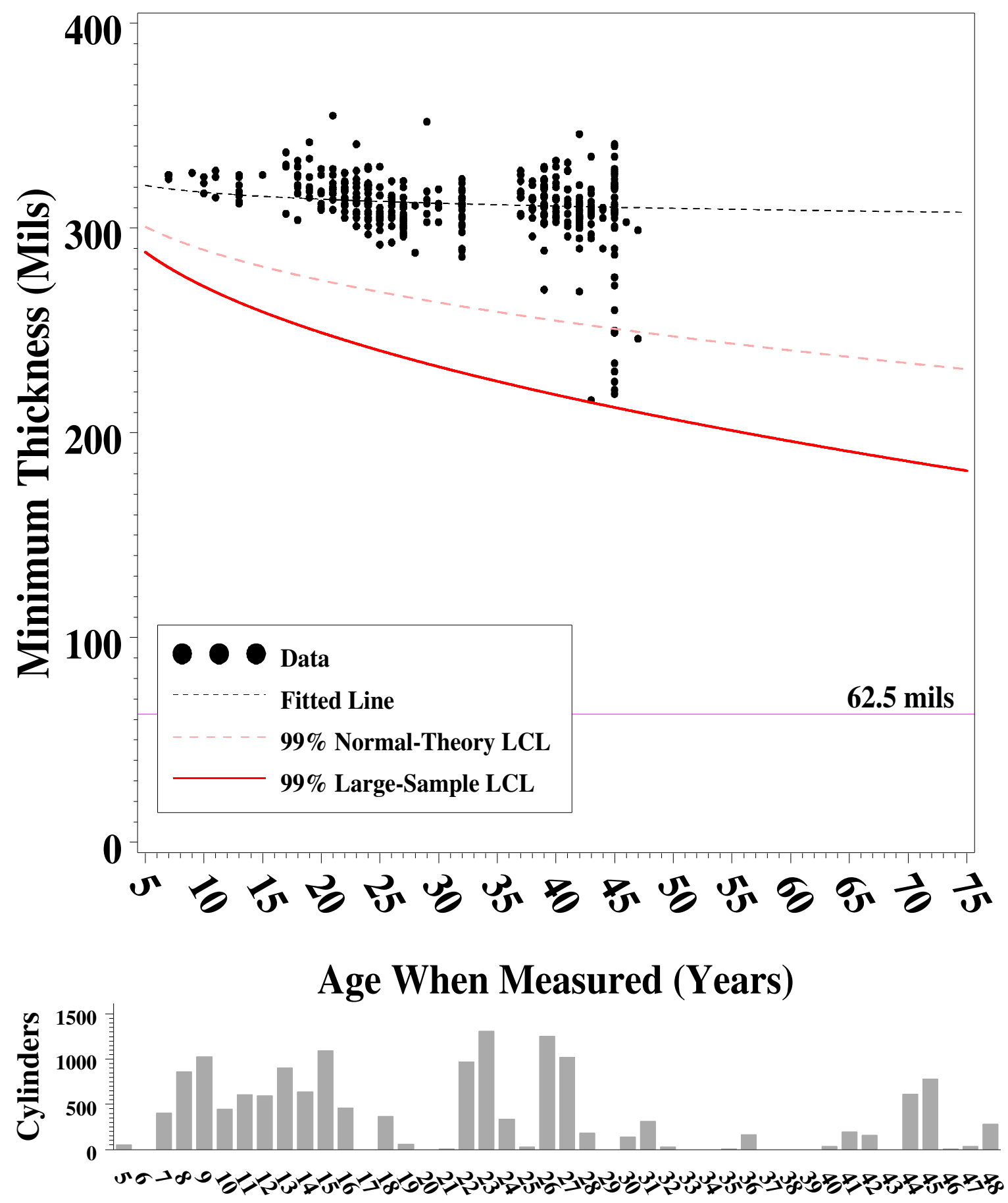

Age in 2004

Figure 26. Minimum thicknesses (top) and age distribution (below) for PGDP thin btm, excpt fmr G-yard cylinders. 

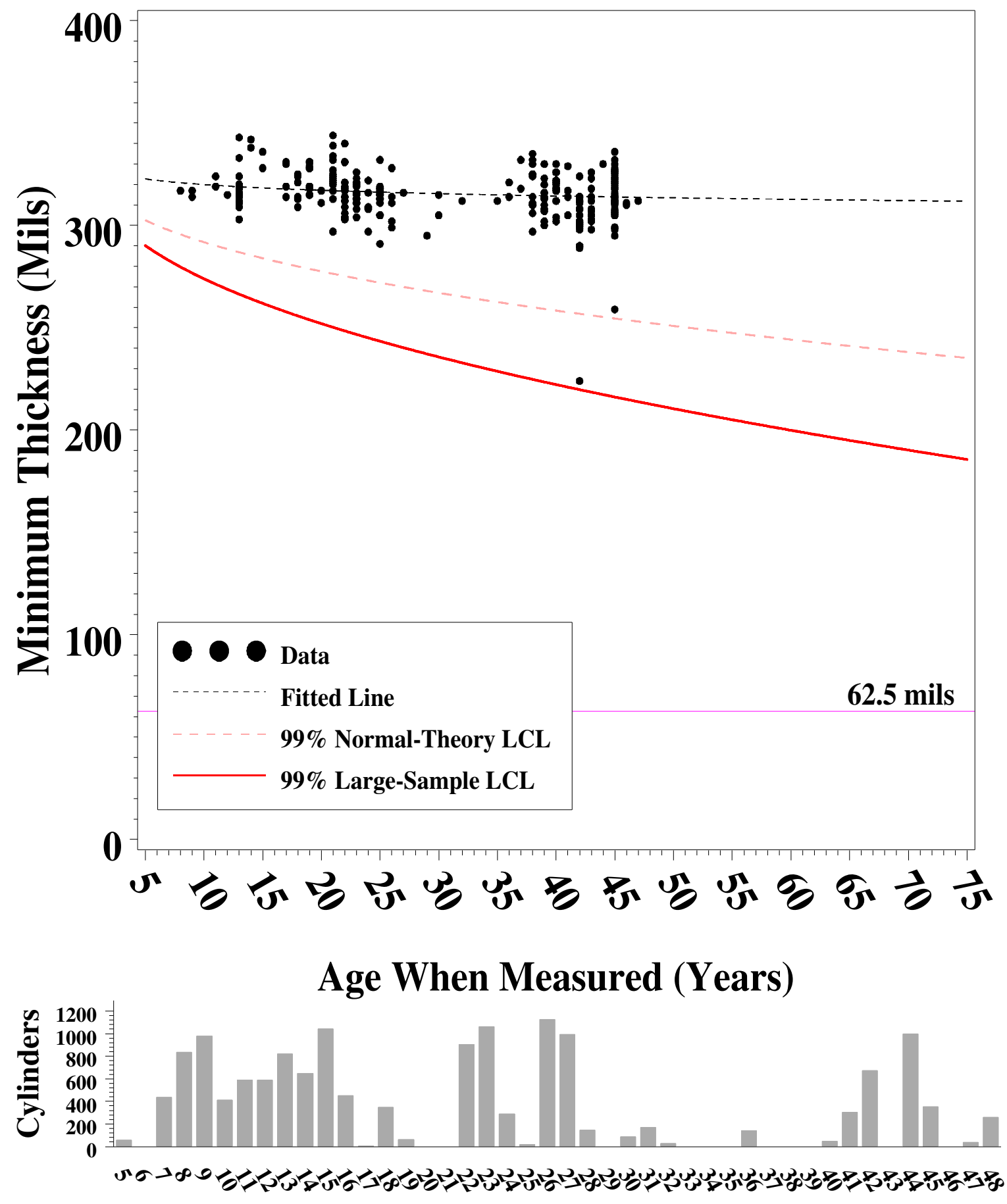

Age in 2004

Figure 27. Minimum thicknesses (top) and age distribution (below) for PGDP thin top cylinders. 

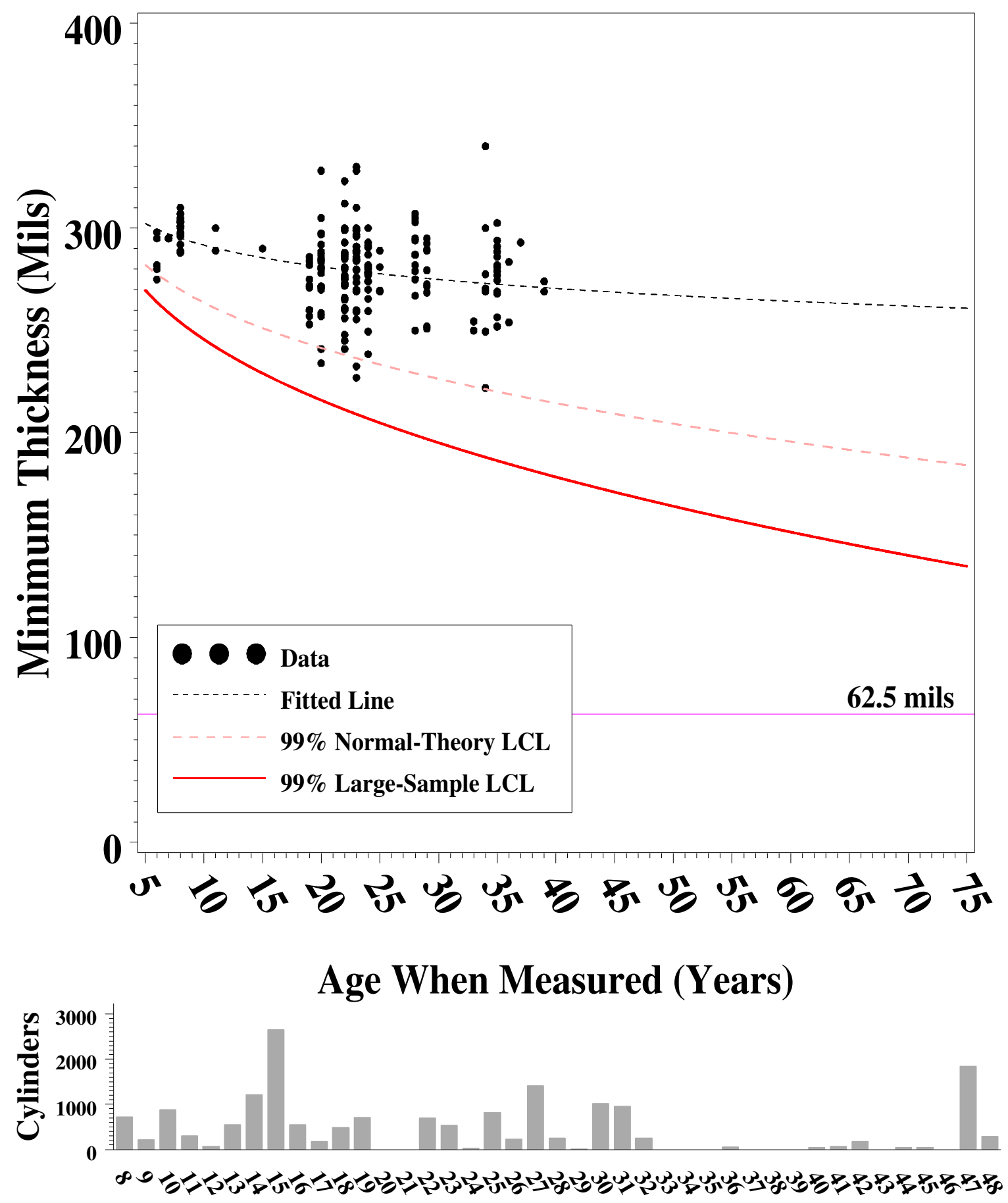

Age in 2004

Figure 28. Minimum thicknesses (top) and age distribution (below) for PORTS thin (P-scan data) cylinders. 

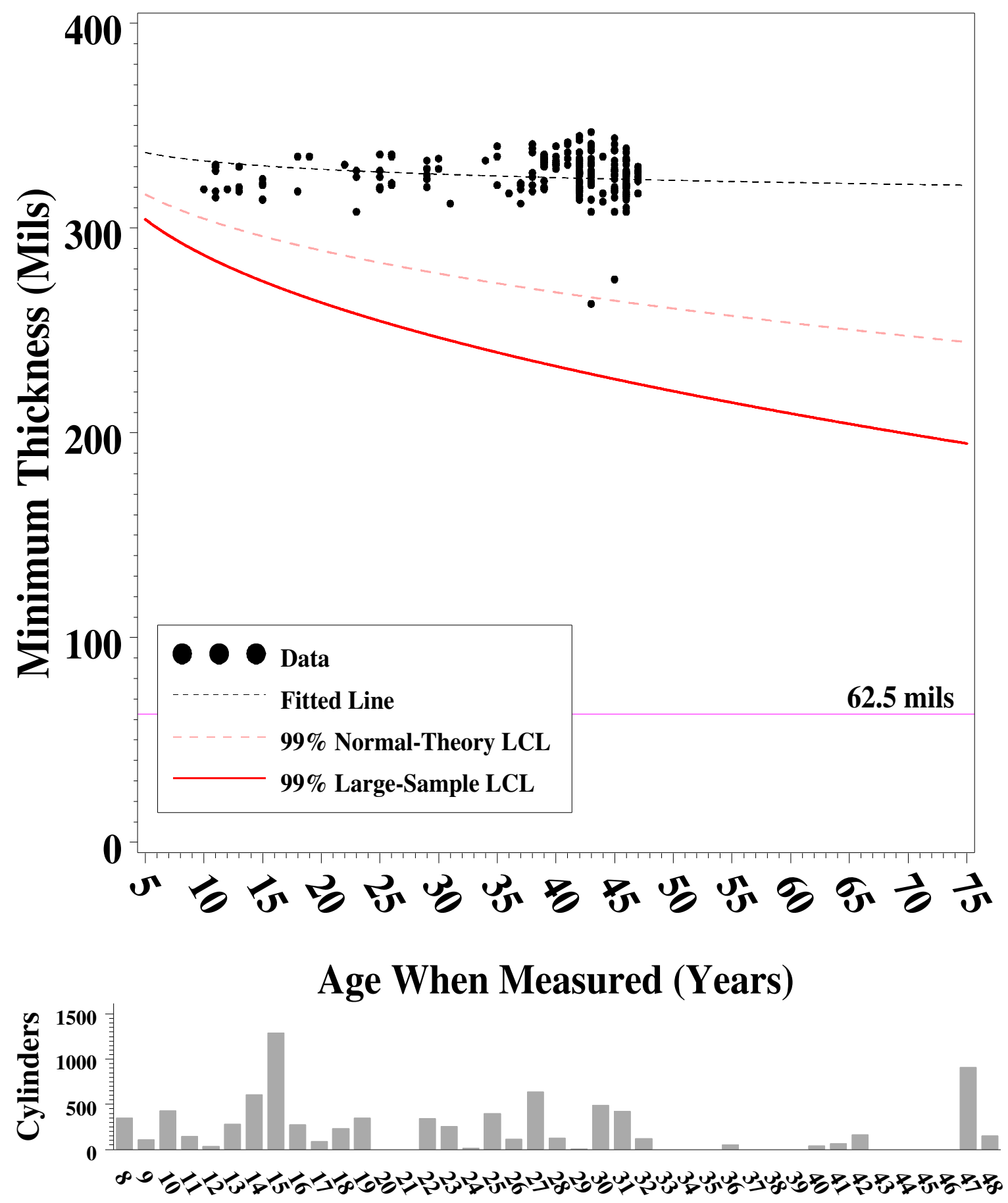

Age in 2004

Figure 29. Minimum thicknesses (top) and age distribution (below) for PORTS thin top cylinders. 

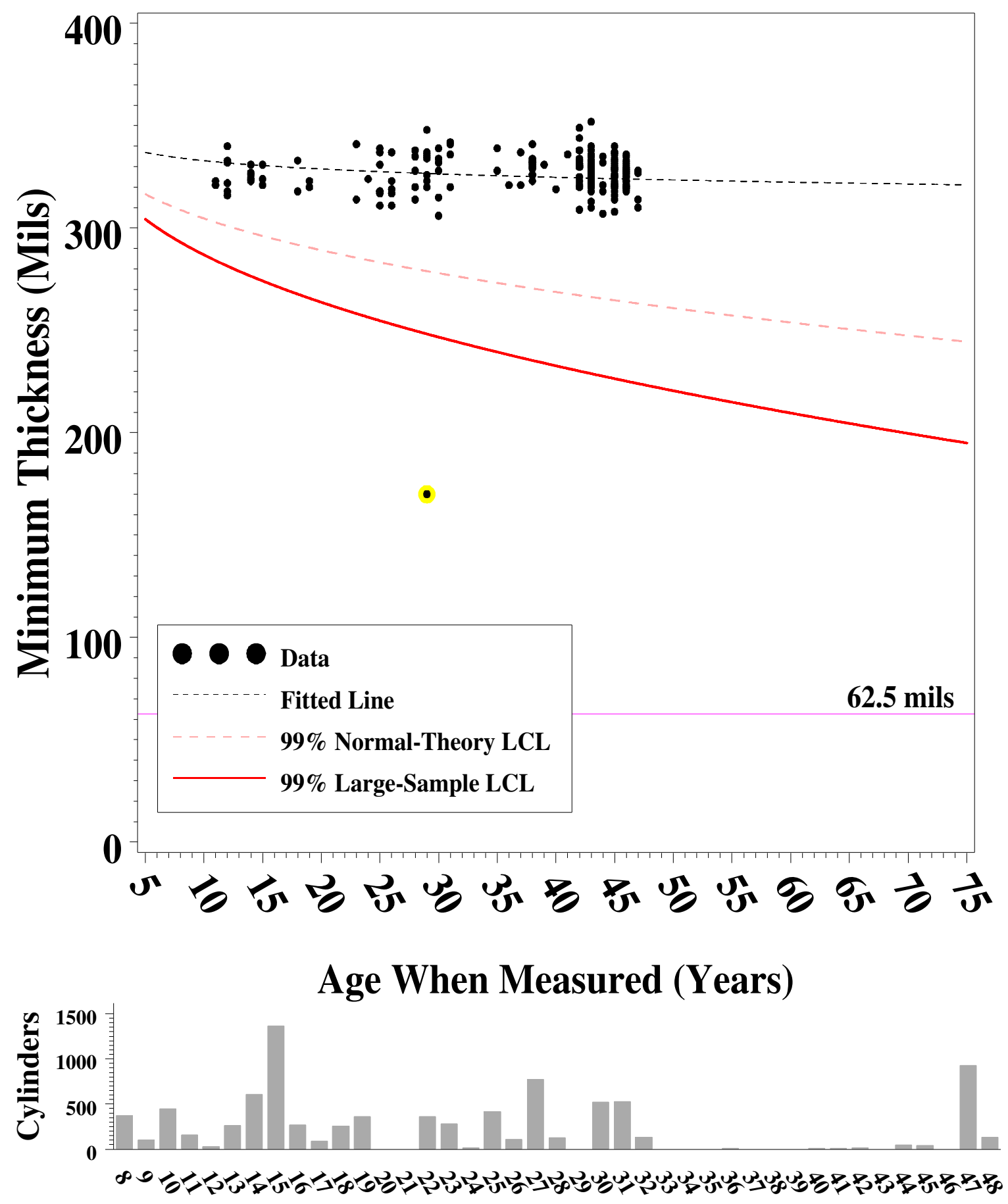

Age in 2004

Figure 30. Minimum thicknesses (top) and age distribution (below) for PORTS thin bottom cylinders. 

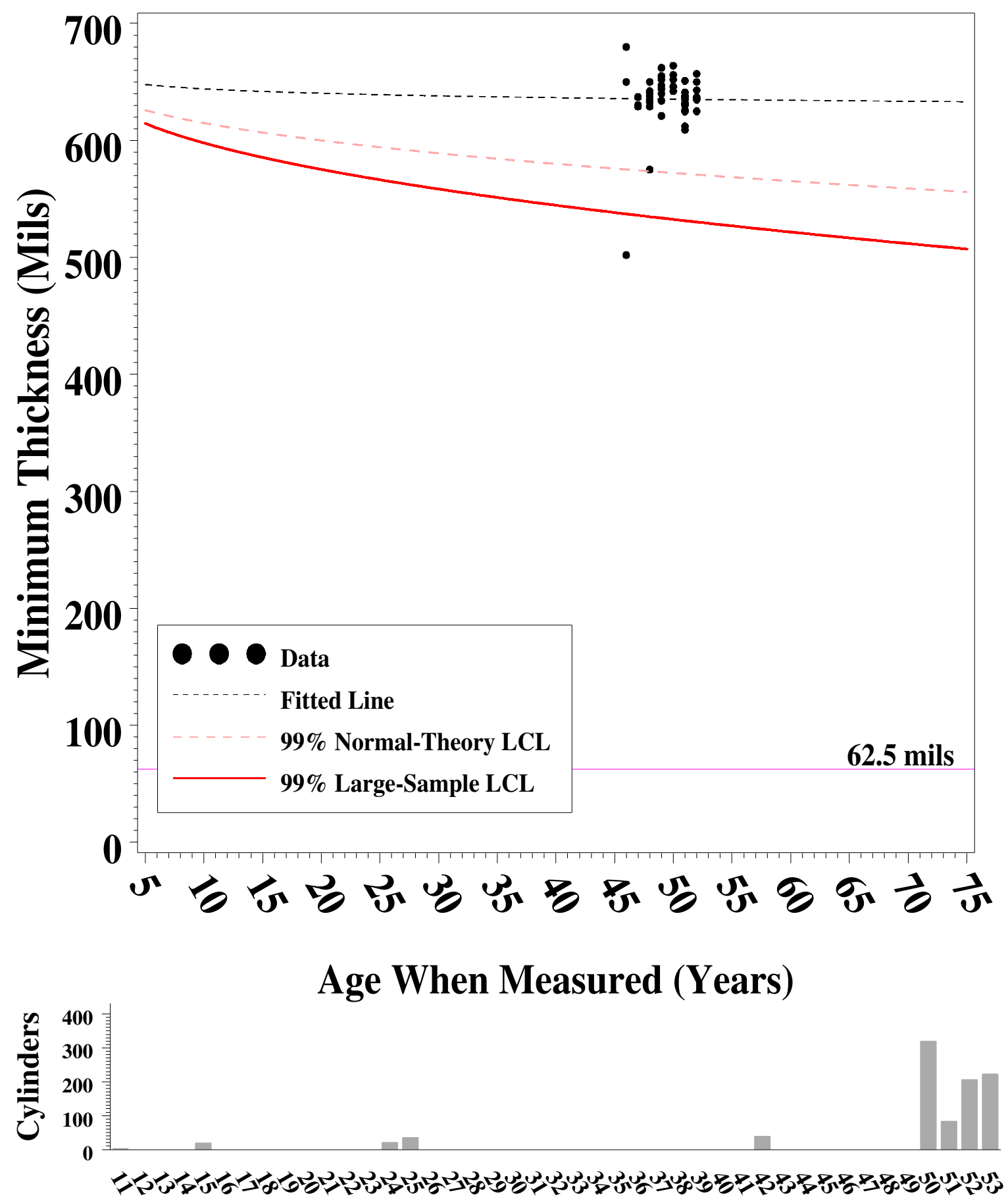

Age in 2004

Figure 31. Minimum thicknesses (top) and age distribution (below) for ETTP/PGDP/PORTS thick top cylinders. 

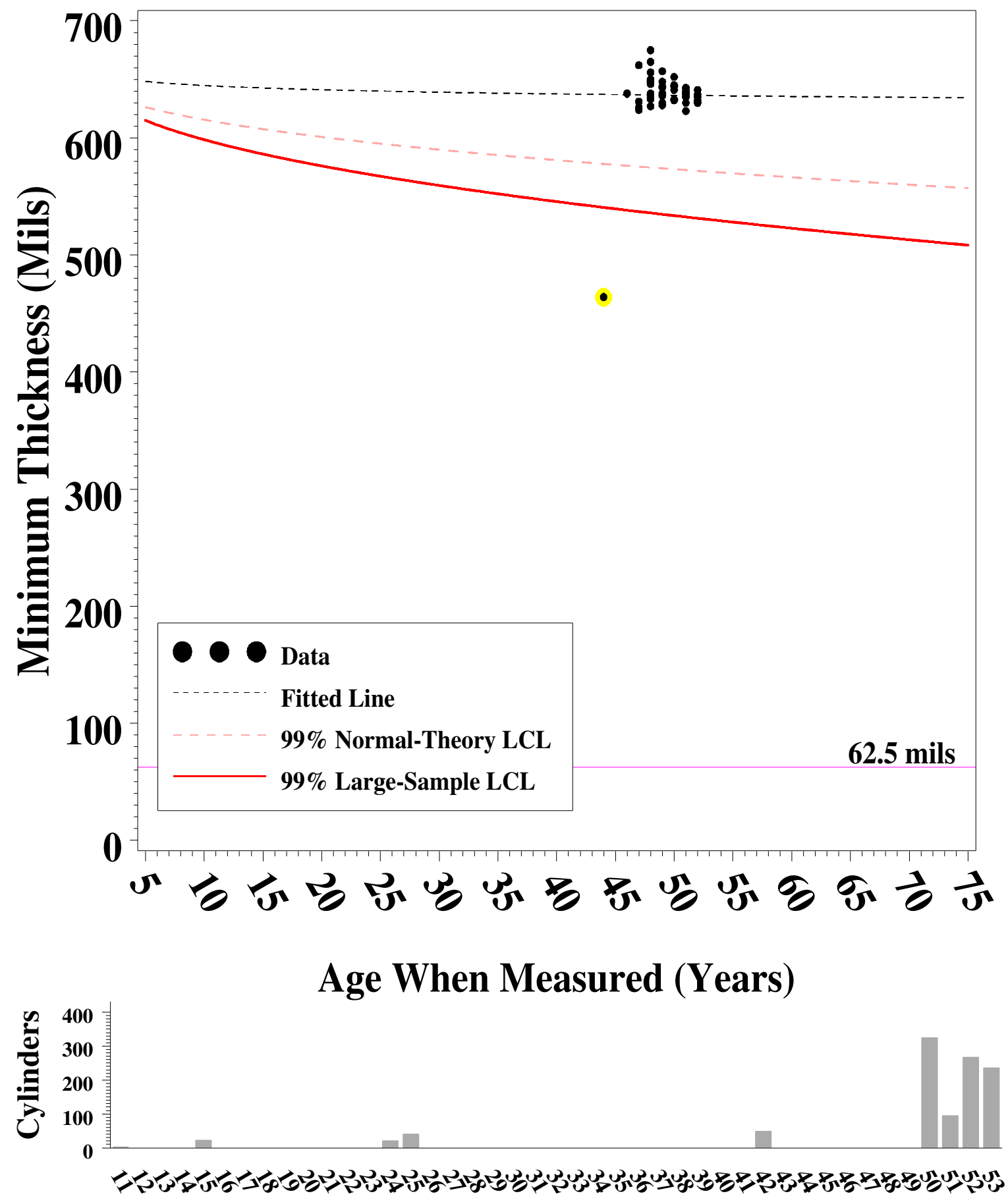

Age in 2004

Figure 32. Minimum thicknesses (top) and age distribution (below) for ETTP/PGDP/PORTS thick bottom cylinders. 

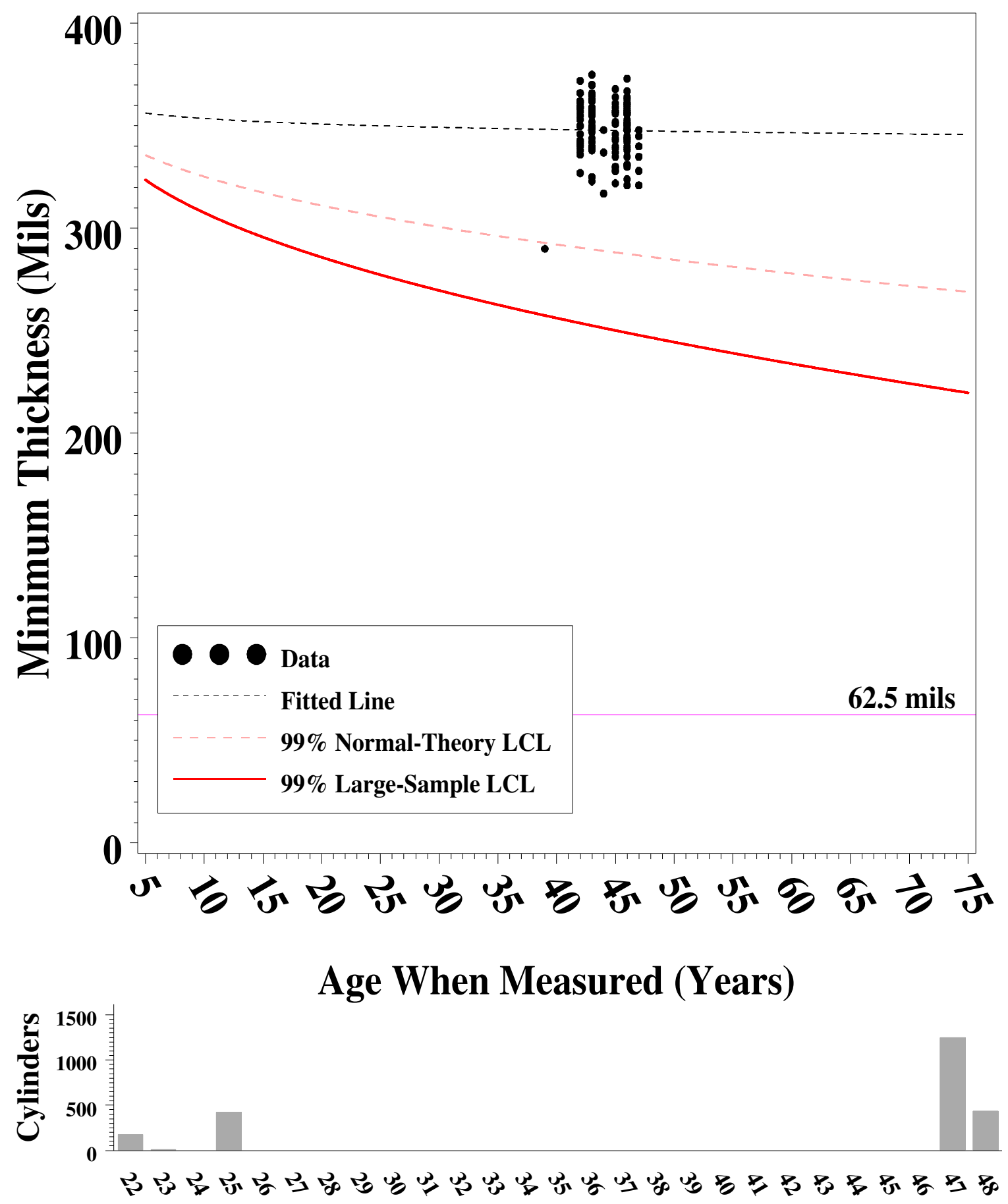

Age in 2004

Figure 33. Minimum thicknesses (top) and age distribution (below) for ETTP/PGDP/PORTS thin skirted top cylinders. 

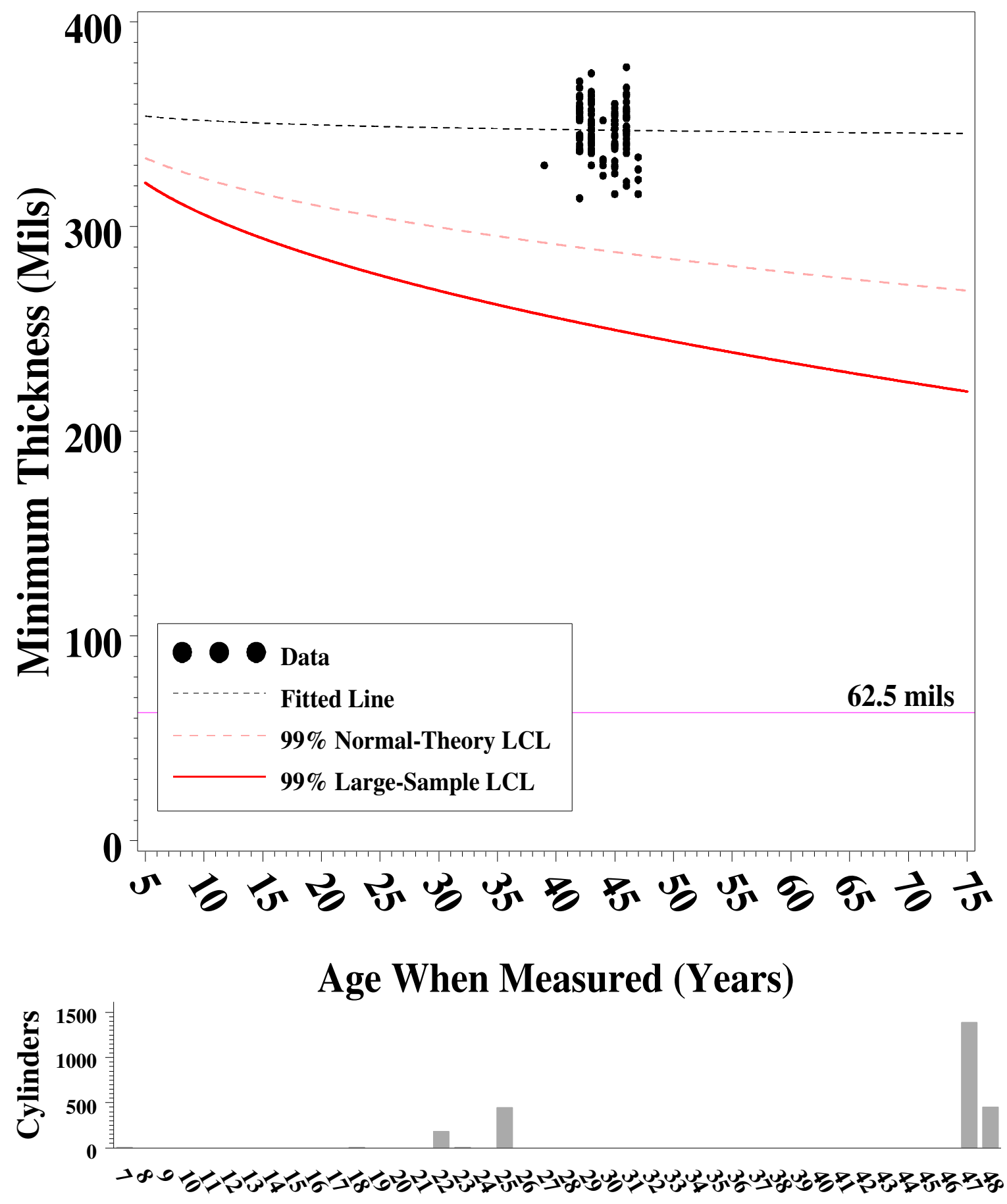

Age in 2004

Figure 34. Minimum thicknesses (top) and age distribution (below) for ETTP/PGDP/PORTS thin skirted btm cylinders. 

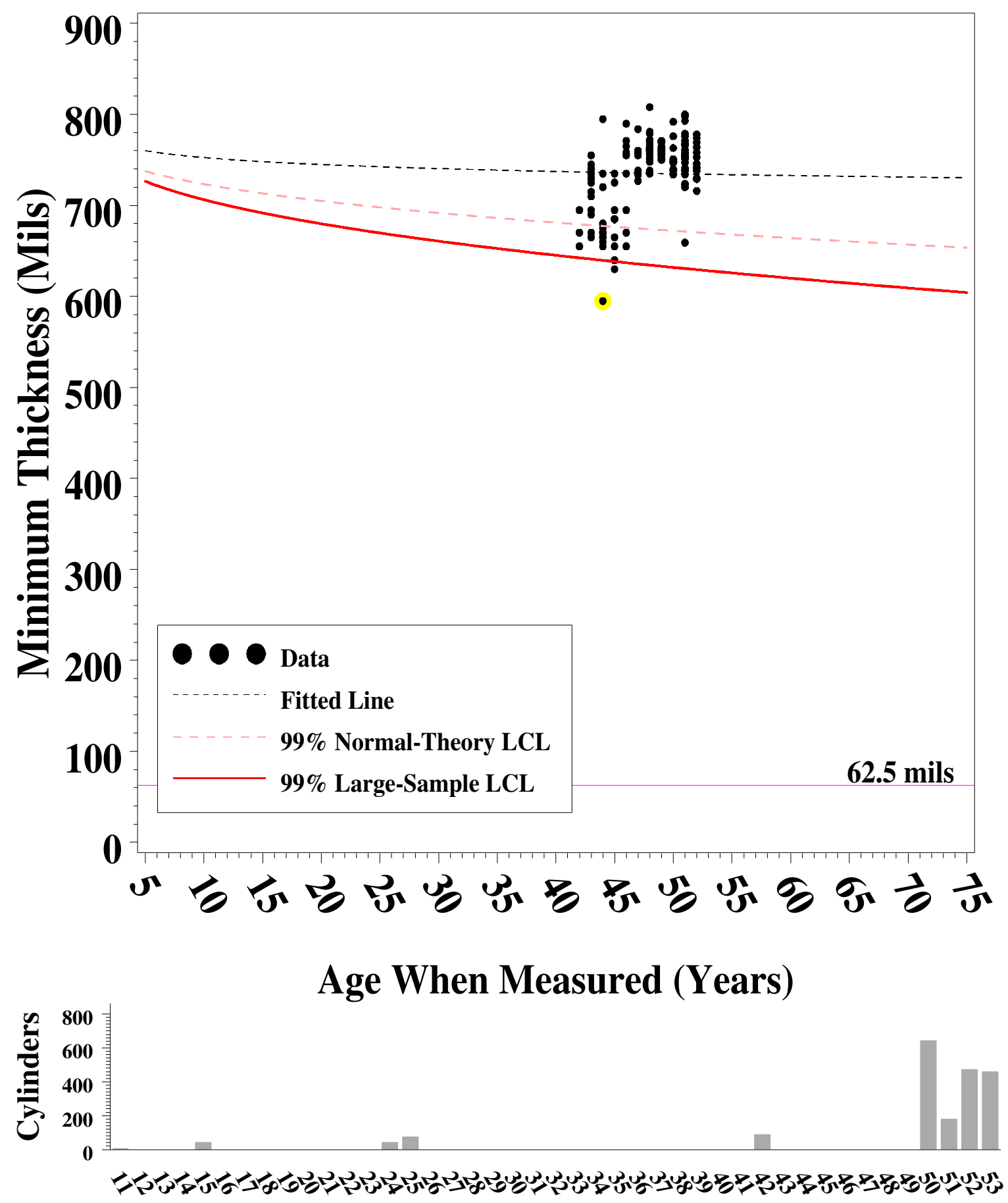

Age in 2004

Figure 35. Minimum thicknesses (top) and age distribution (below) for ETTP/PGDP/PORTS thick skirted cylinders. 

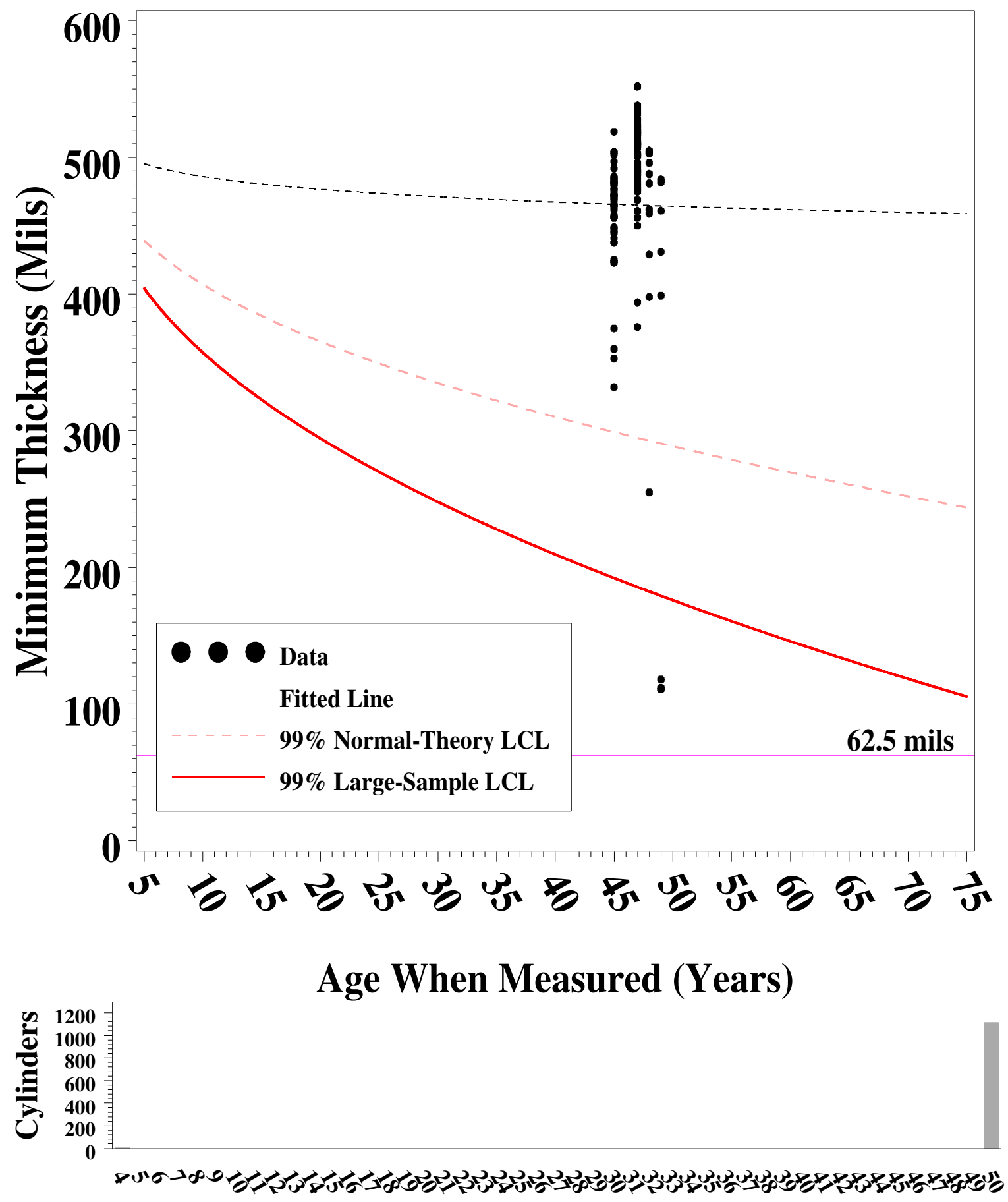

Age in 2004

Figure 36. Minimum thicknesses (top) and age distribution (below) for ETTP/PGDP/PORTS 1/2" (30" dia.) top cylinders. 

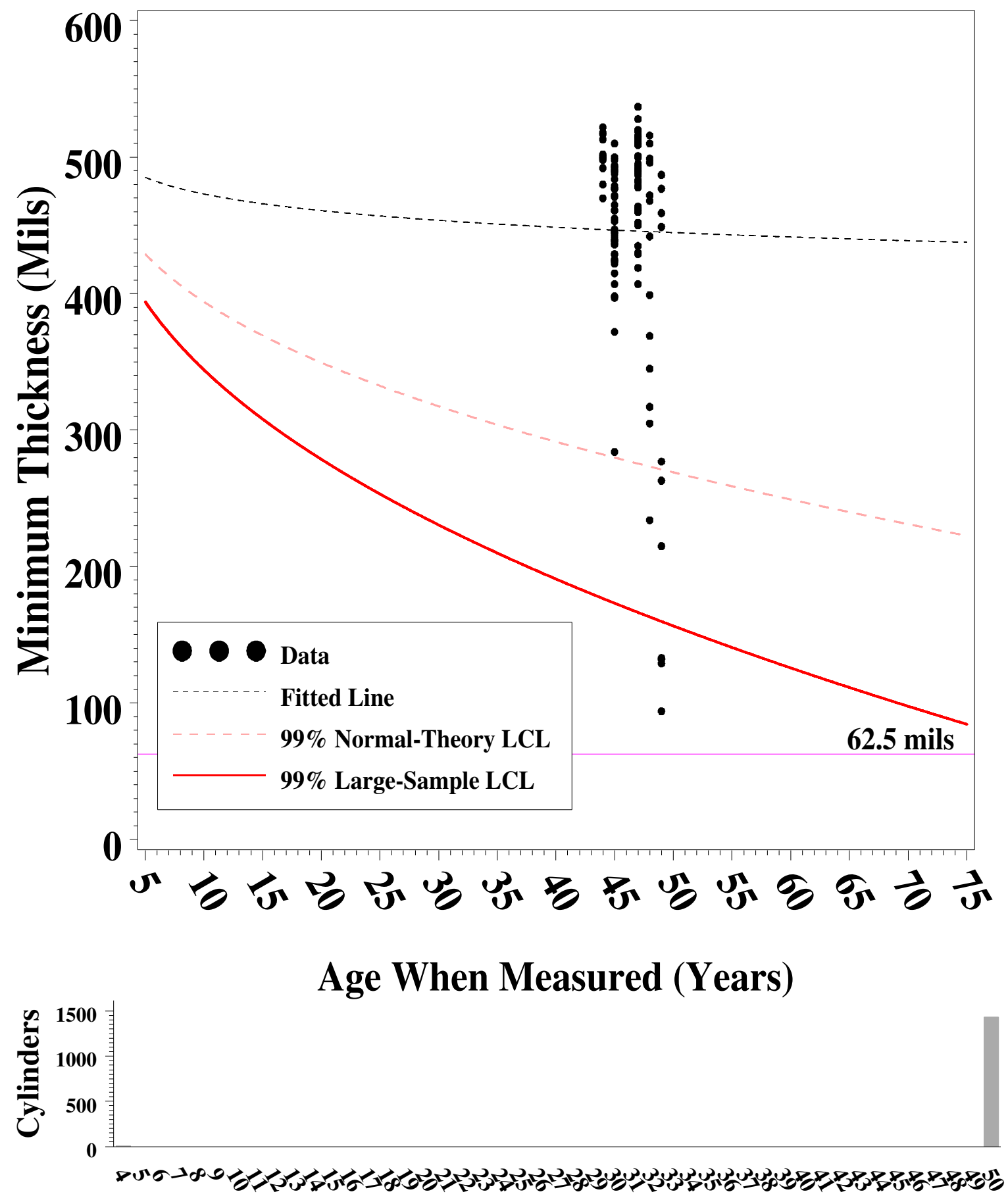

Age in 2004

Figure 37. Minimum thicknesses (top) and age distribution (below) for ETTP/PGDP/PORTS 1/2" (30" dia.) btm cylinders. 


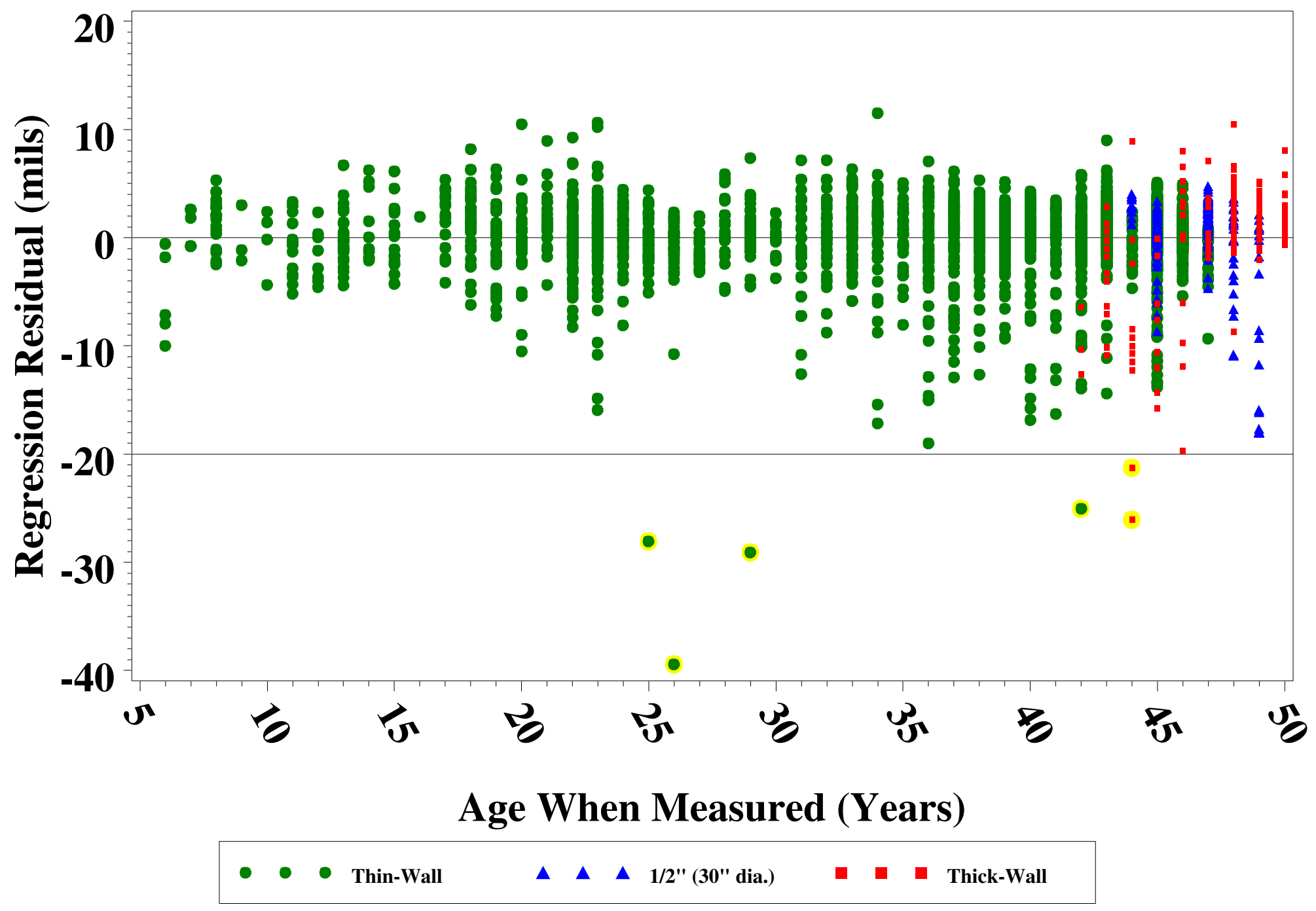

Figure 38. Residuals from minimum thickness regression. Residuals below -20 mils are highlighted (yellow) and corresponding cylinders are not used to compute Table 14B. 


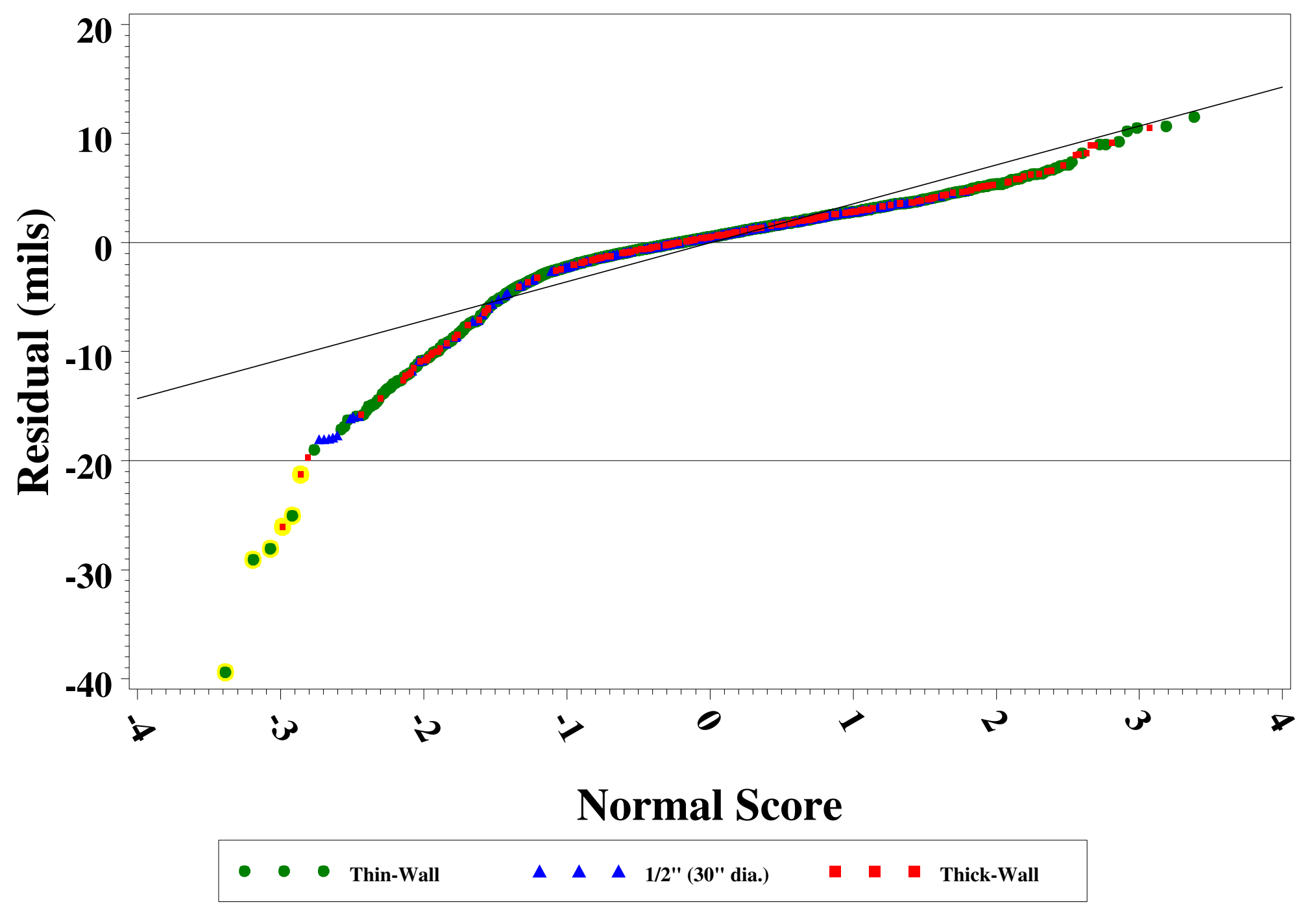

Figure 39. Normal probability plot for the regression residuals. Systematic departures from the straight reference line suggest non-normal data. 


\section{ENGINEERING SCIENCE AND TECHNOLOGY DIVISION \\ Document Rcview Form}

Secsion A: (for the author)

Tiule: Prediction of External Corrosion for Steel Cylinders-2004 Report

Author(s): R. L. Schmoyer

Date Nceded: June 1.2004

Charge No.:

Document Type:

$\square$ Joumal (refereed) $\square$ Invited Conference Paper

$\square$ Joumal (unreferecd) $\square$ Contributed Conference Paper

Abstract

Oral Prescntition

ORNL Report: $\frac{\text { ORNLTTM-2004/88 }}{\text { Report No. }}$

NRC Report:

Repor No.

Other (specify):

(e.g. testimony, video/scripc, ncwsletter, encyclopedia article, misc.)

Publication Information

\begin{tabular}{|l|l|l|}
\hline $\begin{array}{c}\text { Other } \\
\text { (provide additional information) }\end{array}$ & \multicolumn{1}{|c|}{ Published in a Journal } & \multicolumn{1}{|c|}{ Conference Proceedings } \\
\hline \multirow{4}{*}{} & Name: & Title: \\
\cline { 2 - 3 } & Volume: & Location: \\
\cline { 2 - 3 } & Date: & Date: \\
\hline
\end{tabular}

$\begin{array}{llll}\text { Classification Review Waived: } & \square \text { Yes } & \square \text { Ro } & \text { RLS } \\ \text { Patent Review Waived: } & \checkmark \text { Yuthor's Initials }\end{array}$

NOTE: If classification or patent review is needed, provide the name of the reviewer, the datc reviewed, and the location of the original hardcopy of the Document Registry Form in the Rcmarks section of the CPPR wcb-based form (UCN-119).

\section{Sectien B: (Pecr Review)}

Please review the above-noted document for suitability and worth of the subject for presentation or publication, soundncss of technical content, and clarity of presentation with zespect ra text, tables, graphs, and visual aids. Note comments on the document or lise them below. Indicatc below your summary recommenplation by cheqling the appropriate box.

Revicwer's Name: Steve Pawel 23341 (Please sign here.)

I recommend publication as submitted. I recommend publication if revised as noted.

I do not recommend publication of document (indicate reason in comments below).

Comments:

Hard copy returned with many minor suggestions and thanghts. Also, a corresponding email sent with a few summary suggestions.

Section C: (for the author)

I agree with the reviewer's suggestions and they have been incorporated in this document.

I have not incorporated the reviewer's suggestions in this document for the $\square$ following $\square$ attached reasuns.

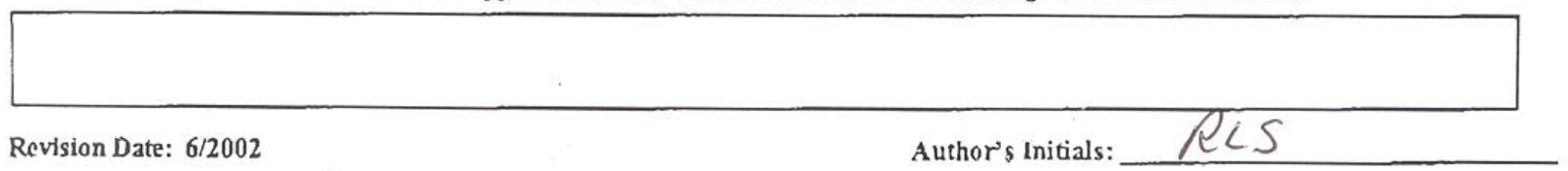




\section{ENGINEERING SCIENCE AND TECHNOLOGY DIVISION \\ Document Review Form}

Section A: (for the author)

Title: Prediction of External Corrosion for Steel Cylinders-2004 Report

Author(s): R. L. Schmoyer

Date Necded: June 1, 2004

Charge No.:_ $\quad+3420141$

Document Type:

$\square$ Joumal (refereed) $\square$ Invited Conference Paper

$\checkmark$ Joumal (unrefereed) $\square$ Contributed Conference Paper

Abstract

Oral Presentation

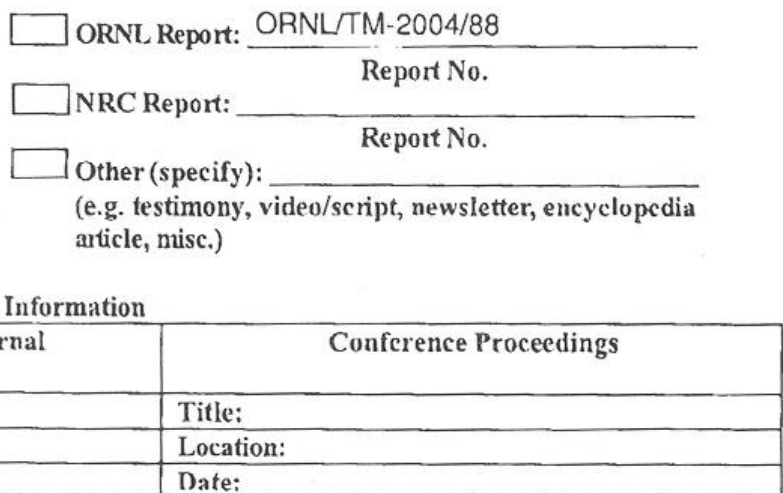

Publication Information

\begin{tabular}{|l|l|l|}
\hline \multicolumn{1}{c|}{$\begin{array}{c}\text { Other } \\
\text { (provide additional information) }\end{array}$} & \multicolumn{1}{|c|}{ Published in a Journal } & \multicolumn{1}{c|}{ Conference Proceedings } \\
\hline \multirow{4}{*}{} & Name: & Title: \\
\cline { 2 - 3 } & Volume: & Location: \\
\cline { 2 - 3 } & Date: & Date: \\
\hline
\end{tabular}

Classification Review Waived: Patent Review Waived: $\checkmark$ Yes $\checkmark$ Yes

$\square$ No $\quad$ RLS

RLS

NOTE: If classification or patent review is needed, pmvide the name of the reviewer, the date reviewed, and the location of the original hardcopy of the Document Registry Furm in the Remarks section of the CPPR web-based form (UCN-119).

Section B: (Peer Review)

Please review the above-noted document for suitability and worth of the subject for presentation or publication, soundness of technical content, and clarity of presentation with respect to text, tables, graphs, and visual aids. Note comments on the document or list them below. Indicate below your summary recommendation by hecking the appropriate box.

Reviewer's Name: Brad Lyon

$\square$ I do not recommend publication of document (indicate reason in comments below).

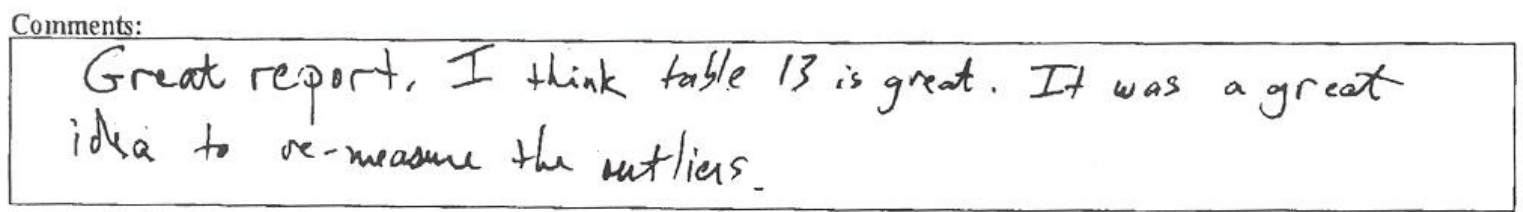

Section C: (for the author)

DI agree with the reviewer's suggestions and they have been incorporated in this document.

I have not incorporated the reviewer's suggestions in this document for the $\square$ following $\square$ attached reasons. 


\section{DISTRIBUTION}

1. ORNL Central Research Library

2. ORNL Laboratory Records-OSTI

3. Halen Philpot (Bechtel Jacobs Company)

4. Guy Wilson (Bechtel Jacobs Company)

5. Craig Dowdy (Bechtel Jacobs Company)

6. Roger McDermott (Theta Technologies, Inc.)

7. Ted Fox

8. Steve Pawel

9. Carolyn Moser 